\title{
FUNDAMENTOS DO CONCRETO DE ALTO DESEMPENHO E SUA APLICAÇÃO NO PROJETO DE PILARES
}

\section{ANTONIO GUILHERME CANHASSI BACCIN}

Dissertação apresentada à Escola de Engenharia de São Carlos, da Universidade de São Paulo, como parte dos requisitos para obtenção do Título de Mestre em Engenharia de Estruturas.

ORIENTADOR: Prof. Dr. Libânio Miranda Pinheiro

São Carlos

1998 


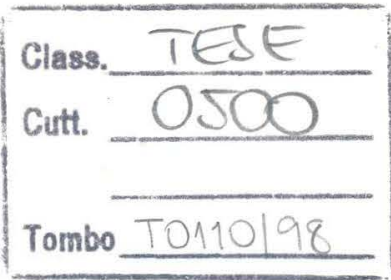

Engenharia de esturitias.

Ficha catalográfica preparada pela Seção de Tratamento da Inform ação do Serviço de Biblioteca - EESC-USP

Baccin, Antonio Guilherme Canhassi

$B 117 f$

Fundamentos do concreto de alto desempenho e sua aplicação no projeto de pilares / Antonio Guilherme Canhassi Baccin. -- São Carlos, 1998.

Dissertação (Mestrado). -- Escola de Engenharia de São Carlos-Universidade de São Paulo, 1998.

Área: Engenharia de Estruturas.

Orientador: Prof. Dr. Libânio Miranda Pinheiro.

1. Concreto de alto desempenho. 2. Propriedades mecânicas. 3. Pilares. I. Título. 

pela Comissão Julgadora:

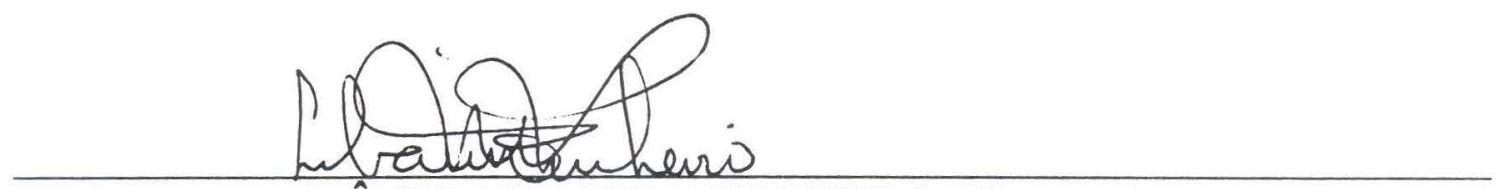

Prof. Doutor LIBÂNIO MIRANDA PINHEIRO (Orientador) (Escola de Engenharia de São Carlos - Universidade de São Paulo)

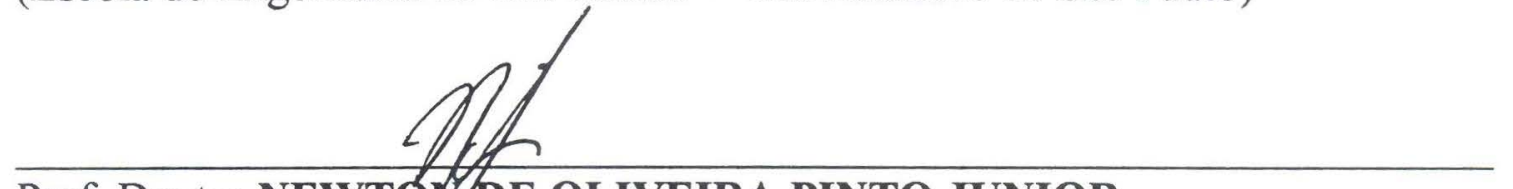

Prof. Doutor NEWTO DE OLIVEIRA PINTO JUNIOR (Universidade Estaduaf de Campinas - UNICAMP)

Lr. hele Aur Profa. Doutora ANA LÚCIA HOMCE DE CRESCE EL DEBS (Escola de Engenharia de São Carlos - Universidade de São Paulo)

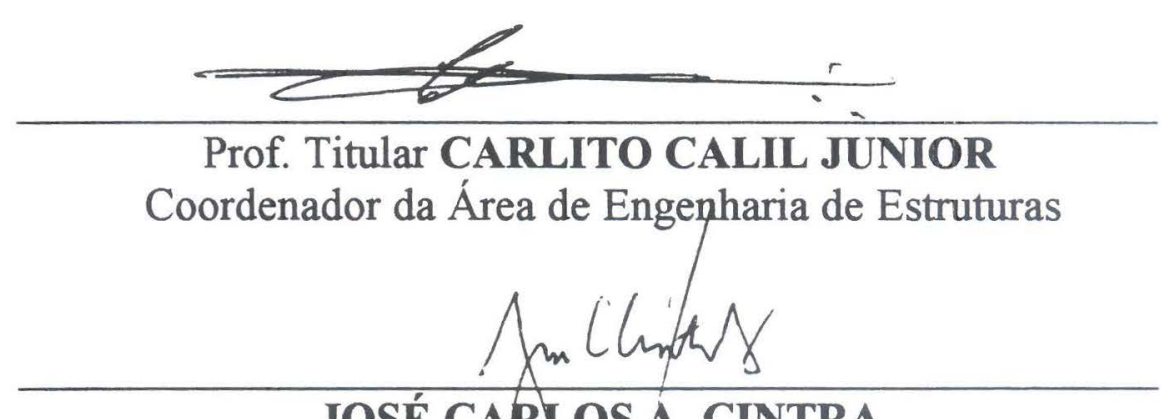

\section{JOSÉ CARLOS A. CINTRA}

Presidente da Comissão de Pós-Graduação da EESC 
Aos meus pais, Antonio Guilherme e Laura, agradeço o carinho e o incentivo ao longo de todos esses anos. 


\section{AGRADECIMENTOS}

Agradeço a Deus, pela proteção e pelas oportunidades oferecidas a cada dia.

Ao Prof. Dr. Libânio Miranda Pinheiro, pela cuidadosa orientação profissional e apoio dedicado ao longo deste trabalho.

Aos professores do Departamento de Estruturas da EESC - USP e da Universidade Federal de São Carlos, pelas importantes contribuições e sugestões relativas ao presente trabalho.

À Maria Nadir Minatel, pela constante dedicação e disposição para pesquisas e revisões bibliográficas.

Às secretárias do Departamento de Engenharia de Estruturas da EESC USP, Rosy A. J. Rodrigues, Marta R. C. Faria e demais funcionários, pela eficiência nos serviços prestados.

À Coordenadoria de Aperfeiçoamento de Pessoal de Nível Superior CAPES, pelo auxílio financeiro concedido. 
À Eliane Fiorin, que com amor e carinho sempre esteve presente no desenvolvimento deste trabalho. 


\section{SUMÁRIO}

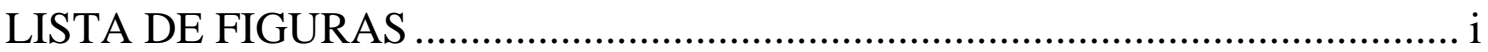

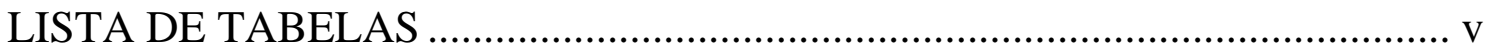

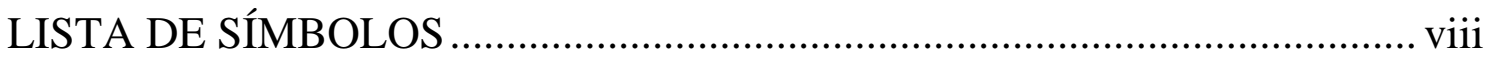

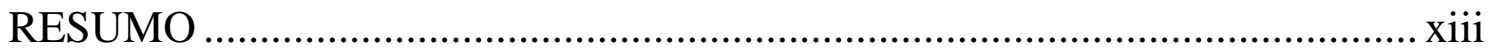

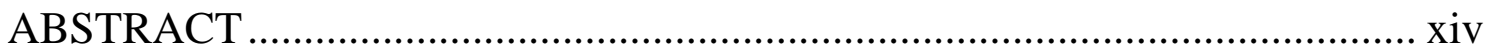

1. INTRODUÇÃO

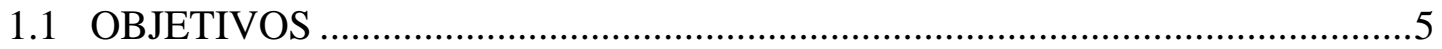

1.2 APRESENTAÇÃO DO TRABALHO .........................................................

1.3 APLICAÇÕES DO CONCRETO DE ALTO DESEMPENHO ..............................

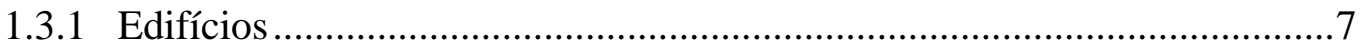

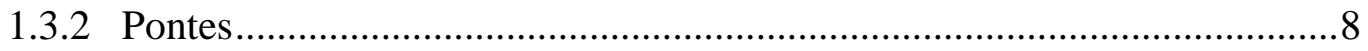

1.3.3 Plataformas de petróleo ....................................................................

1.3.4 Aplicações especiais ..............................................................................

2. MATERIAIS CONSTITUINTES E PRODUÇÃO DO CAD ......................... 12

2.1 MICROESTRUTURA DO CONCRETO.......................................................13

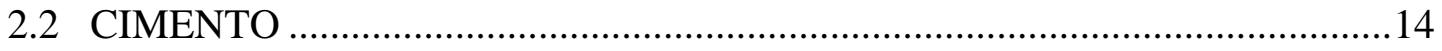

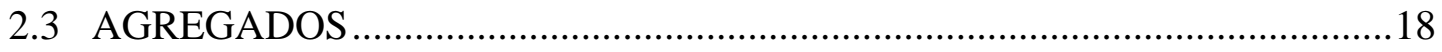

2.3.1 Agregado graúdo................................................................................. 18

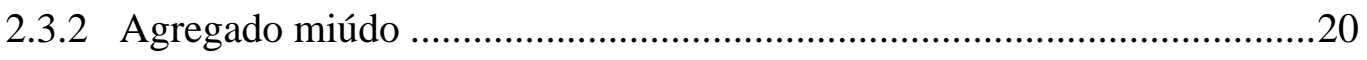

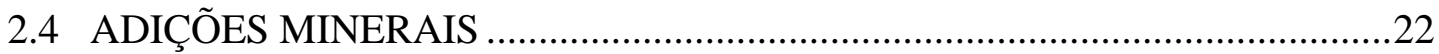

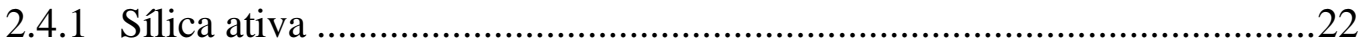

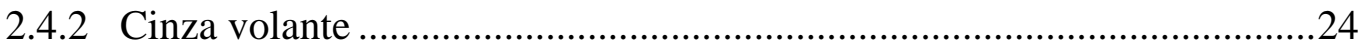

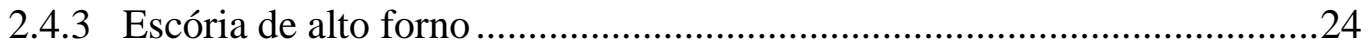

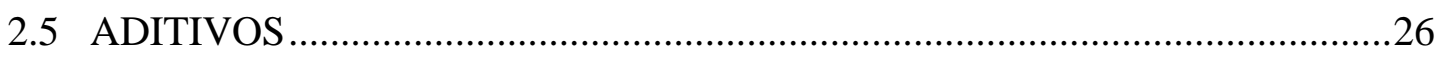

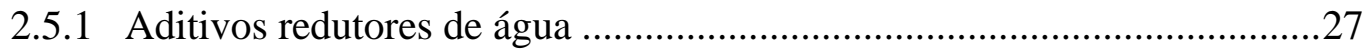




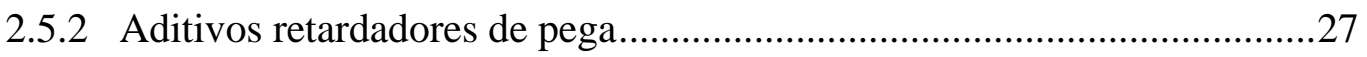

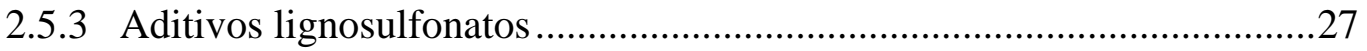

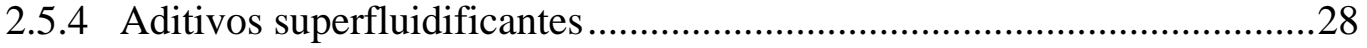

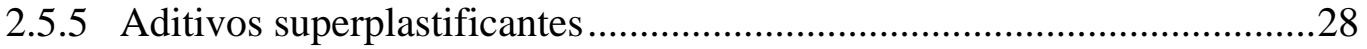

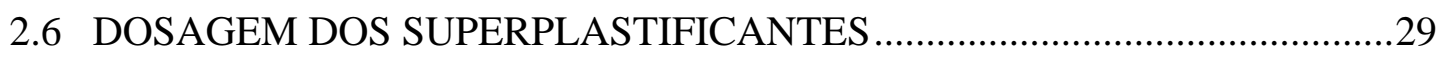

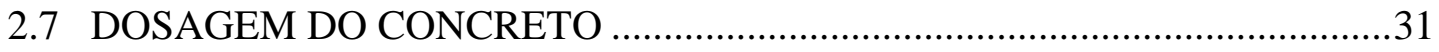

2.7.1 Determinação da fluidez da argamassa de cimento ................................32

2.7.2 Estimativa da resistência à compressão (Fórm. Feret modificada)............33

2.7.3 Dosagem de componentes pelo método de LARRARD ............................34

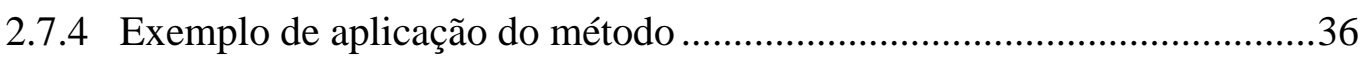

2.8 FABRICAÇÃO DO CONCRETO DE ALTO DESEMPENHO .........................39

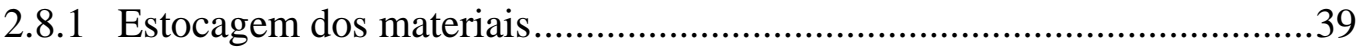

2.8.2 Dosagem dos componentes................................................................4

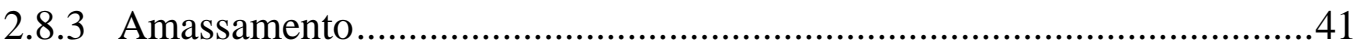

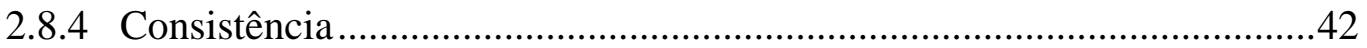

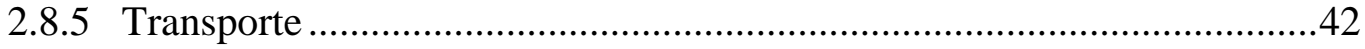

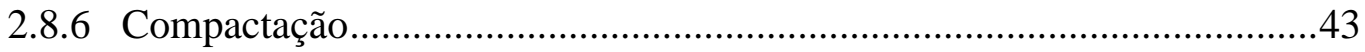

2.9 CONTROLE DE QUALIDADE E ENSAIO...............................................4

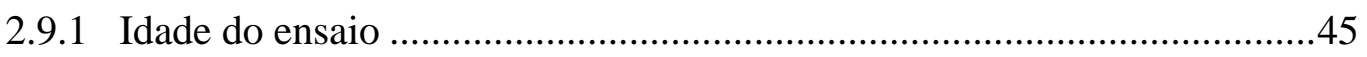

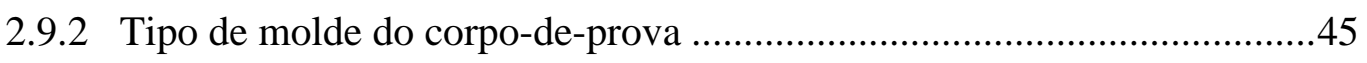

2.9.3 Condições de capeamento do corpo-de-prova ........................................46

2.9.4 Características das máquinas de ensaio .................................................48

3. PROPRIEDADES MECÂNICAS DO CAD .......................................... 50

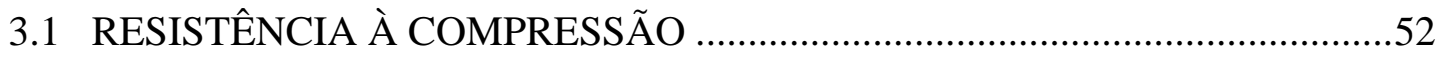

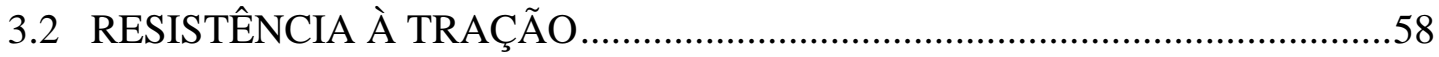

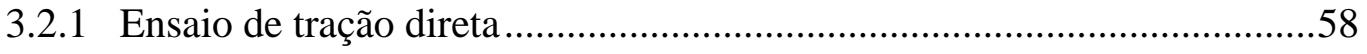

3.2.2 Ensaio de compressão diametral ...........................................................60

3.2.3 Ensaio de flexão em vigas ou módulo de ruptura.....................................64

3.3 RELAÇÃO TENSÃO-DEFORMAÇÃO NA COMPRESSÃO ..........................66

3.4 MÓDULO DE DEFORMAÇÃO LONGITUDINAL ESTÁTICO.....................72

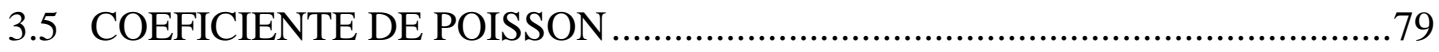




\subsection{COMPARAÇÃO DE VALORES TEÓRICOS E RESULTADOS}

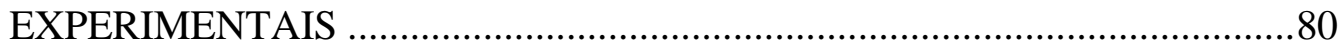

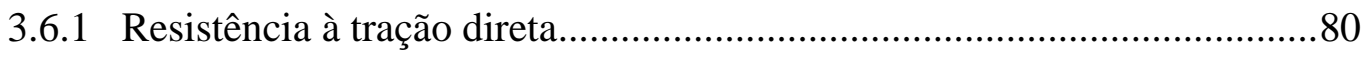

3.6.2 Módulo de deformação longitudinal .........................................................

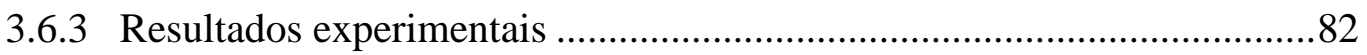

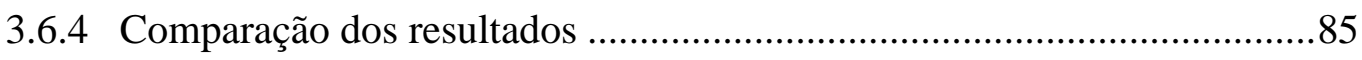

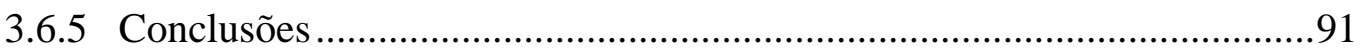

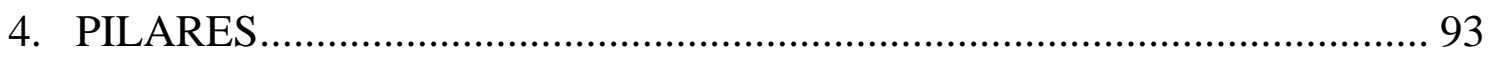

4.1 PERDA DO RECOBRIMENTO ………………………………………........

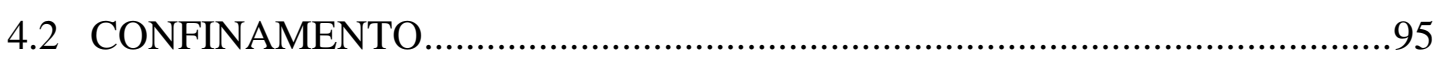

4.2.1 Taxa de armadura de confinamento .........................................................96

4.2.2 Resistência da armadura de confinamento...............................................96

4.2.3 Espaçamento da armadura de confinamento..............................................98

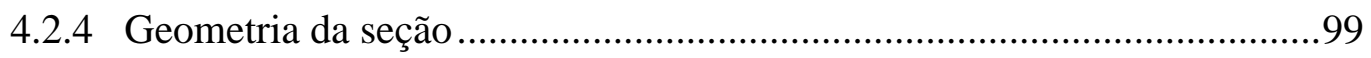

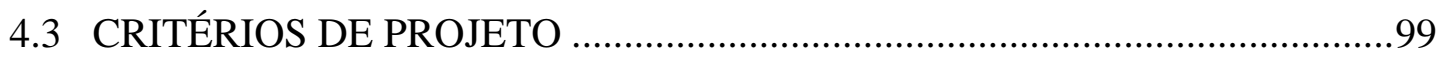

4.3.1 Dimensão mínima para os pilares ............................................................99

4.3.2 Escolha do tipo de armadura transversal .............................................100

4.3.3 Diâmetro mínimo para os estribos ............................................................101

4.3.4 Espaçamento máximo dos estribos ..............................................................101

4.3.5 Taxa mínima para armadura transversal ................................................102

4.3.6 Escolha da configuração dos estribos ......................................................103

4.3.7 Efeito da resistência à plastificação da armadura transversal ...................104

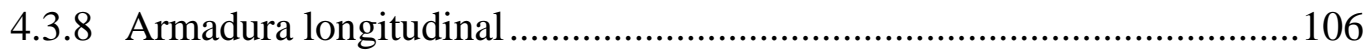

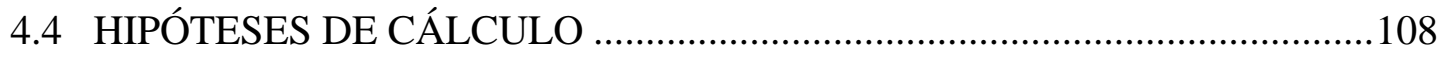

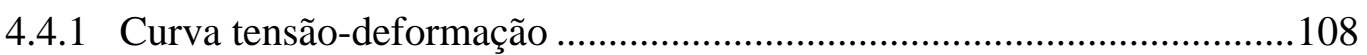

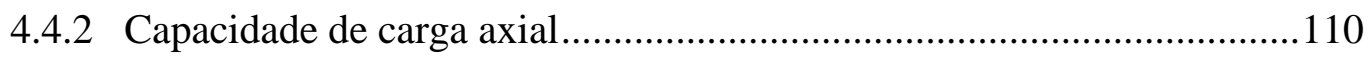

4.4.3 Diagrama de interação para pilares de concreto ………………………....113

4.5 DIMENSIONAMENTO SEGUNDO O ACI 318-89 ………….......................118

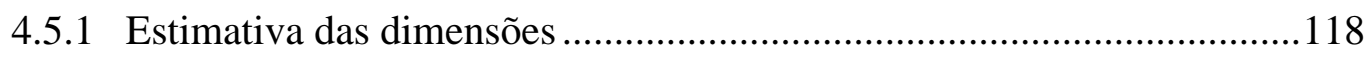

4.5.2 Verificação da esbeltez do pilar.........................................................119

4.5.3 Verificação dos momentos mínimos...........................................................120 
4.5.4 Carga axial e momento majorados.....................................................122

4.5.5 Momento atuando em duas direções....................................................124

4.6 DIMENSIONAMENTO SEGUNDO A NORMA INGLESA (BS 8110) ........125

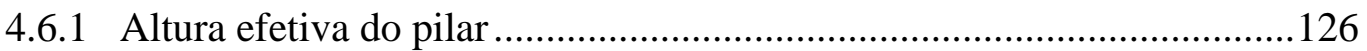

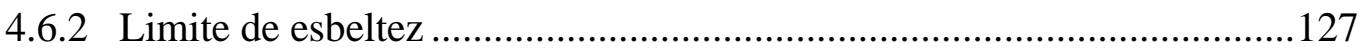

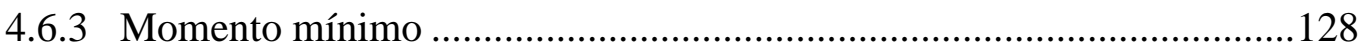

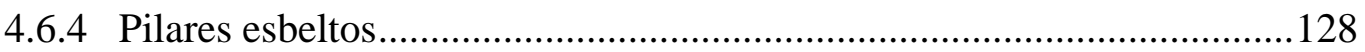

4.6.5 Pilares esbeltos contraventados .......................................................... 129

4.6.6 Pilares esbeltos não contraventados.......................................................133

5. EXEMPLOS DE DIMENSIONAMENTO ............................................ 135

5.1 EXEMPLOS DE DIMENSIONAMENTO SEGUNDO O ACI 318-89...........135

5.2 DIMENSIONAMENTO DE PILAR INTERIOR ............................................136

5.2.1 Pré-dimensionamento da seção do pilar .................................................136

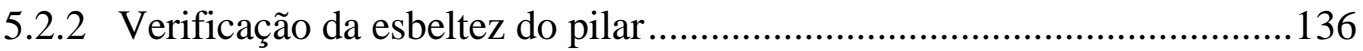

5.2.3 Verificação dos momentos mínimos...................................................... 138

5.2.4 Cálculo do fator de comprimento efetivo ............................................138

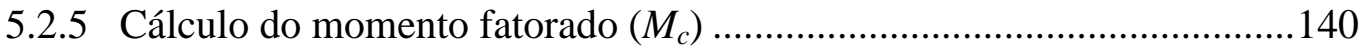

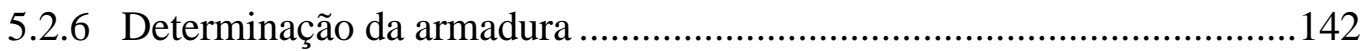

5.3 DIMENSIONAMENTO DE PILAR DE EXTREMIDADE …......................... 144

5.3.1 Pré-dimensionamento da seção do pilar de extremidade ........................144

5.3.2 Verificação da esbeltez do pilar............................................................. 144

5.3.3 Verificação dos momentos mínimos.......................................................145

5.3.4 Cálculo do fator de comprimento efetivo ..............................................145

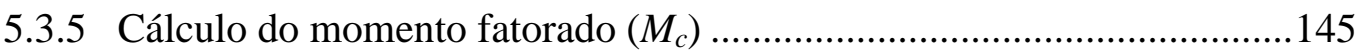

5.3.6 Determinação da armadura ...............................................................146

5.4 DIMENSIONAMENTO DE PILAR DE CANTO …......................................147

5.4.1 Pré-dimensionamento da seção do pilar .................................................148

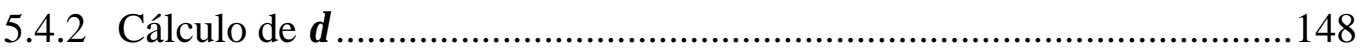

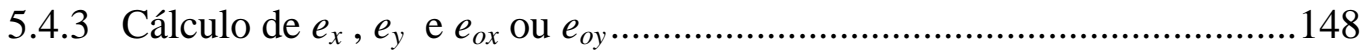

5.4.4 Cálculo do momento equivalente .......................................................149

5.4.5 Cálculo de $\left(\delta_{t}\right)$ através de diagramas de interação ................................149 


\subsection{DIMENSIONAMENTO DE PILAR CONTRAVENTADO SEGUNDO A}

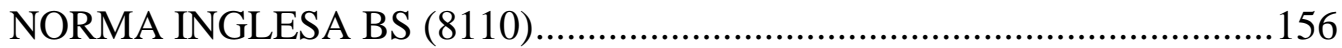

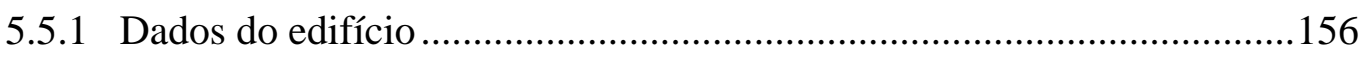

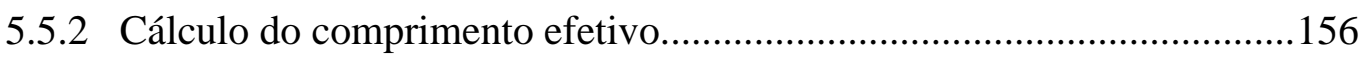

5.5.3 Determinação do momento de cálculo $\left(M_{x}\right)$.......................................157

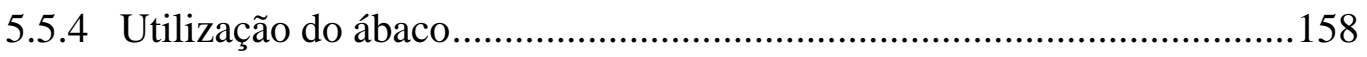

5.6 DIMENSIONAMENTO DE PILAR NÃO CONTRAVENTADO SEGUNDO A NORMA INGLESA BS (8110).............................................160

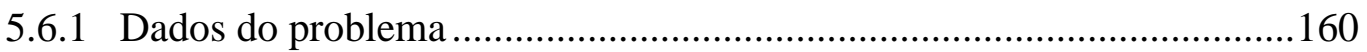

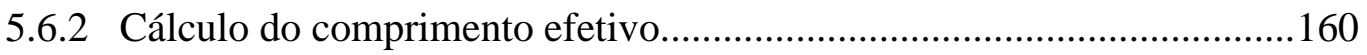

5.6.3 Cálculo do momento mínimo ................................................................. 161

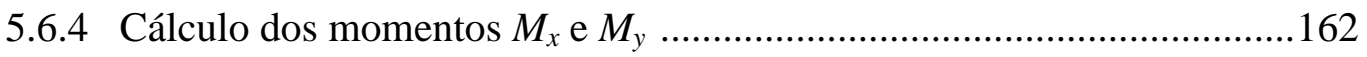

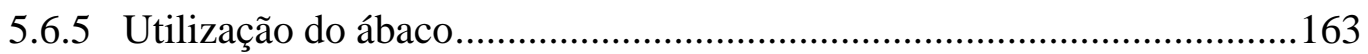

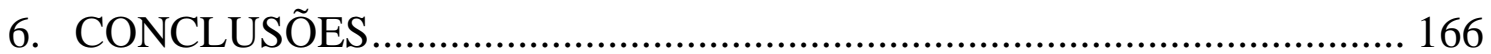

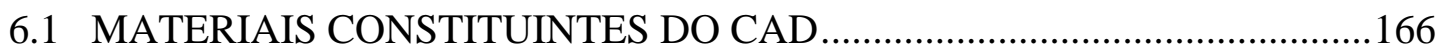

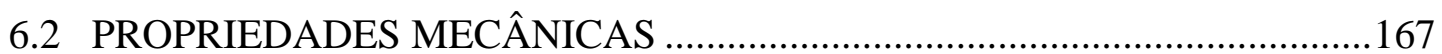

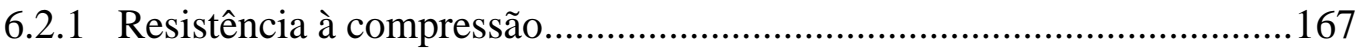

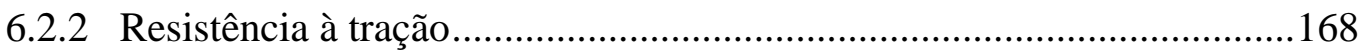

6.2.3 Módulo de deformação longitudinal .......................................................168

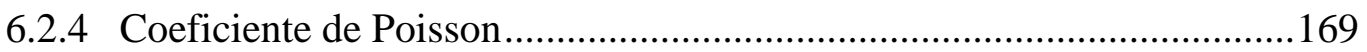

6.2.5 Relação tensão-deformação na compressão..........................................169

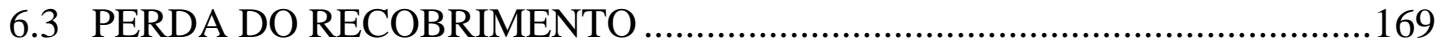

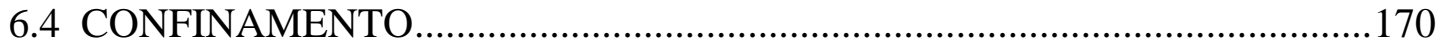

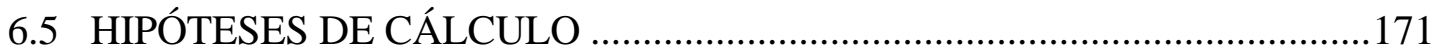

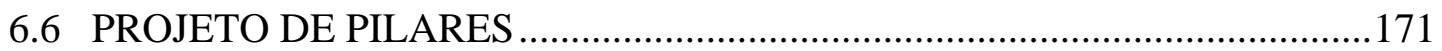

6.7 SUGESTÕES PARA CONTINUAÇÃO DO TRABALHO ….........................172

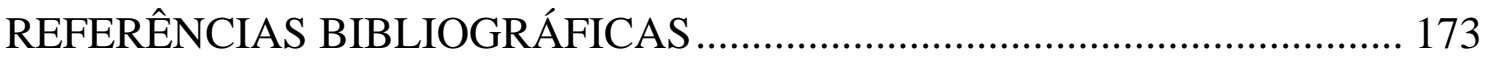




\section{LISTA DE FIGURAS}

FIGURA 1.1 - Evolução no tempo do concreto de alto desempenho segundo GONZALEZ (1993) .02

FIGURA 2.1 - Variação da fluidez do concreto com o tempo segundo HANNA et al. (1989) 16

FIGURA 2.2 - Dimensões do cone de Marsh .33

FIGURA 2.3 - Representação gráfica da Fórmula de Feret modificada por LARRARD (1990) 34

FIGURA 3.1 - Fatores que afetam a resistência do concreto

FIGURA 3.2 - Tensão/resistência e deformação para concretos sob ação de longa duração segundo FIP/CEB-197 (1990) 55

FIGURA 3.3 - Esquema do ensaio de compressão diametral 60

FIGURA 3.4 - Variação da resistência à tração em ensaios de compressão diametral com a resistência à compressão

FIGURA 3.5 - Resultados da correlação obtida entre resistência à compressão e resistência à tração indireta em concretos de alto desempenho .63

FIGURA 3.6 - Esquema de ensaio de tração na flexão .64

FIGURA 3.7 - Variação do módulo de ruptura com a resistência à compressão .65

FIGURA 3.8 - Efeito do tipo de agregado na parte ascendente da curva tensão-deformação do concreto aos 28 dias .67

FIGURA 3.9 - Diagrama tensão-deformação para concreto Classe I e CAD .68

FIGURA 3.10 - Diagrama tensão-deformação para compressão uniaxial (Tipo A) obtido por MacGREGOR et al. (1995)

FIGURA 3.11 - Diagrama tensão-deformação para compressão uniaxial (Tipo B) obtido por MacGREGOR et al. (1995) 
FIGURA 3.12 - Diagrama tensão-deformação para compressão uniaxial (Tipo C) obtido por MacGREGOR et al. (1995) ...........................................71

FIGURA 3.13 - Curvas tensão-deformação para o CAD sob compressão axial .72

FIGURA 3.14 - Relação tensão-deformação em argamassas e concretos de alto desempenho .73

FIGURA 3.15 - Efeito de diferentes condições de cura na variação da média do módulo de elasticidade para concretos de baixa resistência ensaiados por MITCHELL et al. (1995) .74

FIGURA 3.16 - Efeito de diferentes condições de cura na variação da média do módulo de elasticidade para concretos de média resistência ensaiados por MITCHELL et al. (1995) .75

FIGURA 3.17- Efeito de diferentes condições de cura na variação da média do módulo de elasticidade para concretos de alta resistência ensaiados por MITCHELL et al. (1995) .75

FIGURA 3.18 - Módulo de elasticidade secante x resistência do concreto .77

FIGURA 3.19 - Módulo de elasticidade secante x resistência do concreto com densidade normal .77

FIGURA 3.20 - Tensão axial x deformação axial e deformação lateral para concretos normais e concretos de alto desempenho .79

FIGURA 3.21 - Comparação de valores teóricos de resistência à tração direta do concreto com resultados experim. de OLUOKUN et al.(1991b) .86

FIGURA 3.22 - Comparação de valores teóricos de resistência à tração direta do concreto e resultados experim. de GRIEB \& WERNER (1962) .87

FIGURA 3.23 - Comparação de valores teóricos de resistência à tração direta do concreto com resultados experim. de FERRARI et al. (1995) 88

FIGURA 3.24 - Comparação de valores teóricos de módulo de elasticidade do concreto com resultados experim. de OLUOKUN et al.(1991a)

FIGURA 3.25 - Comparação de valores teóricos de módulo de elasticidade do concreto com resultados experim. de FERRARI et al. (1995) .90 
FIGURA 4.1 - Fatores que promovem a descamação do recobrimento em pilares de CAD segundo COLLINS et al. (1993)

FIGURA 4.2 - Arranjo dos estribos utilizados no estudo paramétrico realizado por XIE, J. et al. (1997)

FIGURA 4.3 - Momento na linha central x deformação por compressão obtido por XIE, J. et al. (1997)

FIGURA 4.4 - Momento na linha central x deformação por compressão obtido por XIE, J. et al. (1997) 105

FIGURA 4.5 - Momento na linha central x deformação por compressão obtido por XIE, J. et al. (1997) 106

FIGURA 4.6 - Distância máxima permitida para armadura longitudinal sem contenção do estribo 107

FIGURA 4.7 - Deformação no pilar 108

FIGURA 4.8 - Curvas tensão-deformação para concreto de alto desempenho sob compressão axial 109

FIGURA 4.9 - Diagrama tensão-deformação segundo Código Modelo - MC 90 (1991) do CEB-FIP 110

FIGURA 4.10 - Carga axial e momento fletor atuando na extremidade do pilar 111

FIGURA 4.11 - Diagrama de interação para um pilar elástico $\left|f_{c u}\right|=\left|f_{t u}\right| \ldots \ldots \ldots \ldots \ldots . . . .113$

FIGURA $4.12-P_{n}$ e $M_{n}$ para uma dada distribuição de deformação 113

FIGURA 4.13 - Distribuição de deformações correspondentes a pontos do diagrama de interação 114

FIGURA 4.14 - Notação e convenção de sinais 115

FIGURA 4.15 - Forças internas e distâncias para os momentos 117

FIGURA 4.16 - Ábaco para determinação do coeficiente de comprimento efetivo .....123

FIGURA 4.17 - Convenção de sinal para o momento 123

FIGURA 4.18 - Seção transversal com momentos em duas direções ..... .125

FIGURA 4.19 - Momentos em um pilar contraventado 129

FIGURA 4.20 - Máximo momento que pode ocorrer ao longo da altura do pilar 130 
FIGURA 4.21 - Momento atuando em duas direções 132

FIGURA 4.22 - Momentos em um pilar esbelto não contraventado 133

FIGURA 5.1 - Esquema de um edifício de 5 pavimentos 137

FIGURA 5.2 - Recobrimento e dimensões do pilar - cálculo de $(\delta)$ .143

FIGURA 5.3 - Seção transversal e armaduras adotadas para pilar interior .144

FIGURA 5.4 - Recobrimento e dimensões do pilar - cálculo de $(\delta)$ .147

FIGURA 5.5 - Seção transversal e armaduras adotadas para pilar de extremidade ...147

FIGURA 5.6 - Recobrimento e dimensões do pilar - cálculo de $(\delta)$ .148

FIGURA 5.7 - Seção transversal e armaduras adotadas para pilar de canto 149

FIGURA 5.8 - Diagrama de interação carga-momento para pilares (ACI 318-83) ....150 FIGURA 5.9 - Diagrama de interação carga-momento para pilares (ACI 318-83) ....150 FIGURA 5.10 - Diagrama de interação carga-momento para pilares (ACI 318-83) ....151 FIGURA 5.11 - Diagrama de interação carga-momento para pilares (ACI 318-83) ... 151 FIGURA 5.12 - Diagrama de interação carga-momento para pilares (ACI 318-83) ....152 FIGURA 5.13 - Diagrama de interação carga-momento para pilares (ACI 318-83) ... 152 FIGURA 5.14 - Diagrama de interação carga-momento para pilares (ACI 318-83) ....153 FIGURA 5.15 - Diagrama de interação carga-momento para pilares (ACI 318-83) ... 153 FIGURA 5.16 - Diagrama de interação carga-momento para pilares (ACI 318-83) ....154 FIGURA 5.17 - Diagrama de interação carga-momento para pilares (ACI 318-83) ... 154 FIGURA 5.18 - Diagrama de interação carga-momento para pilares (ACI 318-83) ....155 FIGURA 5.19 - Diagrama de interação carga-momento para pilares (ACI 318-83) ... 155 FIGURA 5.20 - Esquema da estrutura dos pavimentos 157

FIGURA 5.21 - Seção transversal e armaduras adotadas 159

FIGURA 5.22 - Esquema da estrutura dos pavimentos 161

FIGURA 5.23 - Seção transversal e armaduras adotadas 165

FIGURA 5.24 - Ábaco para dimensionamento de pilar (KONG \& EVANS - 1987) .. 165 


\section{LISTA DE TABELAS}

TABELA 1.1 - Edifícios construídos com concreto de alto desempenho 10

TABELA 1.2 - Pontes construídas com concreto de alto desempenho 11

TABELA 1.3 - Plataformas de petróleo construídas com CAD 11

TABELA 2.1 - Conteúdo de aluminato tricálcico $\left(\mathrm{AC}_{3}\right)$ nos cimentos segundo HANNA et al. (1989) .15

TABELA 2.2 - Composição de cimentos especiais para CAD segundo Norcem Cement (1990) 17

TABELA 2.3 - Condições exigidas dos cimentos espanhóis segundo RC-88 (1988) ...17

TABELA 2.4 - Relação entre tensões para diferentes dimensões máximas de agregado graúdo obtidas por AITCIN (1989) .20

TABELA 2.5 - Composição do concreto de controle proposta por LARRARD (1990) 36

TABELA 2.6 - Composição de pastas alternativas e previsão da resistência proposta por LARRARD (1990) .36

TABELA 2.7 - Composição teórica do concreto proposta por

LARRARD (1990)

TABELA 2.8 - Dosagens de concreto de alto desempenho segundo GONZALEZ (1993) .38

TABELA 2.9 - Capacidade da máquina de ensaio requerida para concretos de alto desempenho calculadas por AITCIN (1989) .49

TABELA 3.1 - Fatores de conversão propostos pelo CEB (1991) 52

TABELA 3.2 - Fatores de conversão propostos pela Norma Norueguesa (NS 3473, 1989) 
TABELA 3.3 - Fatores de conversão entre os corpos-de-prova obtidos por

LARRARD (1991) .53

TABELA 3.4 - Resistência do concreto (N/mm²) segundo a NS 3473 E (1992) .59

TABELA 3.5 - Valores médios de resistência à tração e resistência à compressão obtidos pela INTEMAC (1992) .63

TABELA 3.6 - Traços de CAD desenvolvidos por MacGREGOR et al. (1995) .69

TABELA 3.7 - Geometria dos corpos-de-prova e resultados dos ensaios de compressão uniaxial realizados por MacGREGOR et al. (1995) .70

TABELA 3.8 - Expressões para cálculo da resistência do concreto na tração direta ....81

TABELA 3.9 - Expressões para cálculo do módulo de elasticidade do concreto .82

TABELA 3.10 - Traço de concreto por $\left(\mathrm{m}^{3}\right)$ utilizado nos ensaios de OLUOKUN et al. (1991a) .83

TABELA 3.11 - Módulo de elasticidade e coeficiente de Poisson obtidos nos ensaios de OLUOKUN et al. (1991a) .83

TABELA 3.12 - Resistência do concreto à tração direta obtida nos ensaios de OLUOKUN et al. (1991a)

TABELA 3.13 - Resistência à compressão e à tração direta obtidas nos ensaios de GRIEB \& WERNER (1962) .84

TABELA 3.14 - Traços de concreto utilizados nos ensaios de FERRARI et al. (1995) .85

TABELA 3.15 - Resultados de ensaios obtidos por FERRARI et al. (1995) .85

TABELA 3.16 - Comparação de resultados teóricos com resultados experimentais obtidos por OLUOKUN et al. (1991a) .86

TABELA 3.17 - Comparação de resultados teóricos com resultados experimentais obtidos por GRIEB \& WERNER (1962) .87

TABELA 3.18 - Comparação de resultados teóricos com resultados experimentais obtidos por FERRARI et al. (1995) .88 
TABELA 3.19 - Comparação de resultados teóricos com resultados experimentais obtidos por OLUOKUN et al. (1991b)

TABELA 3.20 - Comparação de resultados teóricos com resultados experimentais obtidos por FERRARI et al. (1995) 90

TABELA 4.1 - Efeito da taxa volumétrica $\left(\rho_{\mathrm{s}}\right)$ e $\left(\rho_{\mathrm{s}} f_{y} / f_{c}^{\prime}\right)$ no aumento da resistência e na taxa de deformação dúctil segundo RAZVI et al. (1994)

TABELA 4.2 - Efeito do espaçamento dos estribos na resistência e na taxa de deformação dúctil obtidas por RAZVI et al. (1994) .98

TABELA 4.3 - Detalhe dos pilares armados com estribos utilizados no estudo paramétrico realizado por MacGREGOR et al. (1997)

TABELA 4.4 - Detalhe dos pilares armados com estribos para o estudo paramétrico realizado por MacGREGOR et al. (1997) .104

TABELA 4.5 - Coeficiente de comprimento efetivo para estrut. contraventadas .121

TABELA 4.6 - Valores de $\beta$ para pilares contraventados segundo a Norma Inglesa BS 8110 (1985)

TABELA 4.7 - Valores de $\beta$ para pilares não contraventados segundo a Norma Inglesa BS 8110 (1985)

TABELA 4.8 - Valores de $\beta_{\mathrm{a}}$ segundo a BS 8110 (1985) 128

TABELA 4.9 - Valores de $\beta$ para as expressões (4.56) e (4.57) - BS 8110 (1985): $\sec 3.8 .4 .5$ 132

TABELA 5.1 - Esforços nos pilares devido a forças de gravidade 135

TABELA 5.2 - Esforços nos pilares devidos ao peso próprio 156

TABELA 5.3 - Esforços nos pilares devidos ao peso próprio 160 


\section{LISTA DE SÍMBOLOS}

a massa de água por unidade de volume de concreto / altura do diagrama retangular de tensão equivalente / distância média entre o plano de ruptura e o apoio mais próximo da viga;

$a_{\mathrm{u}} \quad$ deslocamento do pilar no estado limite último;

$a_{\text {uav }}$ deslocamento médio de todos os pilares de um dado nível, para o estado limite último;

$A_{c} \quad$ área da seção transversal de concreto;

$A_{c h} \quad$ área da seção transversal medida até a parte externa da armadura transversal;

$A_{g} \quad$ área total da seção transversal do pilar;

$A_{s} \quad$ soma das áreas das seções transversais das barras longitudinais;

$A_{s h} \quad$ área total da seção transversal de estribos retangulares;

$A_{s t} \quad$ área total da armadura longitudinal;

b largura do prisma, largura;

b' dimensão efetiva da seção do pilar, perpendicular ao eixo de menor inércia (y-y);

c massa de cimento por unidade de volume de concreto / distância da fibra extrema comprimida à linha neutra;

d altura útil, distância da fibra extrema de compressão até o centróide da armadura de tração;

C abatimento do tronco de cone;

$\mathrm{C}_{\mathrm{m}}$ fator que relaciona o diagrama real de momento com um diagrama de momento uniforme equivalente;

$d_{i} \quad$ distância da camada de armadura até a fibra mais comprimida;

D dimensão máxima do agregado graúdo;

$e \quad$ excentricidade da força longitudinal em um pilar;

$\mathrm{e}_{\min } \quad$ excentricidade mínima de projeto $(=0,05 \mathrm{~h} \leq 20 \mathrm{~mm}$ na BS 8110$)$;

E módulo de deformação longitudinal;

$\mathrm{E}_{\mathrm{c}}$ módulo de deformação longitudinal do concreto;

$\mathrm{E}_{\mathrm{s}} \quad$ módulo de elasticidade da armadura;

$\mathrm{E}_{\mathrm{cs}}$ módulo de deformação secante do concreto; 
$f_{c} \quad$ resistência do concreto à compressão;

$f_{c(o b r a)}$ resistência do concreto obtida na obra;

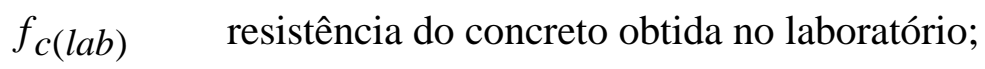

$f_{c}^{\prime} \quad$ resistência à compressão aos 28 dias;

$f_{c c}$ resistência média do concreto à compressão (corpo-de-prova cilíndrico);

$f_{c d}$ resistência de cálculo do concreto à compressão (corpo-de-prova cilíndrico);

$f_{c j}$ resistência média do concreto à compressão, prevista para a idade de j dias;

$f_{c k} \quad$ resistência característica do concreto à compressão;

$f_{c c k}$ resistência característica à compressão referida ao corpo-de-prova cilíndrico, aos 28 dias de idade;

$f_{c n}$ resistência à compressão do concreto na estrutura;

$f_{c t}$ resistência à tração do concreto (ensaio de compressão diametral);

$f_{c t k}$ resistência característica do concreto à tração;

$f_{r} \quad$ resistência à tração do concreto (módulo de ruptura);

$f_{S} \quad$ tensão de cálculo na armadura para cargas de serviço;

$f_{s k} \quad$ resistência característica de plastificação da armadura;

$f_{s p}^{\prime} \quad$ resistência à tração do concreto (ensaio de compressão diametral);

$f_{t} \quad$ resistência à tração do concreto;

$f_{t k}$ resistência característica do concreto à tração;

$f_{\text {tn }}$ resistência nominal à tração do concreto na estrutura;

$f_{y}$ resistência média de escoamento da armadura longitudinal;

$f_{y d}$ resistência de cálculo de escoamento da armadura;

$f_{y h}$ resistência de escoamento da armadura transversal;

$f_{y t}$ resistência de escoamento da armadura transversal;

$h \quad$ altura total da seção transversal;

$h$ ' dimensão efetiva da seção, na direção perpendicular ao eixo de maior inércia (x-X); 
$h_{c} \quad$ dimensão da seção transversal do pilar, medida de centro a centro da armadura de confinamento;

I momento de inércia da seção transversal;

$I_{g}$ momento de inércia da seção total de concreto com relação à linha do centro geométrico, desprezando-se as armaduras;

$k \quad$ fator de comprimento efetivo para elementos comprimidos;

$k_{g} \quad$ parâmetro dependente do tipo de agregado (agregados comuns se aplica o valor de 4,91);

$\ell \quad$ comprimento do vão;

$\ell_{c} \quad$ altura do pilar, centro a centro de lajes;

$\ell_{e} \quad$ altura efetiva de um pilar ou uma parede;

$\ell_{e x} \quad$ altura efetiva com relação ao eixo de maior inércia;

$\ell_{e y} \quad$ altura efetiva com relação ao eixo de menor inércia;

$\ell_{u} \quad$ comprimento não suportado para elementos comprimidos;

$\ell_{o} \quad$ distância livre de um pilar ou parede até as vinculações;

$M_{a d d}$ momento adicional produzido pelo deslocamento da viga;

$M_{c} \quad$ momento fatorado para ser utilizado no cálculo de elementos comprimidos;

$M_{F} \quad$ módulo de finura do agregado graúdo;

$M_{i}$ momento inicial de cálculo em um pilar, antes da consideração dos momentos adicionais de cálculo;

$M_{n} \quad$ resistência nominal ao momento;

$M_{x} \quad$ momento último de projeto com relação ao eixo (x);

$M_{y} \quad$ momento último de projeto com relação ao eixo (y);

$M_{t} \quad$ momento de projeto transferido entre lajes e pilares;

$M_{u} \quad$ momento fatorado da seção;

$M_{1} \quad$ menor valor do momento inicial atuando na extremidade do pilar, devido a cargas últimas de projeto;

$M_{2}$ maior valor do momento inicial atuando na extremidade do pilar, devido a cargas últimas de projeto;

$M_{1 b}$ menor valor do momento fatorado atuando na extremidade do elemento comprimido, devido a cargas que não resultam em deslocamento apreciável. $M_{1 b}$ é positivo se o elemento é fletido com curvatura simples e negativo se for fletido com dupla curvatura; 
$M_{2 b}$ maior valor do momento fatorado atuando na extremidade do elemento comprimido, devido a cargas que resultam em apreciável deslocamento, sempre positivo;

$M_{2 s}$ maior valor do momento fatorado atuando na extremidade do elemento comprimido, devido a cargas que resultam em deslocamento lateral apreciável, calculado através de análise elástica convencional de pórtico;

$n$ número de pilares resistindo deslocamento em um dado nível ou andar;

$N_{d} \quad$ força axial de projeto;

$N_{c r} \quad$ carga crítica elástica de flambagem;

$N_{s d} \quad$ força axial de compressão;

$P \quad$ carga de ruptura / carga axial;

$P_{b} \quad$ resistência à carga axial nominal para condições de deformação balanceada;

$P_{o} \quad$ resistência à carga axial nominal, considerando-se excentricidade zero;

$P_{n} \quad$ resistência à carga axial nominal para uma dada excentricidade;

$P_{u} \quad$ esforço de compressão axial majorado;

r raio de giração da seção transversal de um elemento comprimido;

$R_{C} \quad$ resistência da argamassa de cimento normalizada a 28 dias de idade;

s massa de sílica ativa por unidade de volume de concreto / distância de centro a centro do estribo, medida ao longo da altura do pilar;

$\mathrm{V}_{\mathrm{u}} \quad$ força cortante última;

W peso próprio do concreto (libras/pé cúbico);

$\mathrm{W}_{\mathrm{c}} \quad$ peso próprio do concreto (libras/pé cúbico);

x menor dimensão da seção transversal

y distância do centro geométrico até a fibra mais comprimida / maior dimensão da seção transversal retangular;

z braço de alavanca;

$\alpha \quad$ fator de forma que leva em conta a diferença no tamanho do corpo-de-prova;

$\beta_{1}$ razão entre a altura do diagrama retangular de tensão $(a)$, pela distância até a linha neutra $(c)$;

$\beta_{\mathrm{d}} \quad$ valor absoluto da razão entre o valor do momento máximo fatorado, devido a carga permanente, pelo valor do máximo momento fatorado devido a todas as cargas, sempre positivo; 
$\delta$ razão entre a distância de centro a centro dos níveis de armadura mais externos pela altura do pilar;

$\delta_{b} \quad$ fator de majoração do momento;

$\delta_{S} \quad$ fator de majoração do momento para pórticos não contraventados contra deslocamento, para levar em conta deslocamentos laterais resultantes das cargas laterais e de peso próprio;

$\varepsilon \quad$ deformação específica;

$\varepsilon_{c}^{\prime} \quad$ deformação específica do concreto correspondente a tensão máxima;

$\varepsilon_{\mathrm{cu}}$ deformação última do concreto à compressão;

$\varepsilon_{\ell} \quad$ deformação longitudinal do pilar;

$\varepsilon_{\text {si }} \quad$ deformação em cada camada de armadura;

$\varepsilon_{01}$ deformação correspondente a tensão de pico do concreto não confinado;

$\varepsilon 85$ deformação do concreto para $85 \%$ da tensão de pico na parte descendente da curva;

$\phi \quad$ diâmetro nominal da barra de armadura / coeficiente de redução da resistência;

$v \quad$ coeficiente de Poisson;

$\rho_{s} \quad$ taxa volumétrica da armadura transversal determinada através do volume total da armadura transversal dividido pelo volume de concreto;

$\rho_{t} \quad$ taxa de armadura transversal;

$\rho_{\ell} \quad$ taxa total de armadura longitudinal;

$\sigma_{c} \quad$ tensão normal de compressão do concreto;

$\varphi \quad$ rigidez relativa do elemento;

$\Delta_{u} \quad$ deslocamento lateral computado com teoria elástica de $1^{\circ}$ ordem, devido a forças laterais totais atuando em um pavimento, com relação à parte superior do pavimento e à parte inferior do pavimento. 


\section{RESUMO}

BACCIN, A.G.C. (1998). Fundamentos do concreto de alto desempenho e sua aplicação no projeto de pilares. São Carlos. Dissertação (Mestrado) - Escola de Engenharia de São Carlos, Universidade de São Paulo.

Grandes vantagens econômicas e estruturais são obtidas com a utilização do concreto de alto desempenho (CAD), tais como: redução das seções dos elementos, baixa porosidade e permeabilidade, elevada resistência ao desgaste e menor custo de manutenção. Isto tem contribuído para a crescente aplicação do concreto de alto desempenho, o qual está sendo empregado em vários países, entre os quais: EUA, Noruega, Canadá, Inglaterra, França e Japão.

No Brasil, o concreto de alto desempenho já está sendo utilizado em diferentes tipos de obras, apesar de não existir ainda uma norma específica. Os procedimentos de cálculo e critérios de projetos, recomendados pela Norma Brasileira, ainda estão baseados em resultados experimentais de concretos de baixa resistência.

Em vista disso, este trabalho apresenta um estudo teórico sobre os materiais constituintes do CAD, as quantidades que devem ser empregadas nos concretos e as diferenças existentes na forma de produção e no controle de qualidade.

São também estudadas algumas propriedades mecânicas do concreto de alto desempenho, como resistência à compressão, resistência à tração, módulo de deformação longitudinal, curva tensão-deformação e coeficiente de Poisson.

Várias recomendações são indicadas para projeto de pilares, como taxa mínima de armadura longitudinal e transversal, resistência ao escoamento, espaçamento e configuração da armadura transversal, a fim de se garantir apropriada ductilidade de pilares de concreto de alto desempenho. E por último, têm-se exemplos de dimensionamento de pilares, com base nos procedimentos indicados na norma americana ACI 318-89 e na britânica BS 8110.

Palavras-chave: Concreto de alto desempenho; Propriedades mecânicas; Pilares. 


\section{ABSTRACT}

BACCIN, A.G.C. (1998). Fundamentals of high-performance concrete and its application to columns design. São Carlos. Dissertação (Mestrado) - Escola de Engenharia de São Carlos, Universidade de São Paulo.

Many advantages not only an economical but also from a structural point of view are obtained when using the high-performance concrete (HPC), such as: reduction of element section, low porosity and permeability, high wearing resistance and less cost of maintenance. This has contributed to a growing use of HPC in several countries, among them: USA, Norway, Canada, England, France and Japan.

In Brazil, HPC is being used in different kinds of construction work, although there are no existing standards yet. Procedures of the sizing and desing criteria, recommended by Brazilian standards, are still based in experimental results obtained with low-strength concretes.

Given that, this paper presents a theoretical study on material components of HPC, the amount to be employed on preparation of those concretes and the existing differences on ways of production and quality control.

Also studied are some mechanical properties of HPC, such as: compression strength, tension strength, elasticity modulus, strain-strength curve and Poisson's ratio.

Several recommendation are pointed out for columns design, such as: minimun rate of both longitudinal and transverse reinforcements, yielding strength, spacing and lay out of transversal reinforcement to provide adequate ductility of columns made with HPC. Lastly examples of design of columns based on American standard ACI 318-89 and British standard BS 8110 are given.

Keywords: High-performance concrete; Mechanical properties; Columns. 


\section{1)}

Atualmente, observa-se um grande dinamismo da tecnologia face à evolução do conhecimento. Dentro dessa evolução, pode-se dizer que ocorreram notáveis progressos na técnica e no cálculo estrutural, a partir da utilização de novos programas e recursos computacionais. Aliado à revolução obtida com a informática, tem-se um melhor conhecimento das propriedades físicas e mecânicas tanto do concreto como do aço. Isto tem possibilitado o desenvolvimento de estruturas cada vez mais ousadas, tanto de concreto armado como de concreto protendido.

Nessas estruturas, o concreto passou a ser submetido a tensões mais elevadas, criando a necessidade do desenvolvimento de técnicas e estudos científicos mais apurados, que permitissem um melhor entendimento da distribuição dos esforços e comportamento da estrutura, bem como da necessidade de se elevar a resistência característica do concreto empregado nos diferentes tipos de obras.

A partir dos anos 60, ou mais especificamente dos anos 70, ocorreram vários fatores que iriam contribuir para o desenvolvimento da indústria do concreto, tais como:

- A tecnologia alcançada pelas indústrias produtoras de cimento possibilitou a produção de cimentos com melhores características de desempenho;

- No Japão e na Alemanha, as indústrias químicas começaram a desenvolver aditivos químicos superfluidificantes, baseados em complexas moléculas orgânicas, os quais permitiriam uma drástica redução da água de amassamento, proporcionando um grande acréscimo na resistência do concreto; 
- Começaram a ocorrer pesquisas no Canadá e nos países nórdicos, com o objetivo de encontrar destino viável para o subproduto volátil das indústrias produtoras de silício e ligas de ferro-silício, denominado sílica ativa, o qual iria revolucionar a produção do concreto.

A resistência do concreto foi aumentando com o passar dos anos, como pode ser acompanhado na figura 1.1.

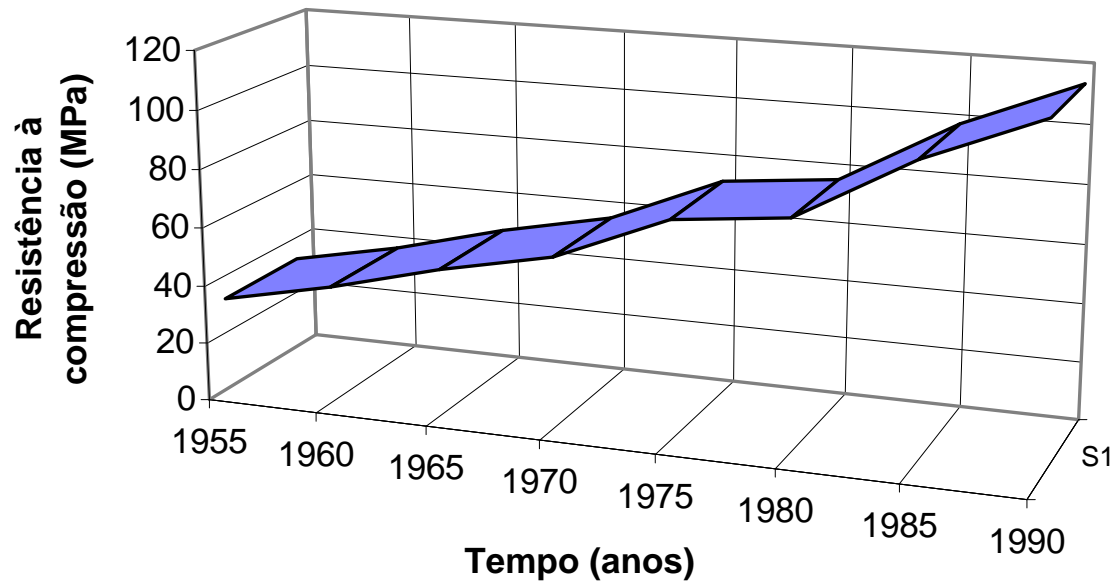

FIGURA 1.1 - Evolução no tempo do concreto de alto desempenho. FONTE: GONZALEZ G. I. (1993).

Ainda hoje, não há uma concordância entre os especialistas na aceitação de um valor que possa representar o limite entre os concretos de baixa e de alta resistência.

Por volta da metade da década de 1950, nos EUA, um concreto com resistência à compressão de $34 \mathrm{MPa}$ era considerado de alta resistência. Nos anos 60, concretos com resistência compreendida entre $41 \mathrm{MPa}$ e $52 \mathrm{MPa}$ passavam a receber a classificação de concreto de alta resistência. Hoje em dia, concretos com resistência à compressão entre $98 \mathrm{MPa}$ e $112 \mathrm{MPa}$ estão sendo produzidos comercialmente e utilizados na indústria da construção nos EUA. Outros países, tais como Noruega, Canadá, Inglaterra, França e Japão, estão empregando em larga escala a tecnologia do concreto de alto desempenho na construção civil.

O termo concreto de "alta resistência" é constantemente discutido e deve ser reconsiderado, pois não só a resistência à compressão é melhorada, mas também outras propriedades, tais como: facilidade de compactação, maior resistência ao 
ataque de agentes agressivos, permeabilidade, porosidade, durabilidade e deformações. Portanto, o termo mais adequado para designar esses concretos é "concreto de alto desempenho", também denominado CAD.

Portanto, concretos de alto desempenho são aqueles com propriedades ou atributos que satisfazem a vários critérios de desempenho.

Segundo os pesquisadores da Strategic Highway Research Program on High Performance Concrete ${ }^{1}$ apud SHAH \& AHMAD (1994), o concreto de alto desempenho pode ser definido em termos da resistência, da durabilidade e da relação água/cimento, como pode ser visto a seguir:

a) Com relação à resistência, deve-se ter alguma das seguintes características:

- Resistência à compressão $\geq 17,5 \mathrm{MPa}$ às 4 horas de idade,

- Resistência à compressão $\geq 35$ MPa depois de 24 horas de idade,

- Resistência à compressão $\geq 70 \mathrm{MPa}$ depois de 28 dias de idade.

b) Deve ter um fator de durabilidade maior do que $80 \%$ depois de 300 ciclos de congelamento e descongelamento.

c) Deve ter relação água/cimento $<0,35$.

Na América do Norte, concreto de alta resistência é admitido como tal quando se tem uma resistência à compressão aos 28 dias de pelo menos $42 \mathrm{MPa}$.

Segundo AITCIN² apud GONZALEZ (1993), a classificação do concreto de alto desempenho pode ser feita em quatro categorias, definidas mediante valores crescentes de resistências: $75 \mathrm{MPa}, 100 \mathrm{MPa}, 125 \mathrm{MPa}$ e $150 \mathrm{MPa}$ (referidas ao corpo-de-prova cilíndrico de $100 \mathrm{~mm}$ x $200 \mathrm{~mm}$ e aos 91 dias de idade). A justificativa dessa classificação se dá em função da dificuldade tecnológica em se obter cada uma dessas resistências.

${ }^{1}$ SHRP-C/FR-91-103 (1991). High performance concretes, a state of the art report. Strategic Highway Research Program, National Research Council, Washington, DC. apud SHAH, S.P. \& AHMAD, S.H., eds (1994). High performance concretes and applications. London, Edwar Arnold. 403p.

${ }^{2}$ AITCIN, P.C. (1989). Les bétons à très haute resistance. Bull. Liaison Lab. P.et Ch. $\mathrm{N}^{\circ}$ 162, apud GONZALEZ G. I. (1993). Hormigon de alta resistencia. Madrid. Abril. pp.24. 
De LARRARD ${ }^{3}$ et al. apud GONZALEZ (1991) definem o CAD como o concreto cuja resistência, medida em corpos-de-prova cilíndricos, está compreendida entre $50 \mathrm{MPa}$ e $80 \mathrm{MPa}$. Para estes autores, concretos com resistência superior

$80 \mathrm{MPa}$ merecem a classificação de concretos de resistência muito alta.

$\mathrm{Na}$ Noruega, um dos países pioneiros no estudo dos concretos de alto desempenho, considera-se como tal aqueles concretos com resistência à compressão superior a $55 \mathrm{MPa}$, referida ao corpo-de-prova cúbico (aresta de $10 \mathrm{~cm}$ ). Adicionalmente, são exigidas duas condições: uma relativa à sua relação água/(cimento + adições) e outra referida ao seu coeficiente de permeabilidade.

Ao que tudo indica, o FIP/CEB-197 (1990) é possivelmente o código que melhor reconhece as perspectivas atuais e futuras destes concretos. Para o FIP/CEB197 (1990), concretos de alto desempenho são concretos cuja resistência à compressão, determinada em corpos-de-prova cilíndricos, está compreendida entre os limites de $60 \mathrm{MPa}$ e $130 \mathrm{MPa}$.

Um dos processos mais usuais para a obtenção do concreto de alto desempenho consiste na utilização de cimento Portland comum, adição de sílica ativa ( $8 \%$ a $10 \%$ do peso de cimento), uso de superplastificante (5 a 20 litros $/ \mathrm{m}^{3}$ ), dimensão máxima do agregado graúdo $(10 \mathrm{~mm}$ a $12 \mathrm{~mm})$ e agregado miúdo (módulo de finura entre 2,7 a 3,2), a fim de se obter uma relação água/(cimento + adições) muito baixa, em torno de 0,25 a 0,3 .

Em linhas gerais, pode-se dizer que as vantagens obtidas a partir da utilização do concreto de alto desempenho são:

- $\quad$ Baixa porosidade e permeabilidade;

- Baixas deformações, sejam por retração, deformação imediata ou fluência;

- Elevada resistência ao desgaste ou abrasão;

- Utilização de métodos convencionais de mistura, lançamento, adensamento e cura;

\footnotetext{
${ }^{3}$ De LARRARD, F. \& BOSTVIRONNOIS, J. L. (1991). Mag. Conc-Res. № 155. pp. 109-119. apud GONZALEZ G. I. (1993). Hormigon de alta resistencia. Madrid. Abril. pp. 24.
} 
- Grande fluidez na moldagem;

- Altas resistências nas primeiras idades;

- Diminuição das dimensões dos elementos estruturais;

- Menor volume de concreto e menor superfície de formas;

- Diminuição das cargas nas fundações;

- $\quad$ Ausência de exsudação;

- Excelente aderência a concretos já endurecidos.

\subsection{OBJETIVOS}

Atualmente, a bibliografia a respeito do concreto de alto desempenho é ampla e está sendo bastante difundida no meio acadêmico. Este promove inúmeras pesquisas, gerando informações necessárias para a aplicação desse novo material. Entretanto, apesar da crescente aplicação do concreto de alto desempenho em diferentes tipos de obras no Brasil, tem-se que os procedimentos de cálculo e os critérios de projetos, recomendados pela Norma Brasileira, ainda estão baseados em resultados experimentais de concretos de baixa resistência. Em função de evidentes mudanças no comportamento e nas propriedades físicas e mecânicas do concreto de alto desempenho, comparadas com o concreto usual, faz com que seja necessária uma reavaliação dos procedimentos descritos nessa norma.

Em vista disso, tem-se como proposta de trabalho um melhor conhecimento dos materiais constituintes do concreto de alto desempenho, da quantidade que os mesmos devem ser empregados nos traços de concretos, das alterações existentes na forma de produção do concreto de alto desempenho e dos diferentes procedimentos adotados para controle de qualidade do CAD.

Pretende-se também estudar algumas propriedades mecânicas do concreto de alto desempenho, tais como: resistência à compressão, resistência à tração, módulo de deformação longitudinal, relação tensão-deformação e coeficiente de Poisson, para posteriormente analisar o comportamento de pilares submetidos a compressão simples e compressão excêntrica, quando da aplicação do CAD. 
No estudo de pilares, pretende-se verificar se as hipóteses de cálculo e os critérios de projetos usuais podem ser aceitos para o CAD, fornecer subsídios para cálculo de pilares, através do estudo de normas estrangeiras (ACI, Norueguesa, FIPCEB, Eurocode), comparar os resultados obtidos através da utilização dessas normas com resultados experimentais, contribuindo dessa forma para a normalização e a utilização desse material com maior segurança e economia.

\subsection{APRESENTAÇÃO DO TRABALHO}

Ao longo deste trabalho, serão apresentados no capítulo 2 os materiais constituintes do concreto de alto desempenho, tais como: tipo de cimento, agregado graúdo, agregado miúdo, adições minerais como sílica ativa, cinza volante, escória de alto forno e aditivos. Serão feitas considerações sobre dosagem do concreto de alto desempenho e os cuidados necessários para produção, tais como: estrito controle de qualidade dos componentes, atenção especial para invariabilidade da relação água/cimento, dosagem em peso de todos os materiais constituintes, determinação periódica da granulometria e umidade dos agregados. Ainda no capítulo 2, serão discutidos os procedimentos para controle de qualidade do concreto de alto desempenho, como tipos de ensaios, idade de realização dos ensaios, tipo de molde para os corpos-de-prova, condições de capeamento do corpode-prova e características das máquinas de ensaio.

No capítulo 3, serão estudadas algumas propriedades mecânicas do concreto de alto desempenho, tais como: resistência à compressão e à tração, relação tensãodeformação, módulo de deformação longitudinal e coeficiente de Poisson.

No capítulo 4, serão estudados os pilares de concreto de alto desempenho, procurando destacar quais as diferenças existentes no comportamento desses pilares com relação aos pilares de concreto de resistência usual, tais como: perda prematura do recobrimento das armaduras no $\mathrm{CAD}$ e maior necessidade de armadura de confinamento, em função de seu comportamento frágil. Ainda no capítulo 4, serão estudados alguns critérios de projeto de pilares, tais como: dimensão mínima recomendada para seção transversal dos pilares, escolha do tipo de armadura transversal, taxa mínima de armadura transversal, taxa mínima de armadura 
longitudinal, diâmetro mínimo para armadura transversal, espaçamento máximo dos estribos, detalhamento dos estribos, hipóteses de cálculo para dimensionamento de pilares submetidos a compressão centrada e a compressão excêntrica, recomendadas por algumas normas como ACI e Norma Inglesa (BS 8110), que já estão adequadas ao concreto de alto desempenho.

No capítulo 5, têm-se aplicações numéricas, com o dimensionamento de pilares esbeltos interiores, de extremidade e de canto, de um edifício de 5 pavimentos, conforme recomendações de cálculo do ACI 318-89. Ainda no capítulo 5, são feitos exemplos de dimensionamento de pilar contraventado e não contraventado, de acordo com as recomendações existentes na Norma Inglesa (BS 8110).

\subsection{APLICAÇÕES DO CONCRETO DE ALTO DESEMPENHO}

Em função da grande resistência e durabilidade, os concretos de alto desempenho têm sido utilizados em diferentes tipos de construções ao longo de todo mundo, como pode ser visto a seguir.

\subsubsection{Edifícios}

Pode-se dizer que a maior aplicação do concreto de alto desempenho é na execução de pilares, em edifícios de grande altura. Nestes, o concreto de alto desempenho possibilita diminuir as dimensões das seções, em função do acréscimo de resistência, principalmente para os pilares dos pavimentos inferiores, onde os carregamentos são maiores, proporcionando um melhor aproveitamento do espaço útil.

Outro aspecto vantajoso, na utilização do concreto de alto desempenho para os edifícios, consiste no aumento do módulo de deformação longitudinal, proporcionando maior rigidez para os pilares.

E por último, cabe destacar a facilidade de colocação e de compactação do concreto, que é de fundamental importância em estruturas com elevadas taxas de armadura. 
No Brasil, a obra pioneira no uso de concreto de alto desempenho foi o Edifício Trianon, que abriga o Museu de Arte de São Paulo (MASP), construído em meados da década de 60. O concreto empregado apresentou uma resistência característica à compressão de $45 \mathrm{MPa}$ aos 28 dias.

Tem-se na tabela 1.1 uma relação de edifícios construídos com concreto de alto desempenho.

\subsubsection{Pontes}

Nas pontes com grandes vãos, o concreto de alto desempenho é empregado com o objetivo de reduzir o peso próprio e aumentar a durabilidade de pilares e vigas protendidas de tabuleiros, em função da sua menor porosidade e permeabilidade, pois impede a ação de agentes químicos como sulfatos, nitratos e cloretos.

Na Noruega, o ministério de transporte exige nas pontes o uso de concretos cuja relação água/(cimento + adições) seja inferior a 0,40 , sendo obrigatória a incorporação de cinza volante ou de sílica ativa.

$\mathrm{Na}$ Dinamarca, as características de durabilidade se impõem mediante a utilização de concretos com relação água/(cimento + adições) inferiores a 0,35 e resistência à compressão compreendida entre 50MPa e $60 \mathrm{MPa}$.

Tem-se na tabela 1.2 uma relação de pontes, nas quais foi empregado o concreto de alto desempenho.

\subsubsection{Plataformas de petróleo}

O concreto de alto desempenho tem sido utilizado nas estruturas de todas as plataformas de petróleo construídas no Mar do Norte. Essa grande utilização se dá em função da grande capacidade do material de suportar a ação de agentes agressivos, menor custo de manutenção e grande durabilidade.

Convém destacar ainda a facilidade de moldagem dos elementos em função da grande fluidez do concreto, possibilitando em alguns casos a concretagem de estruturas cujas taxas de armadura em determinadas posições alcançam os $1.000 \mathrm{~kg}$ de aço por metro cúbico de concreto. Ainda com relação às propriedades favoráveis 
do concreto de alto desempenho, tem-se: resistência à abrasão e resistência ao choque.

Tem-se na tabela 1.3 uma relação de algumas plataformas de petróleo construídas com concreto de alto desempenho.

\subsubsection{Aplicações especiais}

Numerosos exemplos de diversas obras encontram-se espalhados por vários países. A seguir encontram-se alguns exemplos da aplicação do concreto de alto desempenho.

- Estrutura de sustentação de tubulação de gás, construída em 1982, na costa da Noruega, com um comprimento total de 590 metros, disposta em diferentes profundidades, atingindo uma profundidade máxima de $30 \mathrm{~m}$. Foram empregados elementos pré-fabricados com concretos de resistência compreendida entre $65 \mathrm{MPa}$ e $75 \mathrm{MPa}$.

- Coberturas de um hipódromo em Doncaster (Inglaterra) e outro em Leopardstown (Irlanda), fabricadas com concreto de alto desempenho, feito a partir de agregados leves, com resistência de $52 \mathrm{MPa}$.

- Estrutura de elementos pré-fabricados de concreto de alto desempenho (75 MPa) no Japão, para proteção de estradas com relação a avalanches de neve e de materiais soltos.

- Depósito e caixas fortes de segurança, utilizando concretos com níveis de resistência compreendidos entre 95 MPa e 100 MPa, em Turim (Itália), em 1988.

- Pavimentos de autovias foram realizados na Noruega, empregando-se concreto de alto desempenho, com a finalidade de verificar seu comportamento frente aos esforços de abrasão, impostos por condições de tráfico especialmente agressivas (pneus reforçados com cravos metálicos para melhorar sua aderência ao pavimento e baixas temperaturas 
superficiais). Após 6 anos de análise, os resultados obtidos foram muito positivos.

- Passarela pré-fabricada em tramos e protendida com pós-tensão, construída em Montreal (Canadá). A passarela foi construída com concreto de alto desempenho com resistência à compressão de $250 \mathrm{MPa}$ e apresenta espessura da laje do tabuleiro do piso de apenas $3 \mathrm{~cm}$.

- Pátio da indústria de papel e celulose Domtar Papers, em Windsor (Canadá), construído para depósito de toras de madeira, com área de $87.000 \mathrm{~m}^{2}$ equivalente a 16 campos de futebol, de concreto de alto desempenho compactado com rolo. A laje construída sem juntas, ao longo de 45 dias, é a sexta maior do mundo.

TABELA 1.1 - Edifícios construídos com concreto de alto desempenho.

\begin{tabular}{||l|c|c|c|c||}
\hline \multicolumn{1}{|c|}{ Edifício } & $\begin{array}{c}\text { Localizaçã } \\
\text { o }\end{array}$ & Ano & $\begin{array}{c}\mathbf{N}^{\circ} \text { de } \\
\text { pavimentos }\end{array}$ & $\begin{array}{c}\text { Resistência } \\
\text { (MPa) }\end{array}$ \\
\hline Lake Point Tower & Chicago & 1965 & 70 & 52 \\
\hline Water Tower Place & Chicago & 1975 & 79 & 62 \\
\hline Royal Bank Plaza & Toronto & 1975 & 43 & 61 \\
\hline Helmsley Palace Hotel & New York & 1978 & 53 & 55 \\
\hline Texas Commerce Tower & Houston & 1981 & 75 & 52 \\
\hline Columbia Center & Seattle & 1983 & 76 & 66 \\
\hline Interfirst Plaza & Dallas & 1983 & 76 & 69 \\
\hline 900 N. Mich. Annex & Chicago & 1986 & 15 & 97 \\
\hline $\begin{array}{l}\text { Grande Arche de la } \\
\text { Défense }\end{array}$ & Paris & 1988 & --- & 65 \\
\hline Bank of China Tower & Hong Kong & 1988 & 72 & ---- \\
\hline South Wacker Tower & Chicago & 1989 & 79 & 83 \\
\hline Two Union Square & Seattle & 1989 & 58 & 115 \\
\hline
\end{tabular}

FONTE: FIP/CEB-197 (1990). 
TABELA 1.2 - Pontes construídas com concreto de alto desempenho.

\begin{tabular}{||l|c|c|c|c||}
\hline \multicolumn{1}{|c|}{ Ponte } & $\begin{array}{c}\text { Localizaçã } \\
\text { o }\end{array}$ & Ano & $\begin{array}{c}\text { Vão máximo } \\
\text { (m) }\end{array}$ & $\begin{array}{c}\text { Resistência } \\
\text { (MPa) }\end{array}$ \\
\hline Willows Bridge & Toronto & 1967 & 48 & 41 \\
\hline Kaminoshima Highway B. & Japão & 1970 & 86 & 59 \\
\hline Ootanabe Railway Bridge & Japão & 1973 & 24 & 79 \\
\hline Selbjorn Bridge & Noruega & 1977 & 212 & 40 \\
\hline Pasco-Kennewick intercity & Washington & 1978 & 299 & 41 \\
\hline Deutzer Bridge & Alemanha & 1978 & 185 & 43 \\
\hline Parrot Ferry Bridge & California & 1979 & 195 & 41 \\
\hline Houston Ship Chanal & Texas & 1981 & 229 & 55 \\
\hline Huntington to Proctorville & Ohio & 1984 & 274 & 65 \\
\hline Pont du Pertuiset & França & 1988 & 110 & 60 \\
\hline Boknasundet & Noruega & 1990 & 190 & 65 \\
\hline Helgelandsbrua & Noruega & 1990 & 425 & \\
\hline
\end{tabular}

FONTE: FIP/CEB-197 (1990).

TABELA 1.3 - Plataformas de petróleo construídas com concreto de alto desempenho.

\begin{tabular}{||l|c|c|c|c||}
\hline \multirow{2}{*}{\multicolumn{1}{c|}{ Plataforma }} & \multirow{2}{*}{ Ano } & \multicolumn{3}{c|}{$\begin{array}{r}\text { Resistência aos 28 dias em MPa } \\
\text { (corpo-de-prova cilíndrico) }\end{array}$} \\
\cline { 3 - 5 } & & De projeto & Média obtida & Resist. real \\
\hline Ekofisk 1 & 1972 & 40 & 45 & 41,6 \\
\hline Beryl A & 1974 & 45 & 55 & 50,7 \\
\hline Frigg MP-2 & 1976 & 40 & 56 & 49,8 \\
\hline Ninian Central & 1978 & 50 & 59 & 53,1 \\
\hline Statfjord B & 1979 & 55 & 62,5 & 56,9 \\
\hline Gulfaks A & 1984 & 55 & 65,2 & 60,3 \\
\hline T300. Testmodel & 1984 & 65 & 84,5 & 74,4 \\
\hline Oseberg A & 1985 & 60 & 76,7 & 71,5 \\
\hline Gulfaks C & 1986 & $65 / 70$ & 79 & 75 \\
\hline
\end{tabular}

FONTE: FIP/CEB-197 (1990). 


\section{MATERIAIS CONSTITUINTES E PRODUÇÃO DO CONCRETO DE ALTO DESEMPENHO}

Os materiais constituintes do concreto de alto desempenho são em princípio os mesmos empregados em concretos tradicionais. Entretanto, o objetivo de se obter resistências à compressão iguais ou superiores a $60 \mathrm{MPa}$, aos 28 dias de idade, implica na necessidade de adotar materiais selecionados e relações água/cimento não superiores a 0,40. Devido à utilização de relações água/cimento muito baixas, tornase indispensável a utilização de aditivos superplastificantes. Com um estudo adequado das características dos materiais disponíveis, uso de proporções corretas, e baixas relações água/cimento, conseguem-se resistências à compressão por volta de $80 \mathrm{MPa}$.

Níveis de resistências superiores a $80 \mathrm{MPa}$ resultam na necessidade de utilização de adições minerais na composição do concreto, onde freqüentemente emprega-se a sílica ativa.

O concreto de alto desempenho apresenta particularidades, que o distingue claramente, dos concretos utilizados normalmente na estrutura dos edifícios, tanto com relação às suas propriedades mecânicas, quanto à sua forma de obtenção.

São estritamente proibidas a maneira habitual de se armazenar a matéria prima ao ar livre, a medição de componentes em volume, a adição de água (sem muito controle) e a incorporação de aditivos de qualidade não comprovada para a produção de concretos de alto desempenho.

Outra modificação importante com relação aos concretos de alto desempenho, diz respeito a relação água/cimento, que deve ser a mínima possível, para conseguir a hidratação dos materiais cimentícios (cimento + adições minerais).

Outra diferença existente entre o concreto de alto desempenho e o concreto 
tradicional, e que merece destaque, é que nos concretos tradicionais, a dosagem de cimento e água habitualmente utilizada, conferem à pasta de cimento uma característica resistente muito inferior à do agregado graúdo. Como conseqüência, tem-se a ruptura do concreto geralmente por esgotamento da capacidade da pasta. Isto pode ser comprovado nos processos de controle de qualidade do concreto, onde as fissuras propagam-se na matriz de cimento até encontrar o agregado graúdo, circundando-o sem afetá-lo. Já no concreto de alto desempenho, tem-se um aumento da capacidade resistente da argamassa, a qual supera a resistência do agregado, fazendo com que a fissura ocorra através do agregado cortando-o e não mais contornando-o. Dessa maneira, a resistência dos agregados usuais passam agora a ser os delimitadores da resistência do concreto.

\subsection{MICROESTRUTURA DO CONCRETO}

O concreto é considerado tradicionalmente, como um material formado por agregados envoltos em uma matriz de pasta de cimento. As propriedades mecânicas desse concreto dependem das propriedades dos referidos componentes básicos, da proporção entre eles e das características físico-químicas da sua interface.

Com relação à composição do concreto, pode-se dizer que ele é composto de $65 \%$ a $75 \%$ de agregados e $25 \%$ a $35 \%$ de pasta de cimento. Quantidades de agregados inferiores a $65 \%$ (em volume) do total de componentes, afetam negativamente a estabilidade dimensional do concreto, devido à retração.

A pasta de cimento endurecida é um material poroso e heterogêneo. Seu grau de porosidade e heterogeneidade constitui um fator decisivo na durabilidade e resistência do concreto.

Segundo MINDESS ${ }^{1}$ apud GONZALEZ (1993), são três as alternativas que conduzem ao aumento da resistência para a pasta de cimento:

- Diminuição da porosidade total;

- Melhora na distribuição e tamanho dos poros (reduzindo tanto sua quantidade, como seu tamanho máximo e eliminando defeitos pontuais

${ }^{1}$ MINDESS, S. (1984). Relationships between strength and microstructure for cement-based materials: an overview. Material Research Society Symposia Proceedings, Volume 42, 
localizados);

- Melhora da qualidade dos silicatos cálcicos hidratados do cimento.

E finalmente, pode-se dizer que a obtenção de concretos de alta resistência, pode ser feita através das seguintes considerações:

- Adoção de uma baixa relação água/cimento;

- Uso obrigatório de aditivos superplastificantes;

- Utilização de cimentos que proporcionem resistência adequada;

- Para resistências muito elevadas, geralmente, faz-se uso de adições minerais.

\subsection{CIMENTO}

Segundo HOWARD \& LEATHAM² apud DAL MOLIN (1995), não existem critérios científicos que especifiquem o cimento mais adequado para a produção de concreto de alto desempenho. Mas de qualquer forma, o cimento deve proporcionar apropriada resistência e comportamento reológico.

MEHTA \& $\operatorname{AITCIN}^{3}$ (1990) comentam que com qualquer tipo de cimento é possível produzir concretos de alto desempenho, sendo preferível, no entanto, cimento Portland comum e aqueles com elevados teores de $\mathrm{C}_{3} \mathrm{~S}$ (silicato tricálcico) e $\mathrm{C}_{2} \mathrm{~S}$ (silicato bicálcico). Além desses dois componentes, tem-se na composição do cimento o $\mathrm{C}_{3} \mathrm{~A}$ (aluminato tricálcico).

$\mathrm{O} \mathrm{C}_{3} \mathrm{~S}$ contribui decisivamente para a resistência nas primeiras idades e na resistência final do concreto. $\mathrm{O} \mathrm{C}_{2} \mathrm{~S}$ tem menor incidência no começo, porém sua importância é no ganho de resistência final do concreto. Já o $\mathrm{C}_{3} \mathrm{~A}$ tem uma particular influência nas primeiras idades.

Se não for necessária uma alta resistência inicial, pode-se escolher um

Pennsylvania apud GONZALEZ G. I. (1993). Hormigon de Alta Resistencia. Madrid, Intemac. Abril. pp. 24.

${ }^{2}$ HOWARD, N. L. \& LEATHAM, D. M. (1989). Silica in concrete: permeability. Trondheim: Cement and Concrete Research Institute, The Norwegian Institute of Technology apud DAL MOLIN, D.C.C. Contribuição ao estudo das propriedades mecânicas dos concretos de alta resistência com e sem adições de microssílica. São Paulo, 1995. 224p. Tese (Doutorado) Escola Politécnica, Universidade de São Paulo.

${ }^{3}$ MEHTA, P. K. \& AITCIN, P. C. (1990). Microstructural basis of selection of materials and mix proportions for high strength concrete. In: INTERNATIONAL SYMPOSIUM ON 
cimento que contenha uma menor quantidade de $\mathrm{C}_{3} \mathrm{~A}$ e uma maior quantidade de $\mathrm{C}_{3} \mathrm{~S}$ e especialmente $\mathrm{C}_{2} \mathrm{~S}$, conseguindo dessa maneira, uma composição do cimento que trará efeitos favoráveis para a resistência final do concreto.

Segundo GONZALEZ (1993), a perda de consistência da pasta de cimento constituída de cimento Portland está associada à formação de um composto denominado etringita (sulfoaluminato de cálcio hidratado - $\mathrm{C}_{6} \mathrm{AS}_{3} \mathrm{H}_{32}$ ).

Em um estudo publicado por HANNA ${ }^{4}$ et al. (1989) apud GONZALEZ (1993), fica claramente demonstrada a influência das características físicas e químicas do cimento na reologia de distintas pastas de cimento hidratadas. Estes autores empregaram 13 cimentos Portland diferentes, procedentes da América, Canadá e França e um superplastificante (um formaldeído nafto-sulfonado), nos quais para avaliar a perda de fluidez, fez-se passar 1 litro de pasta de cimento através de um êmbolo como o cone de Marsh modificado $(350 \mathrm{~mm}$ de altura, $150 \mathrm{~mm}$ de diâmetro e $5 \mathrm{~mm}$ de diâmetro inferior).

Os resultados desse experimento para uma relação água/cimento de 0,35 podem ser vistos na figura 2.1. É indicado também os conteúdos de $\mathrm{C}_{3} \mathrm{~A}$ nos cimentos empregados, na tabela 2.1 .

TABELA 2.1 - Conteúdo de aluminato tricálcico $\left(\mathrm{C}_{3} \mathrm{~A}\right)$ nos cimentos. HANNA et al. (1989).

\begin{tabular}{||c|c|c|c|c|c|c|c||}
\hline $\mathbf{N}^{\circ}$ do cimento & 1 a $4,7,8$ e 11 & 5 & 6 & 9 & 10 & 12 & 13 \\
\hline Conteúdo de $\mathbf{C}_{3} \mathbf{A}(\%)$ & $<8,0$ & $<9,7$ & $<8,3$ & $<12,7$ & $<11,0$ & $<8,9$ & $<14,4$ \\
\hline
\end{tabular}

Com base nos resultados, HANNA (1989) estabelece que o conteúdo de $\mathrm{C}_{3} \mathrm{~A}$ é determinante na velocidade e quantidade de formação de etringita, destacando ainda que valores superiores a $8 \%$ são a causa fundamental da perda de fluidez no concreto, juntamente com elevados conteúdos de álcali, sulfatos e excessiva finura do cimento.

UTILIZATION OF HIGH STRENGTH CONCRETE, 2., Detroit, American Concrete Institute, p.265-286. (SP-121).

${ }^{4}$ HANNA, E. \& LUKE, K. \& PERRATON, D. \& AITCIN, P. C. (1989). Rheological Behavior of Portland Cement Pastes in the Presence of a Superplasticizer. ACI SP-119, pp.171-188 apud GONZALEZ G. I. (1993). Hormigon de Alta Resistencia. Madrid, Intemac. Abril. pp.34. 


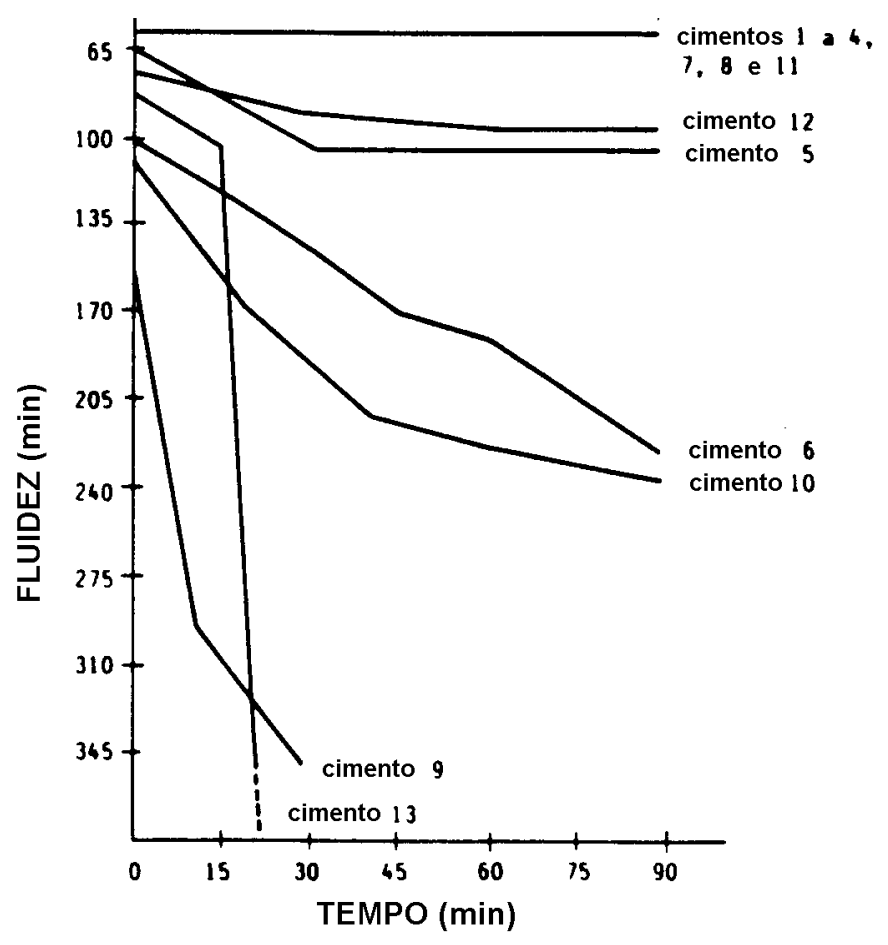

FIGURA 2.1 - Variação da fluidez com o tempo. FONTE: GONZALEZ G. I. (1993).

Concreto de alto desempenho tem sido produzido com sucesso, utilizando-se as especificações da American Society for Testing and Materials (ASTM) C150 para cimentos Portland tipos I, II, e III. Entretanto, na escolha do cimento, deve-se tomar cuidado com a sua textura. Cimentos com textura muito fina proporcionam um aumento da resistência nas primeiras idades, pois a área superficial em contato com a água é maior e isso leva a uma hidratação mais rápida.

Atualmente, além dos cimentos existentes em conformidade com a ASTM, estão sendo formulados novos cimentos destinados especialmente para a produção de concretos de alto desempenho. Na Noruega, já existem dois tipos de cimentos especiais para produção de CAD (SP30-4A e SP30-4A MOD).

A tabela 2.2, apresenta uma comparação da composição química desses cimentos com o SP30, que é o cimento Portland comum.

Na tabela 2.3 são apresentadas algumas especificações exigidas pela RC- $88^{5}$, aos distintos tipos de cimentos espanhóis, cuja utilização poderia ser considerada, a princípio, para a fabricação de concretos de alto desempenho.

\footnotetext{
${ }^{5}$ Norma de Prescrições Técnicas Gerais Espanhola para recebimento de cimentos de 1988.
} 
TABELA 2.2 - Composição de cimentos especiais para CAD segundo Norcem Cement (1990).

\begin{tabular}{|c|c|c|c|}
\hline Cimentos/Composição & SP30* & SP30-4A & SP30-4AMOD \\
\hline $\mathrm{C}_{2} \mathrm{~S}(\%)$ & 18 & 28 & 28 \\
\hline $\mathrm{C}_{3} \mathrm{~S}(\%)$ & 55 & 50 & 50 \\
\hline $\mathrm{C}_{3} \mathrm{~A}(\%)$ & 8 & 5,5 & 5,5 \\
\hline $\mathrm{C}_{4} \mathrm{AF}(\%)$ & 9 & 9 & 9 \\
\hline $\mathrm{Mg}_{\mathrm{g}} \mathrm{O}(\%)$ & 3 & $1,5-2,0$ & $1,5-2,0$ \\
\hline $\mathrm{SO}_{3}(\%)$ & 3,3 & $2,0-3,0$ & $2,0-3,0$ \\
\hline $\mathrm{Na}_{2} \mathrm{O}(\%)$ & 1,1 & 0,6 & 0,6 \\
\hline Finura $\left(\mathrm{m}^{2} / \mathrm{kg}\right)$ & 300 & 310 & 400 \\
\hline Calor de hidratação (kcal/kg) & 71 & 56 & 70 \\
\hline $\begin{array}{c}\text { Tempo de pega (min) } \\
\text { inicial ..................... } \\
\text { final ......................... }\end{array}$ & $\begin{array}{l}120 \\
180\end{array}$ & $\begin{array}{l}140 \\
200\end{array}$ & $\begin{array}{l}120 \\
170\end{array}$ \\
\hline
\end{tabular}

FONTE: SHAH \& AHMAD (1994).

$\mathrm{SP} 30^{*}$ - Cimento Portland comum para comparação $\left(1 \mathrm{~m}^{2} / \mathrm{kg}\right)$.

TABELA 2.3 - Condições exigidas aos cimentos espanhóis segundo RC- $88^{5}$ (1988).

\begin{tabular}{|c|c|c|c|c|c|}
\hline \multirow{3}{*}{$\begin{array}{c}\text { Especificações } \\
\text { Composição }\end{array}$} & \multicolumn{5}{|c|}{ Denominação e tipo de cimento } \\
\hline & \multicolumn{5}{|c|}{ PORTLAND } \\
\hline & I-0/55 A & I-0/45 A & I/55 A & I/55 & I/45 A \\
\hline Clínker, C (\%)........ & 100 & 100 & 95 C 99 & 95 C 99 & 95 C 99 \\
\hline Comp. adicionais A (\%) * & 0 & 0 & 1 A 5 & 1 A 5 & 1 A 5 \\
\hline Pozolana natural P (\%)..... & ----- & ----- & ----- & ----- & ----- \\
\hline Resistência mecânica, R: & & & & & \\
\hline 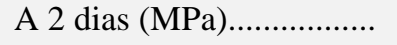 & 30 & 20 & 30 & 30 & 20 \\
\hline A $28 \operatorname{dias}(\mathrm{MPa}) \ldots \ldots \ldots \ldots \ldots \ldots$ & 55 & $45 \mathrm{R} \quad 65$ & 55 & 55 & $45 \mathrm{R} 65$ \\
\hline Características físicas: & & & & & \\
\hline Tempos de pega & & & & & \\
\hline início $(\mathrm{h}, \min )$ & 0,45 & $>1,00$ & 0,45 & 0,45 & $>1,00$ \\
\hline final $(h)$.. & $<12$ & $<12$ & $<12$ & $<12$ & $<12$ \\
\hline Expan. Le Chatelier (mm) & 10 & 10 & 10 & 10 & 10 \\
\hline Características químicas: & & & & & \\
\hline Perda ao fogo $(\%)$ & 3,5 & 3,5 & 5 & 5 & 5 \\
\hline Resíduo insolúvel (\%)......... & 2,5 & 2,5 & 5 & 5 & 5 \\
\hline 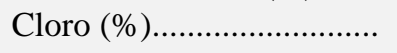 & 0,1 & 0,1 & 0,1 & 0,1 & 0,1 \\
\hline
\end{tabular}

FONTE: GONZALEZ G. I. (1993).

* Componente opcional como: escória de alto forno, pozolana natural ou cinza volante.

A partir da análise da tabela 2.3 conclui-se, imediatamente, que os cimentos tipos I-0/55 A ou I-0/45 A são os mais propícios para a produção de concretos de alto desempenho, baseados nos seguintes princípios: 
a) Trata-se de cimentos Portland puros com um conteúdo de $100 \%$ de clínker, o que possibilita, em seu caso, a incorporação de adições minerais de qualidade comprovada e conhecida.

b) A soma resultante dos conteúdos de perda ao fogo + resíduos insolúveis, implicam num conteúdo médio de substâncias inertes, inferior a 4\%, ao que ocorre com o restante dos outros cimentos, o que favorece o incremento da resistência final.

\subsection{AGREGADOS}

Para escolha dos agregados, deve-se ater às exigências pré-estabelecidas pelas normas pertinentes para produção de concretos de resistências usuais, tais como: NBR 7211-1983 e NBR 12654-1992.

Segundo SHAH \& AHMAD (1994), as propriedades mais importantes dos agregados para produção de CAD são: forma das partículas, distribuição granulométrica das partículas, propriedades mecânicas das partículas, possíveis reações químicas entre o agregado e a pasta que possam afetar a ligação.

A forma e o estado da superfície são características cuja incidência são decisivas, sobre uma propriedade do concreto, que é a compacidade. A máxima compacidade, está associada a agregados arredondados, de forma sensivelmente esférica, ou a agregados triturados de forma próxima a cúbica. Uma certa rugosidade superficial dos agregados graúdos melhorará a aderência necessária à pasta de cimento.

\subsubsection{Agregado graúdo}

Para a produção de concreto de alto desempenho, deve-se utilizar agregados graúdos com elevada resistência. Têm-se utilizado os seguintes tipos de rochas: calcária, dolomita, granito, andesita, diabásio e outras mais. Com relação à forma das partículas, devem-se evitar as partículas planas ou alongadas. Elas são inerentemente fracas e levam a misturas desarmônicas. Devem-se evitar também, partículas altamente polidas, como é o caso do seixo rolado, pois reduzem a ligação cimentoagregado. 
Além disso, as partículas dos agregados devem estar livres de camadas de silte e argila, pois estes materiais reduzem a resistência da ligação do cimento e do agregado e aumentam a demanda de água.

Com relação à granulometria dos agregados é comumente aceito que quanto menor for a dimensão máxima do agregado graúdo, maior será a resistência obtida, uma vez que dimensões menores proporcionam um aumento da trabalhabilidade do concreto e com isso uma diminuição na quantidade de água a ser utilizada.

Além disso, segundo JENNINGS ${ }^{6}$ apud DAL MOLIN (1995), como o agregado é normalmente britado, durante a retirada dos blocos dos maciços rochosos por meio de explosivos, podem ocorrer danos à microestrutura dos agregados, sendo maior a probabilidade de permanecerem falhas e fissuras em agregados de dimensões maiores. Por isso, muitas vezes pode-se dar preferência aos agregados naturais, que através de meios naturais, já sofreram um processo de destruição e eliminação das partículas alteradas e menos resistentes, pertencentes ao material. E portanto, existe então uma tendência de se trabalhar com agregados de menor dimensão possível.

MEHTA \& AITCIN $^{7}$ apud SHAH \& AHMAD (1994) recomendam uma dimensão máxima do agregado de $10 \mathrm{~mm}$ a $12 \mathrm{~mm}$.

AITCIN $^{8}$ apud GONZALEZ (1993), realizou um estudo envolvendo dois traços de concreto de mesma composição, alterando-se somente a dimensão do agregado graúdo. Em um dos traços utilizou-se agregado de $10 \mathrm{~mm}$ e no outro agregado de $20 \mathrm{~mm}$, sendo ambos de mesma procedência.

Os resultados das determinações de resistência à compressão e módulo de elasticidade obtidos a partir dos concretos citados, conduzem aos valores de relação entre tensões indicados na tabela 2.4.

\footnotetext{
${ }^{6}$ JENNINGS, H. M. (1988). Design of high strength cement based materials: Part 2-microstructure. Materials Science ant Technology, $n^{\circ}$ 4, p.285-290, April apud DAL MOLIN, D.C.C. (1995). Contribuição ao estudo das propriedades mecânicas dos concretos de alta resistência com e sem adições de microssílica. São Paulo, 224p. Tese (Doutorado) - Escola Politécnica - USP.

${ }^{7}$ MEHTA, P. K. \& AITCIN, P. C. (1990). Microstructural basis of selection of materials and mix proportions for high-strength concrete, in: INTERNATIONAL SYMPOSIUM ON UTILIZATION OF HIGH STREGTH CONCRETE, 2., Detroit. American Concrete Institute, , p.265-286. ( SP-121) apud SHAH, S. A. \& AHMAD, S. H. (1994). High performance concretes and applications.London, Edward Arnold. pp.13.
} 
TABELA 2.4 - Relação entre tensões para diferentes dimensões máximas de agregado graúdo obtidos por AITCIN (1989).

\begin{tabular}{|c|c|c|}
\hline Determinação efetuada & Idade do ensaio (dias) & $\begin{array}{l}\text { Relação entre tensões } \\
D_{\text {máx }}=10 \mathrm{~mm} / D_{\text {máx }}=20 \mathrm{~mm}\end{array}$ \\
\hline Resistência à compressão & $\begin{array}{c}2 \\
7 \\
28 \\
91\end{array}$ & $\begin{array}{l}1,12 \\
1,13 \\
1,10 \\
1,15\end{array}$ \\
\hline Módulo de elasticidade & $\begin{array}{c}2 \\
28 \\
56\end{array}$ & $\begin{array}{l}1,02 \\
1,04 \\
1,04\end{array}$ \\
\hline
\end{tabular}

FONTE: GONZALEZ G. I. (1993).

Já o ACI 363 (1992) recomenda uma dimensão máxima do agregado de 9,5 mm a 12,5 mm, para se obter concreto com ótima resistência à compressão. Em um estudo realizado por ADDIS $^{9}$ apud SHAH \& AHMAD (1994), concluiu-se que a resistência do $\mathrm{CAD}$ aumentava à medida que, a dimensão máxima do agregado variava no intervalo de $13,2 \mathrm{~mm}$ a $26,5 \mathrm{~mm}$.

\subsubsection{Agregado miúdo}

É o agregado cuja dimensão máxima não ultrapassa $4,8 \mathrm{~mm}$, sendo constituído pelas areias naturais e artificiais. As areias artificiais devem ser evitadas, pois devido ao processo de moagem, apresentam formas excessivamente angulosas. Esse tipo de formato dos grãos de areia faz com que seja excessiva a demanda de água, não sendo portanto aconselhável para a produção de $\mathrm{CAD}$, onde são necessárias baixas relações água/cimento.

O agregado miúdo deve consistir portanto de partículas redondas e polidas, de maneira a reduzir a demanda de água.

A bibliografia recomenda um módulo de finura no intervalo de 2,7 a 3,2, para que se possa diminuir a quantidade de água exigida e melhorar a trabalhabilidade.

${ }^{8}$ AITCIN, P. C. (1989). Du Gigapascal au Namomètre. Annales de I'Institute Technique du batiment es des Travaux publics. March-April. pp.162-166 apud GONZALEZ G. I. (1993). Hormigon de Alta Resistencia. Madrid, Intemac. Abril. pp.49.

${ }^{9}$ ADDIS, B. H. (1992). Properties of High Strength Concrete Made with South African Materials, Ph.D. Thesis, University of the Witwatersrand, Johannesburg, South Africa, apud SHAH, S. A. \& AHMAD, S. H. (1994). High performance concretes and applications.London, Edward Arnold. pp.13. 
GONZALEZ (1993) recomenda um módulo de finura variando no intervalo de 3,0 a 3,2, uma vez que a utilização de areias com granulometria excessivamente fina (módulo de finura inferior a 3,0), implica em uma maior demanda de cimento e água, originando um concreto com consistência "pegajosa" e inadequado para os fins previstos.

Um aspecto de grande importância com relação às areias, é a forma de armazenamento, uma vez que pode ocorrer uma variação na umidade da areia situada na parte superior, com relação a areia situada na parte inferior de $5 \%$. A consideração dessa variação, na dosagem de concretos de alto desempenho é fundamental. Isto pode ser acompanhado no exemplo seguinte, para um determinado traço de concreto de alto desempenho:

- $\quad \underline{\text { Agregado graúdo }} \rightarrow 1310 \mathrm{~kg}$

- $\underline{\text { Areia }} \rightarrow 720 \mathrm{~kg}$

- $\underline{\text { Cimento }} \rightarrow 450 \mathrm{~kg}$

- $\quad$ Sílica ativa $\rightarrow 36 \mathrm{~kg}$ (8\% sobre o peso do cimento)

- $\quad$ Superplastificante $\rightarrow 12,5 \mathrm{~kg}(2,8 \%$ do peso do cimento $)$

- $\underline{\text { Água }} \rightarrow 130 \mathrm{~kg}$

- $\quad$ Relação água total/(cimento + adições) $\rightarrow 0,29$ (c/ o superplastificante)

Para esse traço, uma variação na umidade de $5 \%$ implica em uma quantidade a mais de água incorporada no concreto de 36 litros por metro cúbico $(720$ x $0,05=$ 36 litros), o que conduziria a uma relação água/cimento de 0,37, comparado a 0,29 inicialmente previsto para o traço do concreto.

AMARAL FILHO apud DAL MOLIN (1995), relata que é possível obter concretos com resistência de até $170 \mathrm{MPa}$ com areia quartzosa normal, bem graduada e dentro das especificações. Resistências acima deste valor, só são obtidas com a utilização de agregados especiais, como por exemplo, areia artificial feita com bauxita calcinada. 


\subsection{ADIÇÕES MINERAIS}

As adições minerais, constituem um grupo de componentes, que possuem dimensões de suas partículas menores que aquelas apresentadas pelo cimento e são utilizadas como complemento cimentício, na produção de misturas de concreto.

Como exemplos de adições minerais tem-se: sílica ativa, cinza volante e escória de alto forno.

\subsubsection{Sílica ativa}

Segundo o ACI 363 (1992), a sílica ativa é um subproduto resultante da redução de quartzo de alta pureza com carvão, em fornos aquecidos eletricamente com circulação de ar, na produção de silício e ligas de ferro-silício. Uma das grandes vantagens da utilização da sílica ativa, é que ela possui a propriedade de ser pozolana e "microfiller" ou seja, ela se aloja nos interstícios da pasta, subdividindo os poros dos capilares das partículas de cimento em poros de gel, modificando a microestrutura interna da pasta de cimento. As partículas de sílica ativa são menores que um mícron, o qual é aproximadamente 100 vezes menor que uma partícula média de cimento.

Segundo a Norma Espanhola (UNE 83460), as características químicas exigidas para a sílica ativa são as seguintes:

- Conteúdo de óxido de silício $\left(\mathrm{SiO}_{2}\right) \rightarrow \quad 85 \%$.

- $\quad$ Perda por calcinação $\rightarrow \quad 5 \%$.

- $\quad$ Conteúdo de cloro $\rightarrow \quad 0,1 \%$.

Uma característica indicativa da qualidade da sílica ativa, recomendada pela Norma Espanhola, é o índice de atividade. O índice de atividade consiste no quociente entre, a resistência obtida em um corpo-de-prova moldado com 90\% de cimento e $10 \%$ de sílica ativa, com outro corpo-de-prova moldado apenas com cimento.

Segundo DETWILER \& MEHTA ${ }^{10}$ apud DAL MOLIN (1995), a utilização

\footnotetext{
${ }^{10}$ DETWEILER, R. J. \& MEHTA, P. K. (1989). Chemical and physical effects of silica fume on the mechanical behaviour of concrete. ACI Materials Journal, v. 86, n 6, p.609-614, Nov-Dez.
} 
da sílica ativa no concreto modifica suas propriedades tanto no estado fresco (trabalhabilidade, coesão, estabilidade, segregação, exsudação, etc.), como no estado endurecido (resistência à compressão, resistência à tração, fluência, permeabilidade, durabilidade, etc.).

VIEIRA \& DAL MOLIN (1995) concluíram, através de ensaios de arrancamento direto (Pull-Out-Test) em corpos-de-prova cúbicos de concreto, que a adição de sílica ativa melhora a tensão média de aderência desenvolvida por barras nervuradas. Concretos com $10 \%$ de adição de sílica ativa revelaram um aumento de $15 \%$ a $20 \%$ na tensão média de aderência, comparados com concretos sem adição de sílica ativa.

Segundo SILVA (1995), as vantagens do emprego da sílica ativa são:

- No controle das reações álcali-agregados, com a vantagem adicional de que somente pequenas quantidades são necessárias.

- Na redução da corrosão associada a cloretos e sulfatos, por causa da alta impermeabilidade. Os concretos com sílica ativa possibilitam uma maior durabilidade em tabuleiros de pontes e postos de gasolinas, em função de conter a corrosão associada aos cloretos.

- No aumento da resistência do concreto nas primeiras idades.

Segundo GONZALEZ (1993), as vantagens decorrentes do uso da sílica ativa são:

- As finas partículas de sílica ativa interrompem o fluxo de água entre os canalículos, que normalmente existem entre as partículas de cimento e de agregado, melhorando dessa forma a exsudação e a segregação. A segregação é diminuída em função do aumento da coesão que ocorre entre os diversos constituintes. Convém destacar que a exsudação e a segregação são os maiores causadores de heterogeneidade na microestrutura da pasta de cimento, principalmente na zona de transição.

- A sílica ativa atua como "germe de cristalização" impedindo a cal de se cristalizar em lâminas hexagonais de grandes dimensões, como ocorre 
com os concretos sem a utilização da sílica ativa.

- Atuando como "filler", as partículas de sílica ativa adicionadas ao concreto melhoram alguma de suas propriedades reológicas, tais como coesividade e trabalhabilidade.

\subsubsection{Cinza volante}

Segundo SILVA (1995), cinza volante consiste em um material captado dos gases na combustão de carvão pulverizado em centrais termelétricas, constituídas de resíduos finos, captados por coletores mecânicos ou precipitadores eletrostáticos dos gases da combustão, antes de serem lançados na atmosfera.

Segundo a ASTM, existem duas classes de cinza volante (F e C). A classe F é normalmente obtida da combustão de antracito ou carvão betuminoso, possui baixo teor de cálcio e tem propriedades pozolânicas, com pequena ou nenhuma propriedade cimentante, tendo grande campo de aplicação nos concretos de alto desempenho. A cinza volante classe $\mathrm{C}$ é obtida da combustão de lignita, possui alto teor de cálcio e, além de ter propriedades pozolânicas, tem algumas propriedades cimentícias.

A cinza volante tem sido muito utilizada na produção de concretos de alto desempenho, mas infelizmente a cinza volante é muito mais variável que a sílica ativa, em ambas as suas características físicas e químicas.

Utilizando-se a cinza volante, a resistência do concreto em geral não passará dos $70 \mathrm{MPa}$, ainda que existam poucos registros de concretos de alto desempenho, com resistência superior a $98 \mathrm{MPa}$, no qual tenha sido empregada a cinza volante.

Segundo SHAH \& AHMAD (1994), para aplicações de concretos de alto desempenho, a cinza volante é utilizada com taxas de dosagem de $15 \%$ do conteúdo de cimento. Devido à grande variabilidade deste material, deve-se fazer um controle de qualidade da composição da cinza volante proveniente de uma mesma fábrica.

\subsubsection{Escória de alto forno}

A escória de alto forno é um material não metálico obtido em condição liqüefeita, simultaneamente com ferro em alto forno. A escória sofre um resfriamento 
rápido em água e se solidifica, adquirindo uma textura vítrea e granular, tornando-se um material hidráulico ativo, que atuará no concreto como substituição parcial do cimento. A escória de alto forno é constituída essencialmente de sílica, alumina e cal.

Segundo SHAH \& AHMAD (1994), na América do Norte, a escória de alto forno não é tão extensamente disponível como é na Europa, e por isso não há muita informação disponível sobre o seu comportamento em concretos de alto desempenho.

Entretanto, as indicações são que escórias que possuem um bom desempenho em concretos normais, são adequadas para uso em concretos de alto desempenho, para taxas de dosagens entre $15 \%$ e $30 \%$.

Para concretos de alto desempenho, com resistência superior a $98 \mathrm{MPa}$, é provável que seja necessário o uso da escória em conjunto com a sílica ativa.

Ao que tudo indica, não há efeitos deteriorativos quando se utiliza sílica ativa no concreto. Entretanto quando se utiliza de cinza volante e escória de alto forno podem ocorrer alguns problemas tais como:

a) $\mathrm{O}$ desenvolvimento de elevadas resistências em idades prematuras do concreto, nos quais uma parte de cimento Portland tenha sido substituída por escória de alto forno ou cinza volante, ocorre de maneira mais devagar do que aquela que se obtém utilizando-se apenas cimento Portland. Isso possui um efeito adverso, no tempo segundo o qual é possível fazer a retirada da fôrma. Uma maneira de proceder com esse problema, é por uma nova redução na relação água/cimento, através do uso de mais superplastificante. Claramente, isto não é muito atrativo economicamente, pois se altas resistências iniciais são necessárias, talvez seja necessário, reduzir o conteúdo da cinza volante ou escória de alto forno.

b) Para níveis de substituição de (15\% a 30\%), cinza volante ou escória de alto forno, terão um efeito muito pequeno na temperatura máxima desenvolvida na massa de concretos pobres. 


\subsection{ADITIVOS}

Os aditivos são substâncias químicas utilizadas nos concretos, que melhoram algumas de suas propriedades como trabalhabilidade, ou seja, melhora da plasticidade do concreto sem aumento na relação água/cimento, aumento ou diminuição do tempo de pega, redução da exsudação e segregação.

$\mathrm{Na}$ prática moderna, sem dúvida um dos aditivos que se torna imprescídivel na produção de concretos de alto desempenho são os superplastificantes.

A explicação para esse fato é que para se conseguir o aumento da resistência do concreto deve-se reduzir a relação água/cimento, pois dessa forma diminui-se a porosidade e os vazios existentes, resultando em um acréscimo de resistência.

Segundo DAL MOLIN (1995), algumas das maneiras para reduzir a relação água/cimento são:

- Reduzindo-se apenas a quantidade de água de amassamento, porém com a desvantagem de diminuir a trabalhabilidade do concreto, dificultando o processo de moldagem e adensamento.

- Aumentando-se apenas o consumo de cimento, porém com a desvantagem de elevar o custo do concreto, além de provocar problemas de retração, fluência e fissuração devido ao excesso de finos.

- Através da utilização de superplastificantes, que são aditivos redutores de água. Os superplastificantes são capazes de reduzir o conteúdo de água em até $30 \%$, conseguindo proporcionar com isso incrementos bastantes elevados de resistência.

Segundo a norma ASTM C 494-92 os aditivos podem ser classificados em 7 tipos diferentes:

TIPO A: Redutores de água.

TIPO B: Retardadores de pega.

TIPO C: Aceleradores de pega.

TIPO D: Redutores de água e retardadores de pega.

TIPO E: Redutores de água e aceleradores de pega.

TIPO F: Redutores de água de alto grau.

TIPO G: Redutores de água de alto grau e retardadores de pega. 


\subsubsection{Aditivos redutores de água}

Também conhecidos como dispersantes, são produtos químicos que incorporam um certo número de moléculas orgânicas, capazes de neutralizar as cargas elétricas dos grãos do cimento e por conseguinte, sua capacidade de floculação.

Em função de efeitos secundários negativos, tais como atraso no tempo de pega do concreto e absorção de bolhas de ar, a dosagem deste aditivo não pode ser aumentada à vontade, mesmo porque seu poder dispersante é limitado. Mediante o emprego deste produto, a redução da quantidade de água de amassamento necessária pode alcançar valores entre $8 \%$ e $10 \%$.

\subsubsection{Aditivos retardadores de pega}

São aditivos que retardam a reação de hidratação do cimento. Os retardadores de pega eram recomendados para algumas aplicações de CAD, com o objetivo de minimizar o problema de rápida perda de slump. Entretanto, é difícil de manter a compatibilidade entre o retardador e o superplastificante, para minimizar a perda de slump, sem reduzir excessivamente o ganho de resistência inicial. Na prática moderna, retardadores são recomendados apenas como último recurso.

\subsubsection{Aditivos lignosulfonatos}

As moléculas de lignosulfonato, extraídas do resíduo da pasta de papel, caracterizam-se por possuir uma estrutura molecular mais larga que a dos redutores de água, o que permite um recobrimento mais efetivo das partículas de cimento. Como consequiência, tem-se a redução na quantidade de água de amassamento, a qual está compreendida entre $10 \%$ a $15 \%$ do total.

Possui os mesmos efeitos secundários que os aditivos redutores de água (atraso no tempo de pega e incorporação de bolhas de água), em função da presença de açúcares incorporados na matéria-prima. 
Entretanto, deve-se levar em conta que durante 40 anos os lignosulfonatos têm sido os aditivos mais utilizados na indústria do concreto, permitindo com relativa facilidade a obtenção de resistências próximas dos $50 \mathrm{MPa}$.

\subsubsection{Aditivos superfluidificantes}

Os superfluidificantes ou redutores de água de alto grau consistem em policondensados de formaldeído e melamina sulfonada ou formaldeído e naftaleno sulfonado. Estes compostos possuem moléculas de forma linear e alargada que permitem o recobrimento total das partículas de cimento, neutralizando as cargas de sinal negativo existentes nestas partículas. Com isso, acabam-se as forças de atração eletrostáticas existentes entre as partículas de cimento, dificultando o fenômeno da floculação.

Os aditivos superfluidificantes não são subprodutos de nenhuma transformação industrial. Para sua obtenção é necessário um processo químico específico e de qualidade garantida. Sabendo-se da procedência desse produto, podese incorporá-lo à produção de concretos, com bastante segurança, em quantidades de até 10 vezes a máxima quantidade permitida para o emprego de lignosulfonatos, sem o aparecimento dos efeitos nocivos inerentes ao uso desses produtos. A possibilidade de emprego de elevadas quantidades de superfluidificantes, permite a adoção de valores de relação água/cimento da ordem de 0,22 , o que se traduz na obtenção de um produto com uma porosidade muito baixa e como conseqüência, uma resistência muito alta.

Segundo SHAH \& AHMAD (1994), existem basicamente 3 tipos de superplastificantes: baseados em lignosulfonatos, policondensados de formaldeído e sulfonados de naftaleno.

\subsubsection{Aditivos superplastificantes}

Os aditivos superplastificantes podem ser baseados em lignosulfonatos, sulfonados de melamina e sulfonados de naftaleno. 


\section{a) Superplastificantes lignosulfonatos}

Em concretos de alto desempenho, os superplastificantes lignosulfonatos são geralmente usados em conjunto com os superplastificantes melamina ou naftaleno.

Estes produtos tendem a não ser suficientemente eficientes para a produção econômica de concretos de alto desempenho. Algumas vezes, lignosulfonatos são usados para controle do slump inicial, com o uso subsequente de melamina e naftaleno para controle do slump no campo.

\section{b) Superplastificantes sulfonado de melamina}

Até recentemente, apenas um único superplastificante melamina estava disponível (Melment). Superplastificantes melamina são líquidos claros, contendo $22 \%$ de partículas sólidas. Esse superplastificante tem sido usado por muitos anos, com bons resultados, permanecendo portanto, popular entre os produtores de concreto de alto desempenho.

\section{c) Superplastificantes sulfonados de naftaleno}

Têm sido usados previamente aos superplastificantes citados anteriormente.

As vantagens particulares do uso do superplastificante naftaleno eram as seguintes: inicialmente ele era o superplastificante mais barato, e também em função de se poder controlar facilmente as propriedades de trabalhabilidade do concreto de alto desempenho, devido à sua menor ação retardante.

\subsection{DOSAGEM DOS SUPERPLASTIFICANTES}

Não há, a princípio, uma maneira de se determinar a quantidade exigida de aditivo superplastificante, para um determinado traço de concreto.

Deve-se determinar a dosagem apropriada através de tentativa de acerto e erro. Basicamente, se a resistência é o primeiro critério, então procura-se obter a menor relação água/cimento possível, e dessa forma maiores quantidades de superplastificantes são utilizadas. 
Entretanto, se as propriedades reológicas do concreto de alto desempenho são muito importantes, então uma relação água/cimento maior deve ser empregada, adotando-se portanto menores quantidades de aditivo superplastificante, permitindo a trabalhabilidade desejada.

Às vezes, tem-se comprovado que cimentos e aditivos superplastificantes que satisfazem respectivamente às exigências normativas correspondentes, desenvolvem, ao serem postos em contato, comportamentos reológicos inexplicáveis que conduzem a perda de trabalhabilidade do concreto e perda de resistência. Em tais casos, se fala em incompatibilidade entre o cimento e o aditivo. Segundo NEVILLE (1997) essa incompatibilidade consiste no seguinte: na reação de hidratação do cimento, os superplastificantes interagem com o aluminato tricálcico $\left(\mathrm{C}_{3} \mathrm{~A}\right)$ que consiste no primeiro componente do cimento que se hidrata. Essa reação é controlada pela presença do gesso que é adicionado durante a fabricação do cimento Portland. Assim, tanto o aditivo superplastificante como o gesso podem reagir com o $\mathrm{C}_{3} \mathrm{~A}$. Entretanto, é essencial que todo o superplastificante não seja fixado pelo $\mathrm{C}_{3} \mathrm{~A}$. Essa fixação ocorreria se o gesso não liberasse íons de gesso com suficiente rapidez para que reagissem com o $\mathrm{C}_{3} \mathrm{~A}$. Quando os íons sulfato são liberados muito lentamente, diz-se que o cimento Portland e o aditivo superplastificante são incompatíveis.

A única forma de prevenir a aparição na obra de tais incompatibilidades, consiste na realização de ensaios prévios em condições controladas de laboratório.

As dosagens normalmente utilizadas na fabricação de concretos de alto desempenho oscilam entre 5 e 20 litros $/ \mathrm{m}^{3}$.

A experiência atual do uso destes produtos aconselha sua incorporação no concreto em duas fases.

Primeira fase: durante o amassamento, em quantidade suficiente para conseguir uma trabalhabilidade que permita uma mistura direta dos distintos componentes e seu transporte sem segregação.

Segunda fase: no momento da concretagem, em quantidade suficiente para compensar a perda de trabalhabilidade sofrida durante o transporte. 


\subsection{DOSAGEM DO CONCRETO}

Atualmente, existe na literatura uma pequena quantidade de métodos para definição do traço do concreto, para uma determinada resistência. Isto porque na escolha da proporção de cimento, água, aditivo superplastificante e adições minerais, várias exigências conflitantes estão em jogo, tais como: trabalhabilidade, resistência à compressão, durabilidade, tempo de início e fim de pega, etc. Além disso, a resistência do concreto vai depender também das características e resistência dos agregados de uma determinada região e das características das adições minerais (sílica ativa, escória e cinza volante) empregadas.

Dentre os métodos de dosagem existentes, o indicado pelo ACI Committee 211 é um dos mais expressivos, sendo aplicável para misturas de concreto com as seguintes características:

- resistência à compressão $\Rightarrow 13 \mathrm{MPa} \quad f_{c} \quad 40 \mathrm{MPa}$;

- relação água/cimento $\rightarrow 0,41 \quad$ a/c $\quad 0,82$;

- $\quad$ abatimento de tronco de cone $\rightarrow 25 \mathrm{~mm} \quad \mathrm{C} \quad 175 \mathrm{~mm}$;

- dimensão máxima do agregado graúdo $\rightarrow 9 \mathrm{~mm} \quad$ D $75 \mathrm{~mm}$;

- módulo de finura do agregado miúdo $\Rightarrow 2,4 \quad M_{F} \quad 3,0$.

A dosagem pelo método do ACI 211 é feita com auxílio de tabelas. Com base nessas tabelas, têm-se obtido traços de concretos com resistência moderadamente alta (60 MPa) e relação água/cimento compreendida entre 0,3 e 0,4 .

Entretanto, o método do ACI 211 não é aplicável para concretos com resistência superior a $60 \mathrm{MPa}$, slump acima de $175 \mathrm{~mm}$, e relação água/cimento menor do que 0,3 , pois estes concretos são muito sensíveis a pequenas variações no conteúdo de água de amassamento ou tipo de agregado empregado.

As premissas básicas para se obter a dosagem de um concreto de alto desempenho são as seguintes:

- Deve-se basear na experimentação dos materiais disponíveis, analisando as suas características mais significativas. 
- Não existe uma proporção direta entre a relação água/cimento ou água/(material cimentício) e a resistência, já que a resistência pode estar afetada significativamente pelo tipo e quantidade de adição mineral empregada.

- A maioria das dosagens estão baseadas em numerosos ensaios, e se aplicam exclusivamente aos materiais empregados nos ensaios.

A seguir tem-se o método de dosagem de concreto de alto desempenho proposto por LARRARD ${ }^{11}$ apud GONZALEZ (1993), o qual está baseado na definição de 2 parâmetros básicos:

- Trabalhabilidade - a qual depende da concentração da pasta e de sua fluidez.

- Resistência - estabelecida a partir da fórmula de Feret modificada e controlada fundamentalmente pela natureza da pasta aglomerante.

\subsubsection{Determinação da fluidez da argamassa de cimento}

A fluidez da pasta de cimento pode ser caracterizada pelo tempo necessário para preencher um recipiente de volume conhecido, situado debaixo de um cone normalizado (cone de Marsh), no qual é colocada a pasta em estudo. Com esse procedimento, pode-se variar a quantidade dos componentes da pasta, tais como cimento, água, aditivos e adições minerais, de tal forma que o tempo de fluxo seja igual a um estabelecido como padrão. As dimensões do cone de Marsh podem ser as apresentadas na figura 2.2.

O tempo de fluxo de referência a ser adotado, pode ser de 5 a 20 segundos, sendo o tempo necessário para preencher um recipiente de $200 \mathrm{~cm}^{3}$. O volume da pasta de cimento depositada no cone, deve ser constante em todos os ensaios, sendo aproximadamente 1,5 litros.

\footnotetext{
${ }^{11}$ DE LARRARD, F. (1990). A Method for proportioning high-strength concrete mixtures, cement, concrete and aggregates. CCAGDP, vol.12, n², pp.47-52 apud GONZALEZ, I. G. (1993). Hormigon de Alta Resistencia. Madri, Intemac. Abril.pp.90.
} 


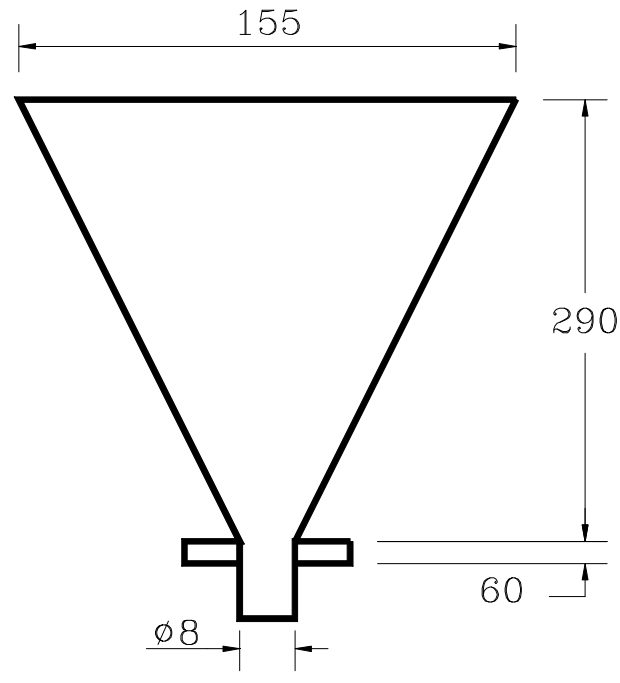

Obs: dimesões em mm

FIGURA 2.2 - Dimensões do cone de Marsh. FONTE: GONZALEZ G. I. (1993).

\subsubsection{Estimativa da resistência à compressão (Fórm. de Feret modificada)}

A fórmula de FERET modificada por LARRARD a fim de que ela pudesse ser aplicada a concretos de alto desempenho é a seguinte:

$$
f_{c}^{\prime}=\frac{k g \times R_{c}}{\left[1+\frac{3,1 \mathrm{a} / \mathrm{c}}{1,4-0,4 \exp (-11 \mathrm{~s} / \mathrm{c})}\right]^{2}}
$$

onde:

$f_{c}^{\prime} \rightarrow$ resistência à compressão aos 28 dias.

$\mathrm{a}, \mathrm{c}, \mathrm{s} \rightarrow$ são massas de água, cimento e sílica ativa respectivamente por unidade de volume de concreto.

$k g \rightarrow$ é um parâmetro dependente do tipo de agregado empregado (agregados comuns se aplica o valor de 4,91).

$R_{c} \rightarrow$ resistência da argamassa de cimento normalizada a 28 dias de idade. 
Essa fórmula permite quantificar, muito aproximadamente, a influência que a variação de qualquer dos componentes exercerá na resistência do concreto obtido.

$\mathrm{Na}$ figura (2.3) tem-se a representação gráfica da equação modificada de FERET por LARRARD, para pasta de cimento de $55 \mathrm{MPa}$, relações água/cimento variando no limite de 0,25 a 0,35 e relações sílica ativa/cimento compreendidas entre 0 e 0,20. Para pastas de cimento com diferentes resistências, pode-se utilizar o diagrama multiplicando-se o valor encontrado pela relação existente entre a resistência da pasta real dividida por $55(\mathrm{MPa})$.

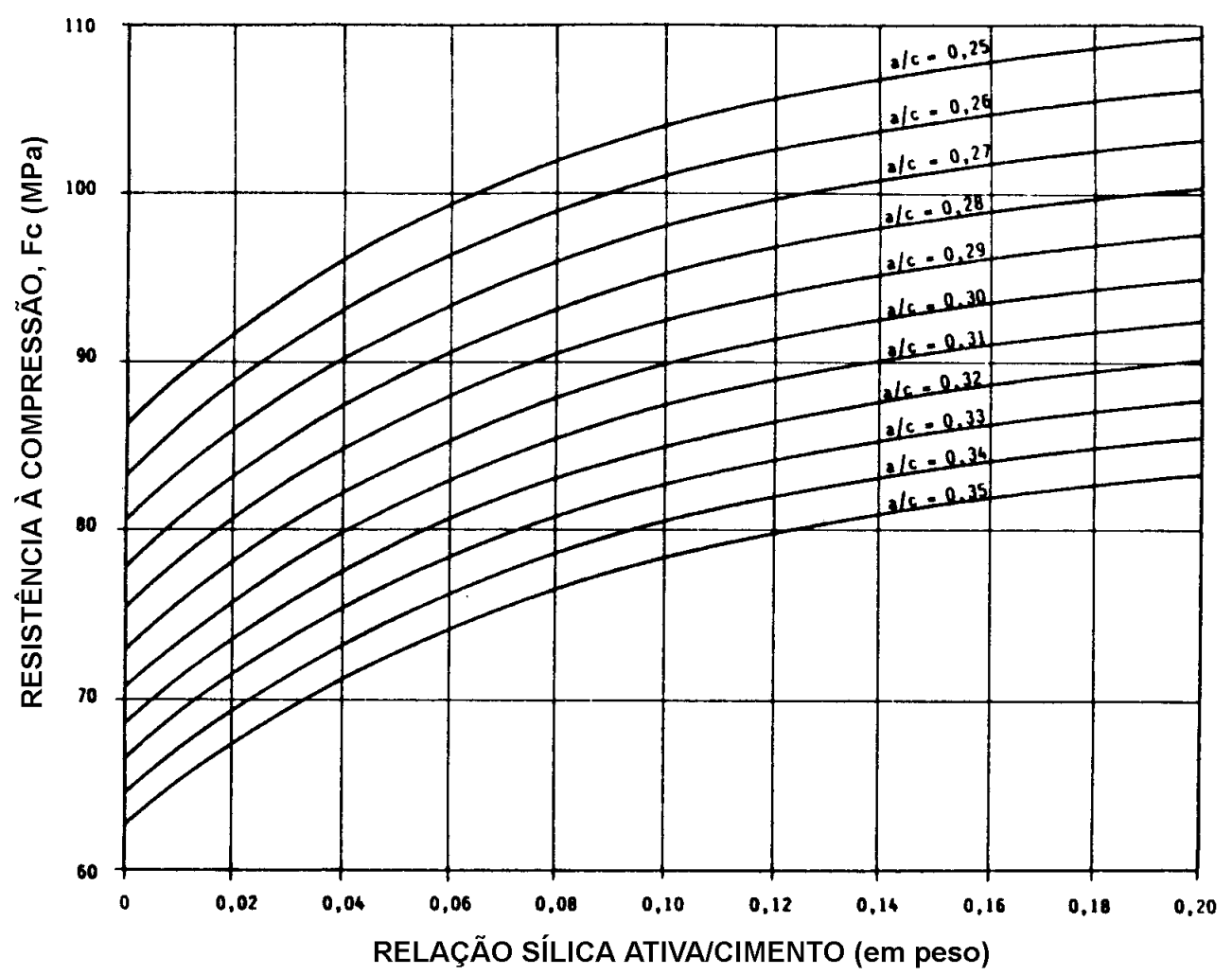

FIGURA 2.3 - Representação gráfica da Fórmula de Feret modificada por Larrard. FONTE: GONZALEZ G. I. (1993).

\subsubsection{Dosagem de componentes pelo método de LARRARD}

Tem-se a seguir o procedimento completo de dosagem de concreto de alto desempenho proposto por LARRARD.

- Adota-se uma composição granulométrica adequada dos agregados, escolhe-se uma dosagem de controle que contenha grande quantidade de 
superplastificante e uma quantidade de cimento que corresponda a menor demanda de água. Como primeira aproximação, pode-se adotar $425 \mathrm{~kg} / \mathrm{m}^{3}$. A quantidade de água deste concreto de controle deve ser adequada à trabalhabilidade exigida.

- Determina-se a fluidez da argamassa de cimento de controle, pela medida do seu tempo de fluxo através do cone de Marsh.

- Fazem-se diferentes traços de concreto através da variação das porcentagens de cimento e adição mineral.

- Para cada traço, adiciona-se uma pequena quantidade de superplastificante e se ajusta a quantidade de água para se obter uma argamassa adesiva (desde que passe através do cone, com tempo de aproximadamente 20 segundos). Com a relação água/cimento fixada, adicionam-se quantidades crescentes de superplastificante, até que o tempo de fluxo não diminua mais.

- Ajusta-se o conteúdo de água, para que se obtenha o mesmo tempo de fluxo que o traço de controle. Em consequiência, a relação água/cimento deve ser ajustada para cada argamassa.

- Determina-se a variação das características de fluxo, de acordo com o tempo de duração previsto para a colocação do concreto na obra. Se o tempo de fluxo aumenta muito, deve-se adicionar um agente retardante para mantê-lo ao valor de referência.

- Determina-se a resistência à compressão das diferentes dosagens de argamassa, mediante ensaios diretos, ou estimando-se através da fórmula de Feret modificada.

- Estabelece-se uma primeira dosagem do concreto de alto desempenho, usando os materiais granulares e o mesmo volume de argamassa que o concreto de controle, incorporando a correção da umidade dos agregados de acordo com sua umidade, no momento da produção do concreto.

- Verifica-se a consistência e a resistência resultante. 


\subsubsection{Exemplo de aplicação do método}

A seguir tem-se um exemplo da aplicação do método de LARRARD, onde se pretende obter um concreto com resistência à compressão de $90 \mathrm{MPa}$ aos 28 dias.

a) Define-se em primeiro lugar uma dosagem correspondente ao concreto de controle, incorporando $425 \mathrm{~kg} / \mathrm{m}^{3}$ de cimento, superplastificante e uma quantidade de água orientada para a obtenção de abatimento de tronco de cone de $200 \mathrm{~mm}$, conforme a tabela 2.5 .

TABELA 2.5 - Composição do concreto de controle proposto por LARRARD (1990).

\begin{tabular}{||c|c|c|c|c|c|c|c|c||}
\hline Componentes & \multicolumn{2}{|c|}{$\begin{array}{c}\text { granulometria do } \\
\text { agregado graúdo }\end{array}$} & $\begin{array}{c}\text { areia } \\
\text { de rio }\end{array}$ & $\begin{array}{c}\text { cimento } \\
\text { I/55 }\end{array}$ & $\begin{array}{c}\text { sílica } \\
\text { ativa }\end{array}$ & $\begin{array}{c}\text { aditivo } \\
\text { superplast. }\end{array}$ & $\begin{array}{c}\text { águ } \\
\text { a }\end{array}$ \\
\hline fração & $0 / 5$ & $5 / 12,5$ & $12,5 / 20$ & $0 / 5$ & ---- & ----- & ---- & ---- \\
\hline peso kg/m & 332 & 422 & 871 & 332 & 425 & ---- & 6,4 & 130 \\
\hline $\begin{array}{c}\text { densidade } \\
\text { relativa kg/m }\end{array}$ & 2,58 & 2,62 & 2,62 & 2,55 & 3,10 & ----- & 1,21 & 1,00 \\
\hline $\begin{array}{c}\text { volumes reais } \\
\left(\mathbf{d m}^{\mathbf{3}}\right)\end{array}$ & 128,8 & 161,1 & 332,4 & 130,3 & 137,1 & ----- & 5,3 & 130 \\
\hline
\end{tabular}

FONTE: GONZALEZ G. I. (1993).

Tempo de fluxo da pasta de cimento, no cone de Marsh igual a 5 segundos.

b) Preparam-se 3 pastas aglomerantes com distintas porcentagens de sílica ativa $(5 \%, 10 \%$ e $15 \%$ respectivamente). Determina-se a quantidade de saturação de superplastificante em cada caso, bem como a quantidade de água necessária para se obter o mesmo tempo de fluxo da pasta de controle de (5 segundos).

Por último, com os valores indicados na tabela 2.6 para as relações água*/cimento $(0,25)$ e sílica ativa/cimento, utiliza-se o gráfico da figura 2.3 e determina-se a resistência à compressão prevista pela fórmula de Feret modificada por LARRARD.

TABELA 2.6 - Composição de pastas alternativas e previsão da resistência proposta por LARRARD (1990).

\begin{tabular}{||c|c|c|c|c|c|c|c||}
\hline Composição & $\begin{array}{c}\text { vol. pasta } \\
\left(\mathbf{d m}^{\mathbf{3}}\right)\end{array}$ & $\begin{array}{c}\text { cimento } \\
(\mathbf{k g})\end{array}$ & $\begin{array}{c}\text { sílica ativa } \\
(\mathbf{k g})\end{array}$ & $\begin{array}{c}\text { superpl. } \\
(\mathbf{k g})\end{array}$ & $\begin{array}{c}\text { água } \\
\left(\mathbf{d m}^{\mathbf{3}}\right)\end{array}$ & $\begin{array}{c}\text { sílica ativa/ } \\
\text { cimento }\end{array}$ & $\begin{array}{c}\text { resistência } \\
(\mathbf{M P a})\end{array}$ \\
\hline $\mathbf{1}(\mathbf{5 \%})$ & 272,4 & 455 & 22,8 & 7,8 & 109 & 0,05 & 98 \\
\hline $\mathbf{2}(\mathbf{1 0 \%})$ & 272,4 & 438 & 43,8 & 8,7 & 104 & 0,10 & 104 \\
\hline $\mathbf{3}(\mathbf{1 5 \%})$ & 272,4 & 422 & 63,3 & 9,3 & 100 & 0,15 & 107 \\
\hline
\end{tabular}

(*) Inclui a água realmente adicionada mais a incorporada pelo aditivo superplastificante. 
c) A partir dos valores obtidos para a resistência média prevista, adota-se a composição $\mathrm{n}^{\circ} 2$, estimando-se um valor médio de $104 \mathrm{MPa}$ para alcançar um valor característico de $90 \mathrm{MPa}$. Tem-se portanto a composição teórica do concreto representado na tabela 2.7 .

TABELA 2.7 - Composição teórica do concreto proposta por LARRARD (1990).

\begin{tabular}{|c|c|c|c|c|c|c|c|c|}
\hline Componentes & & $\begin{array}{l}\text { ulome } \\
\text { gado } \mathrm{g} \\
(\mathrm{mm})\end{array}$ & $\begin{array}{l}\text { ia do } \\
\text { aúdo }\end{array}$ & $\begin{array}{l}\text { areia } \\
\text { de rio }\end{array}$ & $\begin{array}{c}\text { cimento } \\
\text { I/55 }\end{array}$ & $\begin{array}{l}\text { sílica } \\
\text { ativa }\end{array}$ & $\begin{array}{l}\text { aditivo } \\
\text { superpl. }\end{array}$ & água \\
\hline fração & $0 / 5$ & $5 / 12,5$ & $12,5 / 20$ & $0 / 5$ & ----- & ---- & ----- & ----- \\
\hline peso $\left(\mathrm{kg} / \mathrm{m}^{3}\right)$ & 332 & 422 & 871 & 332 & 438 & 43,8 & 8,7 & 104 \\
\hline $\begin{array}{c}\text { dens. relat. } \\
\left(\mathrm{kg} / \mathrm{m}^{3}\right)\end{array}$ & 2,58 & 2,62 & 2,62 & 2,55 & 3,10 & 2,20 & 1,21 & 1,00 \\
\hline $\begin{array}{c}\text { vol. real } \\
\left(\mathbf{d m}^{3}\right)\end{array}$ & 128,8 & 161,1 & 332,4 & 130,3 & 141,3 & 19,91 & 7,19 & 104 \\
\hline
\end{tabular}

Com a composição da tabela 2.7, serão feitos os corpos-de-prova para ensaio no laboratório, podendo ser feito ainda, algum ajuste na quantidade de água e superplastificante. Os ensaios de consistência no concreto fresco e de resistência aos 28 dias, serão decisivos para a aceitação ou recusa da dosagem estudada.

A seguir tem-se a tabela 2.8, a qual foi apresentada por GONZALEZ (1993), contendo 30 dosagens de concreto de alto desempenho selecionados de diferentes bibliografias, que podem servir de base para a experimentação de novos traços de concreto, uma vez que a resistência obtida depende muito dos agregados e dos tipos de cimentos empregados.

Analisando-se a tabela (2.8), percebe-se que todos os traços de concreto tem em comum o seguinte:

- Incorporação exclusiva de sílica ativa como adição mineral;

- Abatimento de tronco de cone igual ou superior a $170 \mathrm{~mm}$;

- Resistência média à compressão obtida em ensaio de corpo-de-prova cilíndrico, igual ou superior a $80 \mathrm{MPa}$, aos 28 dias de idade. 
TABELA 2.8 - Dosagens de concretos de alto desempenho segundo GONZALEZ G. I. (1993).

\begin{tabular}{|c|c|c|c|c|c|c|c|c|c|c|c|c|c|c|}
\hline \multirow[b]{2}{*}{$\begin{array}{c}\text { Dosagen } \\
\text { s }\end{array}$} & \multicolumn{6}{|c|}{ Componentes $\left(\mathrm{kg} / \mathrm{m}^{3}\right)$} & \multirow{2}{*}{$\begin{array}{c}\text { dimensão } \\
\text { agregado } \\
(\mathrm{mm})\end{array}$} & \multirow{2}{*}{$\begin{array}{c}\text { relação } \\
\text { agregado/ } \\
\text { areia }\end{array}$} & \multirow{2}{*}{$\begin{array}{c}\text { relação } \\
\text { água/ } \\
\text { (síl.+cim.) }\end{array}$} & \multirow{2}{*}{$\begin{array}{c}\text { relação } \\
\text { síl./cim. } \\
(\%)\end{array}$} & \multicolumn{4}{|c|}{ Resist. à compressão (MPa) } \\
\hline & cimento & agregado & areia & água & $\begin{array}{l}\text { aditivo } \\
\text { superp. }\end{array}$ & $\begin{array}{l}\text { Sílica } \\
\text { ativa }\end{array}$ & & & & & $\begin{array}{c}7 \\
\text { dias }\end{array}$ & $\begin{array}{c}28 \\
\text { dias }\end{array}$ & $\begin{array}{c}56 \\
\text { dias }\end{array}$ & $\begin{array}{c}90 \\
\text { dias }\end{array}$ \\
\hline 1 & 400 & 1080 & 800 & 140 & 16,0 & 30,0 & 20 & 1,35 & 0,33 & 7,5 & 60,0 & 80,0 & --- & --- \\
\hline 2 & 475 & 1120 & 670 & 135 & 18,5 & 32,0 & 12 & 1,67 & 0,27 & 6,7 & 70,2 & 80,2 & --- & 89,9 \\
\hline 3 & 449 & 1149 & 758 & 130 & 13,3 & 39,0 & 12 & 1,52 & 0,27 & 8,7 & $\begin{array}{l}--- \\
\end{array}$ & 82,0 & --- & --- \\
\hline 4 & 550 & 980 & 690 & 165 & 5,2 & 110,0 & 12 & 1,42 & 0,30 & 20,0 & 73,6 & 82,2 & 95,5 & --- \\
\hline 5 & 452 & 1130 & 745 & 145 & 8,2 & 36,0 & 12 & 1,52 & 0,30 & 8,0 & --- & 83,4 & --- & 93,4 \\
\hline 6 & 500 & 1130 & 675 & 150 & 12,8 & 42,0 & 14 & 1,67 & 0,28 & 8,4 & --- & 84,8 & 88,6 & --- \\
\hline 7 & 500 & 1100 & 700 & 135 & 25,2 & 30,0 & 10 & 1,57 & 0,25 & 6,0 & 71,8 & 86,2 & ---- & $\begin{array}{l}95,0 \\
\end{array}$ \\
\hline 8 & 480 & 1160 & 690 & 135 & 27,8 & 38,0 & 12 & 1,68 & 0,26 & 7,9 & 71,8 & 86,4 & --- & 96,1 \\
\hline 9 & 500 & 1100 & 700 & 135 & 18,2 & 30,0 & 12 & 1,57 & 0,25 & 6,0 & $\begin{array}{l}--- \\
-\end{array}$ & 90,0 & --- & $\begin{array}{l}--- \\
-\end{array}$ \\
\hline 10 & 427 & 1139 & 754 & 132 & $\begin{array}{ll}18,0 \\
\end{array}$ & 59,0 & 12 & 1,51 & 0,27 & $\begin{array}{ll}13,8 \\
\end{array}$ & --- & $\begin{array}{l}91,0 \\
\end{array}$ & --- & --- \\
\hline 11 & 530 & 1100 & 655 & 145 & 12,7 & 40,0 & 14 & 1,68 & 0,25 & 7,5 & 72,0 & 91,2 & --- & --- \\
\hline 12 & 487 & 1068 & 676 & 155 & 10,4 & 47,0 & 12 & 1,58 & 0,29 & 9,7 & 72,9 & 91,9 & 94,2 & 96,0 \\
\hline 13 & 500 & 1100 & 700 & 135 & 17,0 & 30,0 & 12 & 1,57 & 0,25 & 6,0 & $\begin{array}{l}--- \\
\end{array}$ & 92,5 & ---- & 119,0 \\
\hline 14 & 450 & 1108 & 687 & 140 & 20,6 & 50,0 & 12 & 1,61 & 0,28 & 11,1 & --- & 93,0 & --- & --- \\
\hline 15 & 500 & 1130 & 675 & 138 & 12,1 & 42,0 & 12 & 1,67 & 0,25 & 8,4 & --- & 97,0 & --- & --- \\
\hline 16 & 589 & 1070 & 620 & 130 & 14,6 & 40,0 & 12 & 1,73 & 0,21 & 6,9 & --- & 97,0 & 128,0 & $-\cdots$ \\
\hline 17 & 375 & 935 & 600 & 135 & 7,5 & 75,0 & 19 & 1,56 & 0,30 & 20,0 & 91,0 & $\begin{array}{l}98,5 \\
\end{array}$ & $\begin{array}{l}--- \\
-\end{array}$ & --- \\
\hline 18 & 486 & 1112 & 661 & 135 & 24,2 & 54 & 12 & 1,68 & 0,25 & 11,1 & --- & 100,0 & --- & --- \\
\hline 19 & 500 & 1130 & 675 & 150 & 12,8 & 42,0 & 10 & 1,67 & 0,28 & 8,4 & --- & 100,7 & 104,8 & --- \\
\hline 20 & 428 & 1265 & 652 & 117 & 7,6 & 42,1 & 20 & 1,94 & 0,25 & 9,8 & --- & 101,0 & $\begin{array}{l}--- \\
\end{array}$ & $\begin{array}{l}--- \\
\end{array}$ \\
\hline 21 & 580 & 1025 & 620 & 140 & 14,5 & 70,0 & 12 & 1,65 & 0,22 & 12,1 & --- & 103,0 & $\begin{array}{l}--- \\
\end{array}$ & --- \\
\hline 22 & 513 & 1080 & 685 & 120 & 19,0 & 43,0 & 10 & 1,58 & 0,22 & 8,4 & 81,2 & 103,2 & --- & 121,6 \\
\hline 23 & 517 & 1126 & 641 & 126 & 30,2 & 58,0 & 12 & 1,76 & 0,22 & 11,2 & ---- & 107,0 & --- & $\begin{array}{l}--- \\
\end{array}$ \\
\hline 24 & 513 & 1080 & 685 & 120 & 19,4 & 43,0 & 20 & 1,58 & 0,22 & 8,4 & 82,8 & 108,1 & --- & 126,0 \\
\hline 25 & 500 & 1000 & 800 & 145 & 10,0 & 45,0 & 10 & 1,25 & 0,27 & 9,0 & 86,4 & 113,7 & ---- & --- \\
\hline 26 & 513 & 1080 & 685 & 120 & 19,0 & 43,0 & 10 & 1,58 & 0,22 & 8,4 & 96,8 & 117,1 & --- & 133,7 \\
\hline 27 & 564 & 1068 & 593 & 144 & 18,6 & 89,0 & 12 & 1,80 & 0,22 & 15,8 & 95,6 & 118,9 & 121,2 & 131,8 \\
\hline 28 & 513 & 1080 & 685 & 130 & $\begin{array}{l}19,0 \\
\end{array}$ & 43,0 & 12 & 1,58 & 0,23 & 8,4 & 93,2 & 119,0 & --- & 145,0 \\
\hline 29 & 513 & 1080 & 685 & 120 & 19,0 & 43,0 & 10 & 1,58 & 0,22 & 8,4 & 93,2 & 119,4 & $\begin{array}{l}--- \\
\end{array}$ & 145,0 \\
\hline 30 & 564 & 1100 & 682 & 124 & 25,4 & 44,0 & 12 & 1,61 & 0,20 & 7,8 & --- & 120,0 & --- & --- \\
\hline
\end{tabular}




\subsection{FABRICAÇÃO DO CONCRETO DE ALTO DESEMPENHO}

As exigências para a fabricação de concreto de alto desempenho são maiores do que as contempladas pelas normas atuais, como pode ser visto a seguir:

- Estrito controle de qualidade dos componentes;

- Atenção especial para invariabilidade da relação água/cimento;

- Dosagem em peso de todos os materiais constituintes;

- Determinação periódica da granulometria e umidade dos agregados;

- Presença de laboratório junto à obra.

Em termos gerais o processo de fabricação do concreto de alto desempenho é o seguinte.

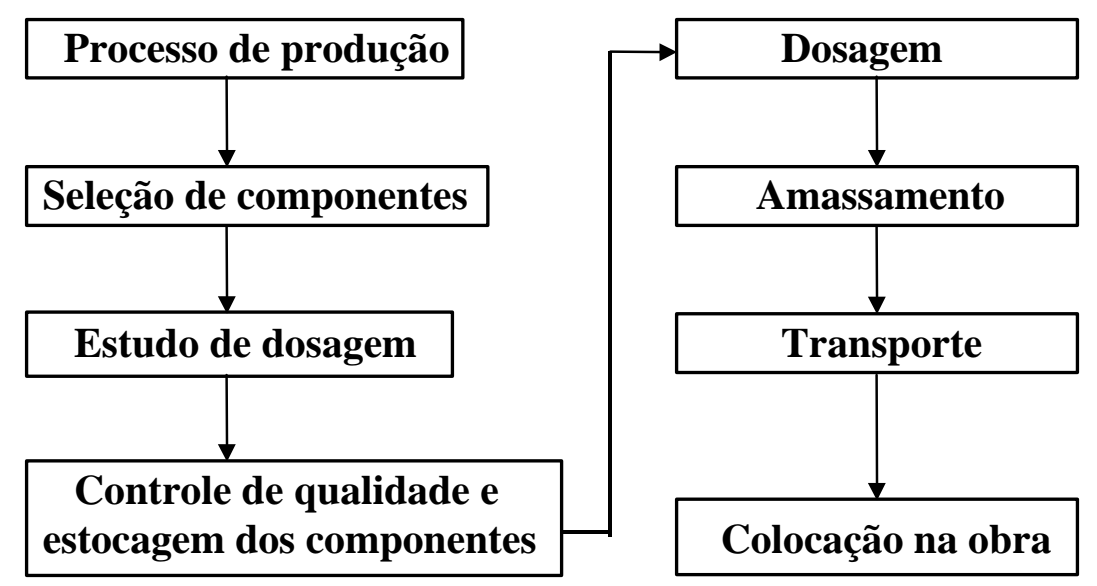

\subsubsection{Estocagem dos materiais}

A estocagem dos materiais constituintes do concreto de alto desempenho deve ser feita de forma adequada, independentemente do material em questão. Geralmente, observa-se um armazenamento correto do cimento, aditivos e adições minerais, sendo o mesmo não observado para os agregados. 


\section{a) Cimento}

Com relação ao cimento, caso esteja contido em sacos, deve ser armazenado em local ventilado e protegido, tanto das intempéries como da umidade do solo e paredes.

Se o cimento estiver a granel, seu armazenamento deverá ser feito em silos, que o isolem da umidade ambiente e, na medida do possível, da temperatura ambiente.

\section{b) Sílica ativa}

A sílica ativa pode ser encontrada no mercado densificada (onde as partículas são compactadas por processo de ar sobre pressão), não densificada (material bastante solto, podendo gerar problema durante o seu manuseio) e em suspensão.

Em pó tem-se:

- a granel

- em sacos plásticos de grande capacidade

Em suspensão tem-se:

- a granel

- em caixas

- em vasilhames

De qualquer forma, o produto deve ser armazenado de acordo com as especificações do fabricante, e sempre protegido da umidade ambiente, e em local seco e ventilado.

\section{c) Aditivos}

Os aditivos empregados na fabricação de CAD podem-se apresentar em estado líquido ou estado sólido (menos habitual), convenientemente ensacados.

\section{d) Agregados}

São os agregados os componentes que apresentam maiores deficiências com 
relação às características exigíveis para emprego em concreto de alto desempenho.

A heterogeneidade no conteúdo de umidade do material é suficiente para impedir a obtenção da resistência adequada, desqualificando qualquer alternativa de estocagem de material ao ar livre.

A estocagem de cada fração de agregado que será utilizada no traço do concreto de alto desempenho, deverá ser feita em caixas ou compartimentos independentes.

É desaconselhável a estocagem direta de material fino em silos que incorporem um elevado conteúdo de umidade, em função da distribuição irregular que a mesma imporá à massa de material, em um tempo relativamente curto de armazenamento.

\subsubsection{Dosagem dos componentes}

A dosagem dos componentes deve ser feita em peso, com exceção da água e dos aditivos líquidos que poderão ser medidos em volume.

Os agregados também devem ser dosados em peso, tendo-se o cuidado de se fazerem as correções de umidade, de acordo com a umidade que esses materiais se encontram, pois as quantidades foram definidas supondo o material em estado seco.

\subsubsection{Amassamento}

A diferença entre o amassamento do concreto normal e do concreto de alto desempenho é que para o concreto tradicional efetua-se o amassamento completo do material antes da chegada do mesmo à obra, não sendo admitida nenhuma mudança no concreto depois que o mesmo saiu da central de produção. Já para o concreto de alto desempenho, é conveniente a incorporação do aditivo em duas fases: a primeira na central de produção, em quantidade suficiente para permitir a obtenção de uma massa com consistência adequada, a fim de possibilitar seu transporte. A segunda deve ser feita na obra, com o objetivo de se obter a consistência prevista. Além dessa mudança, pode-se destacar que alguns autores recomendam que o tempo de amassamento do concreto de alto desempenho deveria ser aumentado de 50\%, em 
relação ao tempo especificado para os concretos tradicionais, a fim de se obter um melhor efeito dos agentes superplastificantes.

\subsubsection{Consistência}

Inicialmente, admitia-se que para a obtenção de um concreto de alta qualidade era necessário que ele apresentasse um reduzido abatimento de tronco de cone. Isto em função da incompatibilidade de grande quantidade de água e elevada resistência.

Já para o concreto de alto desempenho esse aspecto muda radicalmente, pois com a utilização de superplastificantes, a consistência da massa de concreto fica independente do conteúdo de água, sendo possível a obtenção de concretos extremamente fluidos com relação água/cimento não superior a 0,30.

$\mathrm{Na}$ maioria dos casos, o concreto de alto desempenho é utilizado em elementos estruturais com elevada taxa de armadura, o que implica na necessidade de se obter concretos de elevada resistência com abatimento de tronco de cone igual ou superior a $200 \mathrm{~mm}$.

\subsubsection{Transporte}

Os equipamentos e meios de transporte, geralmente utilizados nos concretos tradicionais, podem ser usados para os concretos de alto desempenho. O único problema é com relação à alteração da consistência, devido à perda de umidade da massa, durante o transporte. A perda de umidade no CAD tem maior influência na perda de trabalhabilidade da massa do que nos concretos tradicionais, uma vez que estes utilizam menores quantidades de aditivos redutores de água.

O tempo máximo recomendável entre a adição da água de amassamento ao cimento e agregados e a chegada do concreto na obra não deve exceder ao menor dos seguintes limites:

a) 90 minutos

b) 300 revoluções da caçamba do caminhão betoneira. 


\subsubsection{Compactação}

Em função da exigência de algumas características para o concreto de alto desempenho, tais como: abatimento de tronco de cone igual ou superior a $160 \mathrm{~mm}$, ausência de segregação, alta viscosidade, menor tamanho de agregado graúdo e suficiente volume de partículas finas, a moldagem e a compactação de concreto de alto desempenho ficam bastante facilitadas.

As atividades prévias à moldagem do concreto de alto desempenho não diferem muito das utilizadas para concretos normais. Convém destacar que para os $\mathrm{CAD}$, devido à menor energia de compactação, podem-se utilizar fôrmas menos rígidas e resistentes.

A determinação da consistência real do concreto no momento da chegada do concreto à obra, deve ser norma de rotina. Caso seja necessária a adição de nova quantidade de aditivo, deve-se fazer nova homogeneização do material, mantendo a caçamba do caminhão betoneira durante 2 minutos com velocidade superior a que estava sendo mantida.

Devido à maior coesão existente entre as partículas dos componentes do CAD, tem-se uma diminuição da segregação do material.

Segundo TRIANTAFILLIS ${ }^{12}$ apud GONZALEZ (1993), em concretos sob condições controladas, é possível lançar o concreto de uma altura de até 4,50 metros com pouca ou nenhuma segregação.

TRIANTAFILLIS estabelece as seguintes recomendações para compactação de concretos de alto desempenho:

a) A energia de compactação requerida por um concreto de alto desempenho é da ordem de $25 \%$ da necessária para concretos Classe I, com abatimento de tronco de cone entre $50 \mathrm{~mm}$ e $100 \mathrm{~mm}$.

b) $\mathrm{O}$ diâmetro da agulha do vibrador não deve exceder $40 \mathrm{~mm}$ e a freqüência deve ser maior do que 7000 vibrações por minuto.

12 TRIANTAFILliS, A. (1992). Utilización del hormigón superfluidificado en construcción. Congreso Interncontinental del Hormigón Preparado. Madrid. apud GONZALEZ, I. G. (1993). Hormigon de Alta Resistencia. Madrid, Intemac. Abril.pp.31. 
c) A profundidade da vibração esta relacionada com a espessura da capa de concreto. De qualquer forma, tem-se obtido bons resultados, com apenas uma única penetração em capas com até 2 metros de espessura.

d) A separação entre os pontos de vibração varia entre $30 \mathrm{~cm}$ e $60 \mathrm{~cm}$.

e) Com o objetivo de se evitar segregação e concentração de materiais finos, não se deve vibrar a armadura e nem a forma.

f) O concreto não deve se mover horizontalmente com o vibrador.

\subsection{CONTROLE DE QUALIDADE E ENSAIO}

Segundo SHAH \& AHMAD (1994), o concreto Classe I é um material que apresenta uma certa capacidade de absorção, ou seja, ele é capaz de tolerar algumas pequenas mudanças nos materiais, na proporção da mistura ou na condição de cura, sem grandes mudanças nas suas propriedades mecânicas.

Já o concreto de alto desempenho não é um material com capacidade de absorção, uma vez que os componentes da mistura estão trabalhando em seus limites. Assim, para assegurar a qualidade do concreto de alto desempenho, todos os aspectos da produção do concreto devem ser monitorados, desde a uniformidade da matériaprima, transporte, adensamento, vibração e cura.

Os procedimentos de controle de qualidade tais como os tipos de ensaios para o concreto fresco e o concreto endurecido, a frequiência dos ensaios, e interpretação dos resultados são essencialmente os mesmos que aqueles para o concreto normal.

Entretanto, COOK ${ }^{13}$ apud SHAH \& AHMAD (1994), tem apresentado dados obtidos a partir de ensaios realizados com concreto de alto desempenho que indicam que a resistência à compressão não é normalmente distribuída e o desvio padrão para a mistura dada, não é independente da idade do ensaio e do nível de resistência. Isso o levou a concluir que as técnicas de controle de qualidade usadas para concretos de resistências baixas e moderadas, podem não ser apropriadas para concretos com altíssimas resistências.

\footnotetext{
${ }^{13}$ COOK, J. E. (1989) 10,000 psi Concrete. Concrete International, 11, 10, 67-75.
} 


\subsubsection{Idade do ensaio}

Tradicionalmente, a aceitação padrão para concreto envolve a determinação da resistência do concreto para a idade de 28 dias. Entretanto, para concretos de alto desempenho tem-se tornado comum determinar a resistência à compressão aos 56 dias ou mesmo aos 90 dias. A justificativa para isso é que dificilmente nas estruturas, o concreto será carregado com a carga especificada em projeto, antes de aproximadamente 3 meses de construção.

Entretanto, existem 2 prejuízos na determinação da resistência em idades posteriores. Primeiro, medidas posteriores podem desencaminhar a comparação entre concretos com resistência normal e com alta resistência, se forem medidos em idades diferentes. O segundo fator e de maior importância, é certamente, a margem de segurança. Quando a resistência do concreto é medida aos 28 dias, tem-se uma reserva maior, visto que o concreto, geralmente estará mais forte, quando ele finalmente terá que suportar as cargas de projeto. Se a resistência é especificada para idades posteriores, essa margem é reduzida, e consequentemente, ocorre uma redução implícita no coeficiente de segurança.

\subsubsection{Tipo de molde do corpo-de-prova}

Há muito tempo é conhecido que dependendo das dimensões do corpo-deprova, diferentes resistências à compressão podem ser obtidas, sendo isso válido tanto para concretos com resistência normal, como para concretos de alto desempenho.

Em geral, moldes mais flexíveis produzem resistências mais baixas do que moldes mais rígidos. Isto ocorre porque a deformação dos moldes flexíveis durante a vibração e adensamento, leva a uma compactação menos eficiente do que aquela que se obtém com moldes rígidos.

Deve-se salientar, que independentemente do material do molde, este deve ser bem lacrado para prevenir vazamento da água de mistura do concreto, pois se isso ocorrer, a resistência aparente irá aumentar. 
CARRASQUILLO \& CARRASQUILLO ${ }^{14}$ apud SHAH \& AHMAD (1994) encontraram uma diferença na resistência de corpos-de-prova de $150 \mathrm{~mm}$ x $300 \mathrm{~mm}$ empregando-se moldes de aço por volta de 5\% maior do que a resistência obtida empregando-se moldes plásticos. Já HESTER ${ }^{15}$ encontrou uma diferença por volta de $10 \%$ para esses dois tipos de moldes.

PETERMAN \& CARRASQUILLO (1984) relataram que os moldes de aço deram resistências $10 \%$ maior do que aquelas obtidas com moldes de papelão.

HESTER mostrou que moldes de aço deram resistências por volta de $6 \%$ maior do que os moldes de estanho.

CARRASQUILLO \& CARRASQUILLO (1988) têm relatado que não houve diferença na resistência obtida empregando-se moldes 100 mm x $200 \mathrm{~mm}$ de aço, plástico ou papelão.

A partir desses resultados é conveniente utilizar moldes rígidos de aço, particularmente, para concretos com resistência superior a $98 \mathrm{MPa}$, pelo menos até que mais dados de ensaios estejam disponíveis para os moldes menores.

\subsubsection{Condições de capeamento do corpo-de-prova}

De acordo com ASTM C39 (Resistência à compressão de corpos-de-prova cilíndricos de concreto), a extremidade dos corpos-de-prova para ensaio devem ser planas, respeitando-se um limite de variação de $0,05 \mathrm{~mm}$. Isso pode ser conseguido pelo capeamento final do corpo-de-prova (usualmente com uma argamassa de enxofre), serrando o corpo-de-prova ou ainda esmerilhando.

Diferentes condições de tratamento da extremidade do corpo-de-prova, podem levar a diferentes medidas de resistência. $\mathrm{O}$ método mais comum de preparar a extremidade dos corpos-de-prova de concreto Classe I é através do uso de uma cobertura com argamassa de enxofre.

\footnotetext{
${ }^{14}$ CARRASQUILlO, P. M. \& CARRASQUILlO, R. L. (1988). Evaluation of the use of currente concrete practice in the production of high-strength concrete. ACI Materials Journal, 85, 1, 4954.
} 
Para o CAD argamassas de enxofre de alta resistência estão disponíveis comercialmente. Entretanto, se a resistência do capeamento for menor que a resistência do concreto, o carregamento de compressão não será transmitido uniformemente para o corpo-de-prova, levando a resultados inválidos.

Dessa forma, para concretos de alto desempenho, adicionalmente aos compostos de capeamento de alta resistência, um número de outras técnicas de preparo da cabeça do corpo-de-prova estão sendo investigadas. Dentre essas técnicas, tem-se a esmerilhação do final do corpo-de-prova e o uso de sistemas não aderentes, consistindo de uma base de material elastomérico restrita por um anel que se ajusta ao final do corpo-de-prova.

Muitos ensaios em CAD estão sendo conduzidos usando um capeamento composto de alta resistência. Na América do Norte existem materiais que alcançam resistências no intervalo de $84 \mathrm{MPa}$ a $91 \mathrm{MPa}$.

$\mathrm{COOK}^{16}$ tem usado tais compostos para concretos com resistência até $70 \mathrm{MPa}$, enquanto MORENO ${ }^{16}$ considera ser satisfatório o seu uso até $119 \mathrm{MPa}$.

BURG \& OST $^{17}$ apud SHAH \& AHMAD (1994), relataram que os materiais de capeamento podem ser usados com concretos com resistência até $105 \mathrm{MPa}$, pois além disso, o modo de ruptura dos cilindros mudam de ruptura normal de cone para ruptura tipo pilar.

Eles recomendam esmerilhar o final do corpo-de-prova para resistência além de $105 \mathrm{MPa}$.

Devido à incerteza da utilização dos compostos de capeamento de alta resistência e devido ao custo e tempo envolvido na esmerilhação do corpo-de-prova, uma considerável quantidade de pesquisas tem sido conduzidas em sistemas de capeamento não aderentes.

\footnotetext{
${ }^{15}$ HESTER, W. T. (1980). Field testing high-strengh concretes: a critical review of the state-of-theart. Concrete Internacional, 2, 12, 27-38.

${ }^{16}$ MORENO, J. (1990). 225 W. Wacker Drive. Concrete International, 12,1, 35-9.

${ }^{17}$ BURG, R. G. \& OST, B.W. (1992). Engineering properties of commercially available highstrength concretes. Research and Development Bulletin RD104T, Portland Cement Association, Skokie.
} 
RICHARDSON $^{18}$ apud SHAH \& AHMAD (1994), usou um sistema de neoprene inserido em uma capa de alumínio, para testar concretos com resistência normal no limite de $21 \mathrm{MPa}$ a $42 \mathrm{MPa}$. Nesta pesquisa, encontrou que abaixo de $28 \mathrm{MPa}$, a base de neoprene forneceu uma resistência um pouco abaixo do que o capeamento tradicional com capa de cloreto de enxofre, enquanto que acima de $28 \mathrm{MPa}$, a resistência foi um pouco maior. Entretanto, a resistência à compressão média para esses ensaios não foi significativamente diferente para os dois tipos de capeamento empregado.

CARRASQUILLO \& CARRASQUILLO ${ }^{15}$ compararam um capeamento composto de cloreto de enxofre de alta resistência, com um sistema não aderente composto por uma base de poliuretano em um anel de alumínio. Eles encontraram que até $70 \mathrm{MPa}$, a base de poliuretano restrita pelo anel de alumínio forneceu resultados de resistência por volta de $97 \%$ daqueles obtidos com o capeamento a base de cloreto de enxofre. Além de $70 \mathrm{MPa}$, o sistema não aderente deu uma resistência muito maior. Eles supuseram que isso poderia ser devido a grande restrição do cilindro com tal sistema. Em outro estudo, eles encontraram diferenças substanciais empregando-se dois grupos de capeamento não aderentes de um mesmo fabricante.

Em resumo tem-se que, abaixo de $98 \mathrm{MPa}$, um fino capeamento de argamassa de cloreto de enxofre de alta resistência pode ser usado com sucesso. Além desse nível de resistência, parece que a esmerilhação da extremidade do corpo-de-prova parece ser a maneira mais correta para se garantirem os resultados dos ensaios.

\subsubsection{Características das máquinas de ensaio}

Em geral, para os concretos Classe I as características da máquina de ensaio são assumidas ter um pequeno ou nenhum efeito no carregamento de pico. Entretanto, para concreto com alto desempenho, a máquina talvez tenha uma interferência na resposta do corpo-de-prova quando submetido ao carregamento. HESTER $^{15}$ concluiu que o módulo de rigidez longitudinal da máquina de ensaio não

\footnotetext{
${ }^{18}$ RICHARDSON, D. N. (1990). Effects of testing variables on the comparison of neoprene pad and sulfur mortar-capped concrete test cylinders. ACI Material Journal, 87, 5, 489-95.
} 
afetará a carga máxima, sendo este ponto de vista também compartilhado por $\operatorname{AITCIN}^{19}$ (1989).

Para ensaios de corpos-de-prova de concreto de alto desempenho, devem-se rever as dimensões usuais do corpo-de-prova ou a capacidade das máquinas de ensaio.

AITCIN $^{19}$ apud SHAH \& AHMAD (1994) calculou a capacidade requerida pela máquina de ensaio, para diferentes níveis de resistência e tamanho dos corposde-prova usando a hipótese comum de que a carga de colapso não deveria exceder 2/3 da capacidade da máquina. Alguns de seus resultados estão ilustrados na tabela 2.8 .

TABELA 2.9 - Capacidade da máquina de ensaio requerida para concretos de alto desempenho calculadas por AITCIN (1989).

\begin{tabular}{||c|c|c|c|c||}
\hline Dimensões do CP & \multicolumn{2}{|c|}{ Carga de colapso } & \multicolumn{2}{c||}{ Capacidade da máquina } \\
\hline & $f^{\prime}{ }_{c}=100 \mathrm{MPa}$ & $f^{\prime}{ }_{c}=150 \mathrm{MPa}$ & $f^{\prime}{ }_{c}=100 \mathrm{MPa}$ & $f^{\prime}=150 \mathrm{MPa}$ \\
$\mathbf{1 0 0} \times \mathbf{2 0 0} \mathbf{~ m m}$ & $0,785 \mathrm{MN}$ & $1,18 \mathrm{MN}$ & $1,2 \mathrm{MN}$ & $1,75 \mathrm{MN}$ \\
$\mathbf{1 5 0} \times \mathbf{3 0 0} \mathbf{~ m m}$ & $1,76 \mathrm{MN}$ & $2,65 \mathrm{MN}$ & $2,65 \mathrm{MN}$ & $4,0 \mathrm{MN}$ \\
\hline
\end{tabular}

FONTE: SHAH \& AHMAD (1994).

Relativamente poucos laboratórios comerciais estão equipados para ensaiar corpos-de-prova de concretos de alto desempenho, uma vez que a capacidade comum das máquinas de ensaio é de 1,3 MN. Para ensaiar um cilindro de $150 \mathrm{~mm}$ x $300 \mathrm{~mm}$ de concreto com resistência de $150 \mathrm{MPa}$ é necessário uma máquina de ensaio de 4,0 MN e relativamente poucas máquinas desse porte estão disponíveis. Essa provavelmente seja a grande justificativa para a tendência existente em se adotar o corpo-de-prova cilíndrico de 100 mm x 200 mm como padrão.

\footnotetext{
${ }^{19}$ AITCIN, P. C. (1989). Les essais sue les betons a tres hautes performances, in Annales de L'Institut
} Technique du Batiment et des Travaux Publics, $n^{\circ}$ 473. Mars-Avril. Serie: Beton 263, 167-9. 


\section{PROPRIEDADES MECÂNICAS DO CONCRETO DE ALTO DESEMPENHO}

O concreto deve ser produzido com o objetivo de suportar os carregamentos impostos, resistir à deterioração para o período de vida útil para o qual ele foi projetado e ser dimensionalmente estável.

A qualidade do concreto é caracterizada pelas suas propriedades mecânicas e pela sua capacidade de resistir à deterioração.

As propriedades mecânicas do concreto podem ser classificadas como sendo de curta e de longa duração. Dentre as de curta duração têm-se: resistência à compressão, resistência à tração, módulo de elasticidade e características da argamassa. Já as propriedades de longa duração englobam: retração, fluência, comportamento sob fadiga e características de durabilidade, tais como, porosidade, permeabilidade e resistência à abrasão.

Algumas propriedades do concreto, tais como relação tensão-deformação, módulo de elasticidade, resistência à tração e resistência da ligação, são freqüentemente expressas em termos da resistência à compressão uniaxial de cilindros de concreto, com dimensões de $150 \mathrm{~mm}$ x $300 \mathrm{~mm}$.

Segundo SHAH e AHMAD (1994), a resistência do concreto talvez seja uma das maneiras mais importantes de se medir a qualidade do concreto, uma vez que está diretamente relacionada com a estrutura da pasta de cimento endurecida. Embora a resistência não seja uma medida direta da durabilidade do concreto ou da estabilidade dimensional, ela está intimamente ligada à relação água/cimento, a qual influencia a durabilidade, a estabilidade dimensional e outras propriedades do concreto pelo controle da porosidade. 
A resistência do concreto depende de vários fatores, tais como propriedades e proporção dos materiais constituintes, grau de hidratação, taxa de carregamento, método de ensaio e geometria do corpo-de-prova.

Um resumo dos fatores que afetam a resistência do concreto está mostrado na figura 3.1 .

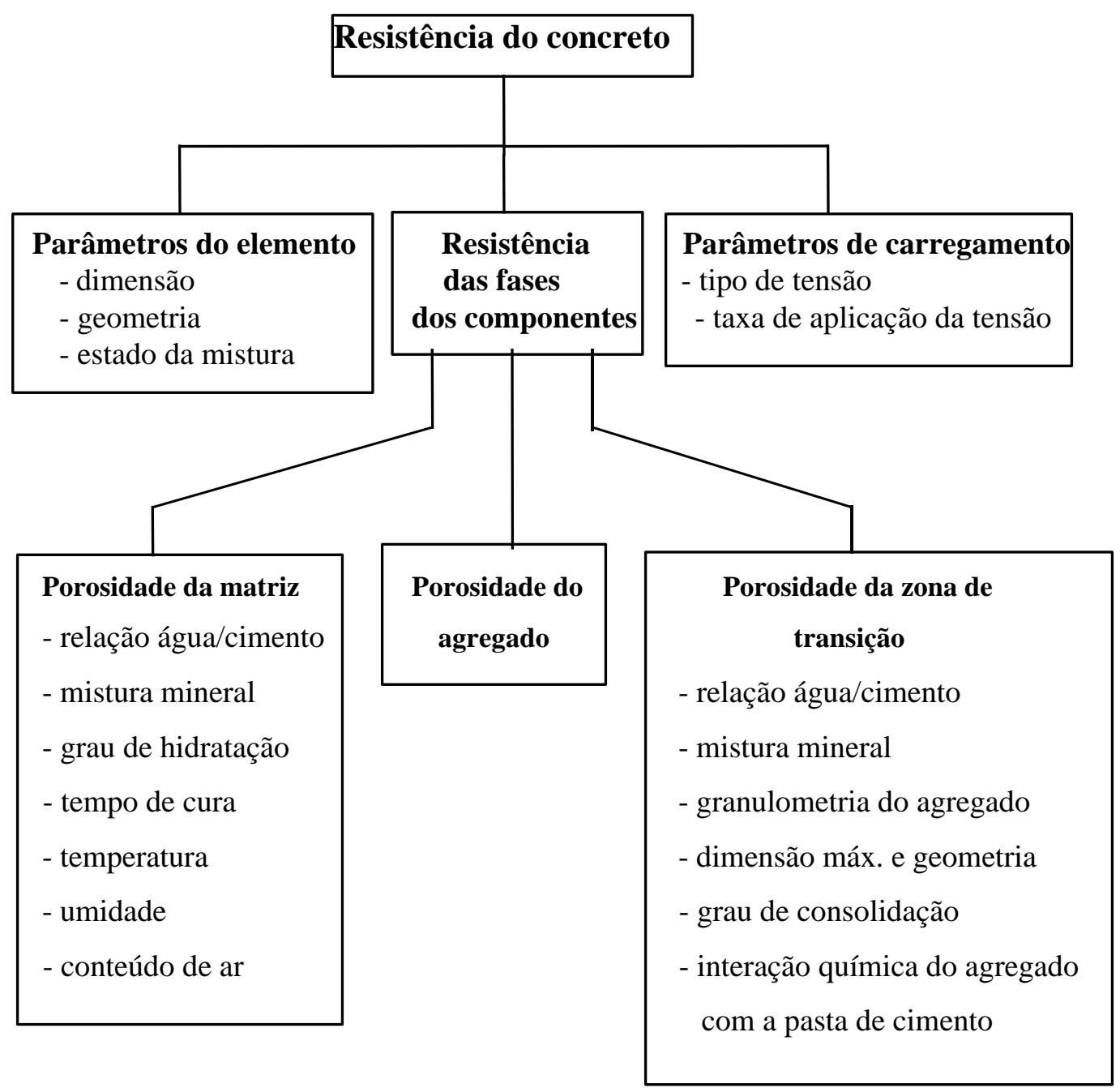

FIGURA 3.1 - Fatores que afetam a resistência do concreto. 


\subsection{RESISTÊNCIA À COMPRESSÃO}

A resistência à compressão é normalmente considerada a propriedade mais importante do concreto. É empregada como método para avaliar a qualidade de uma estrutura.

A resistência à compressão é obtida através de ensaios de corpos-de-prova que geralmente são rompidos aos 28 dias.

O tipo de corpo-de-prova e as dimensões a serem empregadas dependem da normalização vigente em cada país. No Brasil e nos Estados Unidos, por exemplo, adota-se o cilindro com dimensões de $150 \mathrm{~mm}$ x $300 \mathrm{~mm}$, curados umidamente até os 28 dias.

$\mathrm{Na}$ Alemanha e na Noruega são utilizados corpos-de-prova cúbicos com arestas de $14 \mathrm{~cm}$ e $10 \mathrm{~cm}$, respectivamente.

As diferenças nas dimensões dos corpos-de-prova influenciam o valor de resistência à compressão obtida no ensaio. Para os concretos Classe I, o fator de conversão normalmente aplicado entre o corpo-de-prova cúbico e o cilíndrico é de 0,8. Segundo o Código Modelo 90 (CEB, 1991) e a Norma Norueguesa apud DAL MOLIN (1995), tem-se que para o CAD (acima de $50 \mathrm{MPa}$ em cilindros), este fator apresenta uma diferença constante de $10 \mathrm{MPa}$ para o Código Modelo 90 (CEB,1991) e $11 \mathrm{MPa}$ para a Norma Norueguesa NS 3473 (1989), como é ilustrado nas tabelas 3.1 e 3.2 .

TABELA 3.1 - Fatores de conversão propostos pelo CEB (1991).

\begin{tabular}{||c|c|c|c|c|c|c|c|c||}
\hline & C12 & C20 & C30 & C40 & C50 & C60 & C70 & C80 \\
\hline$f_{c k}($ cilindro 15x30 cm) & 12 & 20 & 30 & 40 & 50 & 60 & 70 & 80 \\
\hline $\begin{array}{c}f_{c k}(\text { cubo 15x15x15 } \\
\mathbf{m m})\end{array}$ & 15 & 25 & 37 & 50 & 60 & 70 & 80 & 90 \\
\hline \hline
\end{tabular}

TABELA 3.2 - Fatores de conversão propostos pela Norma Norueguesa (NS 3473, 1989).

\begin{tabular}{||c|c|c|c|c|c|c|c|c|c||}
\hline & C25 & C35 & C45 & C55 & C65 & C75 & C85 & C95 & C105 \\
\hline$f_{c k}($ cilindro $)$ & 20 & 28 & 36 & 44 & 54 & 64 & 74 & 84 & 94 \\
\hline$f_{\text {ck }}($ cubo 10x10x10 cm) & 25 & 35 & 45 & 55 & 65 & 75 & 85 & ---- & ---- \\
\hline \hline
\end{tabular}


Segundo LARRARD ${ }^{1}$ apud DAL MOLIN (1995), os fatores de conversão entre os diferentes tamanhos de corpos-de-prova, para resistências na faixa de $50 \mathrm{MPa}$ a $95 \mathrm{MPa}$, medidas em corpos-de-prova cilíndricos, são os apresentados na tabela 3.3.

TABELA 3.3 - Fatores de conversão entre os corpos-de-prova obtidos por LARRARD (1991).

\begin{tabular}{||c|c|c|c|c||}
\hline \multirow{2}{*}{ Tipo de corpo-de-prova } & \multicolumn{3}{|c||}{ Cubo (aresta em cm) } & Cilindro \\
\cline { 2 - 5 } & 10 & 15 & 20 & $15 \mathrm{~cm} \times 30 \mathrm{~cm}$ \\
\hline cubo de 10 & 1 & 0,99 & 0,95 & 0,82 \\
\hline cubo de 15 & ---- & 1 & 0,96 & 0,83 \\
\hline cubo de 20 & ---- & ---- & 1 & 0,87 \\
\hline
\end{tabular}

A resistência à compressão tem aumentado constantemente nas últimas décadas, e hoje em dia, resistências por volta de $80 \mathrm{MPa}$ são obtidas com certa facilidade.

Devido às diferenças existentes entre a moldagem, compactação e cura aplicadas na obra e no laboratório, as resistências obtidas a partir de amostras de concreto extraídas de elementos de uma estrutura podem não ser coincidentes com as que, para o mesmo concreto, são determinadas em condições de laboratório.

Para o Código Modelo do CEB-FIP (1990), a relação entre a resistência obtida na obra e a resistência obtida no laboratório pode ser expressa através da seguinte expressão:

$$
\frac{f_{c(o b r a)}}{f_{c(l a b)}}=1-\frac{f_{c}}{250} \quad(\mathrm{MPa})
$$

Essa expressão, quando aplicada a concretos de resistência igual ou superior a $80 \mathrm{MPa}$, conduz a um limite não superior a 0,68.

Vários códigos, como ISO ${ }^{2}$ e NS 3473, assumem coeficientes de segurança variando entre os limites de 0,75 a 0,90 .

\footnotetext{
${ }^{1}$ LARRARD, F. (1991). apud DAL MOLIN, D. C. C. (1995). Contribuição ao estudo das propriedades mecânicas dos concretos de alta resistência com e sem adições de microssílica. São Paulo, junho. p.55.
} 
A resistência do concreto obtida em ensaios de longa duração é menor que aquela obtida para ensaios de curta duração. Isso é importante em projetos porque representa uma redução no coeficiente de segurança com respeito à resistência, a qual é geralmente baseada em ensaios de curta duração.

Os resultados de ensaios de longa-duração indicam que o valor da resistência obtida através de carregamentos permanentes é por volta de $70 \%$ a $80 \%$ da resistência última, obtida para ensaios de curta duração, empregando-se concretos de resistência normal.

Segundo $\mathrm{SMADI}^{3}$ et al. apud GONZALEZ (1993), a relação entre a resistência à compressão para cargas instantâneas e permanentes é ligeiramente superior nos concretos de alto desempenho, ficando compreendida no limite de 0,80 a 0,85 .

Segundo FIP/CEB 197 (1990), o aumento relativo na resistência de curta duração do CAD, depois dos 28 dias, é geralmente menor do que para concretos normais. Isso ocorre em função da falta de água livre, que permite uma hidratação posterior combinada com uma possível limitação da capacidade dos agregados.

Para MAAGE ${ }^{4}$ et al. apud FIP/CEB 197 (1990), concretos de alto desempenho contendo sílica ativa apresentam um ganho de resistência menor depois de 28 dias, quando comparado com concretos de alto desempenho sem sílica ativa, com a mesma relação água/cimento.

Assim, a razão entre a tensão a longo prazo que o CAD pode suportar aos 28 dias, e a sua resistência na mesma idade, pode ser um pouco menor ou comparável com aquela do concreto normal $(0,75-0,80)$.

A figura 3.2 indica diagramas mostrando a relação existente entre o nível de tensão e de deformação em concretos de alto desempenho e concretos com resistência tradicional submetidos a cargas permanentes.

${ }^{2}$ INTERNATIONAL STANDARD ORGANIZATION. Methods for assessment of the compressive strength of concrete in structures. Draft proposal ISO/TC71/SC3/WG May 1987.

${ }^{3}$ SMADI, M. M. \& SLATE, F. O. \& NILSON, A. H. (1985). High, medium and low strength concrete subjected to sustained overloads - Strains, strengths and failure mechanisms. ACI Journal Sept-Oct.

${ }^{4}$ MAAGE \& SMEPLASS \& JOHANSEN. (1990). Long-term strength of high strength silica fume concrete. Second International Symposium on the Utilization of High Strength Concrete Berkeley, California. May. 


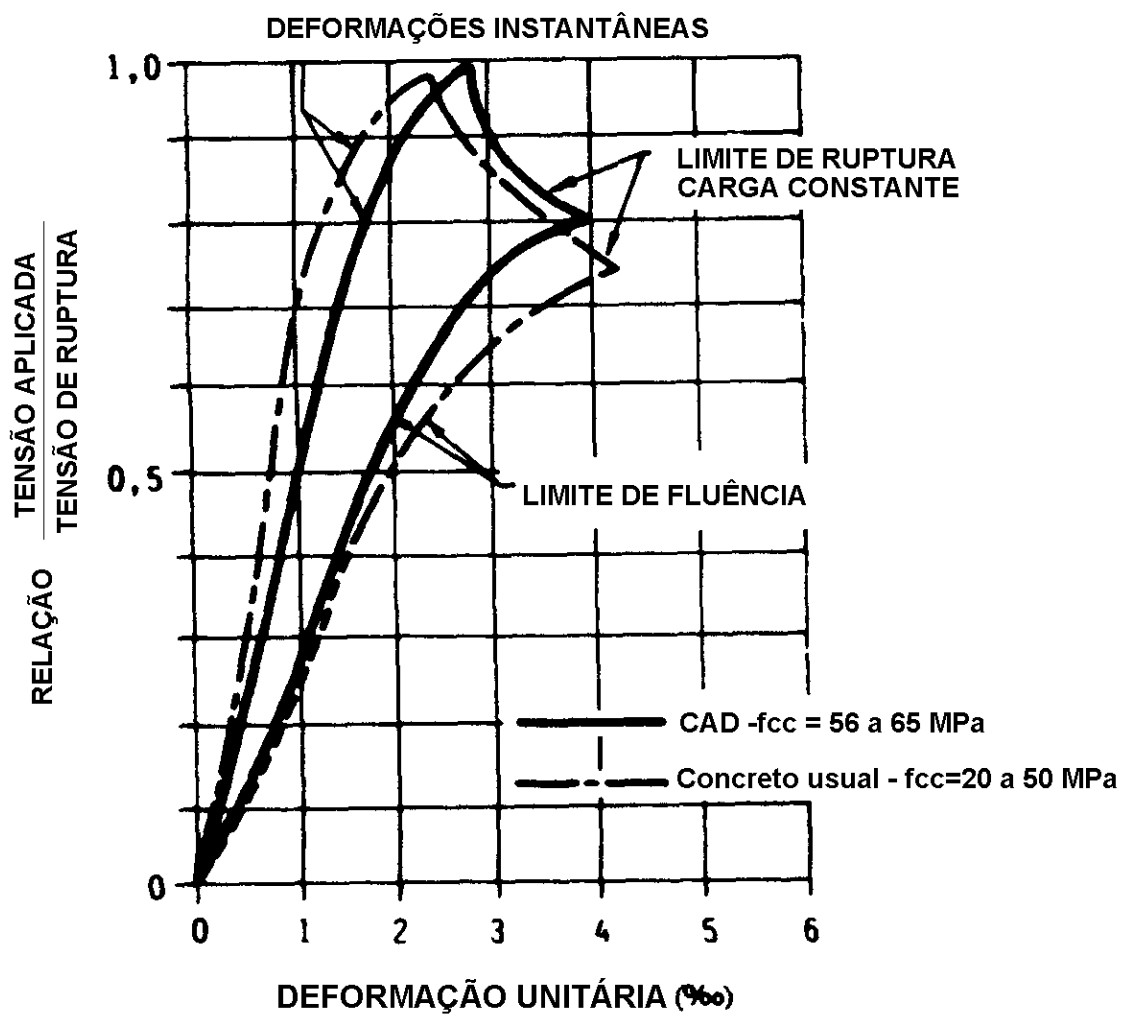

FIGURA 3.2 - Tensão/resistência e deformação para concretos sob ação de longa duração. FONTE: FIP/CEB-197 (1990).

A resistência desenvolvida a longo prazo para concretos com sílica ativa, curados ao ar, tem sido questionada por AITCIN $^{5}$ et al. apud FIP/CEB 197 (1990), que através de um programa de laboratório envolvendo 12 diferentes traços de concreto indicou perda de resistência para 3 séries analisadas, no período de 91 dias a 2 anos, as quais foram curadas ao ar e continham sílica ativa.

Já um estudo realizado por AITCIN \& LAPLANTE ${ }^{6}$ apud FIP/CEB 197 (1990), contendo 4 projetos com níveis de resistência à compressão variando de $40 \mathrm{MPa}$ a $83 \mathrm{MPa}$, indicou que não ocorreu nenhuma tendência de perda

5 CARETTE \& MALHOTRA \& AITCIN (1989). Preliminary data on long-term strength development of condensed silica fume concrete. Third Int. Conference on Fly Ash, Silica Fume, Slag/Natural Pozzolans in Concrete-Trondheim. Norway supplementary papers pp 597-617 apud FIP/CEB (1990). High Strength Concrete State of the Art Report. Bulletin d'Information, $\mathrm{n}^{\circ} 197 . \mathrm{p} .13$.

${ }^{6}$ AITICIN \& LAPLANTE. (1989). Long-term compressive strength of silica fume concrete. Third Int. Conference on Fly Ash, Silica Fume, Slag \& Natural Pozzolans in Concrete - Trondhein, Norway supplementary papers p. 727-737 apud FIP/CEB (1990). High Strength Concrete State of the Art Report. Bulletin d'Information, n 197. p13. 
de resistência depois de 4 a 6 anos de cura no campo, em concretos com ou sem sílica ativa.

Outra pesquisa realizada na Noruega por MAAGE ${ }^{7}$ et al. apud FIP/CEB 197 (1990), em 9 diferentes projetos com sílica ativa, onde a resistência à compressão, para concretos com idade de 2 a 10 anos, variou no limite de $40 \mathrm{MPa}$ a $165 \mathrm{MPa}$, também indicou que não havia nenhuma tendência de perda de resistência, em qualquer dos concretos, com ou sem sílica ativa.

O projeto envolveu corpos-de-prova curados na água, ao ar e corpos-de-prova tirados de diferentes elementos estruturais já construídos.

Segundo FIORATO ${ }^{8}$ apud GONZALEZ (1993), através de um programa de ensaios, no qual foram analisados 5 diferentes traços de concreto, constatou-se que 2 traços apresentaram ligeira regressão na resistência à compressão do concreto aos 14 meses de sua fabricação. Notou-se também a ocorrência da estabilização desse fenômeno transcorrido 18 meses. Pode-se ainda constatar que, posteriormente, o concreto continua seu processo normal de incremento de resistência.

Conclui-se portanto que, em certas ocasiões, produz-se nos concretos de alto desempenho um fenômeno de estabilização ou de ligeira regressão da resistência em idades superiores a 90 dias, cujas causas não são suficientemente conhecidas. Entretanto, tal fenômeno parece afetar em maior grau os concretos curados em condições de laboratório, em comparação com os curados na obra.

Segundo HAN \& WALRAVEN (1994) apud ACI SP-149 (1994), o acréscimo de resistência no concreto depende de um mecanismo relacionado à porosidade e que pode ser explicado da seguinte maneira: quando uma força de compressão é aplicada num elemento de concreto, os poros perpendiculares e paralelos à direção do carregamento irão ter comportamentos diferentes. Os poros perpendiculares à direção do carregamento tendem a fechar, resultando num movimento da água dentro dos poros. Devido à viscosidade, o movimento da água irá causar um gradiente de pressão. Isso talvez produza uma pressão hidrostática nos

\footnotetext{
${ }^{7}$ MAAGE \& SMEPLASS \& JOHANSEN (199). Long-term strength of high strength silica fume concrete, Second Int. Symposium on the utilization of High Strength Concrete. Berkeley, California. May.

8 FIORATO, A. E. (1992). Ready mixed high-strength concrete: Properties for design and construction. Congresso Intercontinental de Hormigón Preparado. Madrid.
} 
poros, a qual pode ajudar o concreto a resistir às forças externas pela adição de uma resistência extra na deformação longitudinal. Adicionalmente, tem-se a contribuição dos poros paralelos à direção de carregamento, a qual pode ser explicada com base no efeito denominado de "Stefan". Este efeito, bem conhecido pelos físicos, pode ser descrito da seguinte maneira: a presença de uma fina camada viscosa (de água ou outro líquido qualquer) entre duas lâminas perfeitas e paralelas, separadas por uma distância (d), ao serem separadas proporcionam o surgimento de uma força contrária ao movimento. No concreto, as lâminas separadas pela água podem ser consideradas como uma analogia às paredes dos poros. Se a carga é aplicada, as paredes paralelas à direção de carregamento tendem a separar entre si, criando uma força de oposição que irá impedir essa separação. Isso favorecerá o bloqueamento do desenvolvimento das microfissuras e restringirá a deformação transversal, resultando numa maior resistência à compressão.

SHAH \& AHMAD (1994), com base em pesquisas e dados de outros autores ${ }^{9}$, propuseram uma expressão para estimar a resistência à compressão sob condições de carregamento rápido. A expressão recomendada é:

$$
\left(f_{c}^{\prime}\right)_{\varepsilon}=f_{c}^{\prime} \cdot\left[0,95+0,27 \cdot \log \frac{\varepsilon}{f_{c}^{\prime}}\right] \cdot \alpha
$$

Onde $\varepsilon$ é a taxa de deformação em $10^{-3} \mathrm{~mm} / \mathrm{seg}$.

O fator de forma $(\alpha)$ leva em conta os diferentes tamanhos de corpos-deprova, ensaiados por diferentes autores, e é dado por:

$$
\begin{aligned}
& \alpha=0,85+0,95 \cdot \mathrm{d}-0,002 \cdot \mathrm{h} \quad \text { para } \rightarrow \frac{h}{d} \leq 5 \\
& \mathrm{~d}=\text { diâmetro ou menor dimensão lateral (polegadas) } \\
& \mathrm{h}=\text { altura (polegadas) }
\end{aligned}
$$

${ }^{9}$ BRESLER, B. \& BERTERO, V. (1975). Influences of high strain rate and ciclic loading on behavior of unconfined and confined concrete in compression. Proceedings, Second Canadian Conference on Earthquake Engineering, Mac-Master University, Hamilton, Ontário, Canada, June.

DILGER, W. H. \& KOCH, R. \& ANDOWALCZYK, R. (1984). Ductility of plain and confined concrete under different strain rates. ACI Journal, 81, 1, Jan-Feb, 73-81. 


\subsection{RESISTÊNCIA À TRAÇÃO}

Ainda que a resistência do concreto à tração seja desprezada, na resistência de peças de concreto armado no estado limite último, ela governa o comportamento na fissuração e afeta outras propriedades, tais como módulo de rigidez, permeabilidade, aderência e durabilidade do concreto. Usualmente, a resistência do concreto à tração aumenta com o crescimento da resistência à compressão, embora de forma não diretamente proporcional.

A resistência do concreto à tração pode ser determinada experimentalmente através de três maneiras diferentes: ensaio de tração axial, ensaio de compressão diametral e ensaio de flexão em vigas.

O primeiro método de se obter a resistência à tração pode ser referido como um método direto; já o segundo e o terceiro podem ser referidos como métodos indiretos.

\subsubsection{Ensaio de tração direta}

O ensaio de tração direta consiste em se aplicar uma força axial de tração no corpo-de-prova. Apesar de ser o único ensaio direto de tração, não é muito utilizado, uma vez que os dispositivos que fixam o corpo-de-prova introduzem tensões secundárias que devem ser consideradas.

É freqüentemente assumido que a resistência à tração direta seja por volta de $10 \%$ da resistência à compressão, o que não é válido para o concreto de alto desempenho. A relação entre a resistência à tração e a resistência à compressão foi estudada por DEWAR ${ }^{10}$ apud GONZALEZ (1993), o qual concluiu que, para concretos com resistência superior a $84 \mathrm{MPa}$, a resistência à tração pode ser estimada como sendo 5\% da resistência à compressão.

Dois estudos recentes têm relatado sobre a resistência à tração direta do concreto. O primeiro estudo foi feito na Universidade de Delft, desenvolvido por

HUGHES, B. P. \& GREGORY, R. (1972). Concrete subjected to high rates of loading and compression. Magazine of Concrete Research, 24, 78, London, March.

${ }^{10}$ DEWAR, J. D. (1984). The indirect tensile strength of concrete of high compresive strength. Technical Report ${ }^{\circ}$ 42.377, Cement and Concrete Association, Wexham Springs. March. 
CORNELISSEN $^{11}$, o qual utilizou cilindros com diâmetro de 120 mm e comprimento de $300 \mathrm{~mm}$. Neste estudo ensaiaram-se concretos lacrados por 4 semanas, curados umidamente por 2 semanas, e curados secos ao ar por 2 semanas. Os resultados indicaram uma resistência à tração $18 \%$ maior para o concreto lacrado quando comparado ao concreto seco ao ar.

O segundo estudo realizado na Northwestern, desenvolvido por GOPALARATHAM $^{12}$ apud SHAH \& AHMAD (1994), incluiu diferentes resistências de concreto até $48 \mathrm{MPa}$ e concluiu que a resistência à tração axial pode ser estimada pela expressão:

$$
f_{t k}=6,5 \sqrt{f_{c}^{\prime}}
$$

A Norma Norueguesa NS 3473E considera o ensaio de tração direta para determinação da resistência à tração e propõe a seguinte tabela para determinação da resistência à tração em função da resistência à compressão.

TABELA 3.4 - Resistência do concreto (N/mm2) segundo a NS 3473 E (1992).

\begin{tabular}{||c|c|c|c|c|c|c|c|c|c|c||}
\hline $\begin{array}{c}\text { Valor } \\
\text { característico }\end{array}$ & LC15 & $\begin{array}{c}\text { C25 } \\
\text { LC25 }\end{array}$ & $\begin{array}{c}\text { C35 } \\
\text { LC35 }\end{array}$ & $\begin{array}{c}\text { C45 } \\
\text { LC45 }\end{array}$ & $\begin{array}{c}\text { C55 } \\
\text { LC55 }\end{array}$ & $\begin{array}{c}\text { C65 } \\
\text { LC65 }\end{array}$ & $\begin{array}{c}\text { C75 } \\
\text { LC75 }\end{array}$ & $\begin{array}{c}\text { C85 } \\
\text { LC85 }\end{array}$ & $\begin{array}{c}\text { C95 } \\
\text { LC95 }\end{array}$ & C105 \\
\hline $\begin{array}{c}\text { Resistência } \\
\text { cúbica à } \\
\text { compressão } f_{c k}\end{array}$ & 15 & 25 & 35 & 45 & 55 & 65 & 75 & 85 & ---- & ---- \\
\hline $\begin{array}{c}\text { Resistência } \\
\text { cilíndrica à } \\
\text { compressão } f_{c c k}\end{array}$ & 12 & 20 & 28 & 36 & 44 & 54 & 64 & 74 & 84 & 94 \\
\hline $\begin{array}{c}\text { Resistência à } \\
\text { compressão } \\
\text { in situ } f_{c n}\end{array}$ & 11,2 & 16,8 & 22,4 & 28,0 & 33,6 & 39,2 & 44,8 & 50,4 & 56,0 & 61,6 \\
\hline $\begin{array}{c}\text { Resistência à } \\
\text { tração } f_{t k}\end{array}$ & 1,55 & 2,10 & 2,55 & 2,95 & 3,30 & 3,65 & 4,00 & 4,30 & 4,60 & 4,90 \\
\hline $\begin{array}{c}\text { Resistência à } \\
\text { tração in situ } \\
f_{t n}\end{array}$ & 1,0 & 1,40 & 1,70 & 2,00 & 2,25 & 2,50 & 2,60 & 2,70 & 2,70 & 2,70 \\
\hline \hline
\end{tabular}

${ }^{11}$ CORNELISSEN, H.A.W. (1984). Fatigue failure of concrete intension. Heron, 29,4, 1-68.

${ }^{12}$ GOPALARATHAM, V. S. \& SHAH, S. P. (1985). Softening response of concrete in direct tension. Research Report, Technological Institute, Northwestern University, Chicago, June 1984, also ACI Journal, 82,3, May-June 1985, 310-323 apud SHAH, S.P. \& AHMAD, S. H. (1994). High performance concretes and applications. London, Edward Arnold. 403p. 
A Norma Brasileira NBR 6118 propõe, para concretos com resistência à compressão superior a $18 \mathrm{MPa}$, a seguinte expressão para estimativa da resistência à tração:

$$
f_{t k}=0,06 \cdot f_{c k}+0,7 \quad(\mathrm{MPa})
$$

\subsubsection{Ensaio de compressão diametral}

Este ensaio consiste na compressão da aresta do cilindro de $150 \mathrm{~mm}$ x $300 \mathrm{~mm}$ como esquematizado na figura 3.3 (NBR 7222, 1982).

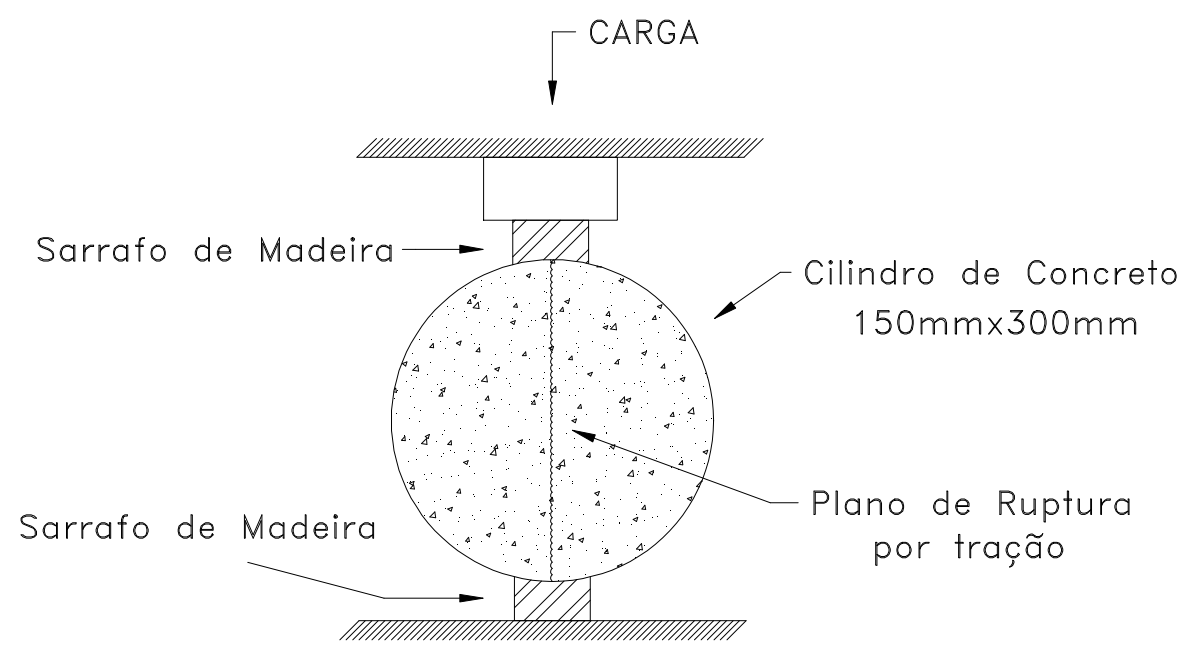

FIGURA 3.3 - Esquema do ensaio de compressão diametral. FONTE: SILVA I. S. (1995).

O ACI Committee 363 indica que a resistência a tração $\left(f_{c t}\right)$ em ensaios de compressão diametral para concretos normais pode ser estimado pela seguinte expressão:

$$
\begin{aligned}
& f_{c t}=7,4 \sqrt{f_{c}^{\prime}} \quad(\mathrm{psi}) \quad \text { para } 3000 \mathrm{psi}<f_{c t}<12000 \mathrm{psi} \\
& f_{c t}=0,59 \sqrt{f_{c}^{\prime}} \quad(\mathrm{MPa}) \quad \text { para } 21 \mathrm{MPa}<f_{c t}<83 \mathrm{MPa}
\end{aligned}
$$


A figura 3.4 mostra os dados experimentais e a previsão usando a equação do ACI Committee 363, a qual parece superestimar os valores de resistência a tração.

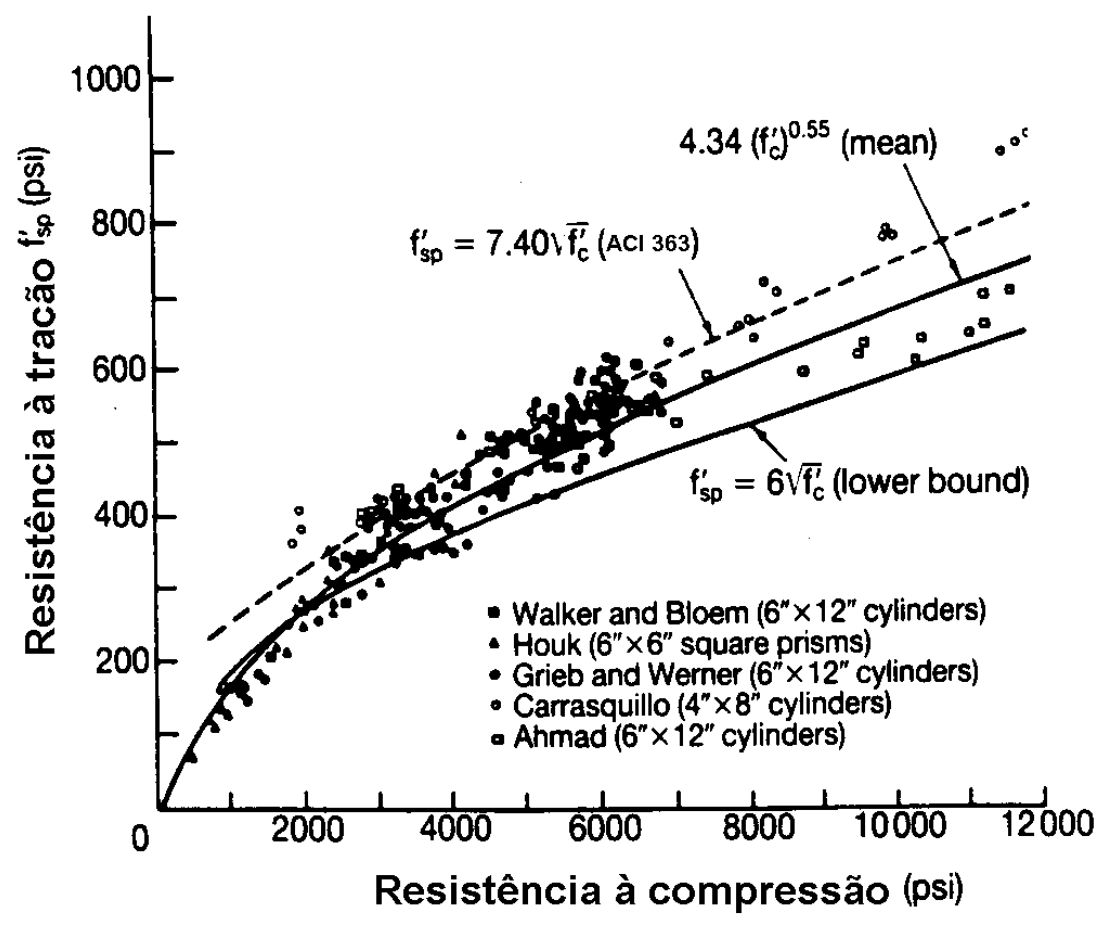

FIGURA 3.4 - Variação da resistência à tração em ensaios de compressão diametral com a resistência à compressão. FONTE: SHAH \& AHMAD (1994).

Em 1985, baseado em dados experimentais disponíveis de compressão diametral em corpos-de-prova de concreto de baixa, média ${ }^{13}$ e alta resistência ${ }^{14}$, uma relação empírica foi proposta por SHAH \& AHMAD (1994) como:

$$
f_{c t}=4,34 \cdot\left(f_{c}^{\prime}\right)^{0,55} \quad(\mathrm{psi}) \quad \text { para } 3000 \quad f^{\prime}{ }_{c} \quad 12000 \mathrm{psi}
$$

Essa expressão também se encontra representada na figura 3.4.

${ }^{13}$ GRIEH, W. E. \& WERNER, G. (1962). Comparison of splitting tensile strength of concrete with flexural and compressive strengths. Public roads, 32,5, Dec.

HOUK, H. (1965). Concrete aggregates and concrete properties investigations, Design Memorandum, $N^{\circ}$ 16, Dworshak Dam and Reservoir, U.S. Army Engineer District, Walla, WA.

WALKER, S. \& BLOEM, D. L. (1960). Effects of aggregate size on properties of concrete. ACI Journal, 32,3, September, 283-98.

${ }^{14}$ SHAH \& AHMAD (1982). Optimization of mix design for high strength concrete. Report $\mathrm{N}^{\circ} \mathrm{CE}$ 001-82, Department of Civil Engineering, North Carolina State University. 
CARRASQUILLO $^{15}$ et al. apud FIP/CEB-197 (1990) propuseram a seguinte equação para previsão da resistência à tração nos ensaios de compressão diametral em concretos com corpos-de-prova cilíndricos de 100 mm x 200 mm:

$$
f_{c t}=0,54 \cdot \sqrt{f_{c k}} \quad(\mathrm{MPa}) \text { para } 21 \mathrm{MPa}<f_{c k}<83 \mathrm{MPa}
$$

Em um programa de ensaio muito amplo realizado pela INTEMAC apud GONZALEZ (1993), durante o ano de 1992, foram abordadas as seguintes variáveis:

- cimento: 3 do tipo I/55A e 1 do tipo I/45A

- areia: 3 tipos diferentes

- sílica ativa: Elken (HALESA) e Condensil (SIKA)

- relação sílica ativa/cimento: 0,8\% e 16\%

- superplastificante: Rheobiuld 1000 (HALESA) e Sikament 300 (SIKA)

- estado de umidade: saturado e seco

- temperatura de cura: $5^{\circ} \mathrm{C}, 20^{\circ} \mathrm{C}$ e $30^{\circ} \mathrm{C}$

- idade dos ensaios: 7, 28 e 90 dias

- ${ }^{\circ}$ corpos-de-prova por determinação: 2

Através de uma redução de variáveis, foi possível reduzir o número de corpos-de-prova para 150, através do qual conseguiu-se obter a seguinte expressão para estimativa da resistência à tração, em função da resistência à compressão:

$$
f_{c t}=0,9 \cdot f_{c}^{0,45} \quad \text { válida para } 50 \mathrm{MPa} \quad f_{c} \quad 120 \mathrm{MPa}
$$

$\mathrm{Na}$ figura 3.5, tem-se um gráfico da correlação citada, na qual pode-se diferenciar os valores correspondentes a cada uma das idades de ensaio. Os valores médios obtidos para cada uma das tensões de compressão e tração no programa de ensaio se apresentam resumidos na tabela 3.5.

\footnotetext{
${ }^{15}$ CARRASQUILLO \& SLAT \& NILSON (1981). Properties of high strength concrete subjected to
} 
A partir desses dados, conclui-se que a resistência à tração pode ser estimada como sendo 8\% da resistência à compressão.

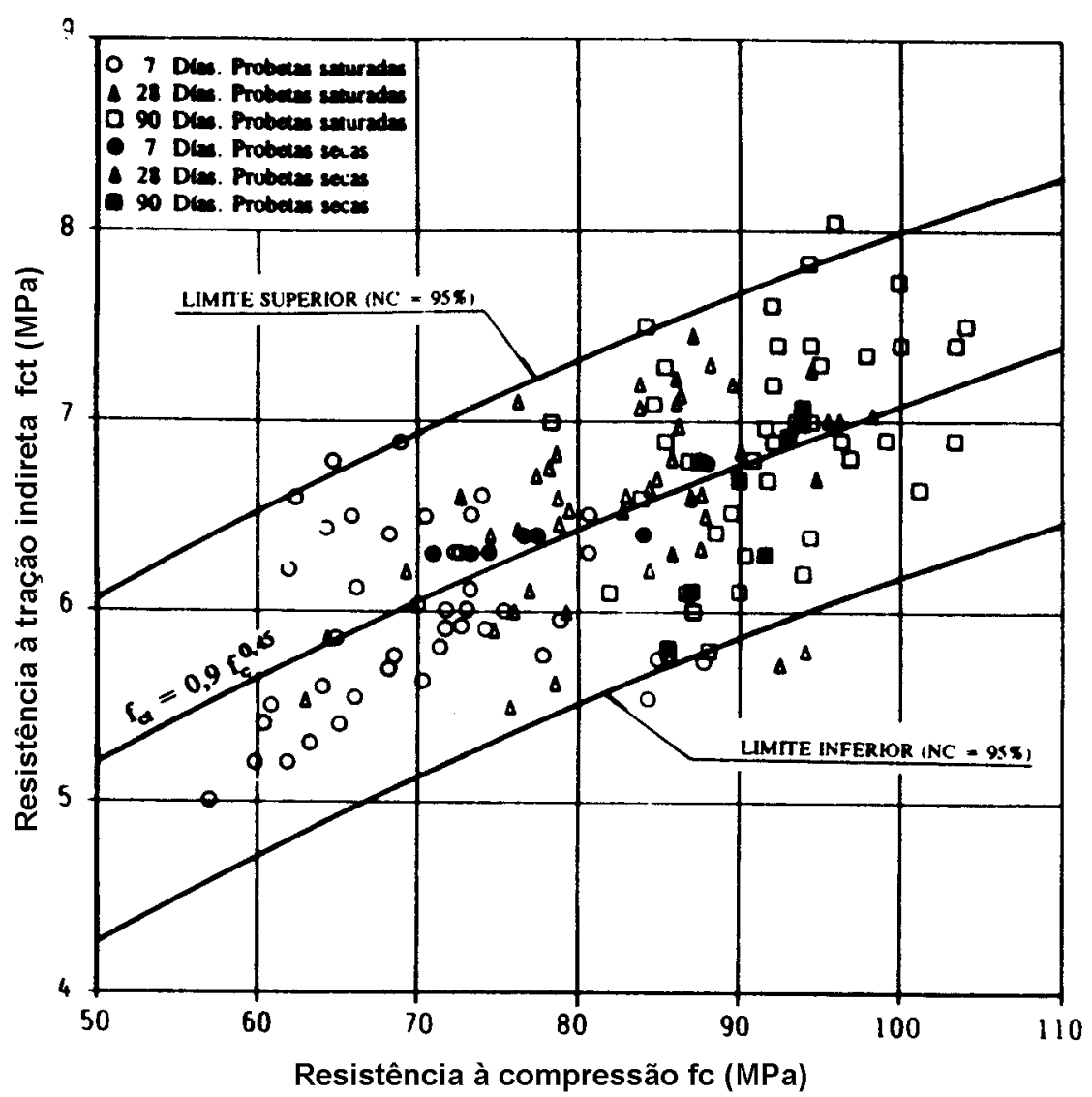

FIGURA 3.5 - Resultados da correlação obtida entre resistência à compressão e resistência à tração indireta em concretos de alto desempenho. FONTE: GONZALEZ G. I. (1993).

TABELA 3.5 - Valores médios de resistência à tração e resistência à compressão obtidos pela INTEMAC (1992).

\begin{tabular}{|c|c|c|c||}
\hline $\begin{array}{c}\text { Idade } \\
(\text { dias})\end{array}$ & $\begin{array}{c}\text { Resist. à compressão }(\mathbf{1}) \\
(\mathbf{M P a})\end{array}$ & $\begin{array}{c}\text { Resistência à tração } \\
(\mathbf{2}) \mathbf{( M P a})\end{array}$ & $\begin{array}{c}\text { Relação (2)/(1) } \\
(\mathbf{\%})\end{array}$ \\
\hline $\mathbf{7}$ & 71,4 & 6,0 & 8,4 \\
\hline $\mathbf{2 8}$ & 81,8 & 6,5 & 8,0 \\
\hline $\mathbf{9 0}$ & 90,2 & 6,8 & 7,5 \\
\hline $\begin{array}{l}\text { valores } \\
\text { médios }\end{array}$ & 81,1 & 6,4 & 7,9 \\
\hline
\end{tabular}

short-term loading. ACI Journal. May-June. Short-Term Loading. ACI Journal. May-June. 


\subsubsection{Ensaio de flexão em vigas ou módulo de ruptura}

Consiste em aplicar uma carga concentrada (no centro do vão ou nos terços do vão) em uma viga padronizada conforme figura 3.6.

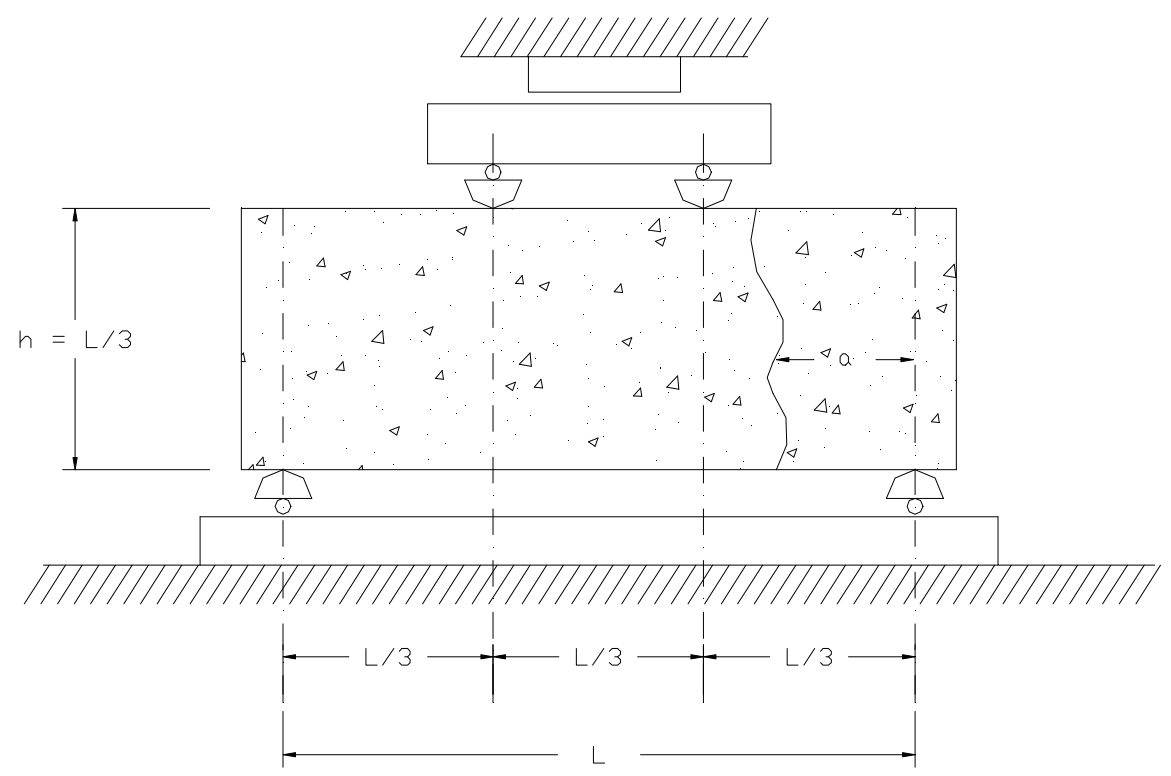

FIGURA 3.6 - Esquema de ensaio de tração na flexão.

FONTE: SILVA I. S. (1995).

A resistência à flexão corresponde à máxima tensão na ruptura, sendo calculada por:

$$
f_{t}=\frac{P \cdot \ell}{b \cdot h^{2}} \quad \text { para } \quad \frac{1}{3} \leq \mathrm{a} \leq 2 \cdot \frac{1}{3}
$$

$P \rightarrow$ carga de ruptura

$\ell \rightarrow$ comprimento do vão

$b \rightarrow$ largura do prisma

$h \rightarrow$ altura

a $\rightarrow$ distância média entre o plano de ruptura e o apoio mais próximo da viga

Se (a) estiver fora do terço médio, mas estiver a uma distância (a >0,28 I )

$$
\text { emprega-se : } \quad f_{t}=\frac{3 \cdot P \cdot a}{b \cdot h^{2}}
$$


A resistência à flexão ou módulo de ruptura é geralmente tomado como sendo um dos indicadores mais confiáveis da resistência do concreto à tração.

O módulo de ruptura é também usado como sendo a resistência do concreto à flexão em projetos de pavimentos.

Na ausência de dados atuais, o módulo de ruptura pode ser estimado por:

$f_{r}=k \sqrt{f_{c}^{\prime}}$, para $k$ variando no limite de 7,5 a 12 . Para concreto de alto desempenho, o ACI Committee 363 recomenda o valor de $\mathrm{k}=11,7$ para concreto com resistência à compressão no intervalo de $21 \mathrm{MPa}$ a $83 \mathrm{MPa}$.

Baseado em dados disponíveis de ensaios de flexão em vigas, com concretos de baixa, média e alta resistência, uma equação empírica para prever o valor da resistência na flexão foi proposta por SHAH \& AHMAD (1994) como:

$$
f_{r}=2,30 \cdot\left(f_{c}^{\prime}\right)^{\frac{2}{3}} \text {, onde } f_{c}^{\prime} \text { é a resistência à compressão em (psi) }
$$

A figura 3.7 mostra os dados experimentais plotados de alguns autores e a equação proposta por SHAH \& AHMAD (1994), para prever o módulo de ruptura do concreto com resistência até $83 \mathrm{MPa}$.

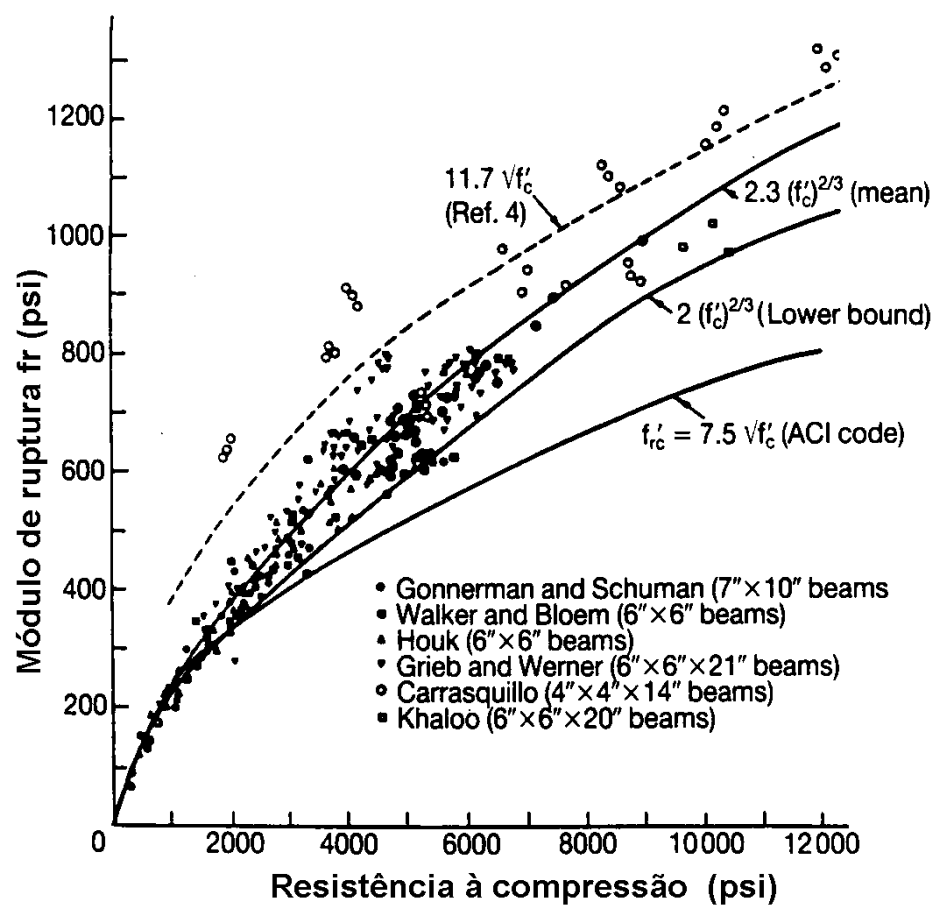

FIGURA 3.7 - Variação do módulo de ruptura com a resistência à compressão. FONTE: SHAH \& AHMAD (1994). 
CARRASQUILLO et al. apud SILVA (1995) propôs a seguinte expressão para ensaios de flexão simples, para prismas de $100 \mathrm{~mm}$ x $100 \mathrm{~mm}$ x $350 \mathrm{~mm}$ :

$$
f_{c t k}=0,94 \sqrt{f_{c k}} \quad(\mathrm{MPa}) \quad \text { para } 21 \mathrm{MPa}<f_{c k}<83 \mathrm{MPa}
$$

Segundo ZIELINSKI ${ }^{16}$ apud SHAH \& AHMAD (1994), os resultados de ensaios de flexão uniaxial e biaxial indicaram que a resistência à tração foi $38 \%$ maior no estado de tensão uniaxial do que no estado de tensão biaxial.

Segundo CARRASQUILLO ${ }^{17}$ apud SHAH \& AHMAD (1994), a resistência à flexão é maior para cura úmida, quando comparada com corpos-de-prova curados no campo. Entretanto, os corpos-de-prova contendo sílica ativa condensada, curados umidamente, exibiram uma taxa menor de resistência à tração do que a resistência à compressão, quando comparados com concretos com sílica ativa curados em local seco.

\subsection{RELAÇÃO TENSÃO-DEFORMAÇÃO NA COMPRESSÃO}

A relação tensão-deformação é dependente de vários parâmetros, os quais incluem variáveis materiais, como tipo de agregado, e variáveis do ensaio, tais como idade do concreto, taxa de carregamento, gradiente de deformação e outras mais.

Na figura 3.8 percebe-se o efeito do tipo de agregado na curva tensãodeformação.

Percebe-se que maiores resistências são obtidas, para deformações correspondentes, quando se utilizam como agregados diabásio e pedra calcárea, comparados com seixo-rolado e granito.

Segundo FIP/CEB-197 (1990), as principais diferenças entre as curvas tensãodeformação para concreto tradicional e de alto desempenho são:

a) Uma relação tensão-deformação mais linear para uma maior porcentagem da tensão máxima nos concretos de alto desempenho.

\footnotetext{
${ }^{16}$ ZIELINSKI, Z. A. \& SPIROPOULOS, I. (1983). An experimental study on the uniaxial and biaxial flexural tensile strength of concrete. Canadian Journal of Civil Engineering, 10, 104-115.
} 
b) Uma deformação ligeiramente maior para uma tensão máxima nos CAD.

c) Deformação última reduzida pode ser observada, em classes intermediárias, de concreto de alto desempenho.

Essas diferenças existentes entre os concretos tradicionais e os concretos de alto desempenho, com relação à resposta ao carregamento, são conseqüências da melhoria na ligação pasta-agregado para o CAD. Nos concretos de alto desempenho existe uma menor quantidade de microfissuras para baixos níveis de carregamento, o que implica uma maior linearidade na relação tensão-deformação.

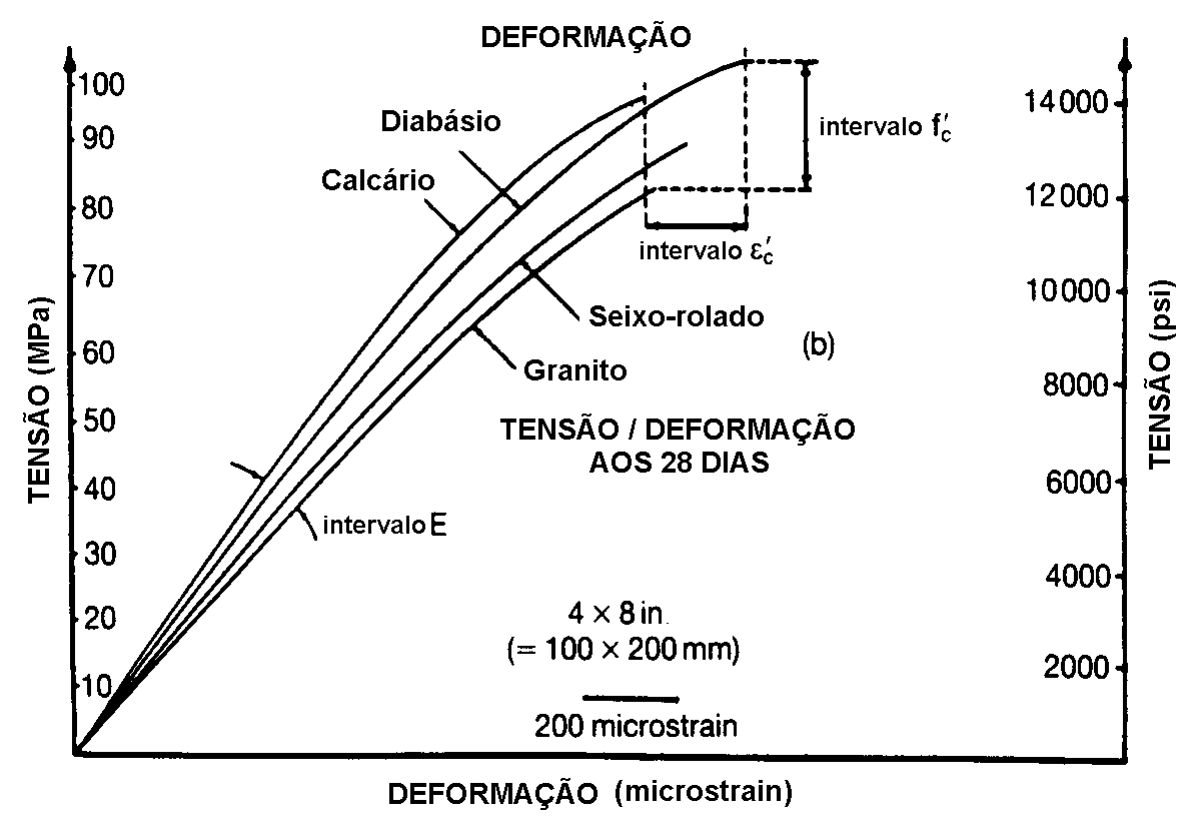

FIGURA 3.8 - Efeito do tipo de agregado na parte ascendente da curva tensão-deformação do concreto aos 28 dias. FONTE: SHAH \& AHMAD (1994).

Empregando-se modernas técnicas de raios-x, CARRASQUILLO ${ }^{18}$ et al. apud GONZALEZ (1993) demonstraram que, em concretos com resistência média de

${ }^{17}$ CARRASQUillo, P. M. \& CARRASQUILlO, R. L. (1988). Evaluation of the uso of current concrete practice in the production of high-strength concrete. ACI Materials Journal, 85,1, JanFev, 49-54.

${ }^{18}$ CARRASQUILLO (1981). Microcracking and behavior of HSC subject to short-term loading. ACI Journal. May-June. 
$31 \mathrm{MPa}$, a microfissuração da interface pasta-agregado começa a ocorrer quando a solicitação é cerca de $65 \%$ da solicitação de ruptura. Para concretos de alto desempenho (76 MPa), os primeiros sintomas de falta de aderência da interface pasta-agregado se manifestam quando é alcançada $90 \%$ da tensão última de carregamento. A partir desse estado de carregamento, a ruptura do material se produz subitamente e com menor deformação que nos concretos tradicionais.

A forma do diagrama tensão-deformação, na compressão axial, está estritamente relacionada com a natureza do material como um composto.

Tanto a pasta de cimento como o agregado são materiais que apresentam um comportamento frágil. Na figura 3.9 pode-se perceber a diferença de rigidez entre o agregado e a pasta de cimento para o concreto Classe I e para o concreto de alto desempenho.
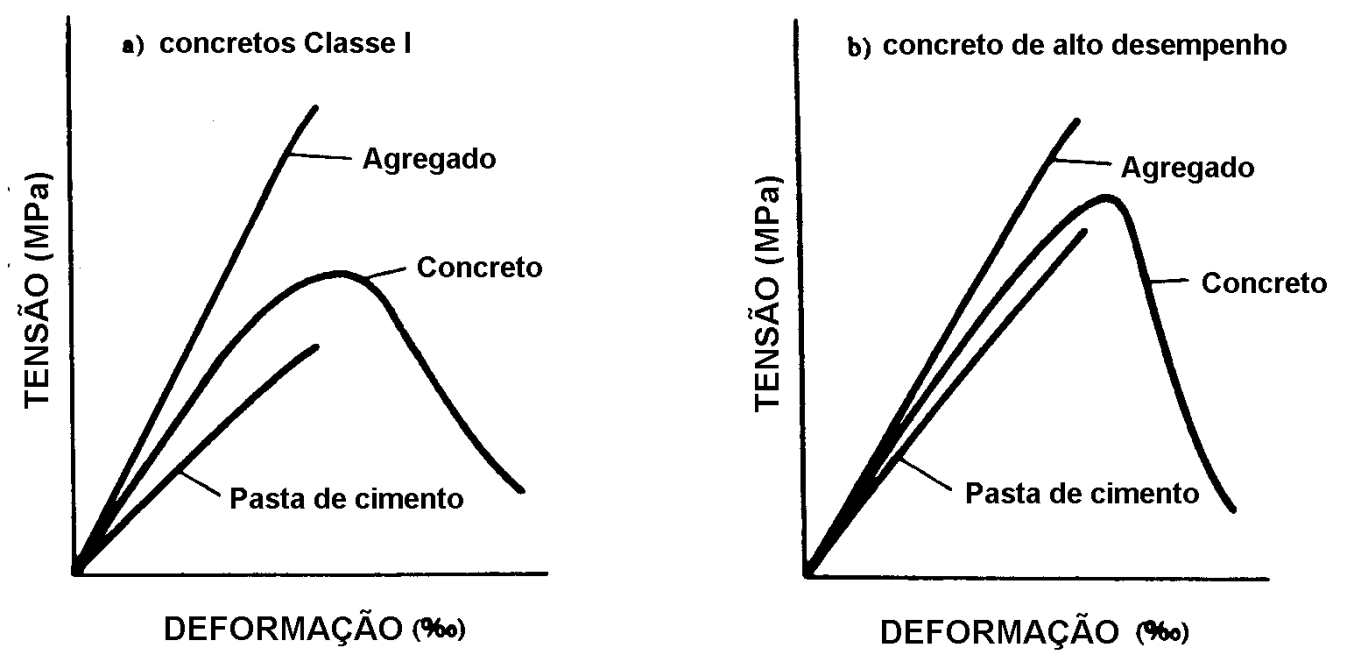

FIGURA 3.9 - Diagrama tensão-deformação para concreto Classe I e CAD. FONTE: FIP/CEB-197 (1990).

O comportamento dúctil do concreto pode ser explicado em função da microfissuração que ocorre quando é atingido um determinado nível de tensão, e que consume parte da energia. Nesse estágio, a curva tensão-deformação tenderá a se desviar do curso elástico-linear. Depois que a tensão última é alcançada, consegue-se uma última redistribuição de tensão e por isso o colapso. Já para o CAD, a diferença de rigidez entre a pasta de cimento e o agregado é menor, conforme mostra a figura 
3.9, o que permite uma distribuição de tensão interna mais uniforme sobre o material, que se traduz na obtenção de valores de resistência mais elevados.

Em contrapartida, o menor desenvolvimento do estado de microfissuração interna nos concretos de alto desempenho reduz a possibilidade de uma redistribuição de tensão no material, caso haja um incremento no carregamento atuante, conduzindo finalmente a ruptura frágil do concreto.

Com isso tem-se uma diminuição na fissuração inicial e um maior trecho linear na curva tensão-deformação.

Com a redução da fissuração tem-se um colapso repentino, sem dar avisos, em função da menor capacidade de redistribuição de esforços.

Várias pesquisas têm sido empreendidas para se obter a curva tensãodeformação completa na compressão.

Por exemplo, tem-se o estudo realizado na Universidade de Alberta, desenvolvido por MAcGREGOR et al. (1995), sobre concreto de alto desempenho contendo sílica ativa, com resistência a compressão de $60 \mathrm{MPa}, 90 \mathrm{MPa}$ e $120 \mathrm{MPa}$, depois de 28 dias de cura. Para tanto, foram desenvolvidos os traços A, B, C que estão representados na tabela 3.6.

TABELA 3.6 - Traços de CAD desenvolvidos por MAcGREGOR et al. (1995).

\begin{tabular}{|c|c|c|c|}
\hline TIPO & $\mathbf{A}$ & B & $\mathbf{C}$ \\
\hline $\begin{array}{l}\text { Resist. à compressão ( } 28 \\
\text { dias) }\end{array}$ & $60 \mathrm{MPa}$ & $90 \mathrm{MPa}$ & $120 \mathrm{MPa}$ \\
\hline Água & $107,2 \mathrm{~N}$ & $110,8 \mathrm{~N}$ & $97,0 \mathrm{~N}$ \\
\hline Cimento & $333,7 \mathrm{~N}$ & $391,6 \mathrm{~N}$ & $449,4 \mathrm{~N}$ \\
\hline $\mathbf{a} / \mathbf{c}$ & 0,321 & 0,283 & 0,216 \\
\hline Agregado graúdo & $918,0 \mathrm{~N}$ & $872,2 \mathrm{~N}$ & $916,7 \mathrm{~N}$ \\
\hline Areia & $633,2 \mathrm{~N}$ & $449,4 \mathrm{~N}$ & $462,8 \mathrm{~N}$ \\
\hline Sílica ativa & $40,0 \mathrm{~N}$ & $43,6 \mathrm{~N}$ & $49,8 \mathrm{~N}$ \\
\hline Superplastificante & $820,0 \mathrm{ml}$ & $1340,0 \mathrm{ml}$ & $1540,0 \mathrm{ml}$ \\
\hline $\begin{array}{l}\text { Resist. à compressão obtida } \\
\text { (dias) }\end{array}$ & $\begin{array}{l}\text { 60,2 MPa } \\
\text { (29) }\end{array}$ & $\begin{array}{l}92,2 \mathrm{MPa} \\
\text { (35) }\end{array}$ & $\begin{array}{l}119,0 \mathrm{MPa} \\
\text { (39) }\end{array}$ \\
\hline
\end{tabular}

O concreto continha agregado graúdo com dimensão máxima de $14 \mathrm{~mm}$ e agregado miúdo com módulo de finura igual a 2,55. A relação água/cimento variou 
no limite de 0,22 a 0,32, sendo necessária a utilizando-se sulfonato de lignina como superplastificante. As dimensões dos corpos-de-prova, bem como o resultado dos ensaios estão representados na tabela 3.7.

TABELA 3.7 - Geometria dos corpos-de-prova e resultado dos ensaios de compressão uniaxial realizados por MAcGREGOR et al. (1995).

\begin{tabular}{||c|c|c|c|c|c||}
\hline & Elemento & $\begin{array}{c}\text { Diâmetro D } \\
(\mathbf{m m})\end{array}$ & $\begin{array}{c}\text { Altura H } \\
(\mathbf{m m})\end{array}$ & $\begin{array}{c}\text { Tensão } \\
\text { Máxima (MPa) }\end{array}$ & $\begin{array}{c}\text { Média } \\
(\mathbf{M P a})\end{array}$ \\
\hline \multirow{3}{*}{ A } & A1 & 99,5 & 199,5 & 59,61 & \\
& A2 & 100,0 & 201,0 & 60,58 & 60,20 \\
& A3 & 100,5 & 203,0 & 60,42 & \\
\hline \multirow{3}{*}{ B } & B1 & 104,0 & 200,0 & 90,42 & \\
& B2 & 99,0 & 200,0 & 93,17 & 92,21 \\
& B3 & 100,0 & 196,0 & 93.03 & \\
\hline \multirow{3}{*}{ C } & C1 & 100,0 & 200,0 & 120,6 & \\
& C2 & 99,0 & 201,0 & 116,6 & 119,0 \\
& C3 & 99,0 & 204,0 & 119,8 & \\
\hline \hline
\end{tabular}

As curvas de tensão-deformação para os respectivos traços de concreto estão representadas nas figuras 3.10, 3.11, e 3.12.

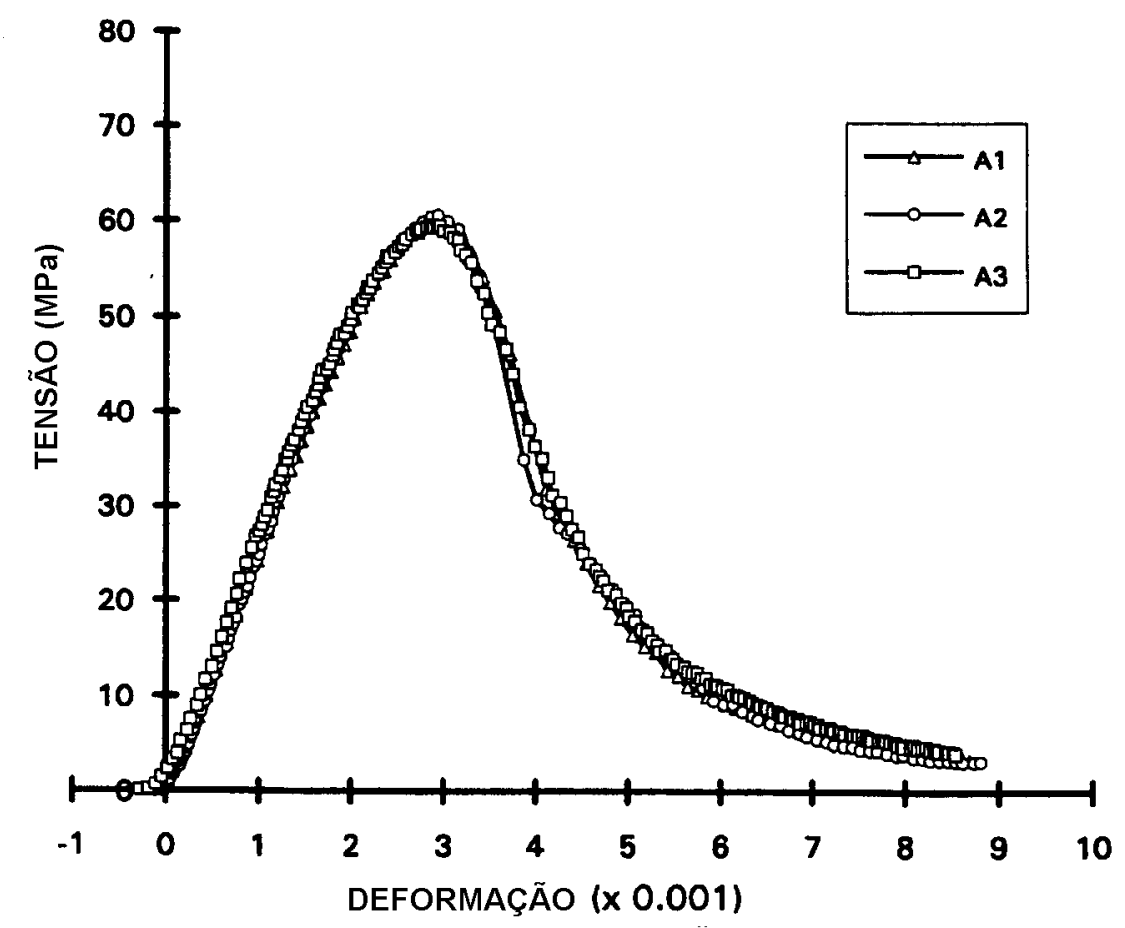

FIGURA 3.10 - Diagrama tensão-deformação para compressão uniaxial (Tipo A). FONTE: MAcGREGOR J. G. et al. (1995). 


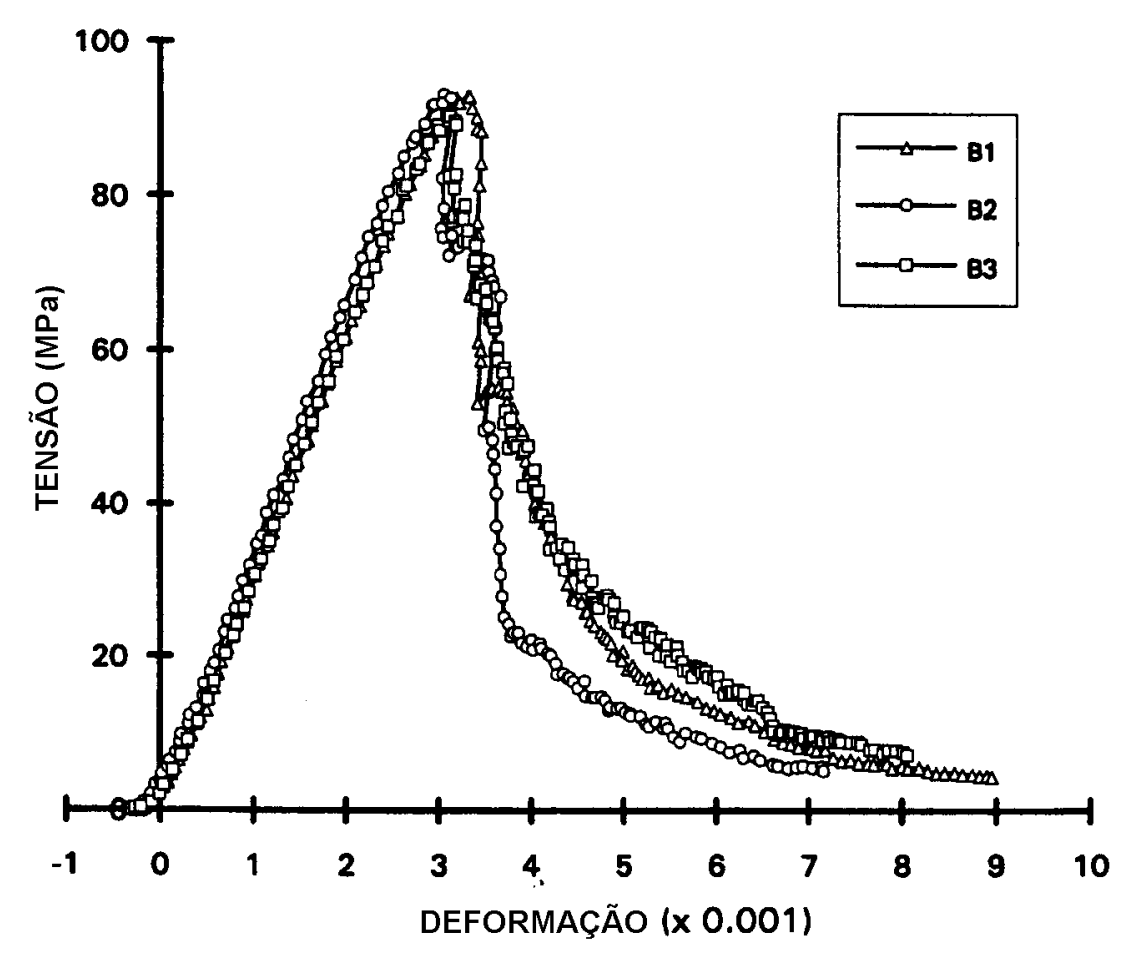

FIGURA 3.11 - Diagrama tensão-deformação para compressão uniaxial (Tipo B). FONTE: MAcGREGOR J. G. et al. (1995).

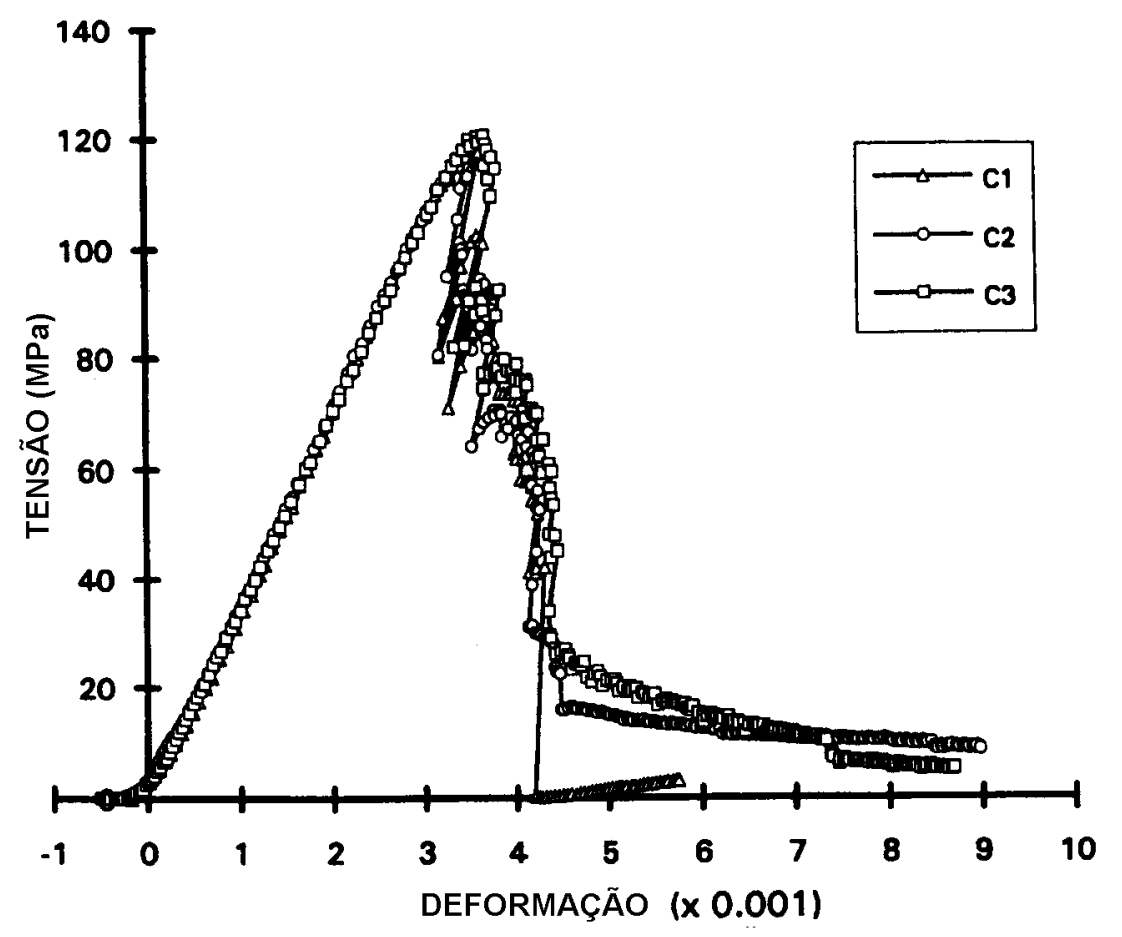

FIGURA 3.12 - Diagrama tensão-deformação para compressão uniaxial (Tipo C). FONTE: MAcGREGOR J. G. et al. (1995). 
A partir da análise das curvas, pode-se perceber que a parte descendente da curva torna-se mais íngreme a medida que a resistência à compressão do concreto aumenta. Isso sugere que concretos de alto desempenho podem ser penalizados pela sua ductilidade pobre. A parte ascendente da curva tensão-deformação apresenta uma maior linearidade à medida que se aumenta a resistência do concreto.

A figura 3.13 mostra curvas tensão-deformação para concretos com resistência à compressão de até $98 \mathrm{MPa}$.

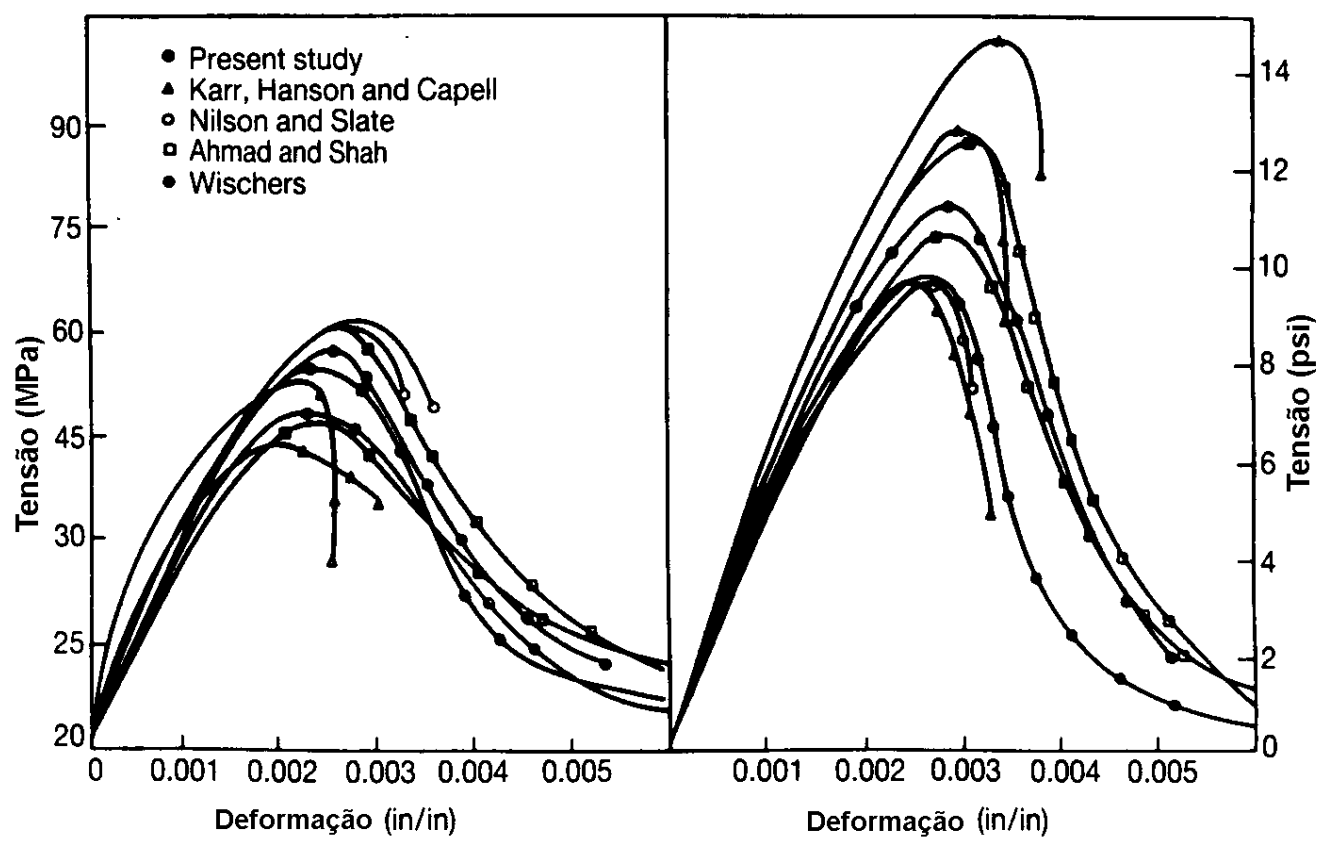

FIGURA 3.13 - Curvas tensão-deformação para o CAD sob compressão axial. FONTE: SHAH \& AHMAD (1994).

\subsection{MÓDULO DE DEFORMAÇÃO LONGITUDINAL ESTÁTICO}

Como o diagrama tensão-deformação do concreto não é linear, diferentes critérios são aplicados para a determinação do módulo de deformação longitudinal estático.

O módulo de deformação longitudinal estático pode ser expresso como módulo secante ou como módulo tangente.

De acordo com as normas brasileiras, o módulo de deformação longitudinal é obtido através do diagrama tensão-deformação do concreto, sujeito à compressão axial, sob carregamento estático. 
O módulo de deformação longitudinal tangente é o valor numérico da inclinação da reta tangente específica em um ponto genérico do diagrama tensãodeformação. O módulo de deformação longitudinal tangente na origem considera a inclinação da reta tangente na origem. O módulo de deformação longitudinal secante é o valor numérico da inclinação da reta secante do diagrama tensão-deformação do concreto, passando pelos pontos correspondentes à tensão de 0,5 MPa e a 40\% da tensão última.

O módulo de deformação longitudinal é um parâmetro básico, necessário para estimar perdas de protensão, deformações imediatas e deformações lentas.

O módulo de deformação longitudinal do concreto está estritamente relacionado com as propriedades da pasta de cimento, com o módulo de rigidez dos agregados e com o método de sua determinação.

Em geral, quanto maior o módulo de rigidez do agregado graúdo empregado na composição do concreto, maior será o módulo de deformação longitudinal resultante do mesmo. A forma das partículas do agregado graúdo e a sua superfície característica podem também influenciar o valor do módulo de deformação longitudinal do concreto. A figura 3.14 permite comparar a correlação existente entre concreto e uma argamassa com baixa relação água/cimento e alta resistência.

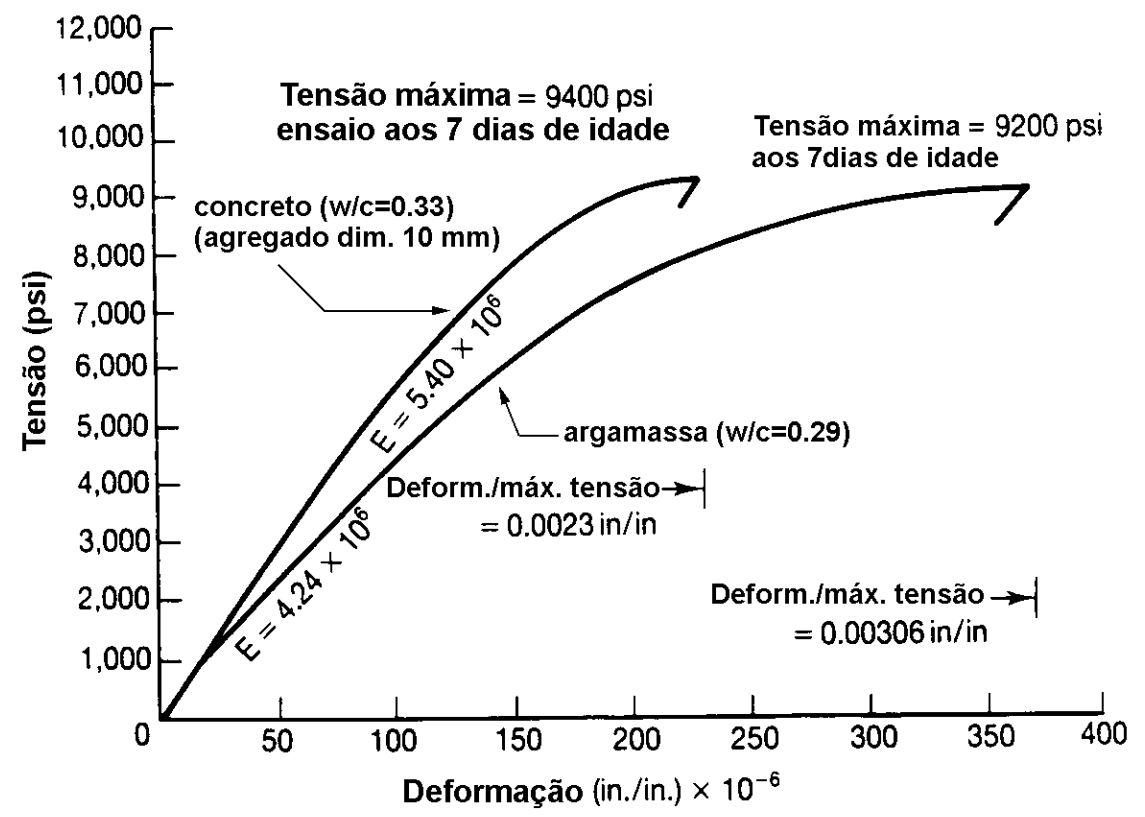

FIGURA 3.14 - Relação tensão-deformação em argamassas e concretos de alto desempenho FONTE: SHAH \& AHMAD (1994). 
Pode-se perceber na figura 3.14 o efeito do tipo de agregado graúdo e a proporção da mistura no módulo de deformação longitudinal.

Dessa figura, conclui-se que, em geral, quanto maior a quantidade de agregado graúdo com alto módulo elástico, maior é o módulo de deformação longitudinal resultante do concreto.

Segundo SHAH \& AHMAD (1994), uma pesquisa utilizando 4 diferentes tipos de agregados graúdos, em traços de concreto de altíssima resistência (água/cimento $=0,27$ ), mostrou que o módulo de deformação longitudinal foi significativamente influenciado pelas características mineralógicas do agregado. Pedra calcárea e agregados triturados de diabásio fornecem um módulo elástico maior do que com seixo rolado e granito triturado.

É geralmente aceito que, independentemente da proporção da mistura ou da idade de cura, corpos-de-prova de concreto ensaiados em condições úmidas fornecem um módulo de deformação longitudinal cerca de $15 \%$ maior do que o correspondente corpo-de-prova ensaiados em condições secas.

Através das figuras $3.15,3.16$ e 3.17 , propostas através de um conjunto de ensaios realizados por COLLINS et al. (1995), pode-se perceber que o módulo de deformação longitudinal cresce muito rápido nas primeiras idades.

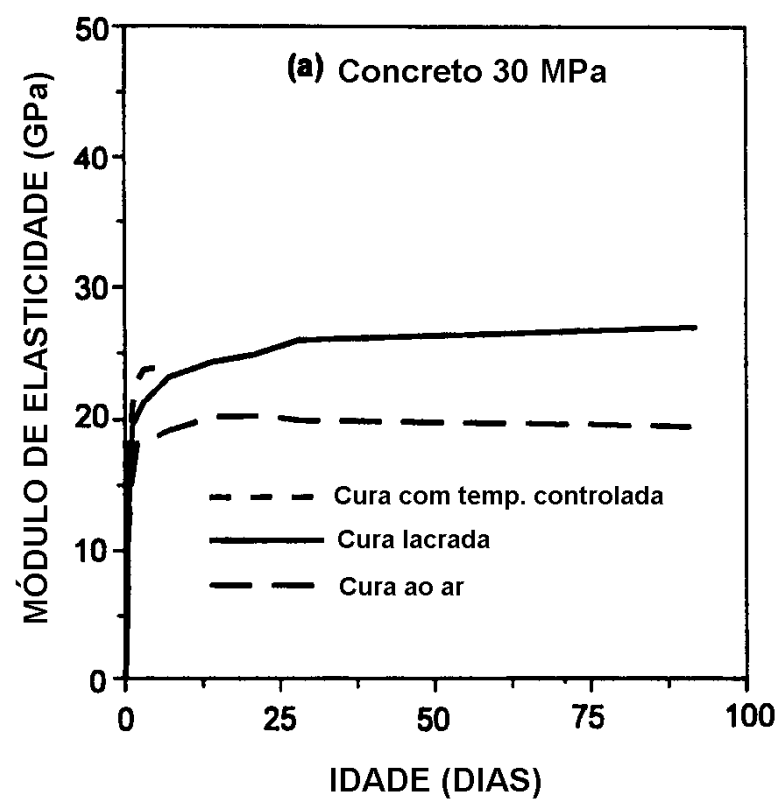

FIGURA 3.15 - Efeito de diferentes condições de cura na variação da média do módulo de deform. longitudinal para concretos de baixa resistência. FONTE: COLLINS, M.P. et al. (1995). 


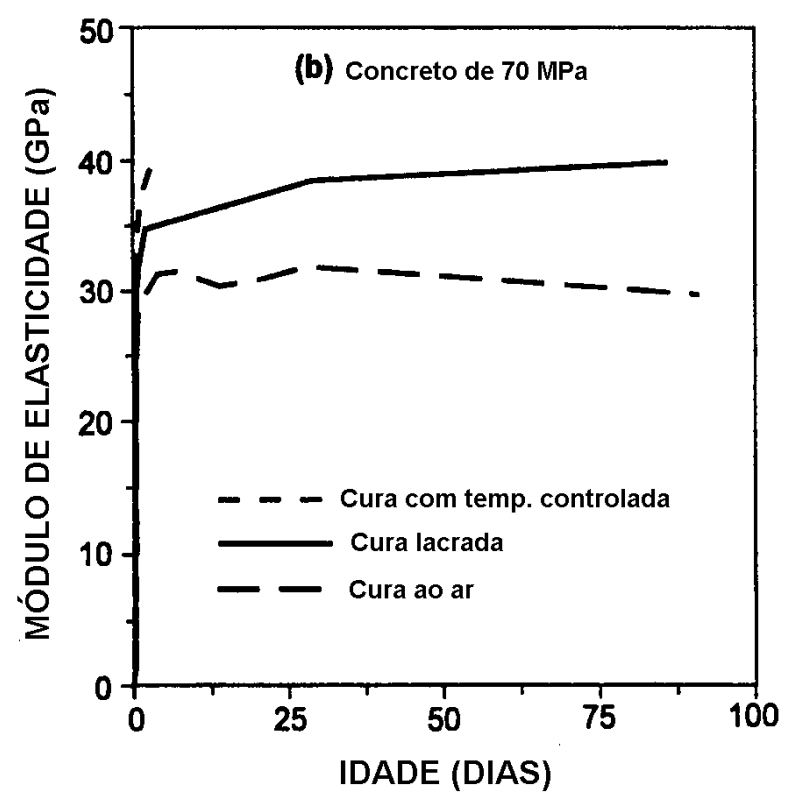

FIGURA 3.16 - Efeito de diferentes condições de cura na variação da média do módulo de deform. longitudinal para concretos de média resistência. FONTE: COLLINS, M.P. et al. (1995).

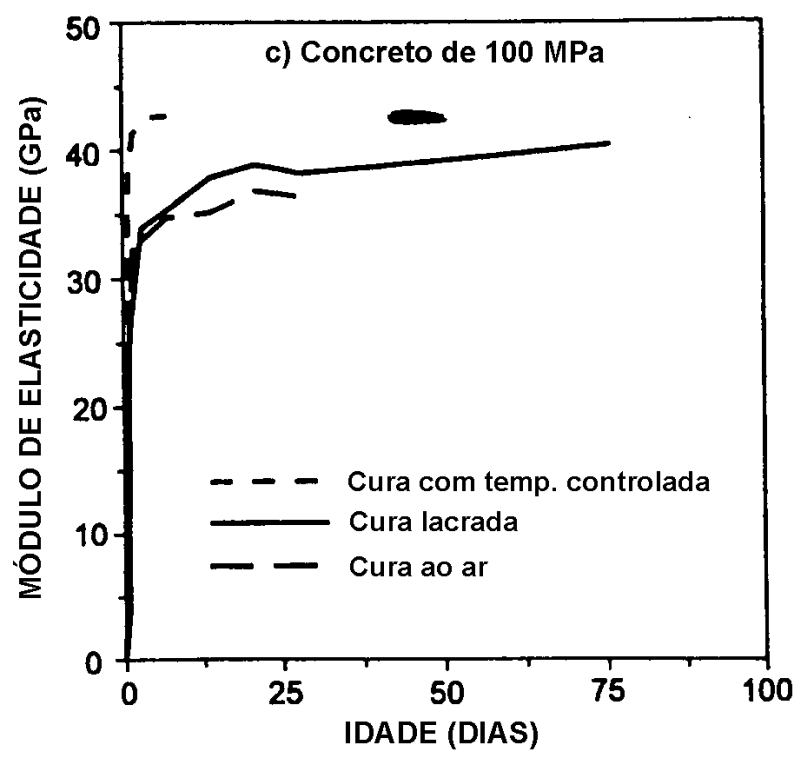

FIGURA 3.17 - Efeito de diferentes condições de cura na variação da média do módulo de deform. longitudinal para concretos de alta resistência. FONTE: COLLINS, M.P. et al. (1995).

A cura com temperatura controlada apresentou maiores taxas de ganho no módulo de deformação longitudinal do que corpos-de-prova curados ao ar e corposde-prova lacrados, para as primeiras idades.

Como esperado, os corpos-de-prova que foram curados lacrados apresentaram maior módulo do que os curados ao ar, particularmente para idades posteriores. 
Atualmente, existem várias expressões para determinação do módulo de deformação longitudinal expressas em normas e propostas por vários autores. A seguir estão relacionadas algumas expressões para determinação do módulo de deformação longitudinal:

a) ACI Committee 363 (1994)

$$
\begin{aligned}
& E_{c}=3320 \sqrt{f_{c}^{\prime}}+6900(\mathrm{MPa}) \\
& \text { para } 21 \mathrm{MPa}<{f^{\prime}}^{\prime}<83 \mathrm{MPa}
\end{aligned}
$$

b) ACI Committee $318(1989)^{19}$

$$
E_{c}=33 \cdot w_{c}^{1,5} \sqrt{f_{c}^{\prime}} \quad(\mathrm{psi})
$$

onde $\mathrm{w}_{\mathrm{c}} \rightarrow$ peso próprio variando no limite de 90 a 155 libras por pé cúbico

\section{c) SHAH \& AHMAD (1994)}

$$
E_{c}=w^{2,5}\left(\sqrt{f_{c}^{\prime}}\right)^{0,65} \quad(\mathrm{psi})
$$

onde $\mathrm{w} \rightarrow$ peso próprio em libras por pé cúbico (pcf)

A figura 3.18 mostra o limite de dispersão de dados com as previsões da expressão do ACI Code, do ACI Committee 363 e a expressão proposta por SHAH \& AHMAD (1994), a qual parece ser a mais representativa da tendência dos dados.

COOK (1989) ${ }^{20}$ apud SHAH \& AHMAD (1994) fez uma comparação dos resultados do módulo de deformação longitudinal de concretos contendo agregados da Carolina do Sul, Tennesse, Texas e Arizona, nos quais as dimensões dos agregados variaram de $10 \mathrm{~mm}$ a $25 \mathrm{~mm}$, empregando-se pedras calcáreas, granito e pedregulho da região, com as expressões do ACI 318 e ACI-363 para previsão do módulo de deformação longitudinal.

\footnotetext{
${ }^{19}$ COMMITTEE 318 (1989). Building code requirements for reinforced concrete. American Concrete Institute.

${ }^{20}$ COOK, J. E. (1989). Research and application of high-strength concrete: 10.000 psi concrete. Concrete International, Oct, 67-75.
} 


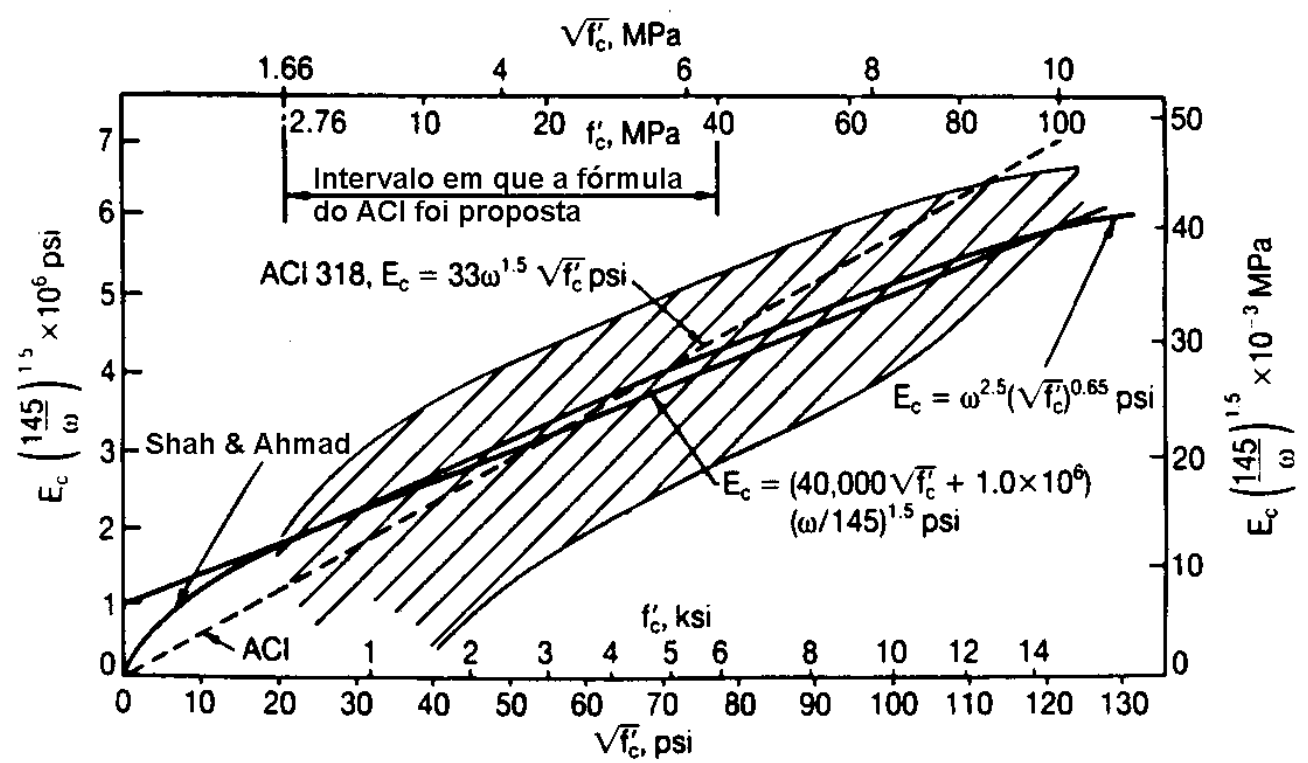

FIGURA 3.18 - Módulo de deformação longitudinal secante x resistência do concreto. FONTE: SHAH \& AHMAD (1994).

d) Através dos dados experimentais, COOK propôs a seguinte expressão:

$$
E_{c}=w^{2,5}\left(\sqrt{f_{c}^{\prime}}\right)^{0,315} \quad(\mathrm{psi}) \quad \text { onde } \mathrm{w}=151 \mathrm{pcf}
$$

$\mathrm{Na}$ figura 3.19, pode-se ver as previsões do ACI-318, do ACI-363 e da expressão proposta por COOK.

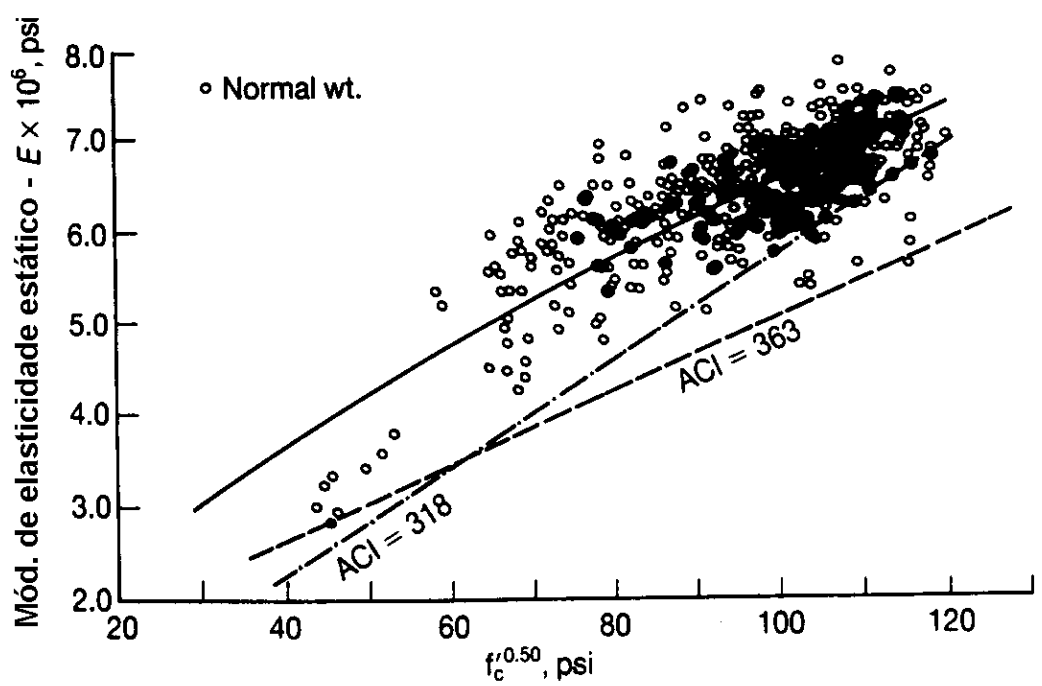

FIGURA 3.19 - Módulo de deformação longitudinal secante x resistência do concreto. FONTE: SHAH \& AHMAD (1994). 
e) A Norma Norueguesa NS 3473 E (1992) propõe a seguinte expressão para determinação do módulo de deformação longitudinal em função da resistência à compressão:

$$
E_{c}=9500\left(f_{c c}\right)^{0,3}(\mathrm{MPa}) \quad \text { para } \quad f_{c c}<85 \mathrm{MPa}
$$

f) A NBR 6118 (1978) propõe a seguinte expressão para determinação do módulo de deformação longitudinal tangente na origem:

$$
E_{c}=6600 \sqrt{f_{c j}} \quad(\mathrm{MPa}) \quad \text { onde: } f_{c j}=f_{c k}+3,5 \mathrm{MPa}
$$

O módulo secante, segundo a Norma Brasileira, é expresso pela seguinte expressão:

$$
E_{c s}=0,9 \cdot E_{c}
$$

g) O CEB-90 (1991) propõe a seguinte expressão para determinação do módulo de deformação longitudinal, para concreto com densidade normal:

$$
E_{c}=10^{4} \sqrt[3]{f_{c k}+8} \quad(\mathrm{MPa})
$$

De acordo com MORENO ${ }^{21}$ apud SHAH \& AHMAD (1994), os resultados dos ensaios indicam que a expressão prevista pelo ACI 318 está bem próxima dos resultados experimentais. Entretanto, para resistências maiores que $105 \mathrm{MPa}$, a expressão proposta pelo ACI 318 superestima os resultados obtidos nos ensaios.

MORENO também afirma que a expressão do ACI-363 sempre prevê resultados mais baixos do que os dados nos ensaios, mesmo para concretos com $117 \mathrm{MPa}$. Sendo assim, concluiu-se que a expressão recomendada pelo ACI-363 é mais apropriada para concretos de alto desempenho.

${ }^{21}$ MORENO, J. (1990). The state of the art of high-strength in Chicago: 225 W. Wacker Drive. Concrete International, Jan, 35-9. 


\subsection{COEFICIENTE DE POISSON}

O coeficiente de Poisson, sob condições uniaxiais, pode ser definido como a razão entre a deformação lateral e a deformação na direção do carregamento.

Devida à limitação de dados experimentais existentes a respeito do coeficiente de Poisson, para concretos de alto desempenho, pode-se observar uma divergência entre os pesquisadores sobre a relação existente entre as características do concreto e o coeficiente de Poisson.

Segundo SHAH \& AHMAD (1994), o coeficiente de Poisson aparente não é constante, mas sim uma função crescente da deformação, isto no limite inelástico, devida à dilatação volumétrica resultante da microfissuração interna.

No limite inelástico, o aumento relativo na deformação lateral é menor para o CAD quando comparado com concreto de Classe I. Isto é, concretos de alto desempenho exibem menor dilatação volumétrica do que concretos de baixa resistência, o que pode ser visto na figura 3.20.
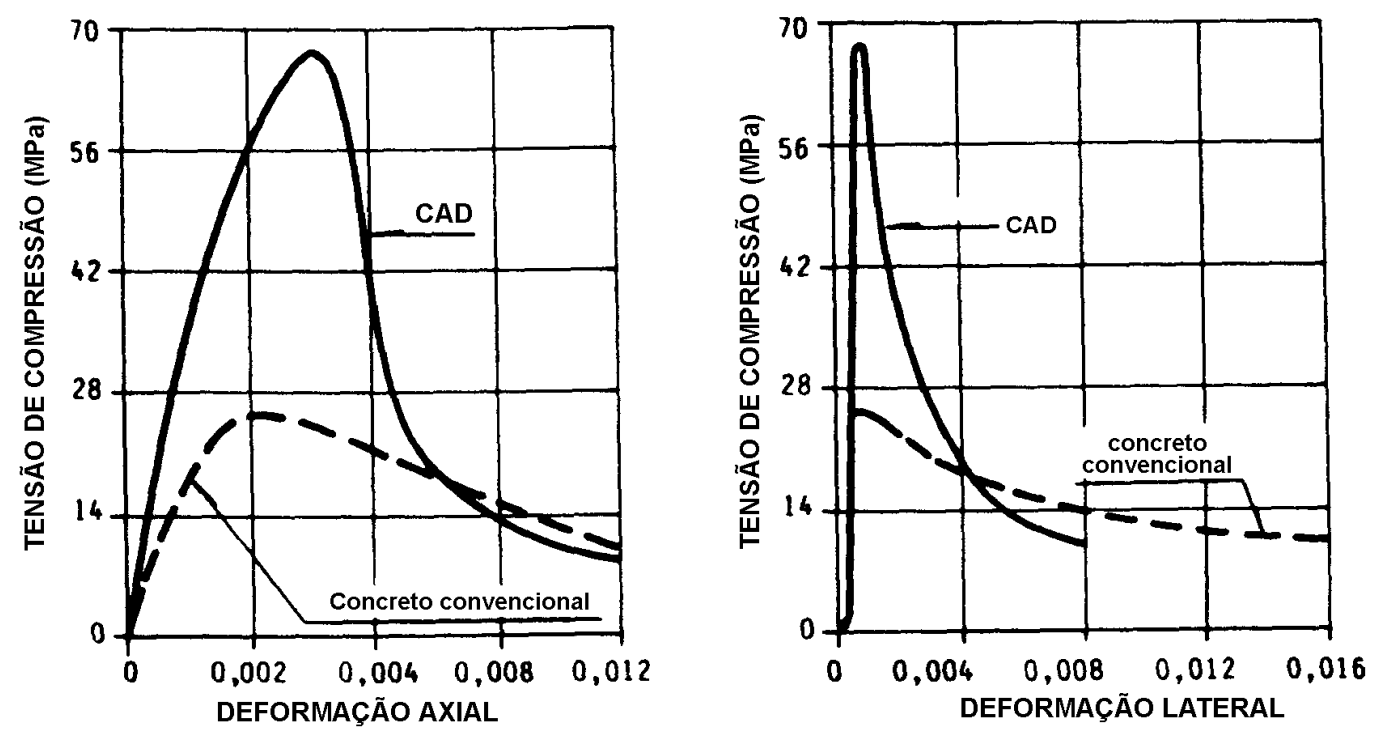

FIGURA 3.20 - Tensão axial x deformação axial e deformação lateral para concretos normais e concretos de alto desempenho: FONTE: SHAH \& AHMAD (1994). 
Segundo PERENCHIO \& KLIEGER ${ }^{22}$ apud ACI Manual of Concrete Practice Part 1 (1994), o coeficiente de Poisson varia no limite de 0,20 e 0,28 para concretos com densidade normal, com resistência à compressão variando no limite de $55 \mathrm{MPa}$ a $80 \mathrm{MPa}$. Eles concluíram também que o coeficiente de Poisson tende a diminuir com o aumento da relação água/cimento.

KAPLAN $^{23}$ apud ACI Manual of Concrete Practice Part 1 (1994) encontrou valores para o coeficiente de Poisson do concreto variando no limite de 0,23 a 0,32, determinados através de medição dinâmica independente da resistência à compressão, agregado graúdo, idade de ensaio, sendo que a resistência alcançada no ensaio variou no limite de $17 \mathrm{MPa}$ a $79 \mathrm{MPa}$.

Baseando-se nas informações disponíveis, o coeficiente de Poisson de concretos de alto desempenho, no limite elástico, parece ser comparável ao limite de valores esperados para concretos Classe I.

\subsection{COMPARAÇÃO VALORES TEÓRICOS VERSUS RESULTADOS EXPERIMENTAIS}

Pretende-se, a seguir, fazer uma comparação entre os valores teóricos de algumas das expressões indicadas nos itens 3.2 e 3.4 e resultados experimentais, de maneira a se conferir quais as expressões que melhor representem os valores obtidos em ensaios com concretos de alto desempenho.

\subsubsection{Resistência à tração}

Algumas das expressões do item 3.2, para cálculo da resistência média do concreto na tração direta, estão indicadas na tabela 3.8.

As expressões assinaladas com (*) tiveram seus coeficientes originais multiplicados pelo fator 0,9 , pois eram referidas a ensaios de compressão diametral.

\footnotetext{
${ }^{22}$ PERENCHIO \& WILLIAM, F. \& KLIEGER P. (1978). Some physical properties of high strength concrete. Research and Development Bulletin $\mathrm{n}^{\circ}$ RD056.01T, Portland Cement Association, Skokie, pp. 7.

${ }^{23}$ KAPLAN, M. F. (1959). Ultrasonic pulse velocity, dynamic modulus of elasticity, Poisson's ratio and the Strength of concrete made with thirteen different coarse aggregates. RILLEM Bulletin (Paris). New Series n ${ }^{\circ}$ 1. Mar. pp. 58-73.
} 
O fator 0,9 é indicado no EUROCODE 2 (1992). Portanto, essas expressões referem-se à tração direta.

TABELA 3.8 - Expressões para cálculo da resistência do concreto na tração direta

\begin{tabular}{|c|c|c|}
\hline FONTE & EXPRESSÃO & RESTRIÇÕES \\
\hline EUROCODE 2 (1992) & $f_{c t}=0,30\left(f_{c k}\right)^{\frac{2}{3}}$ & $f_{c k}<60 M P a$ \\
\hline NS 3473 (1992) & $f_{c t}=0,46\left(f_{c k}\right)^{0,52}$ & $f_{c k} \leq 94 M P a$ \\
\hline ACI-363 (1994) & $f_{c t}=0,53 \sqrt{f_{c k}}$ & $21 \mathrm{MPa}<f_{c k}<83 \mathrm{MPa}$ \\
\hline SHAH \& AHMAD (1994) & $f_{c t}=3,91\left(f_{c k}\right)^{0,55} \quad(*)$ & $3000 \mathrm{psi} \leq f_{c k} \leq 12000 \mathrm{psi}$ \\
\hline GONZALEZ (1993) & $f_{c t}=0,81\left(f_{c k}\right)^{0,45} \quad(*)$ & $50 \mathrm{MPa} \leq f_{c k} \leq 120 \mathrm{MPa}$ \\
\hline NBR 6118 (1978) & $\begin{array}{c}f_{c t}=\frac{f_{c k}}{7} \\
f_{c t}=0,086 f_{c k}+1\end{array}$ & $\begin{array}{l}f_{c k} \leq 18 \mathrm{MPa} \\
f_{c k}>18 \mathrm{MPa}\end{array}$ \\
\hline
\end{tabular}

Fator de conversão: $1 \mathrm{psi}=6,895 \times 10^{-3} \mathrm{MPa}$

(1) Curva em forma de potência obtida interpolando-se os dados indicados na tabela 5 da NS 3473 e plotando-se resistência à tração $\left(f_{t k}\right)$ versus resistência à compressão cilíndrica $\left(f_{c c k}\right)$, considerando-se resistências características de $36 \mathrm{MPa}$ a $84 \mathrm{MPa}$.

(2) A expressão da NBR 6118 foi dividida por 0,7 , conforme recomendação do EUROCODE 2 (1992), para se obter valores médios e não valores característicos.

\subsubsection{Módulo de deformação longitudinal}

As expressões para cálculo do módulo de deformação longitudinal encontram-se na tabela 3.9. Algumas das referências indicam claramente que os valores referem-se ao módulo secante mas outras não fazem esta indicação. Para efeito de comparação, todos os valores serão considerados relativos ao módulo secante. 
TABELA 3.9 - Expressões para cálculo do módulo de deformação longitudinal do concreto

\begin{tabular}{|c|c|c|}
\hline FONTE & EXPRESSÃO & RESTRIÇÕES \\
\hline FIP/CEB (1990) & $E_{c}=10^{4} \sqrt[3]{f_{c k}+8} \quad(M P a)$ & ---------- \\
\hline EUROCODE 2 (1992) & $E_{c}=9,5\left(f_{c k}+8\right)^{\frac{1}{3}}\left(\frac{k N}{m^{2}}\right)$ & $f_{c k}<60 M P a$ \\
\hline NS 3473 (1992) & $E_{c}=9500 f_{c k}^{0,3}(\mathrm{MPa})$ & $f_{c k}<85 \mathrm{MPa}$ \\
\hline ACI-318 (1989) & $E_{c}=33 w_{c} 1,5 \sqrt{f_{c k}}(p s i)$ & --------- \\
\hline ACI-363 (1994) & $E_{c}=3320 \sqrt{f_{c k}}+6900(M P a)$ & $21 \mathrm{MPa}<f_{\mathrm{ck}}<83 \mathrm{MPa}$ \\
\hline SHAH \& AHMAD (1994) & $E_{c}=w_{c}^{2,5}\left(\sqrt{f_{c k}}\right)^{0,65}(p s i)$ & --------- \\
\hline COOK (1994) & $E_{c}=w_{c}{ }^{2,5}\left(\sqrt{f_{c k}}\right)^{0,315}(p s i)$ & --------- \\
\hline NBR 6118 (1978) & $E_{c}=5940 \sqrt{f_{c k}+3,5}(M P a)$ & ---------- \\
\hline
\end{tabular}

Fator de conversão: $1 \mathrm{psi}=6,895 \times 10^{-3} \mathrm{MPa}$

(1) $w_{C}$ é o peso próprio do concreto, sendo adotado $151 \mathrm{pcf}\left(2419 \mathrm{~kg} / \mathrm{m}^{3}\right)$.

\subsubsection{Resultados experimentais}

Apresentam-se resultados dos ensaios de OLUOKUN et al. (1991a), GRIEB \& VERNER (1962) e FERRARI et al. (1995). Foram considerados somente os ensaios relativos à resistência à compressão maiores que $35 \mathrm{MPa}$.

\section{a) Ensaios de Oluokun}

Os materiais utilizados foram: cimento Portland comum (tipo I), pedra britada com dimensão inferior a $25 \mathrm{~mm}$ e seixo rolado como agregado miúdo. Os corpos-deprova foram cilíndros com $150 \mathrm{~mm}$ por $300 \mathrm{~mm}$.

$\mathrm{Na}$ tabela 3.10 tem-se os traços utilizados. Os resultados médios de resistência à compressão, módulo de deformação longitudinal e coeficiente de Poisson estão representados na tabela 3.11 e os de resistência à tração direta, na tabela 3.12. 
Como procedimento de cura, os corpos-de-prova foram cobertos com estopa molhada até que eles fossem removidos dos moldes. Folhas de polietileno foram colocadas por cima da estopa para minimizar a evaporação. Por volta de 20 a 24 horas depois de moldados, os corpos-de-prova foram desmoldados e transferidos para uma sala úmida, onde foram curados a uma temperatura de $23^{\circ} \mathrm{C}$.

TABELA 3.10 - Traço de concreto por $\mathrm{m}^{3}$

\begin{tabular}{|c|c|c|c|c|c|c|c|}
\hline \multirow[t]{2}{*}{ Traço } & \multirow{2}{*}{$\begin{array}{c}\text { Tipo de } \\
\text { Cimento } \\
\end{array}$} & \multirow{2}{*}{$\begin{array}{c}\text { Água } \\
(\mathbf{k g})\end{array}$} & \multirow{2}{*}{$\begin{array}{c}\text { Cimento } \\
\text { (kg) }\end{array}$} & \multicolumn{2}{|c|}{ Agregado (kg) } & \multirow{2}{*}{$\begin{array}{c}\text { Relação } \\
\text { A/C }\end{array}$} & \multirow{2}{*}{$\begin{array}{r}\text { Slump } \\
(\mathbf{m m})\end{array}$} \\
\hline & & & & miúdo & graúdo & & \\
\hline $\mathbf{A}$ & I & 132,5 & 341,0 & 563,4 & 784,7 & 0,388 & 88,9 \\
\hline B & I & 121,0 & 158,8 & 635,0 & 861,8 & 0,763 & 88,9 \\
\hline C & I & 121,0 & 226,8 & 635,0 & 861,8 & 0,534 & 63,5 \\
\hline D & I & 129,7 & 395,5 & 504,8 & 799,2 & 0,329 & 38,1 \\
\hline
\end{tabular}

TABELA 3.11 - Módulo de deformação longitudinal e coeficiente de Poisson

\begin{tabular}{||c|c|c|c|c|c|c|c|c|c|c|c|c||}
\hline \multirow{3}{*}{ Idade } & \multicolumn{3}{|c|}{ Traço A } & \multicolumn{3}{c|}{ Traço B } & \multicolumn{3}{c||}{ Traço C } & \multicolumn{3}{c||}{ Traço I) } \\
\cline { 2 - 14 } & $\begin{array}{c}f_{c} \\
(\mathrm{MPa})\end{array}$ & $\begin{array}{c}E_{c} \\
(\mathrm{MPa})\end{array}$ & $v$ & $\begin{array}{c}f_{c} \\
(\mathrm{MPa})\end{array}$ & $\begin{array}{c}E_{c} \\
(\mathrm{MPa})\end{array}$ & $v$ & $\begin{array}{c}f_{c} \\
(\mathrm{MPa})\end{array}$ & $\begin{array}{c}E_{c} \\
(\mathrm{MPa})\end{array}$ & $v$ & $f_{c}$ & $E_{c}$ & $v$ \\
$(\mathrm{MPa})$ & $(\mathrm{MPa})$ & \\
\hline $6 \mathrm{~h}$ & 10,67 & 15635 & 0,137 & 1,30 & 2843 & 0,132 & 2,63 & 5836 & 0,151 & 10,07 & 15375 & 0,144 \\
\hline $12 \mathrm{~h}$ & 20,28 & 22667 & 0,188 & 4,61 & 13408 & 0,196 & 12,22 & 19150 & 0,181 & 26,77 & 28067 & 0,181 \\
\hline $24 \mathrm{~h}$ & 24,79 & 26196 & 0,184 & 7,82 & 16362 & 0,198 & 18,68 & 22309 & 0,190 & 35,93 & 31194 & 0,189 \\
\hline $2 \mathrm{~d}$ & 27,43 & 27618 & 0,183 & 12,19 & 19405 & 0,199 & 23,90 & 25784 & 0,191 & 44,22 & 35095 & 0,188 \\
\hline $3 \mathrm{~d}$ & 29,92 & 28848 & 0,186 & 14,31 & 21629 & 0,188 & 26,48 & 26509 & 0,191 & 46,21 & 35417 & 0,183 \\
\hline $7 \mathrm{~d}$ & 35,69 & 31688 & 0,195 & 18,57 & 24495 & 0,192 & 35,44 & 30602 & 0,182 & 50,11 & 36206 & 0,183 \\
\hline 28d & 46,33 & 35381 & 0,188 & 27,99 & 31435 & 0,186 & 44,14 & 34326 & 0,190 & 60,96 & 40293 & 0,190 \\
\hline \hline
\end{tabular}

TABELA 3.12 - Resistência do concreto à tração direta

\begin{tabular}{|c|c|c|c|c|c|c|c|c||}
\hline \multirow{2}{*}{ Idade } & \multicolumn{2}{|c|}{ Traço A } & \multicolumn{2}{c|}{ Traço B } & \multicolumn{2}{c|}{ Traço C } & \multicolumn{2}{c||}{ Traço D } \\
\cline { 2 - 9 } & $f_{c}$ & $f_{t}$ & $f_{c}$ & $f_{t}$ & $f_{c}$ & $f_{t}$ & $f_{c}$ & $f_{t}$ \\
$(\mathrm{MPa})$ & $(\mathrm{MPa})$ & $(\mathrm{MPa})$ & $(\mathrm{MPa})$ & $(\mathrm{MPa})$ & $(\mathrm{MPa})$ & $(\mathrm{MPa})$ & $(\mathrm{MPa})$ \\
\hline $8 \mathrm{~h}$ & 10,67 & 1,22 & 1,30 & 0,11 & 2,63 & 0,21 & 10,07 & 0,83 \\
\hline $14 \mathrm{~h}$ & 20,28 & 1,99 & 4,61 & 0,48 & 12,22 & 1,33 & 26,77 & 2,49 \\
\hline $24 \mathrm{~h}$ & 24,79 & 2,52 & 7,82 & 1,07 & 18,68 & 1,94 & 35,93 & 3,32 \\
\hline $2 \mathrm{~d}$ & 27,43 & 2,79 & 12,19 & 1,25 & 23,90 & 2,86 & 44,22 & 4,02 \\
\hline $3 \mathrm{~d}$ & 29,92 & 2,90 & 14,31 & 1,91 & 26,48 & 3,08 & 46,21 & 4,19 \\
\hline $7 \mathrm{~d}$ & 35,69 & 3,50 & 18,57 & 2,10 & 35,44 & 3,88 & 50,11 & 4,34 \\
\hline $28 \mathrm{~d}$ & 46,33 & 4,12 & 27,99 & 3,14 & 44,14 & 4,76 & 60,96 & 5,30 \\
\hline \hline
\end{tabular}




\section{b) Resultados de Grieb \& Werner}

Apresentam-se na tabela 3.13 os resultados experimentais obtidos por GRIEB \& WERNER (1962), para resistência à compressão e resistência à tração direta.

TABELA 3.13 - Resistência à compressão e à tração direta

\begin{tabular}{||c|c||}
\hline $\begin{array}{c}\text { Resistência à } \\
\text { compressão (MPa) }\end{array}$ & $\begin{array}{c}\text { Resistência à } \\
\text { tração (MPa) }\end{array}$ \\
\hline 35,51 & 3,41 \\
\hline 37,09 & 3,48 \\
\hline 38,89 & 3,48 \\
\hline 38,96 & 3,55 \\
\hline 34,61 & 3,52 \\
\hline 34,54 & 3,62 \\
\hline 38,61 & 3,62 \\
\hline 38,33 & 3,62 \\
\hline 39,78 & 3,76 \\
\hline 38,75 & 3,72 \\
\hline 40,61 & 3,76 \\
\hline 39,78 & 3,79 \\
\hline 40,06 & 3,83 \\
\hline 37,92 & 3,86 \\
\hline 41,23 & 3,86 \\
\hline 42,13 & 3,90 \\
\hline 42,75 & 4,00 \\
\hline 44,47 & 4,24 \\
\hline 41,71 & 4,31 \\
\hline 40,95 & 4,17 \\
\hline 42,47 & 3,96 \\
\hline & \\
\hline
\end{tabular}

\section{c) Ensaios de Ferrari}

Nos ensaios de FERRARI et al. (1995), procurou-se obter resistências aos 28 dias de $50 \mathrm{MPa}, 55 \mathrm{MPa}$ e $60 \mathrm{MPa}$, empregando-se cimento de alta resistência inicial (CPV-ARI), brita calcária de diâmetro máximo 9,5 mm e areia natural com módulo de finura 2,23. Para fabricação dos concretos, utilizou-se o superplastificante Adiment.

Os corpos-de-prova eram cilíndricos de $150 \mathrm{~mm}$ por $300 \mathrm{~mm}$. Depois de 
moldados, os corpos-de-prova foram mantidos em seus moldes por 48 horas, cobertos por plásticos molhados.

Após o período de 48 horas, os corpos-de-prova foram desformados e transferidos para uma câmara úmida, a uma temperatura de $24^{\circ} \mathrm{C}$ aproximadamente e umidade relativa de $95 \%$ a $100 \%$.

Tem-se na tabela 3.14 os traços empregados nos ensaios e na tabela 3.15 os resultados de resistência à compressão, resistência à tração direta e módulo de deformação longitudinal.

TABELA 3.14 - Traços de concreto utilizados nos ensaios de Ferrari

\begin{tabular}{|c|c|c|c|c|c||}
\hline Traço & Composição (a) & $\begin{array}{c}\text { Cimento } \\
\left(\mathbf{k g} / \mathbf{m}^{\mathbf{3}}\right)\end{array}$ & $\begin{array}{c}\text { Relação } \\
\text { água/ciment } \\
\mathbf{0}\end{array}$ & $\begin{array}{c}\text { Adit./cimento } \\
(\boldsymbol{\%} \mathbf{e m} \text { peso })\end{array}$ & $\begin{array}{c}\text { Slump } \\
(\mathbf{m m})\end{array}$ \\
\hline A & $1: 0,60: 0,90$ & 620 & 0,360 & ---- & $10 \mathrm{a} 30$ \\
\hline B & $1: 0,88: 1,92$ & 589 & 0,330 & 1,00 & $30 \mathrm{a} 40$ \\
\hline $\mathbf{C}$ & $1: 0,76: 1,64$ & 661 & 0,295 & 1,25 & $30 \mathrm{a} 40$ \\
\hline
\end{tabular}

(a) Cimento : Areia : Brita

TABELA 3.15 - Resultados de ensaios obtidos por Ferrari (em MPa)

\begin{tabular}{||c|c|c|c|c|c|c|c|c|c||}
\hline \multirow{2}{*}{$\begin{array}{c}\text { Idade } \\
\text { (dias) }\end{array}$} & \multicolumn{3}{|c|}{ Traço A } & \multicolumn{4}{c|}{ Traço B } & \multicolumn{3}{c||}{ Traço C } \\
\cline { 2 - 11 } & $f_{c}$ & $E_{c}$ & $f_{c t}$ & $f_{c}$ & $E_{c}$ & $f_{c t}$ & $f_{c}$ & $E_{c}$ & $f_{c t}$ \\
\hline $\mathbf{1}$ & 29,2 & 23192 & 3,10 & 30,7 & 24753 & 3,55 & 33,1 & 27006 & 3,70 \\
\hline $\mathbf{3}$ & 41,2 & 28265 & 3,65 & 51,2 & 28127 & 4,65 & 47,9 & 30788 & 4,80 \\
\hline $\mathbf{7}$ & 52,0 & 29080 & 4,15 & 57,7 & 26875 & 4,90 & 60,2 & 32440 & 5,00 \\
\hline $\mathbf{1 4}$ & 50,5 & 27109 & 3,75 & 56,3 & 33145 & 4,40 & 59,2 & 33066 & 4,40 \\
\hline $\mathbf{2 8}$ & 49,3 & 25932 & 3,90 & 58,1 & 32433 & 4,55 & 58,9 & 33381 & 4,45 \\
\hline $\mathbf{5 6}$ & 58,5 & 26213 & 4,30 & 67,9 & 34421 & 4,70 & 58,7 & 36437 & 4,70 \\
\hline \hline
\end{tabular}

\subsubsection{Comparação dos resultados}

Serão comparados os resultados teóricos com os experimentais, para a resistência do concreto à tração direta e para o módulo de deformação longitudinal.

\section{a) Resistência do concreto à tração direta}

Nas tabelas 3.16, 3.17 e 3.18 e, respectivamente, nas figuras 3.21, 3.22 e 3.23, são apresentadas as comparações relativas aos ensaios de OLUOKUN et al. (1991b), GRIEB \& WERNER (1962) e FERRARI et al. (1995). 
TABELA 3.16 - Comparação com resultados de Oluokun (em MPa)

\begin{tabular}{||c|c|c|c|c|c|c||}
\hline \hline Ensaios & Ensaios $(*)$ & Eurocode & NS 3473 & ACI-363 & Shah & NBR 6118 \\
\hline $\boldsymbol{f}_{\boldsymbol{c}}$ & $\boldsymbol{f}_{\boldsymbol{c t}}$ & $\boldsymbol{f}_{\boldsymbol{c t}}$ & $\boldsymbol{f}_{\boldsymbol{c t}}$ & $\boldsymbol{f}_{\boldsymbol{c t}}$ & $\boldsymbol{f}_{\boldsymbol{c t}}$ & $\boldsymbol{f}_{\boldsymbol{c t}}$ \\
\hline 35,44 & 3,49 & 3,24 & 2,94 & 3,16 & 2,96 & 4,05 \\
\hline 35,69 & 3,15 & 3,25 & 2,95 & 3,17 & 2,97 & 4,07 \\
\hline 35,93 & 2,99 & 3,27 & 2,96 & 3,18 & 2,98 & 4,09 \\
\hline 44,14 & 4,28 & 3,75 & 3,30 & 3,53 & 3,34 & 4,80 \\
\hline 44,22 & 3,62 & 3,75 & 3,30 & 3,53 & 3,34 & 4,80 \\
\hline 46,21 & 3,77 & 3,86 & 3,38 & 3,61 & 3,43 & 4,97 \\
\hline 46,33 & 3,71 & 3,87 & 3,38 & 3,61 & 3,43 & 4,98 \\
\hline 50,11 & 3,91 & 4,08 & 3,52 & 3,76 & 3,58 & 5,31 \\
\hline 60,96 & 4,77 & 4,65 & 3,90 & 4,15 & 3,99 & 6,24 \\
\hline
\end{tabular}

(*) Os resultados experimentais também foram multiplicados por 0,9 para serem referenciados à tração direta, uma vez que foram feitos ensaios de compressão diametral.

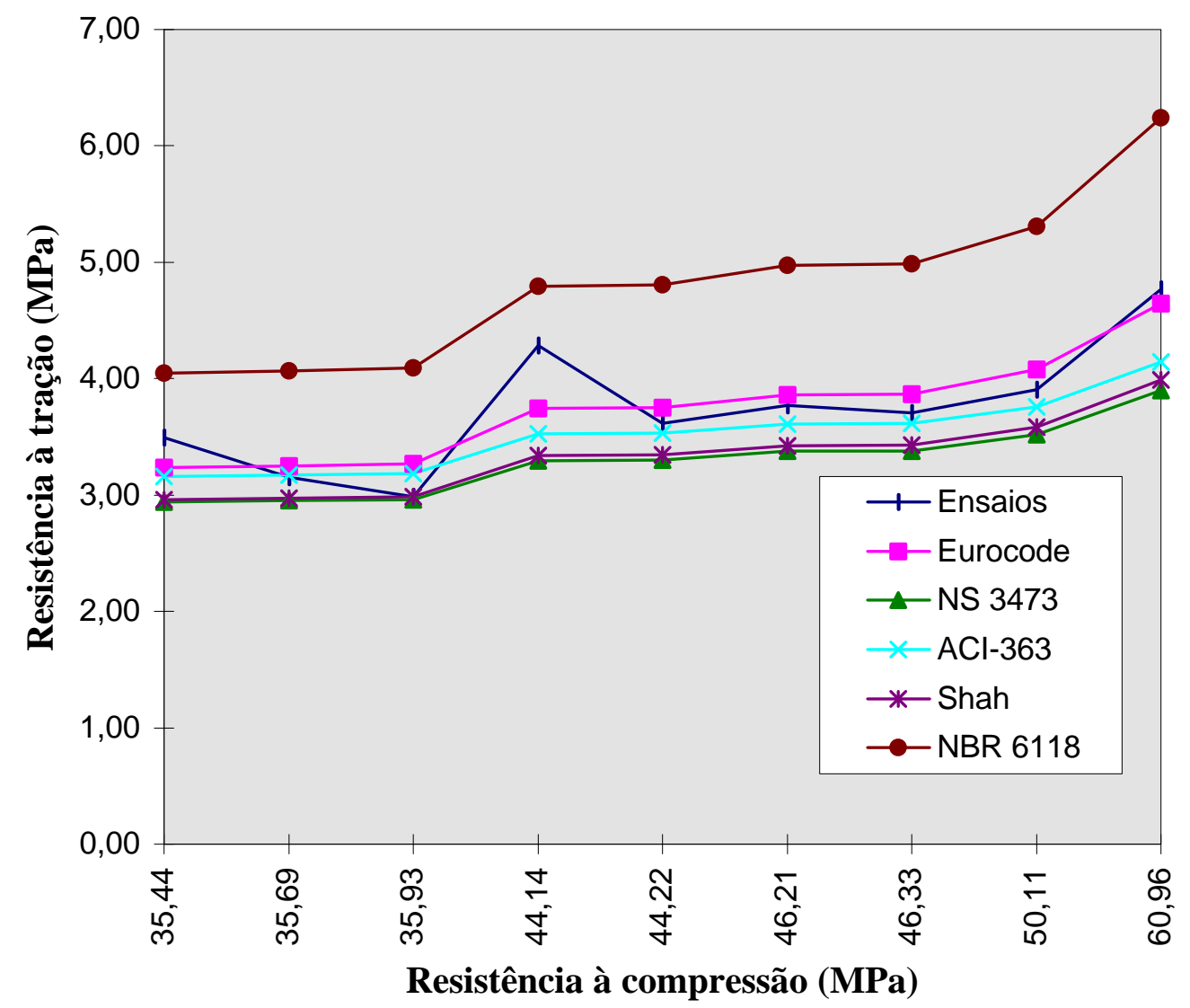

FIGURA 3.21 - Comparação com resultados de Oluokun $\left(f_{c t}\right)$ 
TABELA 3.17 - Comparação com os resultados de Grieb \& Werner (em MPa)

\begin{tabular}{||c|c|c|c|c|c|c||}
\hline Ensaios & Ensaios $\left(^{*}\right)$ & Eurocode & NS 3473 E & ACI-363 & Shah & NBR 6118 \\
\hline $\boldsymbol{f}_{\boldsymbol{c}}$ & $\boldsymbol{f}_{\boldsymbol{c t}}$ & $\boldsymbol{f}_{\boldsymbol{c t}}$ & $\boldsymbol{f}_{\boldsymbol{c t}}$ & $\boldsymbol{f}_{\boldsymbol{c t}}$ & $\boldsymbol{f}_{\boldsymbol{c t}}$ & $\boldsymbol{f}_{\boldsymbol{c t}}$ \\
\hline 35,51 & 3,07 & 3,24 & 2,94 & 3,16 & 2,96 & 4,05 \\
\hline 37,09 & 3,13 & 3,34 & 3,01 & 3,23 & 3,04 & 4,19 \\
\hline 37,92 & 3,47 & 3,39 & 3,05 & 3,27 & 3,07 & 4,26 \\
\hline 38,33 & 3,26 & 3,41 & 3,06 & 3,29 & 3,09 & 4,30 \\
\hline 38,61 & 3,26 & 3,43 & 3,07 & 3,30 & 3,10 & 4,32 \\
\hline 38,75 & 3,35 & 3,44 & 3,08 & 3,31 & 3,11 & 4,33 \\
\hline 38,89 & 3,13 & 3,44 & 3,09 & 3,31 & 3,12 & 4,34 \\
\hline 38,96 & 3,20 & 3,45 & 3,09 & 3,31 & 3,12 & 4,35 \\
\hline 39,78 & 3,38 & 3,50 & 3,12 & 3,35 & 3,15 & 4,42 \\
\hline 39,78 & 3,41 & 3,50 & 3,12 & 3,35 & 3,15 & 4,42 \\
\hline 40,06 & 3,45 & 3,51 & 3,13 & 3,36 & 3,17 & 4,45 \\
\hline 40,61 & 3,38 & 3,54 & 3,16 & 3,38 & 3,19 & 4,49 \\
\hline 40,95 & 3,75 & 3,56 & 3,17 & 3,40 & 3,20 & 4,52 \\
\hline 41,23 & 3,47 & 3,58 & 3,18 & 3,41 & 3,22 & 4,55 \\
\hline 41,71 & 3,88 & 3,61 & 3,20 & 3,43 & 3,24 & 4,59 \\
\hline 42,13 & 3,51 & 3,63 & 3,22 & 3,45 & 3,26 & 4,62 \\
\hline 42,47 & 3,56 & 3,65 & 3,23 & 3,46 & 3,27 & 4,65 \\
\hline 42,75 & 3,60 & 3,67 & 3,24 & 3,47 & 3,28 & 4,68 \\
\hline 44,47 & 3,82 & 3,77 & 3,31 & 3,54 & 3,35 & 4,82 \\
\hline
\end{tabular}

(*) Os resultados experimentais também foram multiplicados por 0,9.

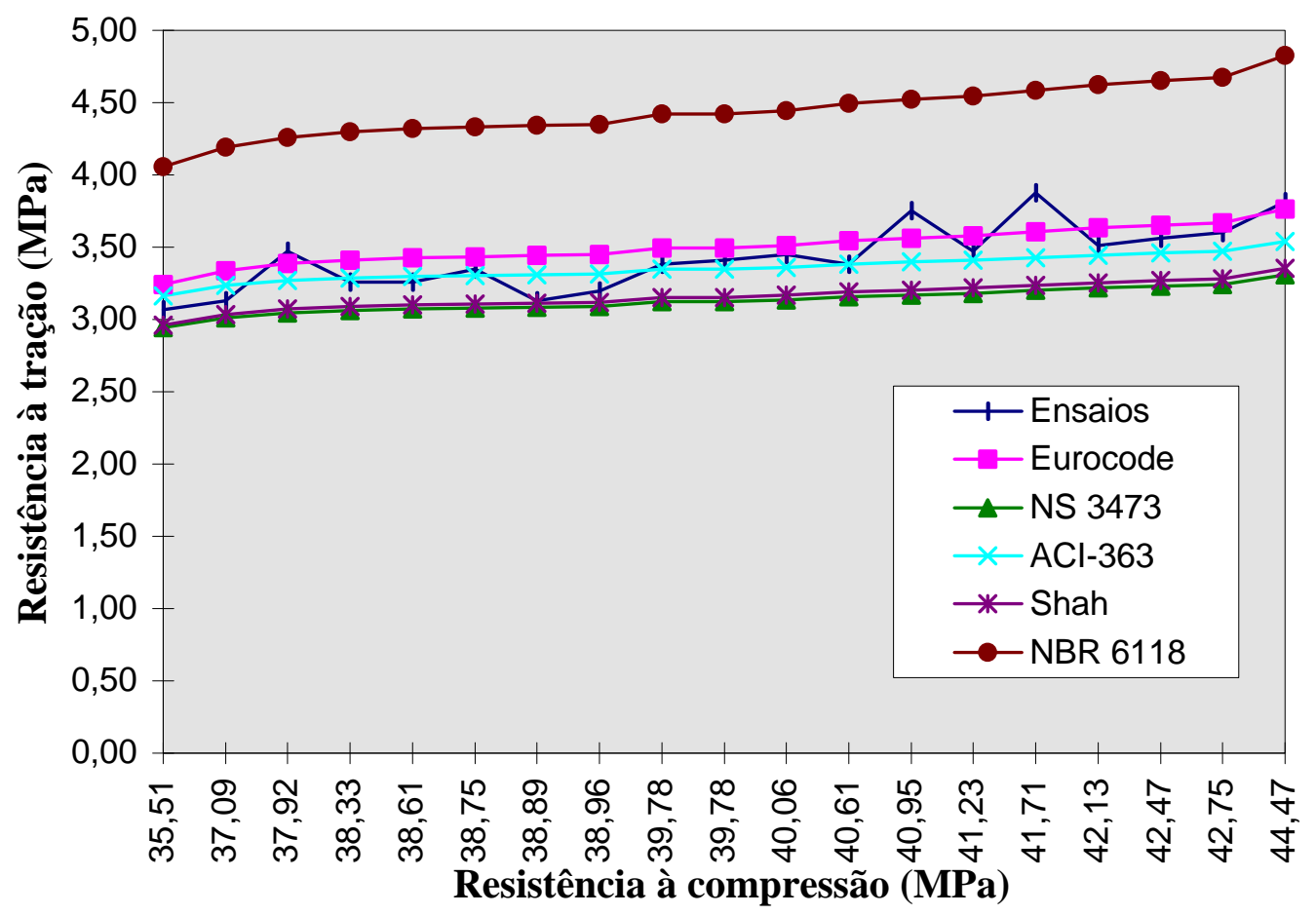

FIGURA 3.22 - Comparação com resultados Grieb \& Werner $\left(f_{c t}\right)$ 
TABELA 3.18 - Comparação com resultados de Ferrari (em MPa)

\begin{tabular}{|c|c|c|c|c|c|c|c||}
\hline Ensaios & Ensaios & Eurocode & NS 3473 & ACI-363 & Shah & NBR 6118 & Gonzalez \\
\hline $\boldsymbol{f}_{\boldsymbol{c}}$ & $\boldsymbol{f}_{\boldsymbol{c t}}$ & $\boldsymbol{f}_{\boldsymbol{c t}}$ & $\boldsymbol{f}_{\boldsymbol{c t}}$ & $\boldsymbol{f}_{\boldsymbol{c t}}$ & $\boldsymbol{f}_{\boldsymbol{c t}}$ & $\boldsymbol{f}_{\boldsymbol{c t}}$ & $\boldsymbol{f}_{\boldsymbol{c t}}$ \\
\hline 41,2 & 3,29 & 3,58 & 3,18 & 3,41 & 3,22 & 4,54 & ---- \\
\hline 47,9 & 4,32 & 3,96 & 3,44 & 3,68 & 3,49 & 5,12 & ----- \\
\hline 49,3 & 3,51 & 4,03 & 3,49 & 3,73 & 3,55 & 5,24 & ---- \\
\hline 50,5 & 3,38 & 4,10 & 3,54 & 3,77 & 3,60 & 5,34 & 4,73 \\
\hline 51,2 & 4,19 & 4,14 & 3,56 & 3,80 & 3,62 & 5,40 & 4,76 \\
\hline 52 & 3,74 & 4,18 & 3,59 & 3,83 & 3,65 & 5,47 & 4,79 \\
\hline 56,3 & 3,96 & 4,41 & 3,74 & 3,98 & 3,82 & 5,84 & 4,97 \\
\hline 57,7 & 4,41 & 4,48 & 3,79 & 4,03 & 3,87 & 5,96 & 5,02 \\
\hline 58,1 & 4,10 & 4,50 & 3,80 & 4,05 & 3,88 & 6,00 & 5,04 \\
\hline 58,5 & 3,87 & 4,52 & 3,82 & 4,06 & 3,90 & 6,03 & 5,05 \\
\hline 58,7 & 4,23 & 4,53 & 3,82 & 4,07 & 3,91 & 6,05 & 5,06 \\
\hline 58,9 & 4,01 & 4,54 & 3,83 & 4,08 & 3,91 & 6,07 & 5,07 \\
\hline 60,2 & 4,50 & ----- & 3,87 & 4,12 & 3,96 & 6,18 & 5,12 \\
\hline 67,9 & 4,23 & ---- & 4,12 & 4,38 & 4,23 & 6,84 & 5,41 \\
\hline \hline
\end{tabular}

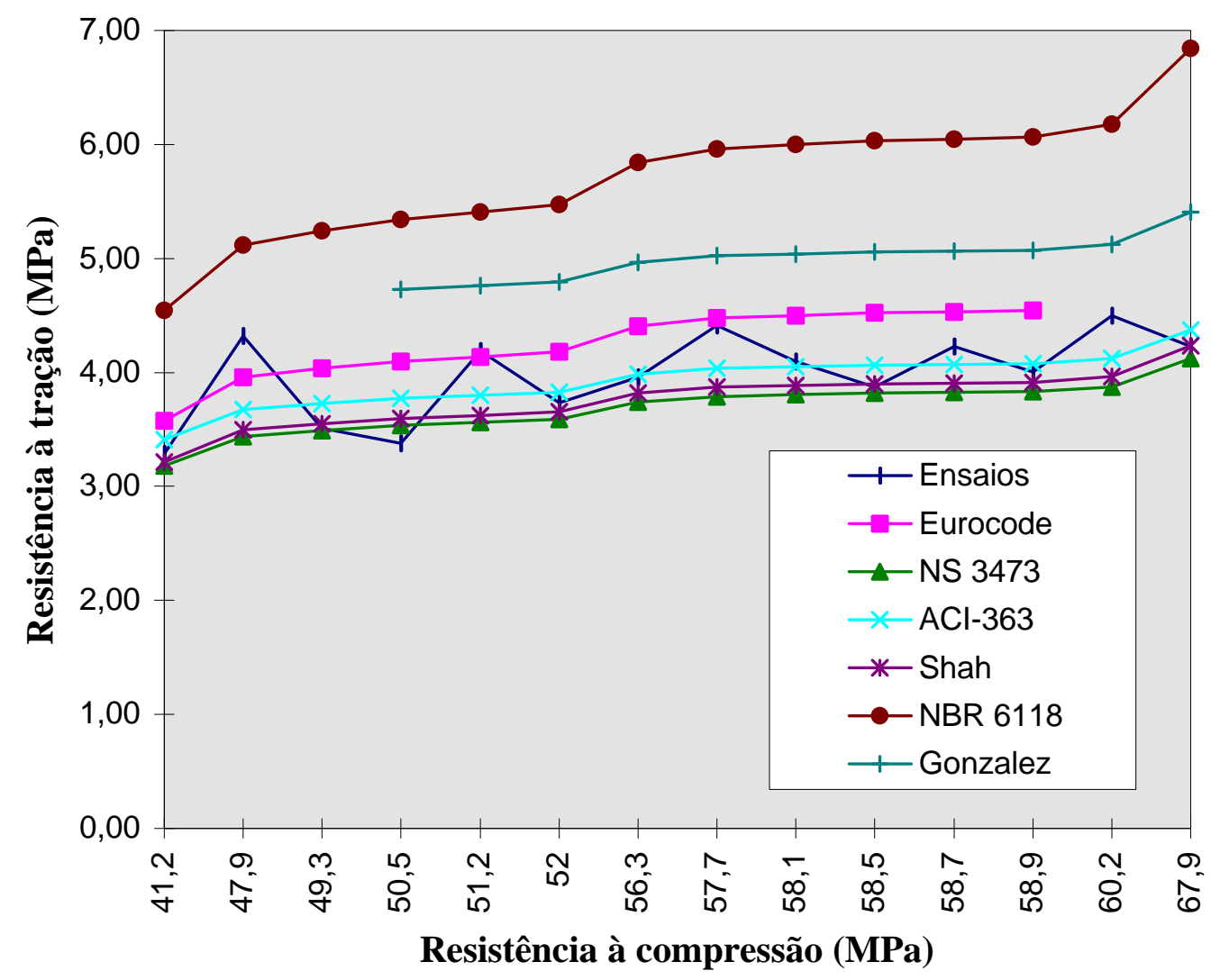

FIGURA 3.23 - Comparação com resultados Ferrari $\left(f_{c t}\right)$ 


\section{b) Módulo de deformação longitudinal do concreto}

Nas tabelas 3.19 e 3.20 e, respectivamente, nas figuras 3.24 e 3.25 , são apresentadas as comparações relativas aos ensaios de OLUOKUN et al. (1991a) e de FERRARI et al. (1995).

TABELA 3.19- Comparação com resultados de Oluokun (em MPa)

\begin{tabular}{|c|c|c|c|c|c|c|c|c||}
\hline \hline Ensaios & Ensaios & CEB-90 & Eurocode & NS 3473 & ACI-363 & ACI-318 & Shah & NBR6118 \\
\hline $\boldsymbol{f}_{\boldsymbol{c}}$ & $\boldsymbol{E}_{\boldsymbol{c}}$ & $\boldsymbol{E}_{\boldsymbol{c}}$ & $\boldsymbol{E}_{\boldsymbol{c}}$ & $\boldsymbol{E}_{\boldsymbol{c}}$ & $\boldsymbol{E}_{\boldsymbol{c}}$ & $\boldsymbol{E}_{\boldsymbol{c}}$ & $\boldsymbol{E}_{\boldsymbol{c}}$ & $\boldsymbol{E}_{\boldsymbol{c}}$ \\
\hline 35,44 & 30602 & 35153 & 33395 & 27706 & 26665 & 30268 & 31048 & 37067 \\
\hline 35,69 & 31688 & 35220 & 33459 & 27764 & 26734 & 30375 & 31119 & 37186 \\
\hline 35,93 & 31194 & 35285 & 33521 & 27820 & 26801 & 30477 & 31187 & 37299 \\
\hline 44,14 & 34326 & 37359 & 35491 & 29592 & 28957 & 33780 & 33344 & 40999 \\
\hline 44,22 & 35095 & 37378 & 35509 & 29608 & 28977 & 33810 & 33364 & 41033 \\
\hline 46,21 & 35417 & 37847 & 35954 & 30002 & 29469 & 34563 & 33844 & 41880 \\
\hline 46,33 & 35381 & 37875 & 35981 & 30025 & 29498 & 34608 & 33873 & 41931 \\
\hline 50,11 & 36206 & 38733 & 36797 & 30740 & 30402 & 35992 & 34747 & 43492 \\
\hline 60,96 & 40293 & 41008 & 38957 & 32602 & 32822 & 39698 & 37033 & 47690 \\
\hline
\end{tabular}

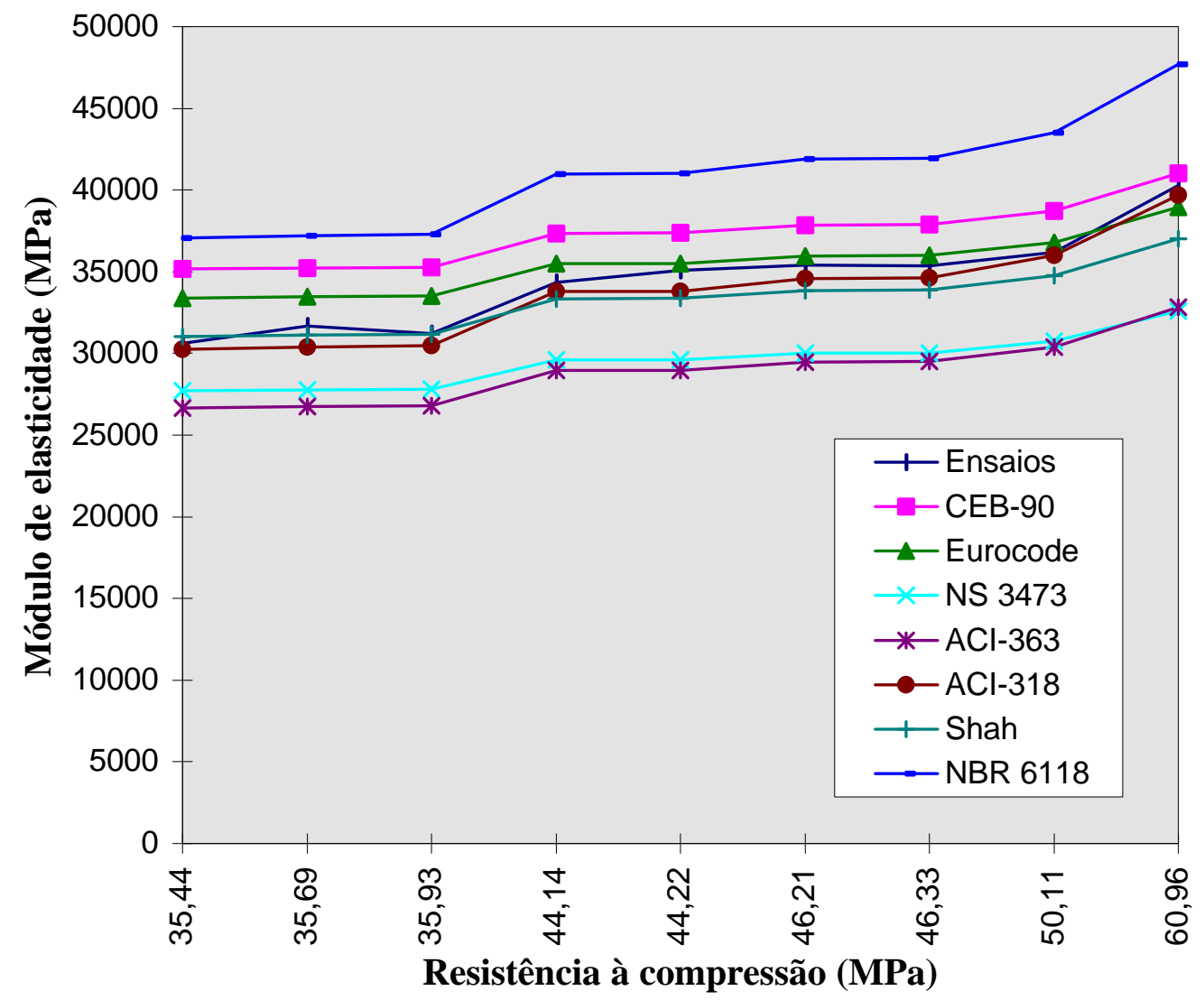

FIGURA 3.24 - Comparação com resultados de Oluokun $\left(E_{C}\right)$ 
TABELA 3.20 - Comparação com resultados de Ferrari (em MPa)

\begin{tabular}{||c|c|c|c|c|c|c|c|c||}
\hline \hline Ensaios & Ensaios & CEB-90 & Eurocode & NS 3473 & ACI-363 & ACI-318 & Shah & NBR 6118 \\
\hline $\boldsymbol{f}_{\boldsymbol{c}}$ & $\boldsymbol{E}_{\boldsymbol{c}}$ & $\boldsymbol{E}_{\boldsymbol{c}}$ & $\boldsymbol{E}_{\boldsymbol{c}}$ & $\boldsymbol{E}_{\boldsymbol{c}}$ & $\boldsymbol{E}_{\boldsymbol{c}}$ & $\boldsymbol{E}_{\boldsymbol{c}}$ & $\boldsymbol{E}_{\boldsymbol{c}}$ & $\boldsymbol{E}_{\boldsymbol{c}}$ \\
\hline 41,2 & 28265 & 36643 & 34811 & 28986 & 28210 & 32636 & 32605 & 39714 \\
\hline 47,9 & 30788 & 38236 & 36324 & 30327 & 29878 & 35189 & 34242 & 42586 \\
\hline 49,3 & 25932 & 38552 & 36625 & 30590 & 30211 & 35700 & 34564 & 43162 \\
\hline 50,5 & 27109 & 38820 & 36879 & 30811 & 30493 & 36132 & 34835 & 43650 \\
\hline 51,2 & 28127 & 38974 & 37025 & 30939 & 30656 & 36381 & 34991 & 43932 \\
\hline 52,0 & 29080 & 39149 & 37191 & 31083 & 30841 & 36664 & 35168 & 44252 \\
\hline 56,3 & 33145 & 40062 & 38059 & 31833 & 31811 & 38150 & 36088 & 45934 \\
\hline 57,7 & 26875 & 40351 & 38334 & 32068 & 32119 & 38622 & 36377 & 46469 \\
\hline 58,1 & 32433 & 40433 & 38411 & 32135 & 32206 & 38755 & 36459 & 46620 \\
\hline 58,5 & 26213 & 40514 & 38489 & 32201 & 32293 & 38888 & 36540 & 46772 \\
\hline 58,7 & 36437 & 40555 & 38527 & 32234 & 32337 & 38955 & 36581 & 46847 \\
\hline 58,9 & 33381 & 40595 & 38566 & 32267 & 32380 & 39021 & 36621 & 46922 \\
\hline 59,2 & 33066 & 40656 & 38623 & 32316 & 32445 & 39120,3 & 36682 & 47035 \\
\hline 60,2 & 32440 & 40857 & 38814 & 32479 & 32659 & 39449,3 & 36882 & 47408 \\
\hline 67,9 & 34421 & 42340 & 40223 & 33673 & 34257 & 41896,4 & 38353 & 50192 \\
\hline
\end{tabular}

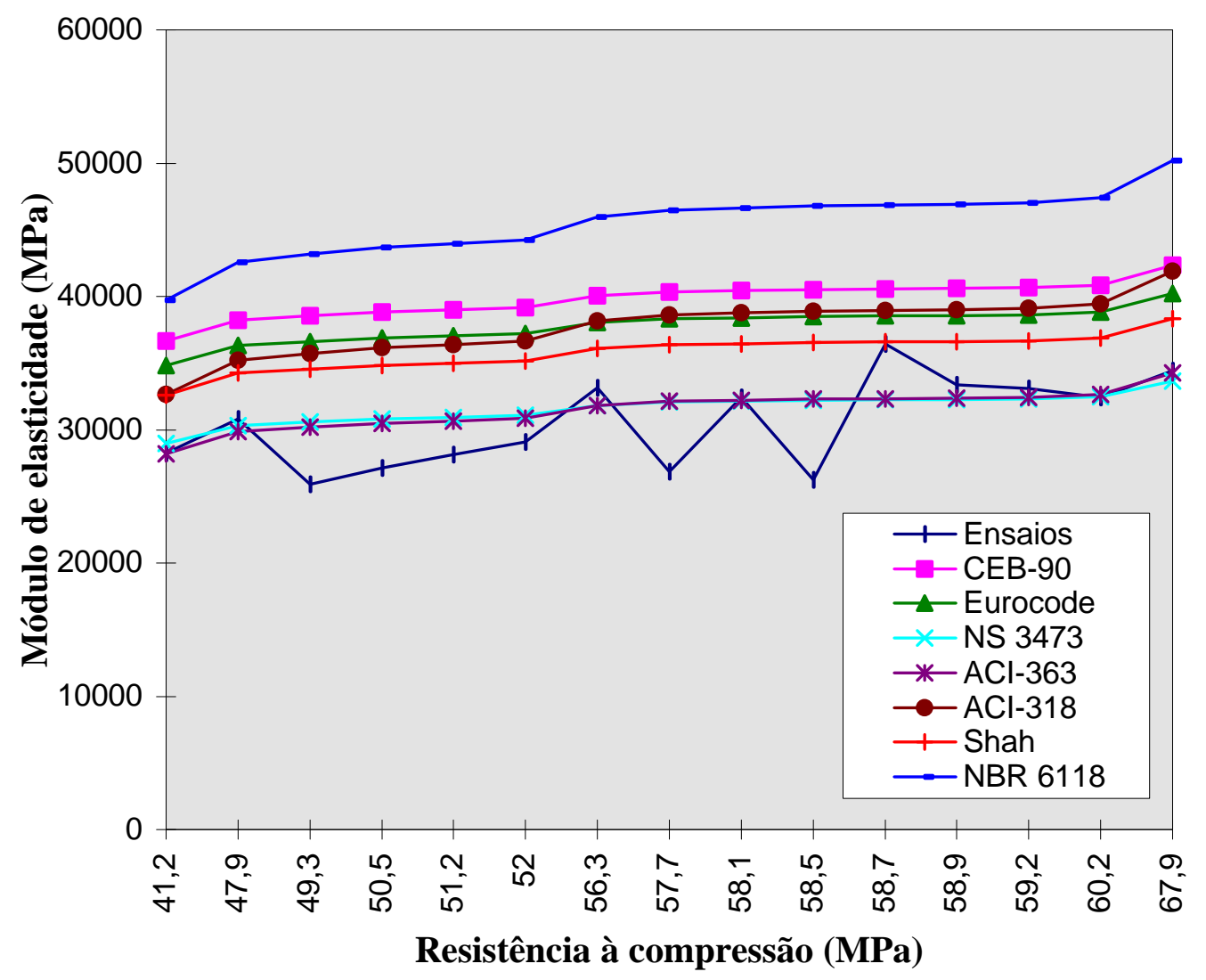

FIGURA 3.25 - Comparação com resultados de Ferrari $\left(E_{C}\right)$ 


\subsubsection{Conclusões}

Foram analisados concretos com resistências variando no intervalo entre $35 \mathrm{MPa}$ e $68 \mathrm{MPa}$, sendo a maior parte inferior a $60 \mathrm{MPa}$.

\section{a) Resistência à tração direta}

Através da análise dos resultados obtidos por OLUOKUN et al. (1991b), GRIEB \& WERNER (1962) e FERRARI et al. (1995), percebe-se que a expressão adotada pela NBR 6118 (1978) apresenta valores muito exagerados para a resistência do concreto à tração, em todo o intervalo analisado.

A expressão proposta pelo EUROCODE 2 (1992) aproxima-se mais dos resultados experimentais, porém fornece valores maiores que os experimentais em muitos casos. As expressões sugeridas por SHAH \& AHMAD (1994) e pela NS 3473 (1992) apresentam praticamente os mesmos resultados, ficando estes um pouco abaixo dos valores experimentais.

A expressão que melhor representa o conjunto de dados analisados é a relativa ao ACI-363 (1994), $f_{c t}=0,53 \sqrt{f_{c k}}$, em MPa, válida para o seguinte intervalo $21 \mathrm{MPa}<f_{c k}<83 \mathrm{MPa}$.

\section{b) Módulo de deformação longitudinal}

A partir dos dados experimentais de OLUOKUN et al. (1991a) e FERRARI et al. (1995), conclui-se que as expressões propostas pela NBR 6118 (1978) e pelo CEB-90 apresentam valores muito exagerados para o módulo de deformação longitudinal. Já o EUROCODE 2 (1992) também superestima o valor do módulo de deformação longitudinal, mas se aproxima mais dos resultados experimentais, principalmente para valores maiores de resistência à compressão do concreto $\left(f_{C}\right)$.

As expressões relativas à NS 3473 (1992) e ao ACI-363 (1994) são as que melhor representam o conjunto de dados analisados, pois se aproximam dos resultados experimentais e são ligeiramente inferiores a estes nos ensaios de Oluokun e em muitos dos ensaios de Ferrari. Dentre essas duas, pode-se optar pela expressão 
da NS 3473 (1992), $E_{c}=9500 f_{c k} 0,3$, em $M P a$, válida para $f_{c k}<85 M P a$, sendo portanto a mais recomendada para a previsão do módulo de deformação longitudinal do concreto, de acordo com os ensaios ora analisados.

Entretanto, recomenda-se a comparação das expressões aqui propostas com mais dados experimentais, com resistência variando principalmente no intervalo de $60 \mathrm{MPa}$ a $90 \mathrm{MPa}$, valores que praticamente não estavam disponíveis nos ensaios considerados. 
4 PILARES

Pilar é um elemento estrutural vertical submetido a forças de compressão, com ou sem momentos fletores. As dimensões da seção transversal dos pilares são em geral consideravelmente menores do que a sua altura. Os pilares suportam as cargas das vigas e da cobertura e transmitem essas cargas para a fundação.

Os efeitos da estabilidade devem ser considerados no projeto de elementos submetidos à compressão. Se os momentos introduzidos por efeitos de esbeltez enfraquecem um pilar apreciavelmente, ele é referido como um pilar esbelto. Alguns pilares de concreto são suficientemente rígidos, podendo-se desprezar a esbeltez. Tais pilares são referenciados como pilares robustos ou pouco esbeltos.

Atualmente, existe uma tendência mundial na aplicação do concreto de alto desempenho na construção dos pilares de edifícios, em função de várias vantagens econômicas e estruturais. O concreto de alto desempenho permite a redução das dimensões dos elementos comprimidos, principalmente nos pavimentos térreos e subsolos, onde as cargas são maiores, proporcionando aumento do espaço útil. Além disso, tem-se uma maior trabalhabilidade do concreto de alto desempenho comparado com o concreto usual, permitindo concretagens mais fáceis, mesmo com formas complexas, peças esbeltas e elevadas taxas de armadura. A grande trabalhabilidade do CAD facilita o lançamento do concreto com a utilização de bombeamento.

Entretanto, deve-se ter em mente o comportamento mais frágil do concreto de alto desempenho comparado com o concreto usual, provocando perda prematura do recobrimento das armaduras dos pilares, juntamente com a necessidade de se utilizar armadura de confinamento apropriada, com objetivo de se evitar um colapso frágil da estrutura dos pilares. 


\subsection{PERDA DO RECOBRIMENTO}

Uma característica importante dos pilares de concreto de alto desempenho consiste na perda prematura do recobrimento da armadura. RAZVI \& SAATCIOGLU (1994) relataram que a perda do recobrimento do concreto, em alguns pilares com resistência cilíndrica à compressão de $124 \mathrm{MPa}$, começaram com aproximadamente $70 \%$ da resistência do concreto sem confinamento. BJERKELI et al. (1990) constataram a perda do recobrimento $(20 \mathrm{~mm})$ de pilares de $(300 \mathrm{~mm} \mathrm{x}$ $500 \mathrm{~mm}$ x $2000 \mathrm{~mm}$ ), quando o carregamento aplicado estava em torno de $85 \%$ a $90 \%$ da capacidade do pilar. Parece que altas tensões presentes no recobrimento do concreto levam a uma instabilidade da camada externa, especialmente se existe um espaçamento muito pequeno entre os estribos que delimitam o núcleo e a face do pilar. Isto cria um plano natural de separação, que provoca a perda completa da capacidade do recobrimento, antes que se tenham alcançadas as deformações associadas à ruptura do concreto.

COLLINS et al. (1993) indicam que a perda do recobrimento está associada, possivelmente, à permeabilidade muito baixa dos concretos de alto desempenho. Isto faz com que apenas a casca mais externa do pilar venha a secar, resultando em tensões devidas ao impedimento da retração do pilar, conforme a figura 4.1.a. Além disso, a retração do concreto de alto desempenho ao redor de grandes barras de armadura pode provocar fissuras radiais saindo das barras, conforme a figura 4.1.b. Sob altas cargas axiais, a combinação desses dois efeitos talvez resulte na perda do recobrimento, figura 4.1.c.

A partir de ensaios realizados por YONG et al. (1988), RANGAN et al. (1991), AGOSTINI (1992), PAIVA (1994) e LIMA (1997), percebeu-se que os pilares submetidos à compressão simples tiveram sua capacidade variando entre $92 \%$ a $118 \%$, com relação aos valores calculados teoricamente empregando-se a expressão (4.1).

$$
P_{o}=0,85 f_{c}^{\prime} \cdot\left(A_{g}-A_{s}\right)+f_{y} \cdot A_{s}
$$

$$
f_{c}^{\prime}=\text { resistência média do concreto à compressão (corpo-de-prova cilíndrico) }
$$




$$
\begin{aligned}
& f_{y}=\text { resistência média de escoamento da armadura longitudinal } \\
& A_{s}=\text { soma das áreas das seções transversais das barras longitudinais } \\
& A_{g}=\text { área total da seção transversal do pilar }
\end{aligned}
$$

Entretanto, um grande número de ensaios tiveram colapso com carga abaixo do valor previsto teoricamente. Isso pode ser explicado pela perda prematura do recobrimento. Dessa forma, concluiu-se que, para a previsão da capacidade resistente de pilares submetidos à compressão simples, deve-se considerar apenas a área do núcleo do pilar. A área do núcleo consiste na área delimitada pelas armaduras transversais, não levando em conta a capacidade resistente do recobrimento.

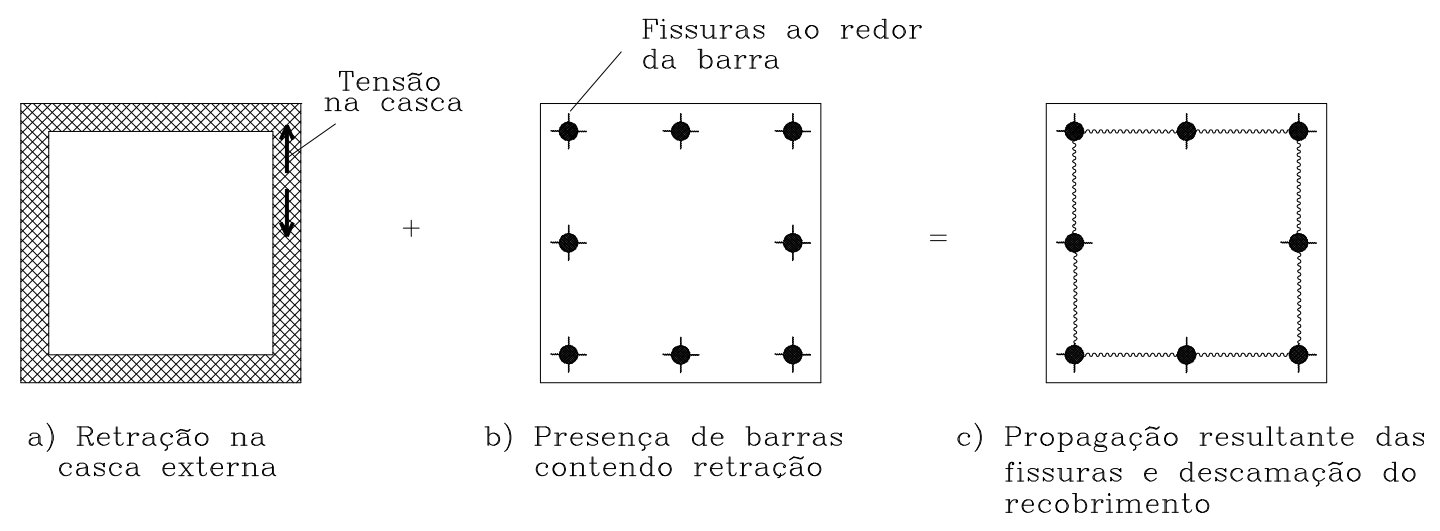

FIGURA 4.1 - Fatores que promovem a descamação do recobrimento em pilares de CAD. FONTE: COLLINS et al. (1993).

\subsection{CONFINAMENTO}

Quando um pilar está submetido a forças de compressão, o concreto sofre um encurtamento longitudinal e, devido ao coeficiente de Poisson, ele expande lateralmente. Essa expansão é contida pela armadura transversal, a qual fica submetida a tensões de tração produzindo uma pressão de confinamento no concreto.

Os pilares de concreto de alto desempenho apresentam um comportamento mais frágil do que o apresentado pelos concretos de resistência usual. Para melhorar a capacidade de deformação axial e aumentar a resistência do núcleo, proporcionando um colapso gradual e dúctil, deve-se aumentar a pressão de confinamento.

Pesquisas realizadas por MARTINEZ et al. (1984), SHAH \& AHMAD 
(1982) e BJERKELI et al. (1990) têm mostrado que a pressão lateral de confinamento, obtida empregando-se armadura em espiral ou estribos, é menos eficiente no aumento da tensão última do concreto e na deformabilidade do núcleo de pilares de concreto de alto desempenho quando comparado com concreto de resistência usual.

Vários são os fatores que influenciam no comportamento do concreto confinado, tais como: quantidade, resistência, espaçamento e detalhamento da armadura de confinamento, dimensão e geometria do elemento, quantidade e distribuição da armadura longitudinal, espessura do recobrimento e resistência do concreto.

\subsubsection{Taxa de armadura de confinamento}

A taxa de armadura de confinamento empregada está diretamente relacionada com a pressão, que poderá ser exercida pela armadura. Um aumento na taxa volumétrica da armadura de confinamento corresponde a um aumento direto na pressão de confinamento, a qual proporciona um aumento na resistência e na ductilidade. Isso pode ser percebido na tabela 4.1, a qual mostra deformabilidade de pilares com diferentes taxas volumétricas. Quando se utilizaram armaduras com resistência de plastificação de $379 \mathrm{MPa}$ e $414 \mathrm{MPa}$, para confinar concretos com resistência à compressão de $50 \mathrm{MPa}$, com taxa volumétrica de 2,2\% a 3,4\%, a taxa de deformação dúctil do concreto ficou limitada a aproximadamente 3. Quando a taxa volumétrica foi aumentada para 7,5\%, a taxa de deformação dúctil foi aumentada para aproximadamente 12 ou até mais. Isso indica a necessidade de um aumento significativo na taxa volumétrica, para pilares de concreto de alto desempenho, a fim de que se tenham as mesmas deformabilidades usualmente esperadas para pilares de concreto de resistência usual.

\subsubsection{Resistência da armadura de confinamento}

A resistência da armadura de confinamento desempenha um papel importante no confinamento do concreto. Entretanto, tensões de tração na armadura transversal 
são geradas a partir da expansão lateral do concreto, a qual por sua vez depende de suas propriedades mecânicas. Se a deformação lateral do concreto não é alta o suficiente para deformar a armadura transversal, provocando altas tensões, a grande capacidade da armadura pode não ser utilizada.

TABELA 4.1 - Efeito da taxa volumétrica $\left(\rho_{s}\right)$ e $\left(\rho_{s} f_{y t} / f_{c}^{\prime}\right)$ no aumento da resistência e na taxa de deformação dúctil segundo RAZVI et al. (1994).

\begin{tabular}{||c|ccccc||}
\hline PILAR & $\left.\boldsymbol{f}^{\prime}{ }_{\boldsymbol{c}} \mathbf{( M P a}\right)$ & $\boldsymbol{f}_{\boldsymbol{y t}}(\mathbf{M P a})$ & $\boldsymbol{\rho}_{\boldsymbol{s}}(\boldsymbol{\%})$ & $\boldsymbol{\rho}_{\boldsymbol{s}} \boldsymbol{f}_{\boldsymbol{y} \boldsymbol{t}} / \boldsymbol{f}_{\boldsymbol{c}}{ }_{\boldsymbol{c}}$ & $\boldsymbol{\varepsilon}_{\mathbf{8 5}} / \boldsymbol{\varepsilon}_{\mathbf{0 1}}$ \\
\hline $\mathbf{C 2 2}$ & 75 & 1364 & 2,1 & 0,38 & 1,8 \\
$\mathbf{C 2 4}$ & 76 & 1364 & 4,2 & 0,76 & 7,6 \\
\hline $\mathbf{C 2 6}$ & 50 & 379 & 2,2 & 0,17 & 3,4 \\
$\mathbf{C 2 7}$ & 50 & 379 & 2,2 & 0,17 & 3,2 \\
$\mathbf{C 2 8}$ & 50 & 379 & 2,2 & 0,17 & 3,2 \\
$\mathbf{C 3 2}$ & 50 & 414 & 7,5 & 0,62 & 12,6 \\
$\mathbf{C 3 3}$ & 50 & 414 & 7,5 & 0,62 & 15,2 \\
$\mathbf{C 3 4}$ & 50 & 414 & 7,5 & 0,62 & 11,9 \\
\hline $\mathbf{C 4 7}$ & 58 & 414 & 3,4 & 0,24 & 2,7 \\
$\mathbf{C 3 4}$ & 50 & 414 & 7,5 & 0,62 & 11,9 \\
\hline $\mathbf{C 8 7}$ & 35 & 546 & 0,9 & 0,14 & 1,0 \\
$\mathbf{C 9 3}$ & 36 & 546 & 1,7 & 0,26 & 1,0 \\
\hline
\end{tabular}

$\varepsilon_{85} / \varepsilon_{01}$ - taxa de deformação dúctil, determinada dividindo-se a deformação axial do concreto confinado, quando se tem $85 \%$ da tensão de pico no ramo descendente da curva, pela deformação do concreto sem confinamento correspondente à tensão de pico.

CUSSON et al. ${ }^{1}$ (1992) apud RAZVI \& SAATCIOGLU (1994) indicaram que o aumento na resistência da armadura de confinamento proporcionou uma melhora na resistência e na tenacidade apenas para pilares bem confinados. Comparações indicam que a deformabilidade de pilares permanecem inalteradas quando a razão $\left(\rho_{s}\right.$ $f_{y t} / f_{c}^{\prime}$ ) é mantida, independentemente da resistência do concreto. Dessa forma, a diminuição na deformabilidade do concreto devida ao aumento da resistência pode ser compensada pelo aumento da taxa volumétrica $\left(\rho_{s}\right)$ e pelo aumento da resistência da armadura de plastificação $\left(f_{y t}\right)$, de tal forma que o produto $\left(\rho_{s} f_{y t}\right)$ seja aumentado na mesma proporção do aumento da resistência do concreto.

\footnotetext{
${ }^{1}$ CUSSON, D. \& PAUlTRE, P. \& AITCIN, P. C. (1992). Le confinement des colonnes en beton a haute performance par des entries rectangulaires. Annual Conference of the Canadian Society for Civil Engineering. May 27-29. Quebec apud Razvi, S. R. \& Murat Saatcioglu (1994). Strength and deformability of confined high-strength concrete columns. ACI Structural Journal. Nov./Dez.
} 
HATANAKA \& TANIGAWA ${ }^{2}$ (1992) apud RAZVI \& SAATCIOGLU (1994) mostraram que a razão $\rho_{s} f_{y t} / f_{c}^{\prime}$ deve ser mantida constante, para se manter a mesma ductilidade de pilares de concreto de resistência usual e concreto de alto desempenho.

\subsubsection{Espaçamento da armadura de confinamento}

O espaçamento da armadura transversal é um parâmetro importante, que afeta a distribuição da pressão de confinamento, bem como a estabilidade da armadura longitudinal. Espaçamentos menores da armadura transversal aumentam a uniformidade da pressão lateral e melhoram a eficiência da armadura de confinamento.

A tabela 4.2 mostra o efeito do espaçamento da armadura transversal na taxa de deformação dúctil. Os resultados indicam melhora na ductilidade, com a redução do espaçamento dos estribos. Entretanto, variando-se somente o espaçamento dos estribos, não se consegue melhorar o mecanismo de confinamento, a menos que outros parâmetros de confinamento sejam favoráveis, como taxa volumétrica e resistência à plastificação da armadura.

TABELA 4.2 - Efeito do espaçamento dos estribos na resistência e na taxa de deformação dúctil obtidas por RAZVI et al. (1994).

\begin{tabular}{||c|cccc||}
\hline PILAR & $\left.\boldsymbol{f}^{\prime}{ }_{\boldsymbol{c}} \mathbf{( M P a}\right)$ & $\boldsymbol{\rho}_{\boldsymbol{s}} \boldsymbol{f}_{\boldsymbol{y} \boldsymbol{t}}(\mathbf{M P a})$ & $\mathbf{s} / \mathbf{h}$ & $\boldsymbol{\varepsilon}_{\mathbf{8 5}} / \boldsymbol{\varepsilon}_{\mathbf{0 1}}$ \\
\hline $\mathbf{C 4 6}$ & 58 & 14,0 & 0,06 & 3,3 \\
$\mathbf{C 4 7}$ & 58 & 14,0 & 0,06 & 2,7 \\
$\mathbf{C 5 0}$ & 58 & 12,8 & 0,17 & 2,0 \\
$\mathbf{C 5 1}$ & 58 & 12,8 & 0,17 & 1,8 \\
\hline $\mathbf{C 4 4}$ & 43 & 9,5 & 0,09 & 4,9 \\
$\mathbf{C 4 5}$ & 43 & 9,5 & 0,09 & 4,4 \\
$\mathbf{C 4 8}$ & 43 & 9,1 & 0,13 & 3,3 \\
$\mathbf{C 4 9}$ & 43 & 9,1 & 0,13 & 3,0 \\
$\mathbf{C 7 4}$ & 54 & 11,6 & 0,07 & 2,1 \\
$\mathbf{C 7 5}$ & 54 & 11,6 & 0,07 & 1,8 \\
$\mathbf{C 7 8}$ & 57 & 9,9 & 0,22 & 1,3 \\
$\mathbf{C 7 9}$ & 57 & 9,9 & 0,22 & 1,4 \\
\hline
\end{tabular}

${ }^{2}$ HATANAKA, S. \& TANIGAWA, Y. (1992). Lateral pressure requirements for compressive concrete. Proceedings of 10th World Conference on Earthquake Engineering. Madrid. pp.26032613 apud Razvi, S. R. \& Murat Saatcioglu (1994). Strength and deformability of confined highstrength concrete columns. ACI Structural Journal. Nov./Dez. 
Al HUSSAINI et al. ${ }^{3}$ apud RAZVI \& SAATCIOGLU (1994) observaram que uma redução do espaçamento dos estribos de 0,8 a 0,2 vezes a dimensão do pilar resultou num aumento da resistência $\left(P / A_{g} f_{c}^{\prime}\right)$ de apenas $6 \%$.

\subsubsection{Geometria da seção}

A geometria da seção também interfere no confinamento obtido. É de conhecimento geral que a armadura em espiral é mais eficiente no confinamento do concreto do que os estribos retangulares. A superioridade das armaduras em espiral advém da sua forma geométrica, a qual produz pressões uniformes e contínuas ao redor da circunferência do núcleo. Os estribos produzem pressões não uniformes, provocando concentrações de pressão nas extremidades. HATANAKA \& TANIGAWA (1992) relataram que a pressão produzida por um estribo quadrado é cerca de 0,3 a 0,5 vezes a pressão fornecida por um estribo circular.

\subsection{CRITÉRIOS DE PROJETO}

Para que se tenha um confinamento e comportamento apropriado de pilares de concreto de alto desempenho, é necessária a utilização de detalhamento apropriado da seção transversal do pilar, respeitando-se taxas mínimas de armadura transversal e armadura longitudinal.

\subsubsection{Dimensão mínima para os pilares}

Segundo a Norma Norueguesa as dimensões mínimas não devem ser menores que os seguintes valores:

- área da seção transversal menor que $40.000 \mathrm{~mm}^{2}$.

- 150 mm para dimensão mínima de pilares armados.

- 200 mm como menor dimensão de pilares não armados.

${ }^{3}$ AL-HUSSAINI, A. \& REGAN, P. E. \& XUE, H.Y. \& RAMDANE, K. E. (1993). Behavior of HSC columns under axial load. Proceedings of the symposium on high-strength concrete. Norway, June 1993. p. 83-90 apud Razvi, S. R. \& Murat Saatcioglu (1994). Strength and deformability of confined high-strength concrete columns. ACI Structural Journal. v.91, n.6, NovemberDezember. p.678-687. 
Já o EUROCODE 2 define os seguintes valores como dimensões mínimas para os pilares:

- $200 \mathrm{~mm}$ para pilares moldados "in situ".

- $140 \mathrm{~mm}$ para pilares moldados horizontalmente.

\subsubsection{Escolha do tipo de armadura transversal}

A armadura transversal pode ser na forma de estribos ou em espiral. Entretanto, do total de pilares construídos, cerca de 95\% são feitos empregando-se estribos como armadura transversal. As armaduras em espirais podem ser circulares, quadradas ou poligonais.

O confinamento proporcionado pela armadura em espiral é maior do que aquele que se obtém empregando-se estribos. A armadura em espiral contém a expansão lateral do concreto provocada por um carregamento axial, estabelecendo um estado triaxial de tensão, no interior do núcleo do pilar. Quando se empregam estribos, a restrição à expansão lateral do concreto é menor, pois os estribos tendem a se dobrar para fora.

Nos pilares, à medida que a carga máxima é alcançada, ao longo do recobrimento do estribo e da espiral, desenvolvem-se fissuras verticais e esmagamento do concreto até que se tenha a perda do recobrimento. Quando se tem a perda do recobrimento em pilares com estribos, a capacidade resistente do núcleo que permanece é menor que o esforço axial atuante, o que provoca esmagamento do núcleo de concreto e flambagem das armaduras longitudinais. Isso ocorre de repente, sem avisos, e de maneira frágil. Em um pilar com armadura em espiral, quando o recobrimento se vai, o pilar não sofre colapso imediatamente, devido à resistência do núcleo ter sido aumentada pelo estado triaxial de tensão. Em função do comportamento mais dúctil obtido utilizando-se armaduras em espiral, o ACI 318-89 permite a utilização do coeficiente de redução da resistência $\phi=0,75$ para espiral e 0,70 para estribos. Apesar do melhor comportamento obtido em pilares com armadura em espiral, os pilares com armadura em estribos são mais utilizados, em função da sua facilidade de execução e menor custo. 
Nos pilares de concreto armado, os estribos são utilizados com o objetivo de impedir flambagem das barras de armadura longitudinal para fora da superfície do pilar, de manter a disposição das armaduras longitudinais durante a construção e de proporcionar apropriado confinamento para os pilares.

\subsubsection{Diâmetro mínimo para os estribos}

De acordo com ACI 318-89, o diâmetro mínimo a ser utilizado para a armadura transversal é de 9,5 mm, enquanto o EUROCODE 2 (1992) e a Norma Inglesa BS 8110 recomendam o maior dos seguintes valores: $6 \mathrm{~mm}$ ou 1/4 do máximo diâmetro da armadura longitudinal. Entretanto, na Inglaterra, alguns projetistas indicam como diâmetro mínimo $8 \mathrm{~mm}$.

\subsubsection{Espaçamento máximo dos estribos}

Com relação ao espaçamento máximo dos estribos, o ACI 318-89 (sec.7.10.5.1, 2, 3) indica que o espaçamento não deve exceder 16 vezes o diâmetro da barra de armadura longitudinal, 48 vezes o diâmetro do estribo ou a menor dimensão do pilar.

O EUROCODE 2 e a Norma Inglesa BS 8110 indicam que o espaçamento dos estribos não deve exceder o menor dos seguintes valores: 12 vezes o diâmetro mínimo da armadura longitudinal, a menor dimensão do pilar e $300 \mathrm{~mm}$. Estes valores devem ser reduzidos por um coeficiente 0,6 , no caso de seções localizadas acima e abaixo de vigas e lajes, ao longo de uma altura igual à maior dimensão da seção transversal do pilar. Já a Norma Norueguesa recomenda que o espaçamento dos estribos não deve ser maior do que 15 vezes o diâmetro da armadura longitudinal. No caso da resistência à compressão superar $54 \mathrm{MPa}$ (corpo-de-prova cilíndrico), os estribos devem ter o espaçamento reduzido para 10 vezes o diâmetro da armadura longitudinal e ser constituídos por barras com mossas e com diâmetro mínimo de $10 \mathrm{~mm}$. 


\subsubsection{Taxa mínima para armadura transversal}

XIE et al. (1997), através de um estudo paramétrico baseado em análise numérica de pilares de concreto de alto desempenho (37,5 MPa a

$75 \mathrm{MPa}$ ), armados com estribos, submetidos a um carregamento de compressão excêntrica, concluíram que a área mínima de armadura transversal a ser utilizada deve ser a área de armadura recomendada pelo ACI 318-89 (sec.21.4.4.1) para ação de sismo, a fim de que o pilar tenha um confinamento adequado e apresente um comportamento dúctil. As expressões recomendadas são:

$$
\begin{array}{ll}
A_{s h}=0,3\left(\frac{s \cdot h_{c} \cdot f_{c}^{\prime}}{f_{y h}}\right) \cdot\left(\frac{A_{g}}{A_{c h}}-1\right) & \text { (ACI 318-89 eq. 21-22) } \\
A_{s h}=\frac{0,09 s \cdot h_{c} \cdot f_{c}^{\prime}}{f_{y h}} & \text { (ACI 318-89 eq. 21-23) }
\end{array}
$$

$A_{s h}$ - área total da seção transversal da armadura em estribos retangulares

$A_{c h}$ - área da seção transversal do elemento estrutural, medida até a parte externa da armadura transversal

$S$ - espaçamento da armadura transversal, medida ao longo do eixo longitudinal do elemento estrutural

$h_{c}$ - dimensão da seção transversal do pilar, medida de centro a centro da armadura de confinamento

$f_{y h}$ - resistência de plastificação da armadura transversal

Introduzindo a taxa de armadura transversal $\left(\rho_{t}\right)$ tem-se:

$$
\rho_{t}=\frac{A_{s h}}{s \cdot h_{c} \cdot\left(f_{c}^{\prime} / f_{y h}\right)}
$$

Rearranjando as expressões (4.2) e (4.3), $\left(\rho_{t}\right)$ deve satisfazer as relações:

$$
\begin{aligned}
& \rho_{t} \geq 0,3\left[\left(\frac{A_{g}}{A_{c h}}\right)-1\right] \\
& \rho_{t} \geq 0,09
\end{aligned}
$$




\subsubsection{Escolha da configuração dos estribos}

No estudo paramétrico descrito anteriormente, realizado por XIE et al. (1997), foi analisada uma série de pilares PA1, PA2, PA3 e PA4, para se verificar a influência da configuração do estribo. Os pilares apresentaram as características indicadas na tabela 4.3 e configurações indicadas na figura 4.2.

TABELA 4.3 - Detalhe dos pilares armados com estribos utilizados no estudo paramétrico realizado por XIE et al.(1997).

\begin{tabular}{|c|c|c|c|c|c|c|c|c|}
\hline \multirow[b]{2}{*}{ Elemento } & \multirow{2}{*}{$\begin{array}{c}\text { Seção } \\
\text { transv. } \\
(\mathrm{mm})\end{array}$} & \multirow{2}{*}{$\begin{array}{c}\text { recob } \\
\cdot \\
(\mathrm{mm})\end{array}$} & \multirow{2}{*}{$\begin{array}{c}f_{c}^{\prime} \\
(\mathrm{MPa} \\
)\end{array}$} & \multirow{2}{*}{$\begin{array}{l}\text { arm. } \\
\text { long. }\end{array}$} & \multicolumn{4}{|c|}{ Armadura transversal } \\
\hline & & & & & diâm. & $\begin{array}{c}f_{y b} \\
(\mathbf{M P a})\end{array}$ & $\begin{array}{l}\text { esp. } \\
\text { (mm) }\end{array}$ & config \\
\hline PA1 & $350 \times 350$ & 20 & 75 & $\begin{array}{c}8 \# 25 \\
M\end{array}$ & $\# 10 \mathrm{M}$ & 400 & 40 & A \\
\hline PA2 & $350 \times 350$ & 20 & 75 & $\begin{array}{c}8 \# 25 \\
M\end{array}$ & $\# 10 \mathrm{M}$ & 400 & 60 & B \\
\hline PA3 & $350 \times 350$ & 20 & 75 & $\begin{array}{c}8 \# 25 \\
M\end{array}$ & $\# 10 \mathrm{M}$ & 400 & 80 & $\mathrm{C}$ \\
\hline PA4 & $350 \times 350$ & 20 & 75 & $\begin{array}{c}8 \# 25 \\
M\end{array}$ & $\# 10 \mathrm{M}$ & 400 & 80 & $\mathrm{D}$ \\
\hline
\end{tabular}

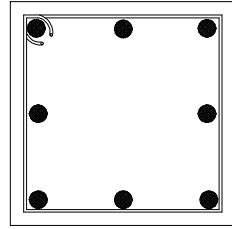

A

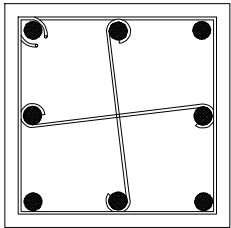

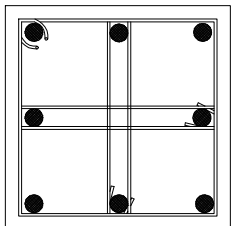

C

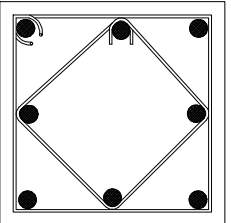

D

FIGURA 4.2 - Arranjo dos estribos do estudo paramétrico.

Nestes ensaios, todos os elementos seguiram as exigências mínimas propostas pelo ACI 318-89, para taxa de armadura transversal com relação a sismo $\left(\rho_{t} \quad 0,09\right)$.

Todos os elementos tiveram um comportamento muito similar antes do momento máximo. Entretanto, a configuração do estribo teve um efeito significativo no comportamento do pilar, após o ponto de momento máximo. Embora os quatro elementos tivessem a mesma taxa de armadura transversal, os elementos com espaçamentos menores dos estribos tiveram um melhor comportamento do que aqueles com espaçamentos maiores, após o momento máximo, conforme a figura 4.3.

Os elementos PA3 e PA4 tiveram uma plastificação anterior aos elementos PA1 e PA2, pois PA1 e PA2 possuíam espaçamento menor. Para o elemento PA4 a 
capacidade ao momento é mantida até a plastificação do estribo em forma de diamante, para uma deformação de 0,0056 na face comprimida. Isso indica que estribos adicionais na forma de diamante fornecem mais confinamento do que estribos duplos (tipo C).

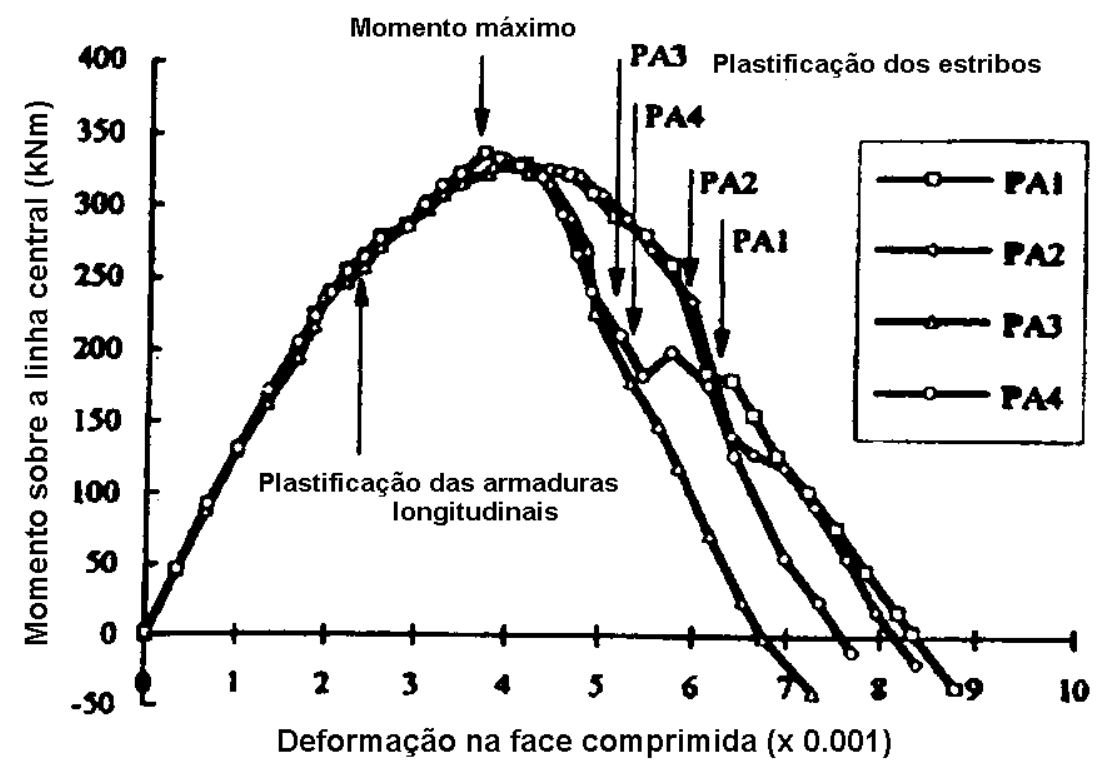

FIGURA 4.3 - Momento na linha central x deformação por compressão.

\subsubsection{Efeito da resistência à plastificação da armadura transversal}

No referido estudo paramétrico, XIE et al. (1997) analisaram outras duas séries de pilares PC e PV13, com o objetivo de analisar o efeito da resistência à plastificação da armadura no comportamento dos pilares. As características dos elementos PC e PV13 estão indicadas na tabela 4.4.

TABELA 4.4 - Detalhe dos pilares armados com estribos para o estudo paramétrico realizados por XIE et al. (1997).

\begin{tabular}{|c|c|c|c|c|c|c|c|c|}
\hline \multirow[b]{2}{*}{ Elemento } & \multirow{2}{*}{$\begin{array}{c}\text { seção transv. } \\
(\mathrm{mm})\end{array}$} & \multirow{2}{*}{$\begin{array}{l}\text { recob. } \\
(\mathrm{mm})\end{array}$} & \multirow{2}{*}{$\begin{array}{c}f_{c}^{\prime} \\
(\mathbf{M P a} \\
\text { (M) }\end{array}$} & \multirow{2}{*}{$\begin{array}{l}\text { arm. } \\
\text { long. }\end{array}$} & \multicolumn{4}{|c|}{ Armadura transversal } \\
\hline & & & & & diâm. & 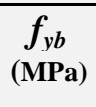 & $\begin{array}{l}\text { esp. } \\
(\mathbf{m m})\end{array}$ & config. \\
\hline PC1 & $350 \times 350$ & 20 & 75 & $8 \# 25 \mathrm{M}$ & $\# 10 \mathrm{M}$ & 400 & 40 & $\bar{A}$ \\
\hline PC2 & $350 \times 350$ & 20 & 75 & $8 \# 25 \mathrm{M}$ & $\# 10 \mathrm{M}$ & 600 & 60 & $\mathrm{~A}$ \\
\hline PC3 & $350 \times 350$ & 20 & 75 & $8 \# 25 \mathrm{M}$ & $\# 10 \mathrm{M}$ & 800 & 80 & $\mathrm{~A}$ \\
\hline PV13 & $200 \times 300$ & 14 & 72,5 & $4 \# 15 \mathrm{M}$ & $\# 8 \mathrm{M}$ & 401 & 100 & $\mathrm{~A}$ \\
\hline PV13A & $200 \times 300$ & 14 & 72,5 & $4 \# 15 \mathrm{M}$ & \#8M & 600 & 100 & $\mathrm{~A}$ \\
\hline PV13B & $200 \times 300$ & 14 & 72,5 & $4 \# 15 \mathrm{M}$ & $\# 8 \mathrm{M}$ & 800 & 100 & $\mathrm{~A}$ \\
\hline
\end{tabular}


Todos os elementos da série PC tinham taxa de armadura transversal $\rho_{t}=0,09$. Os elementos PV13, PV13A e PV13B apresentavam, respectivamente, as taxas de armadura $\rho_{t}=0,02, \rho_{t}=0,04$ e $\rho_{t}=0,06$, não atendendo às exigências do ACI 318-89 para sismo. Como mostrado na figura 4.4, o comportamento antes do momento máximo foi quase o mesmo para todos elementos da série PC. Após o ponto de momento máximo, os elementos com armadura transversal com menor resistência de plastificação, e por isso menor espaçamento dos estribos para se manter $\left(\rho_{t}=0,09\right)$, tiveram maior capacidade de resistir ao momento e à carga axial, comparados com aqueles com estribos com maior resistência de plastificação. Uma vez que todos elementos da série PV13 eram idênticos, exceto pela resistência à plastificação, eles tiveram comportamentos similares para momentos e cargas axiais antes do ponto de momento máximo.

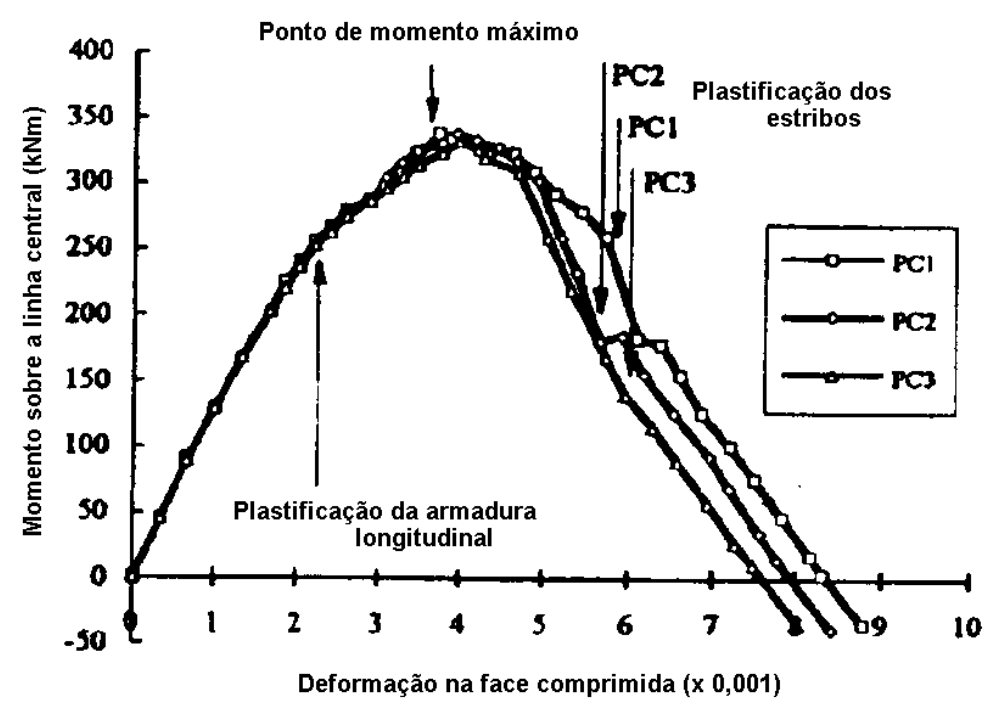

FIGURA 4.4 - Momento na linha central x deformação por compressão.

Como mostrado na figura 4.5, as diferenças tornaram-se significativas depois da plastificação dos estribos do elemento PV13. Como esperado a plastificação dos estribos foi retardada para os elementos que possuíam armadura com maior resistência a plastificação, os quais obtiveram maior capacidade de resistir aos momentos e aos carregamentos axiais. Entretanto, todos os elementos desse grupo tiveram um comportamento frágil, após o momento máximo, quando comparados com a série PC. Isso ocorreu, pois a quantidade de armadura transversal não foi 
suficiente e o colapso do pilar ocorreu antes que o estado de tensão triaxial fosse suficientemente desenvolvido. Isso sugere que a taxa de armadura mínima necessária para produzir um comportamento dúctil, após o momento máximo, é em torno de 0,09. O uso de estribos com alta tensão de plastificação tem sido proposto como meio de se manter o espaçamento utilizado na prática. Entretanto, a partir da análise das séries PC3 e PV13, pode-se concluir que o espaçamento é uma variável mais importante do que a resistência à plastificação do estribo.

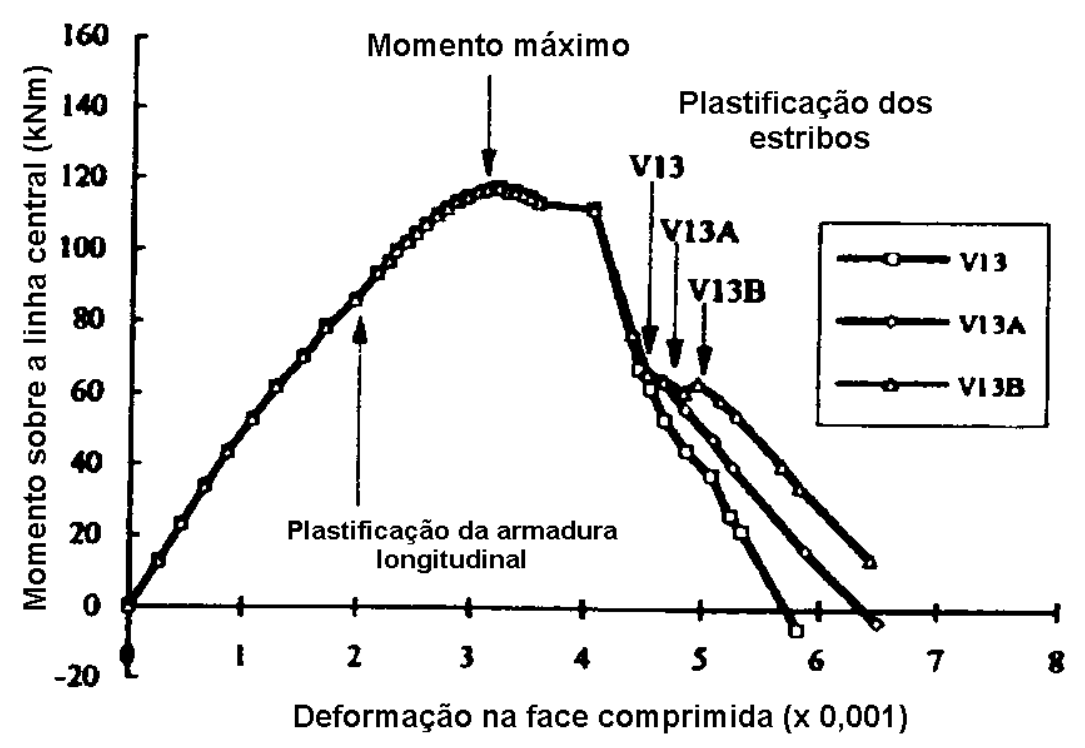

FIGURA 4.5 - Momento na linha central x deformação por compressão.

\subsubsection{Armadura longitudinal}

Segundo a Norma Norueguesa, o diâmetro mínimo da armadura longitudinal não deve ser menor do que 10 mm. Já o EUROCODE 2 (1992) e a Norma Inglesa BS 8110 definem 12 mm como diâmetro mínimo para a armadura longitudinal.

A taxa mínima de armadura longitudinal recomendada pela Norma Norueguesa não deve ser menor do que o maior dos seguintes valores:

- $0,01 A_{c}$ ou $0,2 \cdot \frac{A_{c} \cdot f_{c n}}{f_{s k}}$

$A_{c}$ - área de concreto

$f_{c n}$ - resistência (cúbica) do concreto à compressão na estrutura

$f_{s k}$ - resistência característica da armadura 
A Norma Inglesa recomenda como taxa mínima para armadura longitudinal 0,4\% da área da seção transversal e como taxa máxima $6 \%$ da área da seção transversal para pilares moldados no local, $8 \%$ para pilares moldados na horizontal e $10 \%$ para locais de emenda.

O EUROCODE 2 (1992) indica como quantidade mínima para armadura longitudinal o valor obtido com a seguinte expressão:

- $A_{s, \operatorname{mim}}=\frac{0,15 \cdot N_{s d}}{f_{y d}}$

$f_{y d}$ - resistência de cálculo de plastificação da armadura

$N_{s d}$ - força axial de compressão

Já como taxa máxima de armadura longitudinal, o EUROCODE 2 (1992) indica o valor de $0,08 \cdot A_{c}$, mesmo para as regiões de emenda.

Para os pilares com seção transversal em forma de poligonal, a armadura longitudinal deve ser distribuída ao redor do perímetro da seção, sendo colocada pelo menos uma barra em cada canto.

A armadura longitudinal é garantida contra flambagem lateral se estiver localizada, em um dos cantos de apoio do estribo ou se a barra estiver até uma distância de $152 \mathrm{~mm}$, conforme figura 4.6.

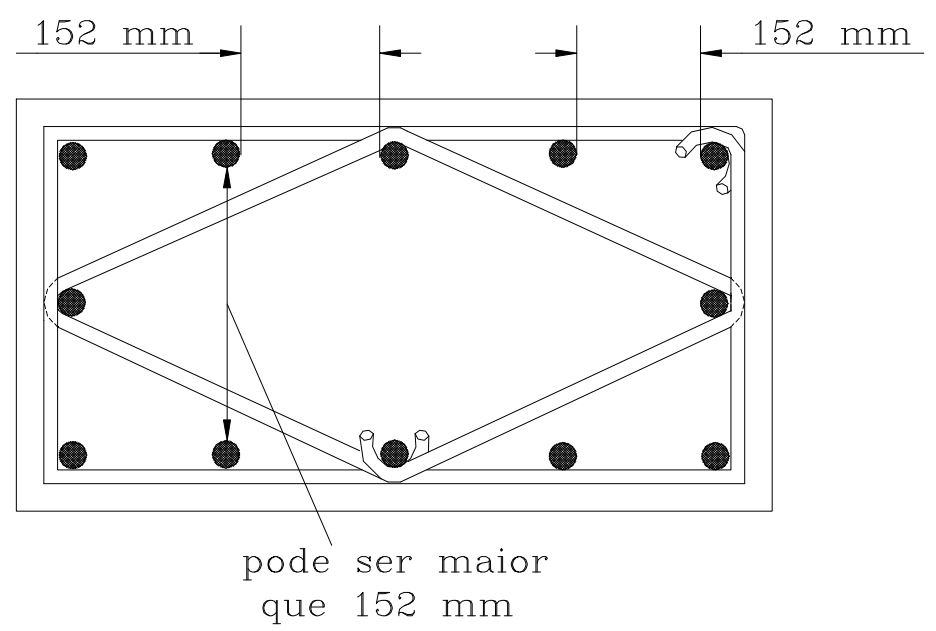

FIGURA 4.6 - Distância máxima permitida para armadura longitudinal sem contenção do estribo. 


\subsection{HIPÓTESES DE CÁLCULO}

Quando um pilar simétrico é submetido a uma carga axial (P), ocorrem deformações longitudinais uniformes $(\varepsilon)$ ao longo da seção, conforme figura 4.7.

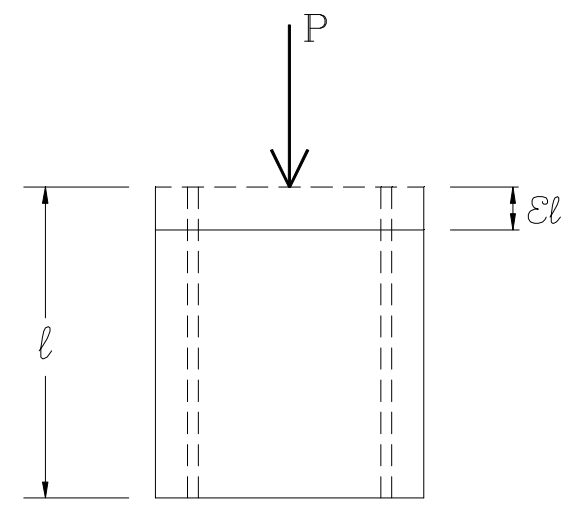

FIGURA 4.7 - Deformação no pilar.

A aderência existente entre a armadura e o concreto faz com que a deformação seja a mesma nestes dois materiais. Para qualquer deformação imposta, é possível computar as tensões no concreto e no aço usando as curvas tensãodeformação respectivas a esses dois materiais.

\subsubsection{Diagrama tensão versus deformação}

A curva tensão-deformação para o concreto de alto desempenho é diferente da curva tensão-deformação para o concreto de resistência normal. Ela apresenta uma maior linearidade na parte ascendente da curva, deformação ligeiramente maior para tensão máxima e a parte descendente da curva torna-se mais íngreme à medida que a resistência aumenta, conforme pode ser visto na figura 4.8 .

Recentemente, COLLINS et al. (1993) propuseram uma relação tensãodeformação para concretos submetidos à compressão que se aplica a todas as classes de concreto. Segundo essa relação, $\sigma_{c}$ é calculado da seguinte maneira:

$$
\sigma_{c}=k_{3} \cdot f_{c}^{\prime} \cdot \frac{\varepsilon_{c}}{\varepsilon_{c}^{\prime}} \cdot \frac{n}{n-1+\left(\varepsilon_{c} / \varepsilon_{c}^{\prime}\right)^{n k}}
$$




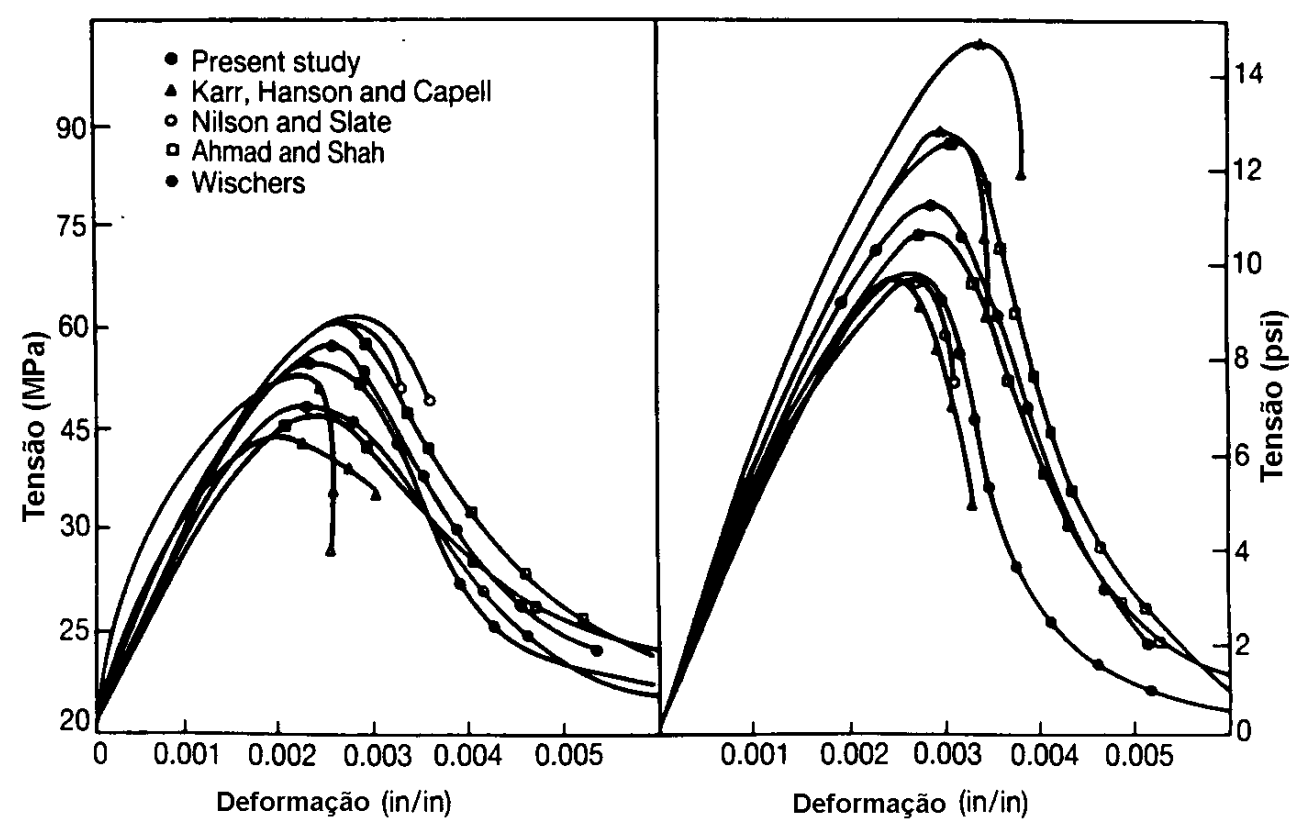

FIGURA 4.8 - Curvas tensão-deformação para concreto de alto desempenho sob compressão axial. FONTE: SHAH \& AHMAD (1994).

$\mathrm{O}$ fator $k_{3}$ de redução da resistência do concreto é dado por:

$$
k_{3}=0,6+\left(10 / f_{c}^{\prime}\right) \leq 0,85
$$

Na expressão (4.7) tem-se:

$$
\begin{aligned}
& n=0,8+\left(f_{c}^{\prime} / 17\right) \quad(\mathrm{MPa}) \\
& k=0,67+\left(f_{c}^{\prime} / 62\right) \quad(\mathrm{MPa}) \quad \text { quando } \varepsilon_{c} / \varepsilon_{c}^{\prime}>1 \\
& k=1 \quad \text { quando } \varepsilon_{c} / \varepsilon_{c}^{\prime} \leq 1 \\
& \varepsilon_{c}^{\prime}=\left(f_{c}^{\prime} / E_{c}\right) \cdot \frac{n}{n-1} \quad(\mathrm{MPa}) \\
& E_{c}=3320 \sqrt{f_{c}^{\prime}}+6900 \quad(\mathrm{MPa})
\end{aligned}
$$


Já o Código Modelo - MC90 (1991) do CEB-FIP apresenta o diagrama tensão-deformação para projeto indicado na figura (4.9), onde são feitas restrições com relação à deformação última, de acordo com a resistência à compressão do concreto. $\mathrm{O}$ coeficiente de 0,85 na expressão para o cálculo da tensão atuante no concreto é indicado para considerar os efeitos de carregamento de longa duração.

No trecho onde $\varepsilon_{c}<\varepsilon_{c l}$ tem-se:

$$
\begin{aligned}
& \sigma_{c d}=0,85 f_{c d} \cdot\left[2 \cdot\left(\frac{\varepsilon_{c}}{\varepsilon_{c 1}}\right)-\left(\frac{\varepsilon_{c}}{\varepsilon_{c 1}}\right)^{2}\right] \\
& \varepsilon_{c l}=0,002 \text { e } \varepsilon_{c u}=0,0035 \text { para } f_{c k} \quad 50 \mathrm{MPa} .
\end{aligned}
$$

Para $50 \mathrm{MPa}<f_{c k} \quad 80 \mathrm{MPa}$ tem-se:

$$
\varepsilon_{c u}=0,0035 \cdot\left(\frac{50}{f_{c k}}\right) \quad(\mathrm{MPa})
$$

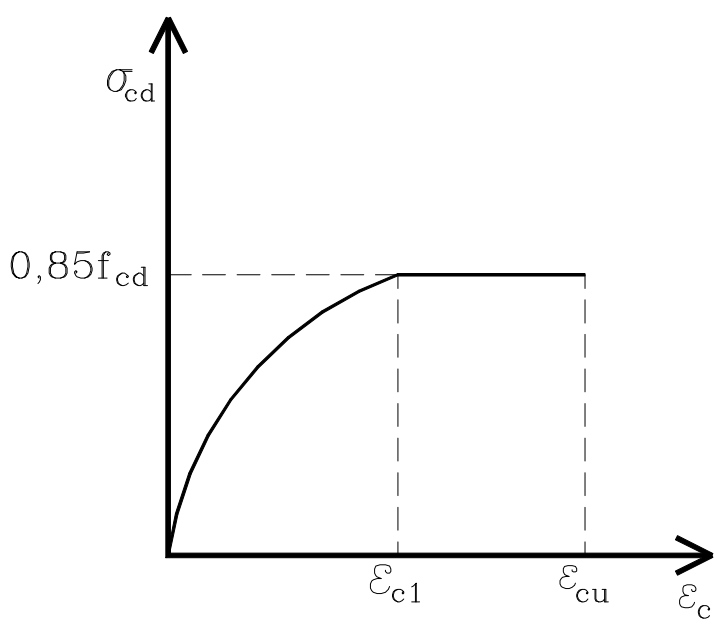

FIGURA 4.9 - Diagrama tensão-deformação. FONTE: LIMA, F. B. (1997).

\subsubsection{Capacidade de carga axial}

A capacidade de carga total em um pilar submetido a carregamento axial $\left(P_{0}\right)$ é dado pela soma das forças $P_{c}$ e $P_{s}$. 
As forças $P_{c}$ e $P_{s}$ no concreto e no aço são iguais à tensão multiplicada pela área correspondente.

$$
P_{s}=f_{y} \cdot A_{s} \quad, \quad P_{c}=f_{c}^{\prime \prime} \cdot A_{c} \quad, \quad \text { e } \quad f_{c}^{\prime \prime}=C \cdot f_{c}^{\prime}
$$

Baseado em ensaios, o ACI 318-89 define o valor de $C=0,85$. Assim para um pilar com armadura de plastificação bem definida, a capacidade de carga axial de um pilar é dada pela expressão (4.16).

$$
P_{0}=0,85 \cdot f_{c}^{\prime} \cdot\left(A_{g}-A_{s}\right)+f_{y} \cdot A_{s}
$$

$f^{\prime}{ }_{c}$ - resistência média do concreto à compressão (corpo-de-prova cilíndrico)

$f_{y}$ - resistência média de escoamento da armadura longitudinal

$A_{s}$ - soma das áreas das seções transversais das barras longitudinais

$A_{g}$ - área total da seção transversal do pilar

Através do estudo de pilares com armaduras de grande resistência à plastificação, submetidos a cargas máximas, o código do ACI 318-89 define a resistência de plastificação da armadura como a tensão obtida para uma deformação de 0,0035 .

Geralmente, a maioria dos elementos submetidos à compressão em uma estrutura de concreto estão submetidos a força normal e a momento fletor. Isso ocorre, pois a carga não é centrada no pilar ou devido a momentos fletores não balanceados, existentes nas extremidades das vigas, conforme figura 4.10.
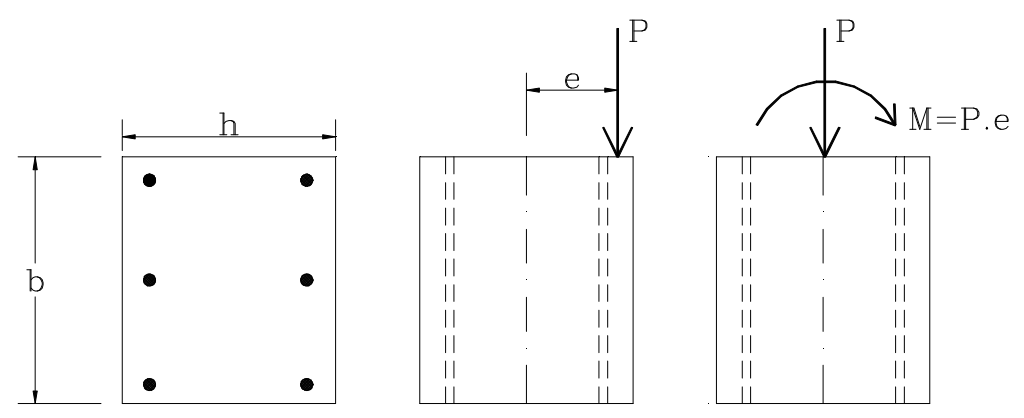

FIGURA 4.10 - Carga axial e momento fletor atuando na extremidade do pilar. 
Quando um pilar está submetido à ação de momentos fletores, a máxima carga axial que ele pode suportar é diminuída em função dos momentos, ou seja, o pilar pode suportar a máxima carga $\mathrm{P}_{0}$ quando o momento for igual a zero. A relação da capacidade de um pilar submetido a carga axial e a momento fletor fica melhor entendida através de um diagrama de interação.

Em um pilar idealizado homogêneo e elástico, com resistência à compressão $\left(f_{c u}\right)$ igual a resistência à tração $\left(f_{t u}\right)$, o colapso só iria ocorrer quando a tensão máxima $\left(f_{c u}\right)$ fosse alcançada. Esta tensão é dada por:

$$
f_{c u}=\frac{P}{A}+\frac{M \cdot y}{I}
$$

$$
\begin{aligned}
& A=\text { área da seção transversal } \\
& I=\text { momento de inércia } \\
& y=\text { distância do cg. até a fibra mais comprimida } \\
& P=\text { Carga axial (positiva na compressão) } \\
& M=\text { momento (positivo no sentido horário) }
\end{aligned}
$$

A máxima carga axial que um pilar pode suportar ocorre quando o momento atuante é igual a zero $(M=0)$, sendo dada por $P_{\text {max }}=f_{c u} \times A$. Similarmente, o máximo momento que o pilar pode suportar ocorre quando a carga axial é igual a zero $(P=0)$, sendo $M_{\max }=\frac{f_{c u} \times I}{y}$. Substituindo na expressão (4.17) tem-se:

$$
\frac{P}{P_{\max }}+\frac{M}{M_{\max }}=1
$$

Essa relação é conhecida como equação de interação, porque ela mostra a relação entre $P$ e $M$ no colapso. Na figura 4.11, tem-se o diagrama de iteração, o qual representa as combinações entre $P$ e $M$ que correspondem à resistência da seção. Um ponto dentro do diagrama, tal como o ponto $\mathrm{B}$, representa uma combinação de $P$ e $M$ que não causará colapso. Um ponto fora do diagrama, como o ponto A, irá exceder a resistência da seção e portanto causará o colapso. 


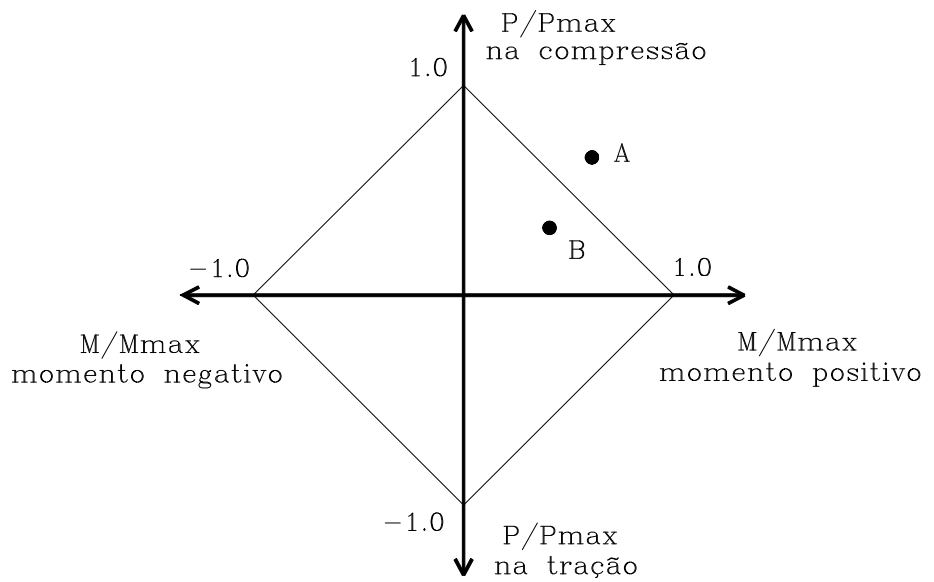

FIGURA 4.11 - Diagrama de interação para um pilar elástico $\left|f_{c u}\right|=\left|f_{\text {tu }}\right|$.

O concreto armado não é um material elástico e tem uma resistência à tração que é menor do que a resistência à compressão. O cálculo do diagrama de interação para o concreto armado é um pouco mais complexo do que o de um material elástico.

\subsubsection{Diagrama de interação para pilares de concreto}

O diagrama de interação é obtido computando-se os valores de $P$ e $M$, os quais correspondem a um ponto particular no diagrama de interação. Cada ponto é obtido assumindo-se uma determinada distribuição de deformações.

$\mathrm{Na}$ figura 4.12, está representado o processo de cálculo para uma particular distribuição de deformação. A máxima deformação na compressão é estabelecida como sendo 0,003 , correspondendo ao colapso da seção. A posição da linha neutra e a deformação em cada nível da armadura são computadas a partir da distribuição de deformações.
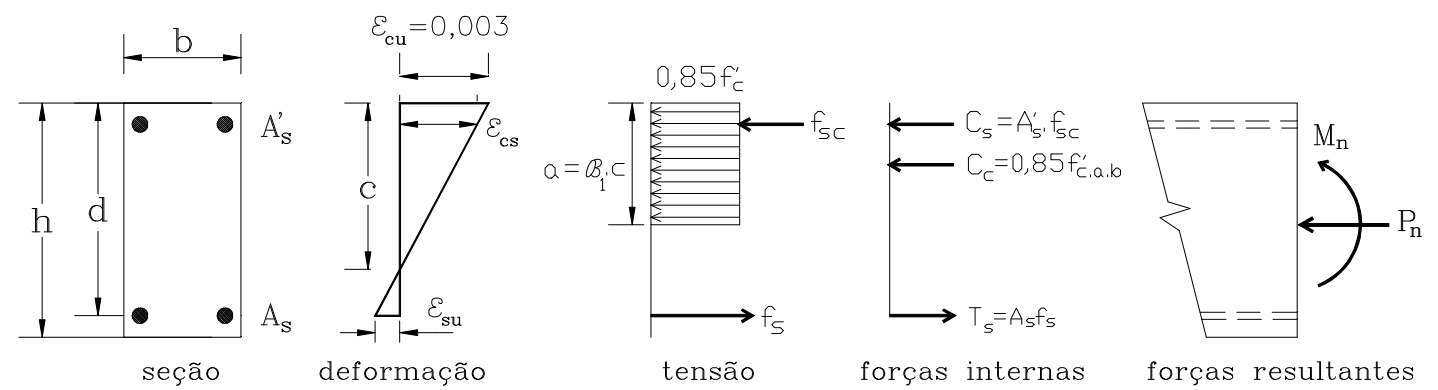

FIGURA 4.12 - $P_{n}$ e $M_{n}$ para uma dada distribuição de deformação. 
Os pontos importantes do diagrama de interação são os indicados na figura 4.13. O ponto A corresponde a uma distribuição de deformações onde se tem compressão axial. No ponto $\mathrm{B}$, tem-se esmagamento do concreto em uma face e tensão zero na outra. $\mathrm{O}$ ponto $\mathrm{C}$ representa o colapso balanceado, onde se tem uma deformação de compressão de 0,003 de um lado da seção e deformação de tração de $\left(\varepsilon_{\mathrm{y}}\right)$, correspondente à plastificação da armadura tracionada. $\mathrm{O}$ ponto $\mathrm{D}$ corresponde $\mathrm{a}$ uma distribuição de deformações onde a armadura tem uma deformação correspondente a várias vezes a deformação de plastificação, antes que o concreto alcance a deformação última. Isso implica em um comportamento dúctil, ao contrário do que ocorre no ponto $\mathrm{B}$, onde se tem um colapso frágil.

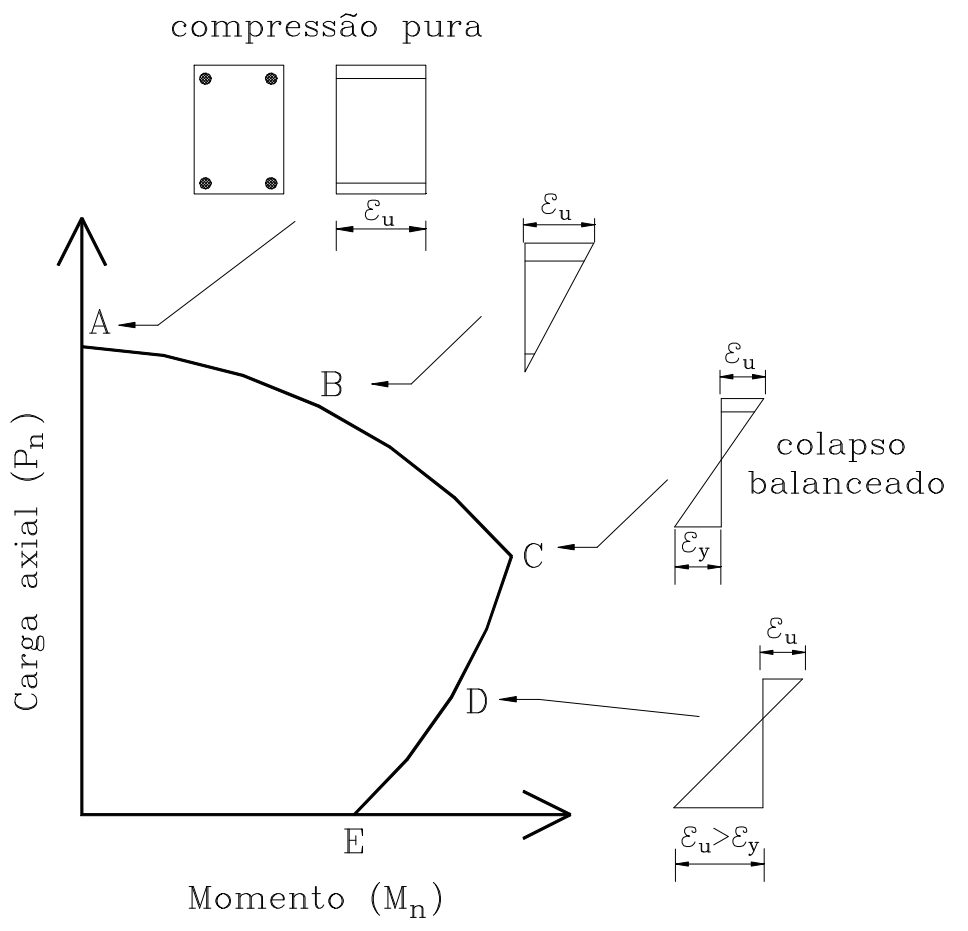

FIGURA 4.13 - Distribuição de deformações correspondentes a pontos do diagrama de interação.

Como comentado anteriormente, a resistência de um pilar sobre carregamento axial real é dado pela expressão (4.16). Entretanto, essa expressão não pode ser aplicada normalmente à estrutura, porque quase sempre tem-se momentos atuando. $\mathrm{E}$ como mostrado na figura 4.11, qualquer momento leva a uma redução na capacidade de carga axial. Os momentos ocorrem em função de momentos não balanceados nas vigas, desaprumo do pilar e mal posicionamento da armadura longitudinal. 
Para levar em conta o efeito de momentos acidentais, o ACI 318-89 (sec.10.3.5 e 10.3.6) especifica que a máxima carga em um pilar não pode exceder 0,85 vezes o valor obtido pela expressão (4.16), para pilares com armadura transversal em espiral, e 0,8 vezes para pilares com armadura transversal em estribos.

$$
\begin{aligned}
& \text { Para espiral: } \phi \cdot P_{(\max )}=0,85 \phi \cdot\left[0,85 f_{c}^{\prime}\left(A_{g}-A_{s}\right)+f_{y}\left(A_{s}\right)\right] \\
& \underline{\text { Para estribo: }} \phi \cdot P_{(\max )}=0,80 \phi \cdot\left[0,85 f_{c}^{\prime}\left(A_{g}-A_{s}\right)+f_{y}\left(A_{s}\right)\right]
\end{aligned}
$$

No projeto de pilares, a capacidade a carga axial e a momento devem satisfazer o seguinte:

$$
\phi P_{n} \geq P_{u} \quad \text { e } \quad \phi M_{n} \geq M_{u}
$$

$P_{u} e M_{u} \odot$ carga e momento fatorado aplicado ao pilar

$P_{n}$ e $M_{n}$ ○ resistência nominal da seção transversal do pilar

$\phi \boldsymbol{\oplus}$ fator de redução da resistência (é o mesmo nas duas relações)

O valor de $\phi$ é dado pelo ACI 318-89 (sec.9.3.2), sendo 0,7 para estribos e 0,75 para espiral, quando se têm altas cargas axiais, e varia até 0,9 quando se tem flexão pura. Para elementos nos quais $f_{y}$ não excede $414 \mathrm{MPa}$, com armadura simétrica, e com $\left(h-d^{\prime}-d_{s}\right) / h$ não menor do que 0,7 , o valor de $\phi$ pode ser aumentado linearmente até 0,90 à medida que $\phi \cdot P_{n}$ diminui de $0,1 \cdot f_{c}^{\prime} \cdot A_{g}$ até zero.

Tem-se, na figura 4.14, o procedimento de cálculo dos pontos do diagrama de interação $\left(P_{n}\right.$ e $\left.M_{n}\right)$.

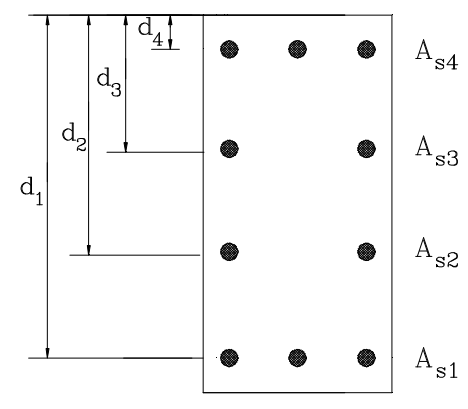

seção

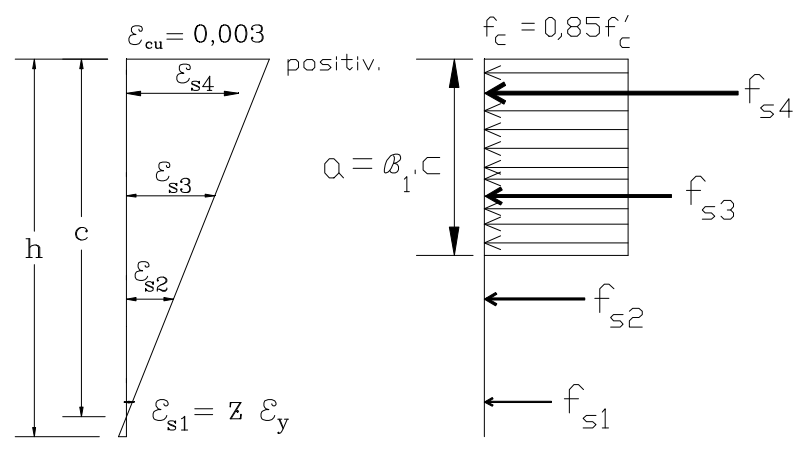

deformação tensão (todas positivas)

FIGURA 4.14 - Notação e convenção de sinais. 
Deve-se calcular $P_{n}$ e $M_{n}$ em relação ao centróide de uma dada distribuição de deformações, $\operatorname{com} \varepsilon_{c u}=0,003$. A distribuição de deformações será definida através de $\varepsilon_{s 1}=$ Z. $\varepsilon_{y}$ e $\varepsilon_{c u}=0,003$, como mostrado na figura 4.14. Cada distribuição de deformações considerada corresponderá a diferentes valores arbitrários escolhidos de $(Z)$, onde valores positivos de $(Z)$ correspondem a deformações positivas (compressão). O colapso balanceado ocorre para $(Z=-1)$.

Através de semelhança de triângulos têm-se:

$$
\begin{aligned}
& c=\left(\frac{0,003}{0,003-Z \cdot \varepsilon_{y}}\right) \cdot d_{1} \\
& \varepsilon_{s i}=\left(\frac{c-d_{i}}{c}\right) \cdot 0,003
\end{aligned}
$$

- $\varepsilon_{s i} \bigcup$ são as deformações em cada camada de armadura

- $d_{i} \bigcup$ distância da mesma até a fibra mais comprimida

Dessa forma, pode-se calcular os valores de $(c),\left(\varepsilon_{1}\right),\left(\varepsilon_{2}\right)$ e assim por diante.

Para uma armadura elastoplástica tem-se $f_{s i}=\varepsilon_{s i} E_{s}$ mas $-f_{y} f_{s i} f_{y}$.

As tensões no concreto são representadas pelo diagrama retangular de tensão. A altura do diagrama é dada por $a=\beta_{1} \times c$. O valor de $\beta_{1}$ é dado em função da resistência do concreto à compressão.

$$
\beta_{1}=\left\{\begin{array}{l}
0,85 \Rightarrow \operatorname{para} f_{c}^{\prime} \leq 28 \mathrm{MPa} \\
1,05-0,05 \cdot\left(\frac{f_{c}^{\prime}}{1.000 p s i}\right) \Rightarrow \text { para } 28<f_{c}^{\prime}<55 \mathrm{MPa} \\
0,65 \Rightarrow \operatorname{para} f_{c}^{\prime}>55 \mathrm{MPa}
\end{array}\right.
$$

A seguir computam-se a força de compressão no concreto $\left(C_{c}\right)$ e as forças em cada camada das armaduras $F_{s 1}, F_{s 2}$ e assim por diante. Isto é feito multiplicando-se a tensão pela área correspondente.

$$
C_{c}=\left(0,85 f_{c}^{\prime}\right) \cdot(a b)
$$


Para o cálculo das forças nas armaduras, deve-se verificar se (a) é maior ou menor que $\left(d_{i}\right)$.

Se for menor que $\left(d_{i}\right)$ então:

$$
F_{s i}=f_{s i} \cdot A_{s i}
$$

Se (a) for maior que $\left(d_{i}\right)$ então a área da armadura daquela camada já foi incluída no cálculo de $\left(C_{c}\right)$, sendo portanto necessário subtrair $0,85 \cdot f_{c}^{\prime}$ de $f_{s i}$ antes de computar $F_{s i}$.

$$
F_{s i}=\left(f_{s i}-0,85 f_{c}^{\prime}\right) \cdot A_{s i}
$$

As forças resultantes $C_{c}$ e $F_{s l}$ a $F_{s 4}$ estão indicadas na figura 4.15.

A capacidade de carga axial $P_{n}$, para a distribuição de tensão assumida, é dada pela seguinte expressão:

$$
P_{n}=C_{c}+\sum_{i=1}^{n} F_{s i}
$$

A capacidade resistente a momento $M_{n}$, para a distribuição de deformação assumida, é feita computando-se os momentos de todas as forças internas.

$$
M_{n}=C_{c} \cdot\left(\frac{h}{2}-\frac{a}{2}\right)+\sum_{i=1}^{n} F_{s i} \cdot\left(\frac{h}{2}-d_{i}\right)
$$

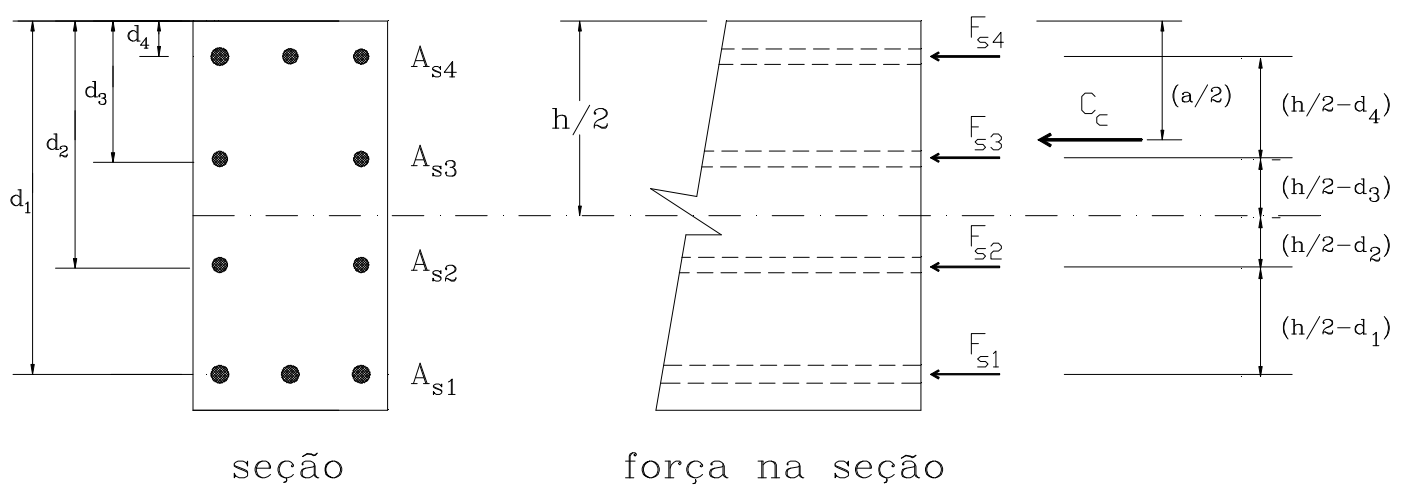

FIGURA 4.15 - Forças internas e distâncias para os momentos. 
Para pilares com estribos, o valor de $\phi$ aumenta linearmente de 0,7 a 0,9 , à medida que a capacidade de carga axial $P_{n}$ diminui de $P_{a}$ até zero, onde $P_{a}$ é igual ao menor dos seguintes valores: $P_{b}$ ou $\left(\frac{0,10}{0,70}\right) \cdot f_{c}^{\prime} \cdot A_{g}=0,143 f_{c}^{\prime} \cdot A_{g}$.

$$
\begin{aligned}
& \text { Se } P_{n} \quad P_{a} \text { ○ } \phi=0,7 \\
& \text { Se } P_{n}<P_{a} \text { ○ } \phi=0,9-\frac{0,2 P_{n}}{P_{a}}
\end{aligned}
$$

\subsection{DIMENSIONAMENTO SEGUNDO O ACI 318-89}

Tem-se a seguir os procedimentos indicados pelo ACI 318-89 (sec.10.11) para cálculo de pilares esbeltos. O método indicado pelo ACI 318-89 consiste na majoração do momento. Quando aplicado ao pilar de um pórtico, o pilar é isolado e substituído por um pilar articulado de comprimento equivalente $\left(k \ell_{u}\right)$ e carregado com carga axial e momentos de primeira ordem que estão atuando na extremidade do pilar real. Define-se $(k)$ como o fator de comprimento efetivo de elementos comprimidos, o qual será explicado com mais detalhes no item 4.5.2.

\subsubsection{Estimativa das dimensões}

O estágio inicial do dimensionamento de um pilar consiste na estimativa das dimensões exigidas. Não existe uma regra simples para se fazer isso, uma vez que a capacidade de carga axial de uma dada seção transversal varia dependendo do momento que está atuando na mesma.

Pode-se utilizar a expressão (4.31), para estimativa da seção do pilar, adotando-se uma taxa de armadura longitudinal $\left(\rho_{\ell}\right)$ variando no intervalo econômico de $1 \%$ a $2 \%$.

$$
A_{g} \geq \frac{P_{u}}{0,45 \cdot\left(f_{c}^{\prime}+f_{y} \cdot \rho_{\ell}\right)}
$$

$$
\begin{aligned}
& A_{g}=\text { área bruta da seção transversal } \\
& P_{u}=\text { esforço de compressão axial majorado }
\end{aligned}
$$




$$
\begin{aligned}
& f_{c}^{\prime}=\text { resistência especificada do concreto à compressão } \\
& f_{y}=\text { resistência de plastificação da armadura } \\
& \rho_{\ell}=\frac{A_{s t}}{A_{g}} \text { (taxa de armadura longitudinal) }
\end{aligned}
$$

Essa expressão tende a subestimar as dimensões do pilar se existirem grandes momentos atuando.

\subsubsection{Verificação da esbeltez do pilar}

A seguir deve-se verificar se o pilar é esbelto ou não. O ACI 318-89 (sec.10.11.4.1) define o seguinte limite para esbeltez de um pilar em uma estrutura contraventada:

$$
\frac{k \ell_{u}}{r} \leq 34-12 \cdot \frac{M_{1 b}}{M_{2 b}}
$$

O ACI 318-89 (sec.10.11.4.2) define o seguinte limite para esbeltez de um pilar em uma estrutura não contraventada.

$$
\frac{k \ell_{u}}{r} \leq 22
$$

A seção (10.11.2) do ACI 318-89 sugere que um pavimento pode ser considerado contraventado se:

$$
Q=\frac{\sum P_{u} \cdot \Delta_{u}}{V_{u} \cdot \ell_{c}} \leq 0,04
$$

$\sum P_{u}=$ carga total de todos os pilares de um andar

$V_{u}=$ é a cortante naquele andar devida a cargas laterais

$\Delta_{\mathrm{u}}=$ é o deslocamento de $1^{\mathrm{a}}$ ordem do topo do andar relativo à parte inferior do andar

Uma estrutura não contraventada depende dos momentos resultantes dos pilares, para resistir a cargas e deslocamentos laterais. Nas estruturas não contraventadas, não é possível considerar os pilares independentemente.

Nas expressões (4.32) e (4.33) tem-se:

$\ell_{\mathrm{u}}=$ vão livre do elemento submetido à compressão, podendo ser a distância de viga a viga, laje a laje ou ainda viga a laje.

$r=$ raio de giração. Para seção retangular $(r=0,3 h)$. 
O valor de $(k)$ para um pilar elástico é função da rigidez relativa $(\psi)$ das vigas e dos pilares, para cada extremidade do pilar. $\mathrm{O}$ valor de $(\psi)$ é dado por:

$$
\psi=\frac{\sum\left(E_{c} \cdot I_{c} / \ell_{c}\right)}{\sum\left(E_{b} \cdot I_{b} / \ell_{b}\right)}=\frac{\sum k_{c}}{\sum k_{b}}
$$

O índice $(c)$ é relativo aos pilares e o índice $(b)$ às vigas.

Se o valor de $(\psi)$ for igual a zero em uma extremidade do pilar, o pilar é considerado completamente engastado nessa extremidade. Similarmente, se o valor de $(\psi)$ tende ao infinito, o pilar é considerado perfeitamente rotulado nessa extremidade.

Assim, à medida que $(\psi)$ se aproxima de zero nas duas extremidades de um pilar, em uma estrutura contraventada, $(k)$ se aproxima de 0,5, o valor para extremidade engastada de pilar. Quando $(\psi)$ se aproxima do infinito nas duas extremidades de um pilar, em uma estrutura contraventada, $(k)$ se aproxima de 1 , o valor para um pilar biarticulado. Isto é ilustrado na tabela 4.5.

$\mathrm{Na}$ prática, não ocorre nem uma coisa e nem outra nas estruturas reais, ou seja, não há pilar completamente engastado e nem perfeitamente rotulado. Segundo o ACI 318-89, o valor de $(k)$ para pilares em estruturas contraventadas não deve ser tomado menor que 0,6 e no caso de estruturas deslocáveis não deve nunca ser tomado menor que 1,2 .

O valor de $(k)$ pode ser calculado utilizando-se ábacos como a da figura 4.16. Para utilizar esse tipo de ábaco, $(\psi)$ é calculado nas duas extremidades do pilar, usando-se a expressão (4.35) e o valor apropriado de ( $k$ ) é encontrado ligando-se os pontos, entre o valor de $\psi$ (no topo) e $\psi$ (na base).

\subsubsection{Verificação dos momentos mínimos}

O ACI 318-89 (sec.10.11.5.4) estabelece que se deve fazer uma verificação dos momentos mínimos, no caso dos momentos fatorados serem pequenos ou próximos de zero. Isto é feito considerando-se uma excentricidade mínima, no projeto de pilares esbeltos, conforme indicado a seguir. 
TABELA 4.5 - Coeficiente de comprimento efetivo para estruturas contraventadas.

\begin{tabular}{|c|c|c|c|c|c|}
\hline TOPO & \multicolumn{5}{|c|}{$\mathbf{k}$} \\
\hline articulado & 0,70 & 0,81 & 0,91 & 0,95 & 1,00 \\
\hline $\begin{array}{l}\text { elástico } \\
(\psi=3,1) \\
\qquad \begin{array}{l}\mid \\
\end{array}\end{array}$ & 0,67 & 0,77 & 0,86 & 0,90 & 0,95 \\
\hline $\begin{array}{l}\text { elástico } \\
(\psi=1,6)\end{array}$ & 0,65 & 0,74 & 0,83 & 0,86 & 0,91 \\
\hline $\begin{array}{c}\text { semi-rígido } \\
=-\end{array}$ & 0,58 & 0,67 & 0,74 & 0,77 & 0,81 \\
\hline engastado & 0,50 & 0,58 & 0,65 & 0,67 & 0,70 \\
\hline & $\begin{array}{l}\text { engastado } \\
\qquad W \mid W\end{array}$ & semi-rígido & $\begin{array}{l}\text { elástico } \\
(\psi=1,6) \\
\qquad \mid\end{array}$ & $\begin{array}{l}\text { elástico } \\
(\psi=3,1) \\
+\left.\right|^{\mid}\end{array}$ & $\stackrel{\text { articulado }}{\text { anw }}$ \\
\hline & & $\mathbf{P}$ & E INFE & & \\
\hline
\end{tabular}

FONTE: MAcGREGOR, J. G. (1988).

a) Se o cálculo indicar que não há momento nas duas extremidades de um elemento comprimido contraventado ou que a excentricidade computada é menor que $(0,6+0,03 \mathrm{~h})$ in, o valor de $M_{2 b}$ na expressão (4.36) deve ser baseado em uma excentricidade mínima de $(0,6+0,03 \mathrm{~h})$ in. A razão $\left(M_{1 b} / M_{2 b}\right)$ na expressão (4.39) deve ser determinado da seguinte maneira:

- Quando as excentricidades calculadas nas extremidades forem menores que $(0,6+0,03 \mathrm{~h})$ in, os valores calculados de momentos devem ser utilizados para cálculo de $M_{1 b} / M_{2 b}$ na expressão (4.39).

- Se o cálculo indicar que não há momento atuando nas duas extremidades, $M_{1 b} / M_{2 b}$ deve ser tomado igual a 1 . 
b) Se o cálculo indicar que não existem momentos atuando nas duas extremidades, do elemento comprimido não contraventado, ou que as excentricidades calculadas forem menores que $(0,6+0,03 \mathrm{~h}) \mathrm{in}, M_{2 s}$ na expressão (4.36) deve ser baseado na excentricidade mínima de $(0,6+0,03 h)$ in

\subsubsection{Carga axial e momento majorados}

O ACI 318-89 indica na seção (10.11.5.1) que os pilares devem ser projetados utilizando-se a carga axial majorada $\left(P_{u}\right)$, da análise convencional de pórticos, e o momento majorado através da expressão:

$$
\begin{aligned}
& M_{c}=\delta_{b} \cdot M_{2 b}+\delta_{\mathrm{s}} \cdot M_{2 s} \\
& \delta_{\mathrm{b}}=\frac{C_{m}}{1-\frac{P_{u}}{\phi \cdot P_{c}}} \geq 1,0 \quad \text { (ACI eq. 10.7) } \\
& \delta_{\mathrm{s}}=\frac{1}{1-\frac{\sum P u}{\phi \cdot \sum P_{c}}} \geq 1,0 \quad \text { (ACI eq. 10.8) }
\end{aligned}
$$

Obs: $\phi=0,7$ para pilares armados com estribos.

Para estruturas contraventadas, o ACI 318-89 (sec.10.11.5.1) fornece $\delta_{s}=1$.

Para elementos contraventados, impedidos de se deslocarem e sem esforços transversais entre os suportes, $\left(C_{m}\right)$ deve ser tomado como:

$$
C_{m}=0,6+0,4 \cdot \frac{M_{1 b}}{M_{2 b}} \geq 0,4 \quad \text { (ACI eq. 10-12) }
$$

Para todos os outros casos, $C_{m}$ deve ser tomado igual a 1. Na expressão (4.39), $M_{1 b}$ e $M_{2 b}$ são os momentos calculados utilizando-se análise elástica de $1^{\mathrm{a}}$ ordem, sendo $M_{1 b}$ o menor valor de momento e $M_{2 b}$ o maior valor. A convenção de sinal para a razão $M_{1 b} / M_{2 b}$ é indicada na figura 4.17 . 


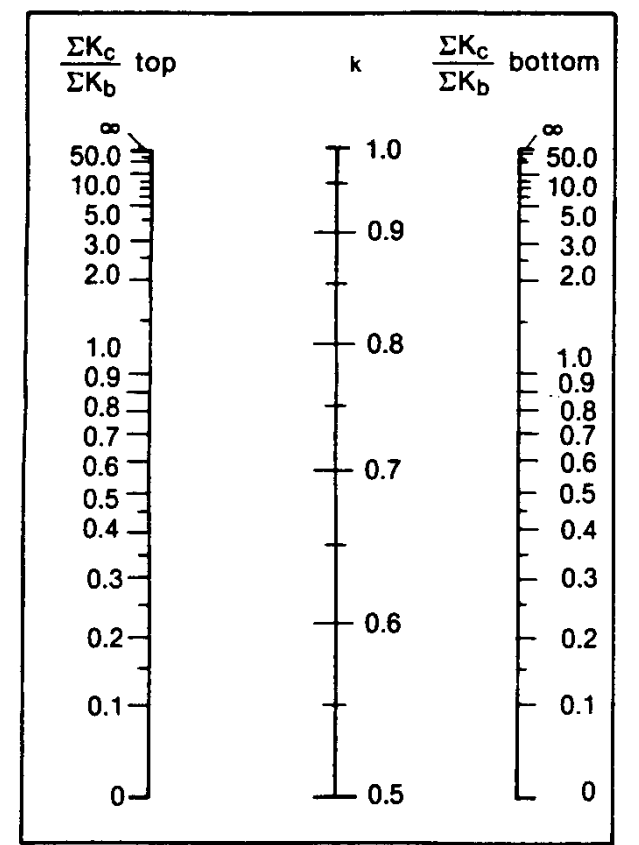

Estrutura contraventada

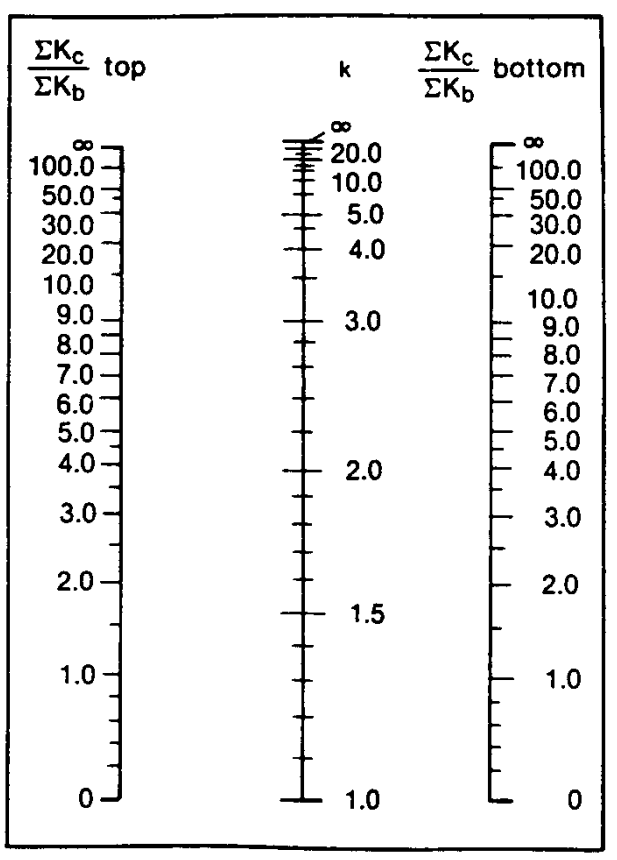

Estrutura não contraventada

FIGURA 4.16 - Ábaco para determinação do coeficiente de comprimento efetivo. FONTE: MacGREGOR, J. G. (1988).

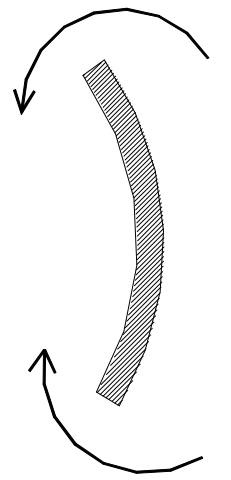

simples curvatura do pilar $0<\mathrm{M} 1 \mathrm{~b} / \mathrm{M} 2 \mathrm{~b}<1$

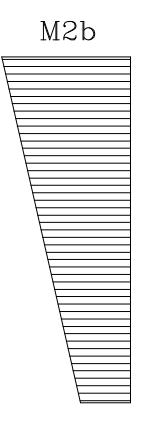

$\mathrm{M} 1 \mathrm{~b}$
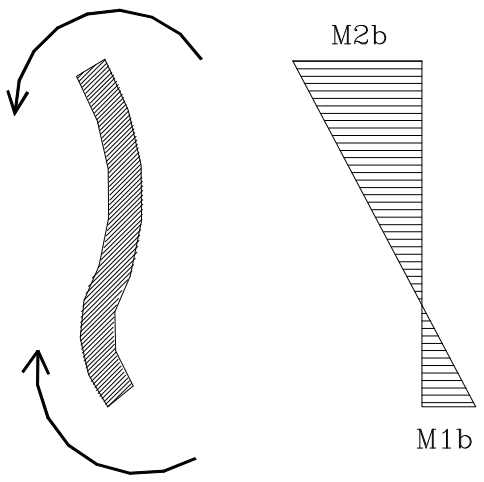

dupla curvatura do pilar $-1<\mathrm{M} 1 \mathrm{~b} / \mathrm{M} 2 \mathrm{~b}<0$

FIGURA 4.17 - Convenção de sinal para o momento.

$$
\begin{aligned}
& P_{c}=\frac{\pi^{2} \cdot E I}{\left(k \ell_{u}\right)^{2}} \\
& E I=\frac{\left(E_{c} \cdot I_{g}\right) / 2,5}{1+\beta_{d}}
\end{aligned}
$$




$$
\begin{aligned}
& E_{c}=3.320 \sqrt{f_{c}^{\prime}}+6.900 \mathrm{MPa} \\
& \beta_{\mathrm{d}}=\frac{\mid M_{2} \text { devido carg. perm. fatorada } \mid}{\mid M_{2} \text { total fatorado } \mid}
\end{aligned}
$$

Se $P_{u}$ excede $\phi \cdot P_{c}$ na expressão (4.37), ou $\sum P_{u}$ excede $\phi \cdot \sum P_{c}$ na expressão (4.38), $\delta_{b}$ ou $\delta_{s}$ serão negativos. Tal pilar ou pavimento será instável. Logo se $\delta_{b}$ ou $\delta_{s}$ for encontrado negativo, o pilar deve ser alargado. Se tanto $\delta_{b}$ ou $\delta_{s}$ excederem 2,0, deve-se providenciar um grande aumento para as seções dos pilares.

\subsubsection{Momento atuando em duas direções}

Um dos procedimentos recomendados pelo ACI 318-89, para o cálculo de pilares retangulares submetidos a momentos em duas direções $(x$ e $y)$, consiste em substituir as excentricidades $\left(e_{x}\right)$ e $\left(e_{y}\right)$ por uma excentricidade equivalente $\left(e_{o x}\right)$, sendo dessa maneira o pilar projetado para um momento em uma única direção, além da força normal atuante.

Define-se $\left(e_{x}\right)$ como a excentricidade paralela o eixo $(x)$ e $\left(e_{y}\right)$ a excentricidade paralela ao eixo (y), conforme figura 4.18. Dessa forma, o pilar pode ser projetado para $\left(P_{u}\right)$ e o momento majorado $M_{o y}=P_{u} \cdot e_{o x}$, onde:

$$
e_{o x}=e_{x}+\frac{\alpha \cdot e_{y}}{y} \cdot x
$$

O coeficiente $\alpha$ é dado através das seguintes expressões:

- $\frac{P_{u}}{f_{c}^{\prime} \cdot A_{g}} \leq 0,4 \Rightarrow \alpha=\left(0,5+\frac{p_{u}}{f_{c}^{\prime} \cdot A_{g}}\right) \cdot \frac{f_{y}+40000}{100000} \geq 0,6 \quad$ (psi)

- $\frac{P_{u}}{f_{c}^{\prime} \cdot A_{g}}>0,4 \Rightarrow \alpha=\left(1,3-\frac{p_{u}}{f_{c}^{\prime} \cdot A_{g}}\right) \cdot \frac{f_{y}+40000}{100000} \geq 0,5$ (psi)

Caso $\frac{e_{y}}{y} \geq \frac{e_{x}}{x}$, o pilar deve ser projetado para $\left(P_{u}\right)$ e o momento majorado

$$
M_{o x}=P_{u} \cdot e_{o y}, \text { sendo: } e_{o y}=e_{y}+\frac{\alpha \cdot e_{x}}{x} \cdot y
$$




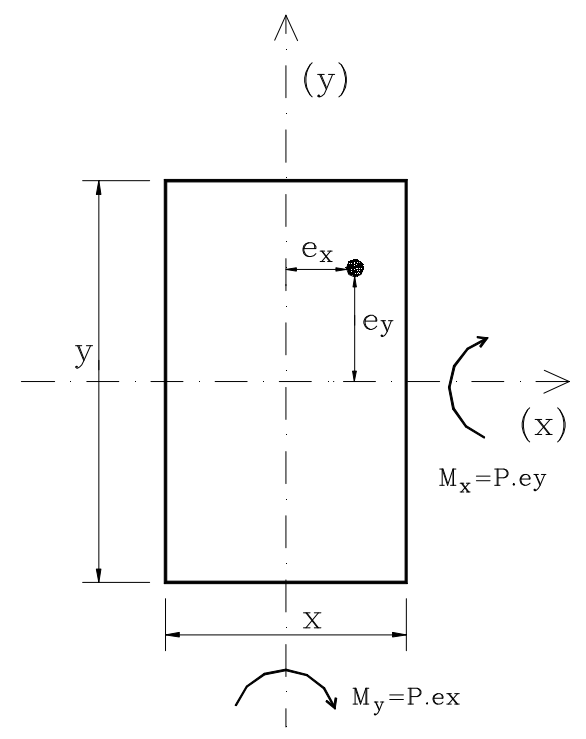

FIGURA - 4.18 - Seção transversal com momentos em duas direções

Esse procedimento é limitado a pilares que são simétricos com relação aos 2 eixos e com relação entre os lados $\frac{x}{y}$ entre 0,5 e 2,0. A armadura deve estar distribuída ao longo das quatro faces.

\subsection{DIMENSIONAMENTO SEGUNDO A NORMA INGLESA BS 8110}

Para o dimensionamento de pilares, uma das primeiras exigências consiste na definição do tipo de pilar. O item 3.8.1.5 da BS 8110 classifica os pilares da seguinte maneira:

- Contraventado - Um pilar é considerado contraventado em um dado plano, se a estabilidade lateral da estrutura como um todo é garantida por paredes ou elementos de contraventamento, projetados para resistir todas as forças laterais naquele plano.

- Não contraventado - Um pilar é considerado não contraventado em um dado plano, se a estabilidade lateral naquele plano é garantida através do pilar. 


\subsubsection{Altura efetiva do pilar}

Outro item importante relacionado ao comportamento do pilar consiste na "altura efetiva" ou "comprimento efetivo" $\left(\ell_{\mathrm{e}}\right)$, onde $\left(\ell_{\mathrm{e}}\right)$ está relacionado com a carga crítica elástica de flambagem $\left(N_{c r}\right)$, a qual é calculada com a expressão (4.47).

$$
N_{c r}=\frac{\pi^{2} \times E I}{\ell_{e}^{2}}
$$

Sendo $E I$ a rigidez a flexão no plano de flambagem.

A razão $\frac{\ell_{e}}{\ell_{0}}$, ou seja, a altura efetiva dividida pela altura livre do pilar, depende das condições de viculação existentes nas extremidades dos pilares. Para um pilar contraventado e impedido de girar nas extremidades, tem-se teoricamente que a razão $\frac{\ell_{e}}{\ell_{0}}$ é igual a 0,5 . Se o pilar for articulado nas duas extremidades, assume-se que a razão $\frac{\ell_{e}}{\ell_{0}}$ é igual a 1 . Entretanto, esses valores são idealizados, não sendo obtidos na prática, pois é sabido que dificilmente tem-se um engaste perfeito. Em uma estrutura real, a razão $\frac{\ell_{e}}{\ell_{0}}$ vai depender da rigidez dos pilares em relação à rigidez das vigas, sendo que para a vinculação de "engaste" o valor se aproxima de 0,75 a 0,5 .

Para prática de projeto, a Norma Inglesa BS 8110 (sec. 3.8.1.6) indica que o comprimento efetivo de um pilar pode ser calculado a partir da expressão (4.48).

$$
\ell_{e}=\beta \cdot \ell_{0}
$$

- $\ell_{0} \bigcup$ distância livre até as vinculações (laje-laje, laje-viga, viga-viga)

- $\beta \boldsymbol{U}$ é dado pelas tabelas 4.6 e 4.7 .

TABELA 4.6 - Valores de $\beta$ para pilares contraventados segundo BS 8110 (1985).

\begin{tabular}{|c|c|c|c||}
\hline \multirow{2}{*}{ Cond. de vinc. (topo) } & \multicolumn{3}{|c||}{ Condição de vinculação (base) } \\
\cline { 2 - 4 } & Engastado $^{(\mathbf{1})}$ & Parcialmente engastado $_{(\mathbf{2})}$ & Articulado $^{(3)}$ \\
\hline Engastado & 0,75 & 0,80 & 0,90 \\
\hline Parcialm. engast. & 0,80 & 0,85 & 0,95 \\
\hline Articulado & 0,90 & 0,95 & 1,00 \\
\hline
\end{tabular}


TABELA 4.7 - Valores de $\beta$ para pilares não contraventados segundo BS 8110 (1955).

\begin{tabular}{||c|c|c|c||}
\hline \multirow{2}{*}{ Cond. de vinc. (topo) } & \multicolumn{3}{|c||}{ Condição de vinculação (base) } \\
\cline { 2 - 4 } & Engastado $^{(\mathbf{1})}$ & Parcialmente engastado $_{\text {(2) }}$ & Articulado $^{(\mathbf{3})}$ \\
\hline Engastado & 1,2 & 1,3 & 1,6 \\
\hline Parcialm. engast. & 1,3 & 1,5 & 1,8 \\
\hline Articulado & 1,6 & 1,8 & --- \\
\hline
\end{tabular}

(1) O pilar é conectado monoliticamente de cada lado com as vigas, as quais apresentam altura igual à espessura do pilar no plano considerado. Quando o pilar é ligado a uma estrutura de fundação, esta deve ser projetada para resistir a momento.

(2) O pilar é conectado a vigas e lajes de cada lado, as quais possuem altura menor do que a espessura do pilar no plano considerado.

(3) O pilar é conectado a elementos os quais, embora não projetados para impedir a rotação do pilar, acabam fornecendo uma certa restrição nominal.

\subsubsection{Limite de esbeltez}

Um pilar é considerado pouco esbelto quando ambas as razões $\frac{\ell_{e x}}{h} \mathrm{e} \frac{\ell_{e y}}{b}$ são menores do que 15 (para pilar contraventado) e 10 (para pilar não contraventado). O pilar é classificado como esbelto quando alguma das razões descritas anteriormente for maior do que 15 (para pilar contraventado) e 10 (para pilar não contraventado). Nessas definições, ( $h$ ) é a dimensão da seção transversal do pilar no plano de flexão, quando a flexão ocorre sobre o eixo de maior inércia, com o comprimento efetivo $\left(\ell_{\mathrm{ex}}\right)$. As dimensões $(b)$ e $\left(\ell_{e y}\right)$ referem-se ao eixo de menor inércia. Segundo a (sec. 3.8.1.7) da BS 8110, para qualquer pilar, contraventado ou não contraventado, a distância livre $\left(\ell_{0}\right)$ não deve exceder 60 vezes a espessura do pilar.

No caso de pilares não contraventados, pode-se dispensar a verificação de deslocamento quando a média de $\frac{\ell_{e}}{h}$ (sendo $h$ a dimensão no plano de flexão), considerando-se todos os pilares de um determinado nível, não for maior do que 30 . 


\subsubsection{Momento mínimo}

A Norma Inglesa BS 8110 (sec. 3.8.2.3) indica que é necessário considerar que a carga está atuando com uma excentricidade mínima, mesmo para os casos onde se considera apenas a carga axial, dizendo ainda que as seções transversais dos pilares não devem ser calculadas para resistirem a ação de momentos inferiores aos momentos produzidos pela carga axial última multiplicada pela excentricidade mínima. O valor da excentricidade mínima deve ser tomado como 0,05 vezes a dimensão total do pilar no plano de flexão considerado, mas não mais do que $20 \mathrm{~mm}$.

\subsubsection{Pilares esbeltos}

No dimensionamento de pilares esbeltos deve-se levar em consideração os momentos adicionais provocados pelo deslocamento lateral do pilar carregado. $\mathrm{O}$ comportamento e os momentos de projeto de pilares contraventados e não contraventados são diferentes e devem ser tratados separadamente, porém o cálculo do momento adicional é comum a ambos. A expressão (4.49) é indicada para o cálculo do momento adicional.

$$
M_{a d d}=N \cdot a_{u}
$$

- $\quad \boldsymbol{U}$ (U) carga axial última atuando no pilar

- $\boldsymbol{a}_{\boldsymbol{u}} \boldsymbol{U}$ é o deslocamento tomado como: $\beta_{a} \cdot K \cdot h$

- $\beta_{a}=\frac{1}{2000} \cdot\left(\frac{\ell_{e}}{b^{\prime}}\right)^{2}$

- $b^{\prime} \boldsymbol{U}$ é a menor dimensão do pilar

Alguns valores de $\beta_{a}$ podem ser obtidos a partir da tabela 4.8.

TABELA 4.8 - Valores de $\beta_{a}$ segundo a BS 8110 (1985).

\begin{tabular}{||c|c|c|c|c|c|c|c|c|c|c|c||}
\hline$\ell_{\mathrm{e}} / b^{\prime}$ & 12 & 15 & 20 & 25 & 30 & 35 & 40 & 45 & 50 & 55 & 60 \\
\hline$\beta_{a}$ & 0,07 & 0,11 & 0,20 & 0,31 & 0,45 & 0,61 & 0,80 & 1,01 & 1,25 & 1,51 & 1,80 \\
\hline
\end{tabular}

$\ell_{\mathrm{e}}$ e $h$ são sempre no plano de flexão em consideração, e quando se considera flexão em duas direções, numa direção tem-se $\ell_{\mathrm{ex}} \mathrm{e} h$ e na outra $\ell_{\mathrm{ey}} \mathrm{e} b$. 
$K$ é um coeficiente de redução, o qual corrige o deslocamento para levar em conta a influência da carga axial. O procedimento de obtenção do valor $K$ será explicado posteriormente, podendo inicialmente ser tomado igual a 1 .

\subsubsection{Pilares esbeltos contraventados}

No caso de pilares contraventados, as extremidades dos pilares são fixadas na posição mas não na direção. A figura 4.19 reproduz a figura 3.20 da Norma Inglesa BS 8110 e indica que o diagrama final é um conjunto de casos possíveis.

A Norma Inglesa BS 8110 indica que o máximo momento adicional pode ser assumido ocorrer na meia altura do pilar. A partir do diagrama da figura 4.20, podese perceber que o máximo momento pode ocorrer em alguma posição ao longo da altura do pilar. Por essa razão, a BS 8110 estabelece (sec. 3.8.3.2) que o momento inicial $\left(M_{i}\right)$ deve ser tomado de acordo com a expressão:

$$
M_{i}=0,4 \cdot M_{1}+0,6 \cdot M_{2}
$$

$M_{1} \bigcup$ é o menor momento inicial atuando na extremidade do pilar, tomado com sinal negativo caso o pilar apresente uma dupla curvatura.

$M_{2} \bigcup$ é o maior momento inicial tomado com sinal positivo.
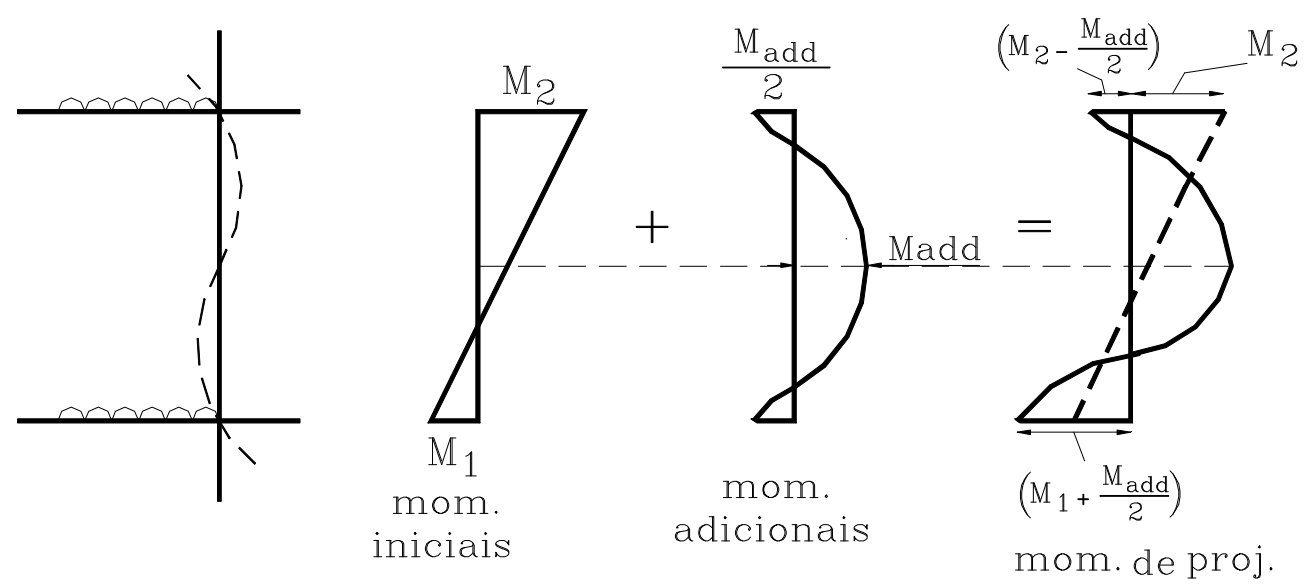

FIGURA - 4.19 - Momentos em um pilar contraventado

A partir do diagrama da figura 4.19 tem-se que o momento de projeto $\left(M_{x}\right.$ para o eixo de maior inércia e $M_{y}$ para o eixo de menor inércia) é o maior valor obtido a partir das expressões (4.52), (4.53), (4.54) e (4.55). 
- $M_{2}$

- $M_{i}+M_{a d d}$

- $M_{1}+\frac{M_{a d d}}{2}$

- $\quad N \times e_{\operatorname{mim}}$

$M_{i}$ é obtido conforme expressão (4.51).

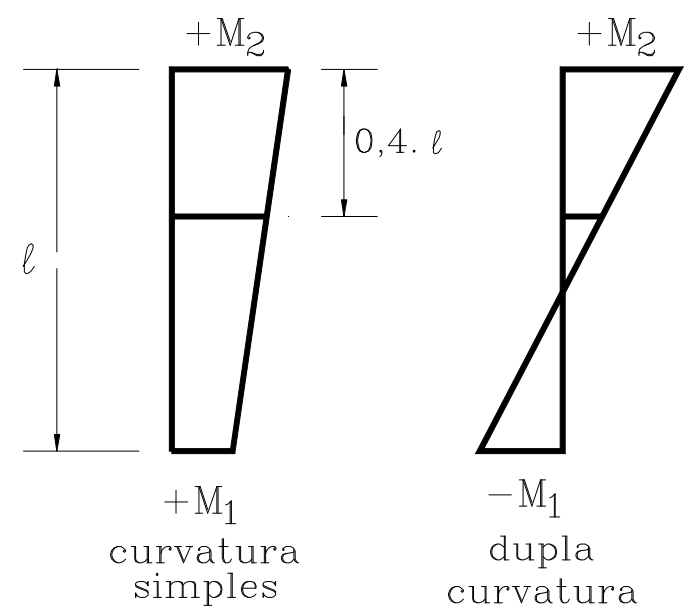

FIGURA - 4.20 - Máximo momento que pode ocorrer ao longo da altura do pilar

Para o cálculo de pilares esbeltos contraventados, devem-se analisar os seguintes itens.

\section{Item 1. - Flexão em relação ao eixo de menor inércia.}

Para flexão em relação ao eixo de menor inércia, o pilar deve ser projetado para a carga axial última $(N)$, juntamente com o momento total $\left(M_{t}\right)$, que é o maior valor obtido a partir das expressões (4.52), (4.53), (4.54), (4.55).

\section{Item 2. - Flexão em relação ao eixo de maior inércia.}

Para flexão com relação ao eixo de maior inércia, devem-se considerar duas condições:

a) A relação entre o maior lado e o menor lado do pilar é menor do que 3.

b) $\frac{\ell_{e}}{h} \quad 20$ 
Caso 1: Se ambas as condições (a) e (b) são satisfeitas, então o pilar é calculado para $(N)$ e $(M)$, utilizando-se os mesmos procedimentos indicados no item 1, sendo $\left(M_{1}\right)$ e $\left(M_{2}\right)$ os momentos com relação ao eixo de maior inércia.

Caso 2: Se alguma das condições (a) ou (b) não forem satisfeitas, então o pilar é dimensionado levando-se em conta a atuação de momentos nas duas direções, com momento inicial zero sobre o eixo de menor inércia, conforme item 3.

Item 3. - Momento ocorrendo em duas direções.

a) $\mathrm{O}$ valor de $M_{y}$ (momento em relação ao eixo de menor inércia) é obtido como o maior momento indicado pelas expressões (4.52), (4.53), (4.54), (4.55), conforme item 1.

b) O valor de $M_{x}$ (momento em relação ao eixo de maior inércia) é obtido como o maior momento indicado pelas expressões (4.51), (4.52), (4.53), (4.54), conforme item 1, exceto que:

- $M_{1}$ e $M_{2}$ são agora os momentos iniciais com relação ao eixo de maior inércia.

- $M_{\text {add }}$ é calculado de acordo com a expressão (4.49). Entretanto, na obtenção de $\left(\beta_{a}\right)$ o valor de $\left(b^{\prime}\right)$ nesse caso particular deve ser tomado igual (h), ou seja, a dimensão no plano de flexão.

c) O pilar é então calculado para carga axial última $(N)$, mais os momentos nas duas direções $\left(M_{x}\right)$ e $\left(M_{y}\right)$ usando as seguintes expressões.

$$
\begin{aligned}
& \text { Para } \frac{M_{x}}{h^{\prime}} \geq \frac{M_{y}}{b^{\prime}} \text { tem-se: } \\
& M_{x}^{\prime}=M_{x}+\beta \cdot \frac{h^{\prime}}{b^{\prime}} \cdot M_{y}
\end{aligned}
$$


Para $\frac{M_{x}}{h^{\prime}}<\frac{M_{y}}{b^{\prime}}$ tem-se:

$M_{y}^{\prime}=M_{y}+\beta \cdot \frac{b^{\prime}}{h^{\prime}} \cdot M_{x}$

$h^{\prime}=$ dimensão da seção na direção perpendicular ao eixo de maior inércia $(\mathrm{x}-\mathrm{x})$, conforme figura 4.21 .

$b^{\prime}=$ dimensão perpendicular ao eixo de menor inércia $(\mathrm{y}-\mathrm{y})$, conforme figura 4.21 .

$\beta=$ valor obtido a partir da tabela 4.9

Obs: $M_{x}$ e $M_{y}$ não devem ser tomados menores do que $N \times e_{\text {mim }}$

TABELA 4.9 - Valores de $\beta$ para as expressões (4.56) e (4.57) - BS 8110: sec. 3.8.4.5

\begin{tabular}{||c|c|c|c|c|c|c|c||}
\hline \hline$\frac{N}{f_{\text {cu.bh }}}$ & 0 & 0,1 & 0,2 & 0,3 & 0,4 & 0,5 & 0,6 \\
\hline$\beta$ & 1,00 & 0,88 & 0,77 & 0,65 & 0,53 & 0,42 & 0,30 \\
\hline
\end{tabular}

$f_{c u}=$ resistência característica do concreto à compressão (CP cúbico)

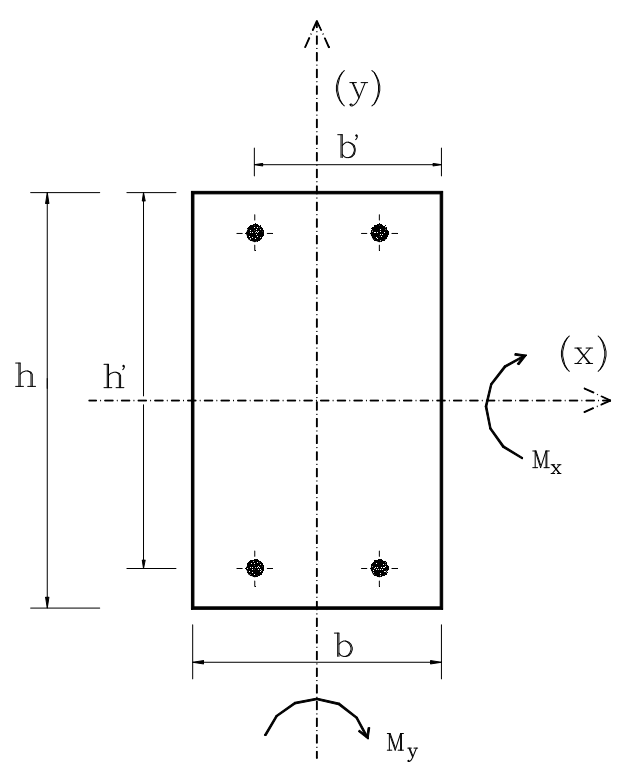

FIGURA - 4.21 - Momentos atuando nas duas direções 


\subsubsection{Pilares esbeltos não contraventados}

Para os pilares não contraventados as extremidades são livres com relação à posição e à direção. No caso de pilares contraventados, pode-se lidar com o deslocamento de apenas um pilar. Porém para os pilares não contraventados, deve-se ter em mente que todos os pilares de um determinado nível irão se deslocar lateralmente na mesma quantidade. Dessa forma, é necessário calcular o deslocamento médio para todos os pilares de um andar particular e isso pode ser feito com a seguinte expressão:

$$
a_{u v}=\frac{\sum a_{u}}{n}
$$

$n$ é o número de pilares envolvidos

Na determinação de $\mathrm{a}_{\mathrm{u}}$ deve-se utilizar o coeficiente $(K)$, tomado igual a 1 .

Uma vez calculado o valor de $a_{u v}$, a Norma Inglesa sugere que seja feita uma comparação entre os valores de $a_{u}$ e $a_{u v}$ e se caso $a_{u}$ for maior do que duas vezes $a_{u v}$, o valor calculado de $a_{u v}$ deve ser rejeitado e uma nova média deve ser calculada com base no valor modificado de $(n)$.

Como as vinculações podem se deslocar lateralmente, os diagramas de momentos fletores são como mostrado na figura 4.22, e pode ser visto que o momento adicional irá aumentar os momentos iniciais nas extremidades dos pilares, ao invés de aumentar ao longo da altura do pilar.
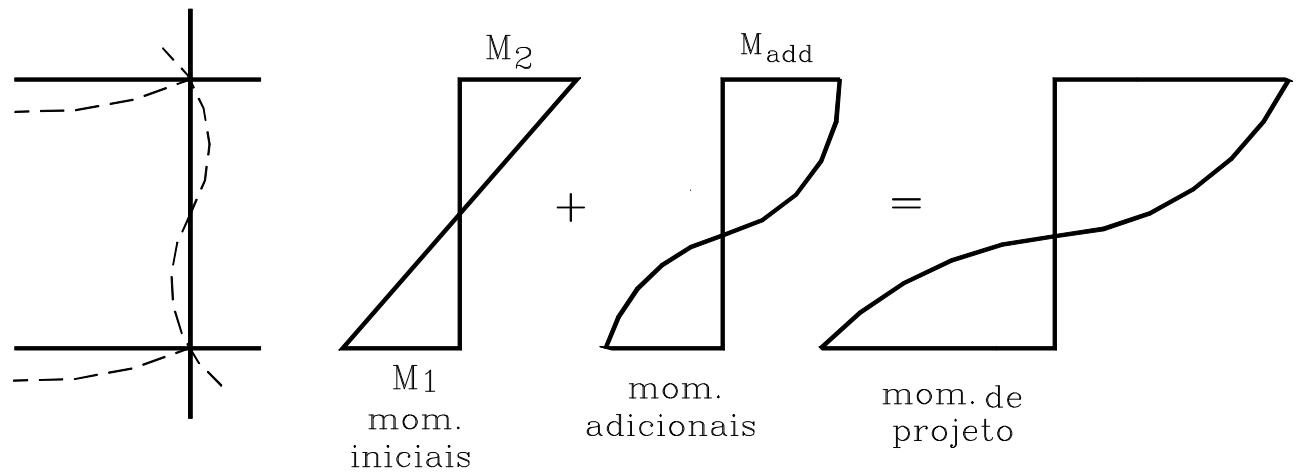

FIGURA - 4.22 - Momentos em um pilar esbelto não contraventado 
Para o cálculo de pilares esbeltos não contraventados deve-se analisar os seguintes itens.

Item 1. - Flexão em relação ao eixo de maior ou menor inércia, onde $(h)$, o comprimento do lado maior, é menor do que três vezes o comprimento do lado menor $(3 b)$.

a) Para flexão sobre o eixo de maior inércia, com $\frac{\ell_{e}}{h}$ não maior do que 20 , o momento de projeto pode ocorrer tanto na parte inferior como na parte superior do pilar. Se $\mathrm{M}_{2}$ é maior do que $\mathrm{M}_{1}$ e ocorre na vinculação mais rígida, tem-se:

$$
M_{t}=M_{2}+M_{a d d}
$$

$M_{a d d}$ é função de $b$, e $M_{t}$ não pode ser menor do que $N \times e_{\operatorname{mim}}$

b) Para flexão em relação ao eixo de maior inércia com $\frac{\ell_{e}}{h}$ maior do que 20, o pilar deve ser tratado como um pilar com momentos atuando em duas direções (conforme item 3) com momento zero sobre o eixo de menor inércia. Como os momentos adicionais são somados no topo e na base do pilar, onde as extremidades são ligadas monoliticamente com outros elementos, deve-se portanto projetar os elementos para resistir ao momento adicional aplicado nas extremidades dos pilares juntamente com aqueles calculados usando os métodos analíticos normais.

c) Flexão em relação ao eixo de menor inércia é obtida como indicado anteriormente, exceto onde $\frac{\ell_{e}}{b}$ for maior do que 20 (sendo $b$ a dimensão obtida no plano de flexão), pois neste caso deve-se seguir o item (1b).

Item 2. - Flexão em relação ao eixo de maior ou menor inércia, onde $h$ é igual a $3 b$ ou maior.

a) Para flexão em relação ao eixo de maior inércia, tratar igual item (1b).

b) Para flexão em relação ao eixo de menor inércia, tratar igual item (1c).

Item 3. - Momentos atuando em duas direções. As mesmas considerações feitas para pilares contraventados ainda se aplicam, mas os momentos totais em relação a cada eixo serão no topo e na base do pilar. 
Neste capítulo são apresentados exemplos de dimensionamento de um pilar central, de um pilar de extremidade e de um pilar de canto, de acordo com os procedimentos recomendado pelo ACI 318-89, e exemplos de dimensionamento de pilar contraventado e não contraventado, de acordo com as recomendações existentes na Norma Inglesa BS 8110.

\subsection{EXEMPLO DE DIMENSIONAMENTO SEGUNDO O ACI 318-89}

Tem-se, na figura 5.1, planta e corte de um edifício de 5 pavimentos. $\mathrm{O}$ edifício é revestido com painéis sem função estrutural. Não existe parede estrutural ou elementos de contraventamento. As vigas na direção norte-sul são todas de $45 \mathrm{~cm}$ de largura por $80 \mathrm{~cm}$ de altura. A laje possui espessura de $18 \mathrm{~cm}$.

A seguir tem-se os esforços devidos a forças verticais, atuando ao nível do primeiro andar. Adotou-se $f_{c}^{\prime}=55 \mathrm{MPa}$ e $f_{y}=414 \mathrm{MPa}$.

TABELA 5.1 - Esforços nos pilares devidos a forças verticais.

\begin{tabular}{||c|c|c|c||}
\hline Esforços & Pilar de canto & Pilar extremidade & Pilar interior \\
\hline força axial & $1460 \mathrm{kN}$ & $2082 \mathrm{kN}$ & $3532 \mathrm{kN}$ \\
\hline momento no topo & $-11931 \mathrm{kN} . \mathrm{cm}$ & $-16948 \mathrm{kN} . \mathrm{cm}$ & $1315 \mathrm{kN} . \mathrm{cm}$ \\
\hline momento na base & $-13965 \mathrm{kN} . \mathrm{cm}$ & $-19931 \mathrm{kN} . \mathrm{cm}$ & $2427 \mathrm{kN} . \mathrm{cm}$ \\
\hline
\end{tabular}

Os momentos são positivos no sentido anti-horário. 


\subsection{DIMENSIONAMENTO DE PILAR INTERIOR}

Apresenta-se, a seguir, o procedimento de cálculo de um pilar interior localizado no pórtico marcado com o eixo $\mathrm{n}^{\circ} 3$ (3B), conforme figura 5.1. Considerou-se o carregamento devido a forças de gravidade atuando no nível do primeiro andar.

\subsubsection{Pré-dimensionamento da seção do pilar}

Inicialmente, adota-se uma taxa de armadura longitudinal $\rho_{\ell}=0,015$.

$$
A_{g} \geq \frac{\mathrm{P}_{\mathrm{u}}}{0,45 \cdot\left(f_{c}^{\prime}+f_{y} \cdot \rho_{\ell}\right)}=\frac{3532}{0,45 \cdot(5,5+41,4 \times 0,015)}=1282,29 \mathrm{~cm}^{2}
$$

Adota-se a seção de $45 \mathrm{~cm}$ x $45 \mathrm{~cm}$ para os pilares interiores, resultando em uma área da seção transversal superior à prevista pela expressão (5.1). Entretanto, já está sendo levada em conta a ação dos momentos. Assume-se que os pilares do nível superior e inferior apresentem a mesma seção de $45 \mathrm{~cm} \mathrm{x} 45 \mathrm{~cm}$.

\subsubsection{Verificação da esbeltez do pilar}

O ACI 318-89 define um pilar não contraventado como sendo esbelto se:

$$
\frac{k \ell_{u}}{r} \geq 22
$$

O valor de $(k)$ não é conhecido neste momento; entretanto ele não deve ser menor que 1,2 e portanto utiliza-se 1,2 .

$$
\begin{aligned}
& \ell_{u}=550 \mathrm{~cm}-80 \mathrm{~cm}=470 \mathrm{~cm} \Rightarrow \mathrm{r}=0,3 \mathrm{~h}=0,3(45)=13,5 \mathrm{~cm} \\
& \frac{k \ell_{u}}{r}=\frac{1,2 \times 470}{13,5}=41,78 \Rightarrow 41,78 \geq 22 \Rightarrow \text { pilar esbelto }
\end{aligned}
$$




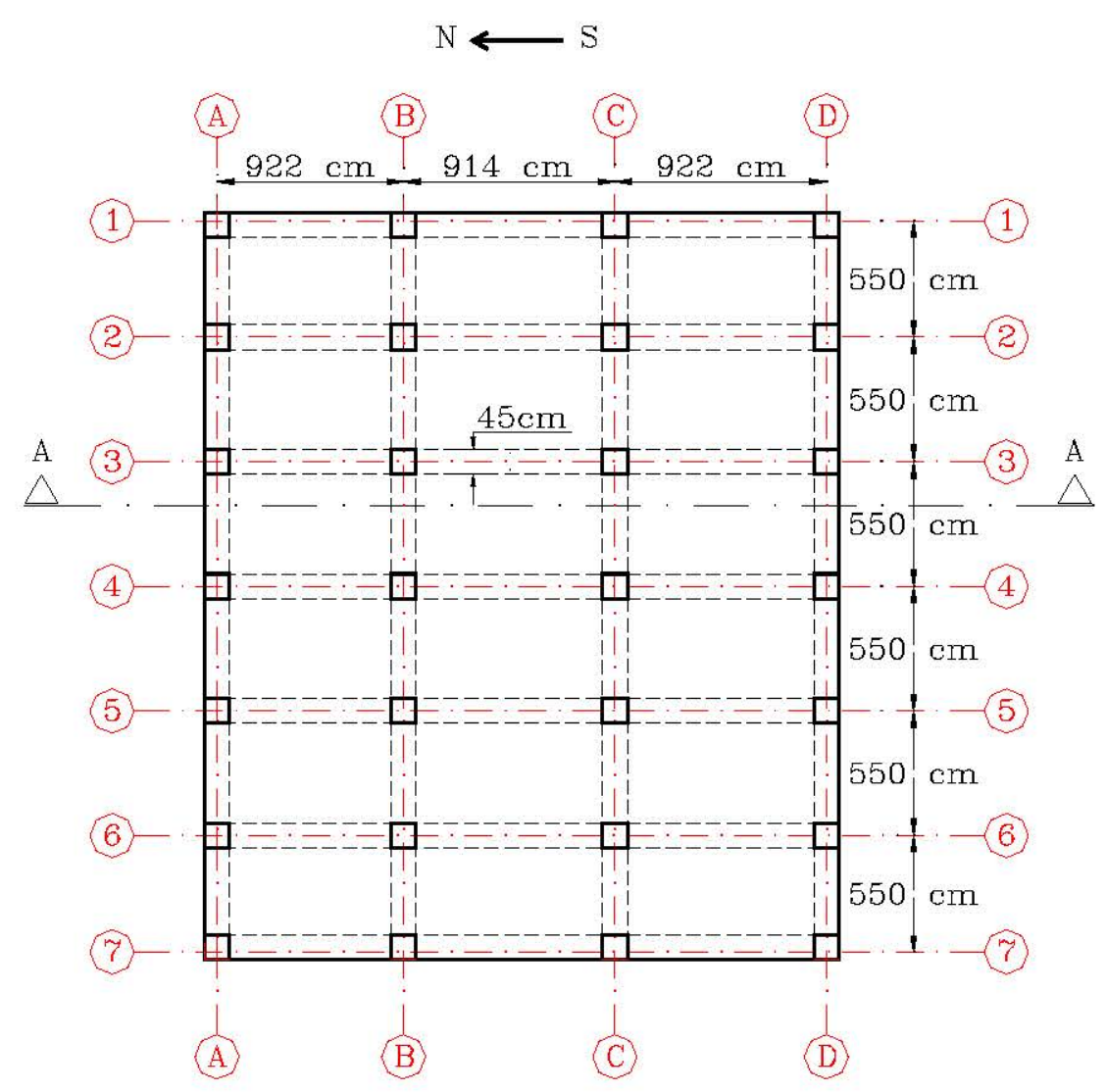

PLANTA BAIXA

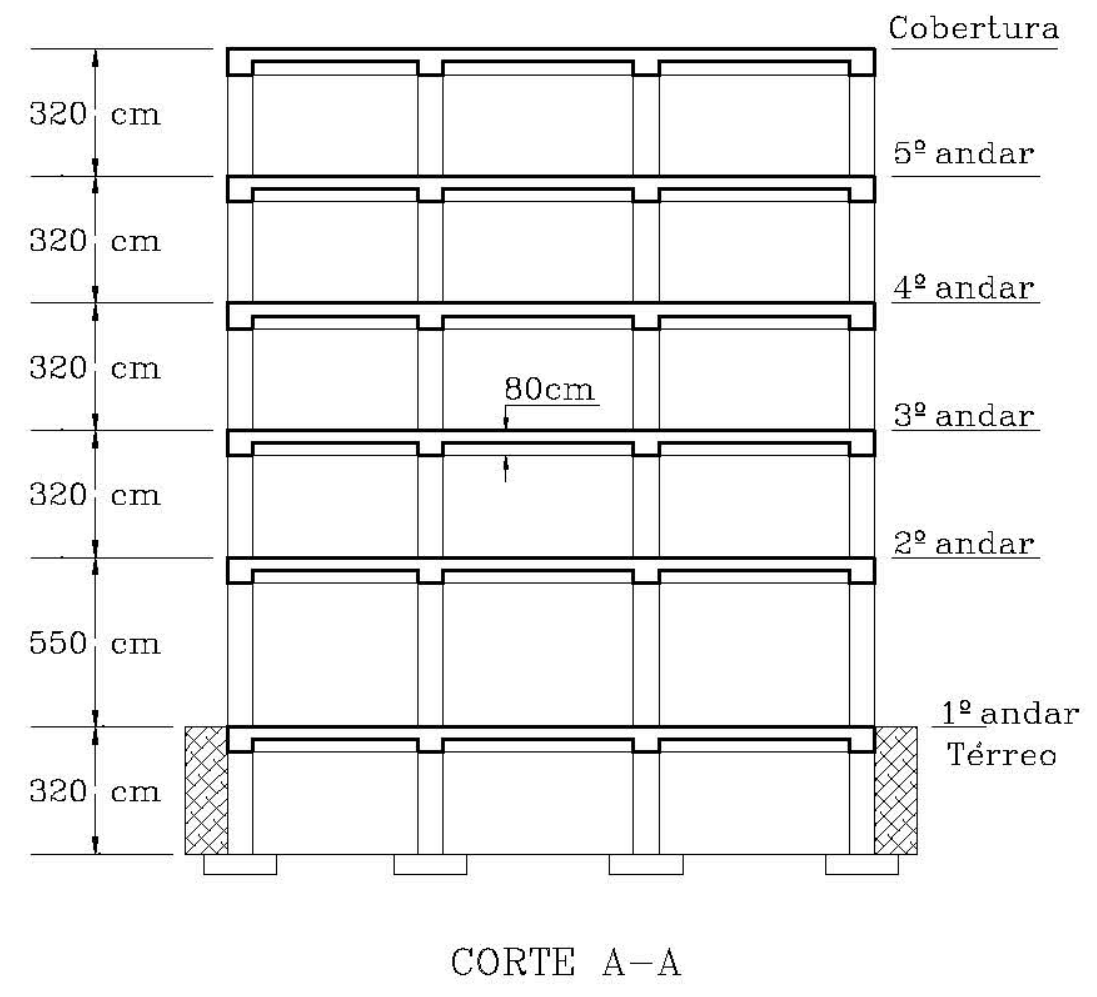

FIGURA - 5.1 - Esquema de edifício de 5 pavimentos. FONTE: MacGREGOR, J. G. (1988). 


\subsubsection{Verificação dos momentos mínimos}

Os pilares esbeltos devem ser projetados com uma excentricidade mínima de $(0,6+0,03 \mathrm{~h})$ in.

$\Rightarrow \quad 45 \mathrm{~cm}=17,72$ in

$\Rightarrow(0,6+0,03 \times 17,72)=1,13$ in $=2,87 \mathrm{~cm}$

$$
P_{u} \cdot e_{\text {mim }}=3532 \times 2,87=10151 \mathrm{kN} . \mathrm{cm}
$$

Para carregamento devido a ação de gravidade $\Rightarrow M_{2 s}=0$. Uma vez que esse pórtico não é contraventado deve-se adotar $M_{2 s}=10151 \mathrm{kN} . \mathrm{cm}, M_{2 b}=2427 \mathrm{kN} . \mathrm{cm}$, $P_{u}=3532 \mathrm{kN}$.

\subsubsection{Cálculo do fator de comprimento efetivo}

Para o cálculo do valor de $(k)$, pode-se utilizar a figura 4.16, onde $(\psi)$ é baseado em $E_{c} . I_{g}$ (pilares) e $E_{c} . I_{g}$ (vigas).

a) Cálculo de $\frac{E I}{\ell_{c}}$ para os pilares

$$
\begin{aligned}
& E_{c}=3320 \sqrt{f_{c}^{\prime}}+6900 \mathrm{MPa} \\
& E_{c}=3320 \sqrt{55}+6900=31521,78 \mathrm{MPa} \Rightarrow 3152,18 \mathrm{kN} / \mathrm{cm}^{2} \\
& I_{g}=\frac{b \cdot h^{3}}{12}=\frac{45 \times 45^{3}}{12}=341719 \mathrm{~cm}^{4}
\end{aligned}
$$

- $\quad$ pilares acima do $2^{\circ}$ andar $-\ell_{c}=320 \mathrm{~cm}$

$$
\frac{E I}{\ell_{c}}=\frac{3152,18 \times 341719}{320}=3366124 \mathrm{kN} \cdot \mathrm{cm}
$$

- $\quad$ pilares entre o $1^{\circ}$ e o $2^{\circ}$ andar $-\ell_{c}=550 \mathrm{~cm}$

$$
\frac{E I}{\ell_{c}}=\frac{3152,18 \times 341719}{550}=1958472 \mathrm{kN} . \mathrm{cm}
$$

- $\quad$ pilares abaixo do $1^{\circ}$ andar - $\ell_{\mathrm{c}}=320 \mathrm{~cm}$

$$
\frac{E I}{\ell_{c}}=\frac{3152,18 \times 341719}{320}=3366124 \mathrm{kN} . \mathrm{cm}
$$


b) Cálculo de $\frac{E I}{\ell_{b}}$ para as vigas

- (entre os eixos A e B ao longo da linha 3)

$$
\begin{aligned}
& I_{g}=\frac{b \cdot h^{3}}{12}=\frac{45 \times 80^{3}}{12}=1920000 \mathrm{~cm}^{4}-\ell_{b}=922 \mathrm{~cm} \\
& \frac{E I}{\ell_{b}}=\frac{3152,18 \times 1920000}{922}=6564193 \mathrm{kN} . \mathrm{cm}
\end{aligned}
$$

- (entre os eixos B e C ao longo da linha 3) $\quad \ell_{b}=914 \mathrm{~cm}$

$$
\frac{E I}{\ell_{b}}=\frac{3152,18 \times 1920000}{914}=6621647 \mathrm{kN} . \mathrm{cm}
$$

c) Cálculo de $\psi$ e $\boldsymbol{k}$ (pilares interiores)

$$
\begin{gathered}
\psi=\frac{\sum\left(E_{c} \cdot \frac{I_{c}}{\ell_{c}}\right)}{\sum\left(E_{b} \cdot \frac{I_{b}}{\ell_{b}}\right)}=\frac{\sum k_{c}}{\sum k_{b}} \\
\psi_{\text {topo }}=\psi_{\text {base }}=\frac{3366124+1958472}{6564193+6621647}=0,404
\end{gathered}
$$

A partir da figura $4.16 \rightarrow\left\{\begin{array}{l}k=0,66 \text { - com contraventamento } \\ k=1,13 \text { - sem contraventamento }\end{array}\right.$

Valor mínimo de $k=1,2$ (para estrutura não contraventada)

d) Cálculo de $\psi$ e k (pilares extremidade, parede norte e sul)

Dois pilares e uma viga se encontram no topo dos pilares de extremidade no primeiro andar.

$$
\psi_{\text {topo }}=\frac{3366124+1958472}{6564193}=0,811
$$

A parte inferior dos pilares externos para A-2 até A-6 e D-2 até D-6 são suportados por uma pilastra construída na parede do subsolo. Quando o pórtico está sendo deslocado na direção norte-sul, a rigidez do pilar e da parede com relação ao momento na direção do eixo paralelo à parede será tomada a mesma para um pilar de mesmo tamanho.

Como resultado tem-se que $\psi$ na base $=0,811$ 
A partir da figura $4.16 \rightarrow\left\{\begin{array}{l}k=0,75-\text { com contraventamento } \\ k=1,25-\text { sem contraventamento }\end{array}\right.$

e) Cálculo de $\psi$ e $\boldsymbol{k}$ (pilares de canto e pilares da parede lateral paralela a direção norte - sul (A-1,B-1, C-1, D-1 e A-7 a D-7).

Esses pilares são aproximadamente engastados na base pela parede do térreo, a qual é perpendicular ao eixo de flexão que está sendo considerado.

Com base na tabela 4.5 tem-se: $\left\{\begin{array}{l}k=0,65-\text { com contraventamento } \\ k=1,2-\text { sem contraventamento }\end{array}\right.$

Valor mínimo de $k=1,2$ (para estrutura não contraventada).

\subsubsection{Cálculo do momento fatorado $\left(M_{c}\right)$}

$$
E I=\frac{\left(E_{c} I_{g}\right) / 2,5}{1+\beta_{\mathrm{d}}} \Rightarrow\left\{\begin{array}{l}
E_{c}=3152,18 \mathrm{kN} / \mathrm{cm}^{2} \\
I_{g}=341719 \mathrm{~cm}^{4}
\end{array}\right.
$$

\section{Pilar interior:}

Dado: Parcela de momento devido a carga permanente fatorada $=868$ kN.m.

$\Rightarrow$ Mom. devido carg. perm. fatorada $=1,4$ x $868=1215 \mathrm{kN} . \mathrm{cm}$ $\beta_{d}=$ (mom. carg. perm. fatorada) / (mom. carg. total fatorada)

$$
\begin{aligned}
& \beta_{d}=\frac{|1215|}{|2427|}=0,501 \\
& E I=\frac{(3152,18 \times 341719) / 2,5}{1+0,501}=287051245 \mathrm{kN} \cdot \mathrm{cm}^{2}
\end{aligned}
$$

\section{Pilar extremidade:}

Dado: Parcela de momento devido a carga permanente fatorada $=8216 \mathrm{kN} . \mathrm{m}$.

$\rightarrow$ Mom. devido carg. perm. fatorada $=1,4$ x $8216=11502 \mathrm{kN} . \mathrm{cm}$ $\beta_{d}=$ (mom. carg. perm. fatorada) / (mom. carg. total fatorada)

$\beta_{d}=\frac{|11502|}{|19931|}=0,577$

$$
E I=\frac{(3152,18 \times 341719) / 2,5}{1+0,577}=273217450 \mathrm{kN} \cdot \mathrm{cm}^{2}
$$




\section{Pilar de canto:}

Dado: Parcela de momento devido a carga permanente fatorada $=5735 \mathrm{kN} . \mathrm{m}$.

$\Rightarrow$ Mom. devido carg. perm. fatorada $=1,4$ x $5735=8029 \mathrm{kN} . \mathrm{cm}$

$$
\beta_{d}=\text { (mom. carg. perm. fatorada) / (mom. carg. total. fatorada) }
$$

$$
\begin{aligned}
& \beta_{d}=\frac{|8029|}{|13965|}=0,575 \\
& E I=\frac{(3152,18 \times 341719) / 2,5}{1+0,575}=273564393 \mathrm{kN} \cdot \mathrm{cm}^{2}
\end{aligned}
$$

Momento majorado (pilar interior) $\Rightarrow M_{c}=\delta_{b} \cdot M_{2 b}+\delta_{s} \cdot M_{2 s}$

$$
\delta_{s}=\frac{1}{1-\frac{\sum P_{u}}{\phi \sum P_{c}}}
$$

Nos andares existem 4 pilares de canto cada um com $P_{u}=1460 \mathrm{kN}, 14$ pilares de extremidade cada um com $P_{u}=2082 \mathrm{kN}$ e 10 pilares interiores cada um com $P_{u}=3532 \mathrm{kN}$.

$$
\sum P_{u}=4 \cdot(1460)+14 \cdot(2082)+10 \cdot(3532)=70308 \mathrm{kN}
$$

- $\boldsymbol{P}_{c}$ para os pilares interiores

$$
P_{c}=\frac{\pi^{2} E I}{\left(k \ell_{u}\right)^{2}}=\frac{\pi^{2} \times 287051245}{(1,20 \times 470)^{2}}=8906 \mathrm{kN}
$$

- $P_{c}$ para os pilares de extremidade (paredes norte e sul)

$$
P_{c}=\frac{\pi^{2} E I}{\left(k \ell_{u}\right)^{2}}=\frac{\pi^{2} \times 273217450}{(1,25 \times 470)^{2}}=7813 \mathrm{kN}
$$

- $P_{c}$ para os pilares de canto (paredes paralelas a direção N-S)

$$
\begin{gathered}
P_{c}=\frac{\pi^{2} E I}{\left(k \ell_{u}\right)^{2}}=\frac{\pi^{2} \times 273564393}{(1,20 \times 470)^{2}}=8488 \mathrm{kN} \\
\sum P_{c}=10(7813)+10(8906)+8(8488)=235094 \mathrm{kN}
\end{gathered}
$$




$$
\delta_{s}=\frac{1}{1-\frac{\sum P_{u}}{\phi \sum P_{c}}} \Rightarrow \delta_{s}=\frac{1}{1-\frac{70308}{0,7 \times 235094}}=1,75
$$

Se $\delta_{S}$ excede 2,0, deve-se considerar a rigidez do pórtico.

- $M_{c}$ para o pilar interior

$$
\delta_{b}=\frac{C_{m}}{1-\frac{P_{u}}{\phi \cdot P_{c}}} \quad 1,0 \Rightarrow C_{m}=0,6+0,4 \cdot\left(\frac{M_{1 b}}{M_{2 b}}\right) \geq 0,4
$$

Como os dois momentos $\left(M_{1 b}\right.$ e $\left.M_{2 b}\right)$ são no sentido anti-horário, o pilar será fletido com dupla curvatura, sendo, portanto, $M_{1 b}$ negativo.

$$
\begin{aligned}
& \frac{M_{1 b}}{M_{2 b}} \rightarrow \text { é negativo (dupla curvatura) } \\
& C_{m}=0,6+0,4 \cdot\left(-\frac{1315}{2427}\right)=0,383 \quad 0,4 \Rightarrow C_{m}=0,4 \\
& P_{c}=\frac{\pi^{2} E I}{\left(k \ell_{u}\right)^{2}} \Rightarrow \ell_{\mathrm{u}}=470 \mathrm{~cm} / E I=287051245 \mathrm{kN} \cdot \mathrm{cm}^{2} \\
& P_{c}=\frac{\pi^{2} \times 287051245}{(0,66 \times 470)^{2}}=29443 \mathrm{kN} \\
& \delta_{b}=\frac{0,4}{1-\frac{3532}{0,7 \times 29443}}=0,483 \quad 1 \quad \rightarrow \delta_{b}=1
\end{aligned}
$$

Para o pilar interior o momento fatorado $\left(M_{c}\right)$ é igual a:

$$
M_{c}=1 \times 2497+1,75 \times 10151=20261 \mathrm{kN} \cdot \mathrm{cm}
$$

\section{Resumindo tem-se:}

Pilar interior: $P_{u}=3532 \mathrm{kN}$ e $M_{c}=20261 \mathrm{kN} . \mathrm{cm}$

\subsubsection{Determinação da armadura}

$$
e=\frac{M_{c}}{P_{u}}=\frac{20261}{3532}=5,74 \mathrm{~cm}
$$




$$
\frac{e}{h}=\frac{5,74}{45}=0,128 \leq 0,2 \mathrm{~cm} \quad \rightarrow \text { armadura nas } 4 \text { faces }
$$

Adotando-se o recobrimento indicado na figura 5.2 e supondo um determinado diâmetro da armadura, calcula-se $(\delta)$.

$$
\delta=\frac{\text { dist. entre niveis de armadura }}{\text { altura do pilar }} \Rightarrow \delta=\frac{45-2 \cdot(2,5+0,63+0,625)}{45}=0,83
$$

Para que se possa utilizar os ábacos das figuras $5.10\left(n^{\circ}\right.$ 7.7.3) e 5.11 ( $n^{\circ}$ 7.7.4), devem-se calcular os seguintes valores de $P_{u} / A_{g}$ e $M_{u} / A_{g} h$.

- $\frac{P_{u}(\text { Kip })}{A_{g}\left(\text { in }^{2}\right)}=\frac{3532 \mathrm{kN}}{45 \times 45 \mathrm{~cm}^{2}}=2,53 \mathrm{Kip} / \mathrm{in}^{2}=2,53 \mathrm{Ksi}$

- $\frac{M_{u}(\text { Kip.in })}{A_{g} \cdot h\left(\text { in }^{3}\right)}=\frac{20261 \mathrm{kN}}{45 \times 45 \times 45 \mathrm{~cm}^{2}}=0,322 \mathrm{Kip} / \mathrm{in}^{2}=0,322 \mathrm{Ksi}$

$\delta=0,75 \Rightarrow \rho_{\ell}=0,01$ e $\delta=0,9 \Rightarrow \rho_{\ell}=0,01$

Interpolando para $\delta=0,83 \rightarrow \rho_{\ell}=0,01$

$A_{s t}=\rho_{\ell} A_{g} \rightarrow A_{s t}=0,01 \times 45 \times 45=20,25 \mathrm{~cm}^{2}$

Adotando-se $\phi 12,5 \mathrm{~mm} \rightarrow$ tem-se 16 barras, conforme figura 5.3.

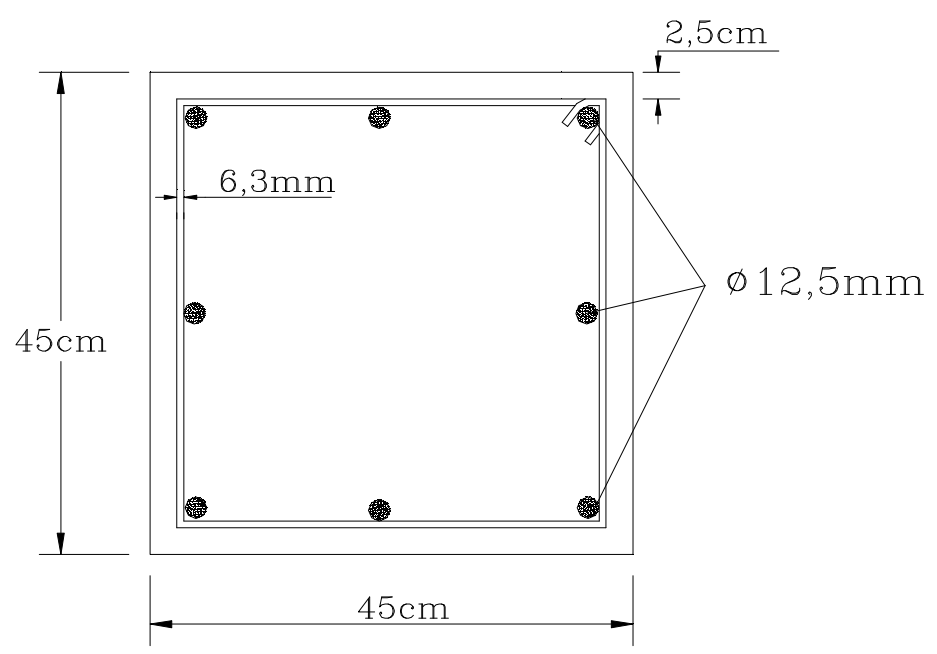

FIGURA - 5.2 - Recobrimento e dimensões do pilar - (cálculo de $\delta$ ) 


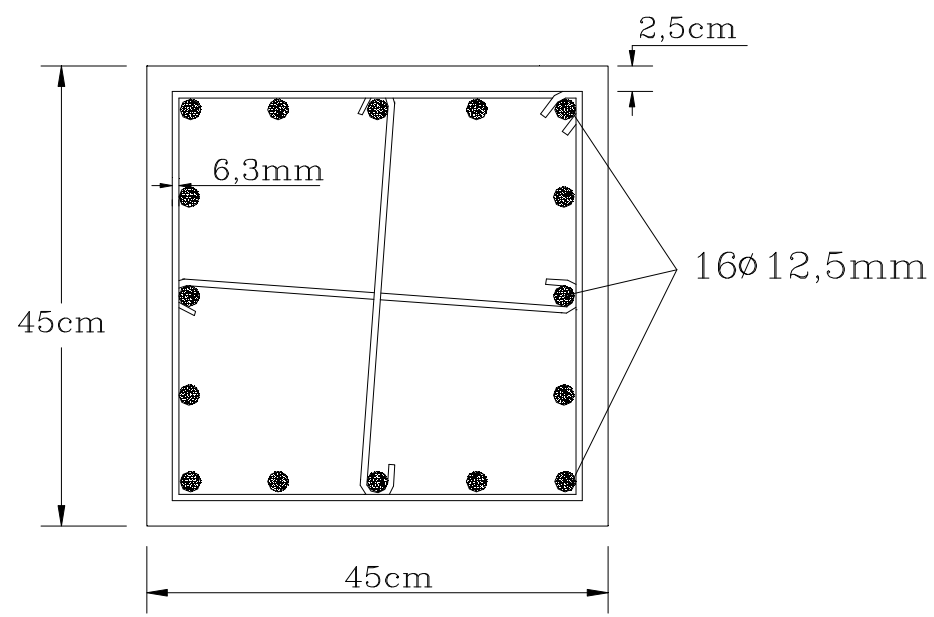

FIGURA - 5.3 - Seção transversal e armaduras adotadas (pilar interior).

\subsection{DIMENSIONAMENTO DE PILAR DE EXTREMIDADE}

É apresentado a seguir o cálculo de um pilar de extremidade do pórtico localizado ao longo do eixo $\mathrm{n}^{\circ} 3$, ao nível do primeiro andar, para carregamento devido a força de gravidade, a partir dos procedimentos recomendados pelo ACI 318-89.

\subsubsection{Pré-dimensionamento da seção do pilar de extremidade}

Inicialmente, adota-se uma taxa de armadura longitudinal $\rho_{\ell}=0,015$.

$$
A_{g} \geq \frac{\mathrm{P}_{\mathrm{u}}}{0,45 \cdot\left(f_{c}^{\prime}+f_{y} \cdot \rho_{\ell}\right)}=\frac{2082}{0,45 \cdot(5,5+41,4 \times 0,015)}=755,87 \mathrm{~cm}^{2}
$$

Adota-se a seção de $45 \mathrm{~cm} \mathrm{x} 45 \mathrm{~cm}$ para os pilares de extremidade, resultando em uma área da seção transversal superior à prevista pela expressão (5.2). Entretanto, já está sendo levada em conta a ação dos momentos. Assume-se que os pilares do nível superior e inferior apresentem a mesma seção de $45 \mathrm{~cm} \mathrm{x} 45 \mathrm{~cm}$.

\subsubsection{Verificação da esbeltez do pilar}

Conforme item 5.2.2, trata-se de pilar esbelto. 


\subsubsection{Verificação dos momentos mínimos}

Os pilares esbeltos devem ser projetados com uma excentricidade mínima de $(0,6+0,03 h)$ in.

$\Rightarrow \quad 45 \mathrm{~cm}=17,72$ in

$\Rightarrow(0,60+0,03 \times 17,72)=1,13$ in $=2,87 \mathrm{~cm}$

$$
P_{u} \cdot e_{\text {mim }}=2082 \times 2,87=5975 \mathrm{kN} . \mathrm{cm}
$$

Para carregamento devido a gravidade $\Rightarrow M_{2 s}=0$. Sendo esse pórtico não contraventado, deve-se tomar $M_{2 s}=5975 \mathrm{kN} . \mathrm{cm}, M_{2 b}=19931 \mathrm{kN} . \mathrm{cm}$, $P_{u}=2082 \mathrm{kN}$.

\subsubsection{Cálculo do fator de comprimento efetivo}

Conforme item 5.2.4.

\subsubsection{Cálculo do momento fatorado $\left(M_{c}\right)$}

$$
E I=\frac{\left(E_{c} I_{g}\right) / 2,5}{1+\beta_{\mathrm{d}}} \Rightarrow\left\{\begin{array}{l}
E_{c}=3152,18 \mathrm{kN} / \mathrm{cm}^{2} \\
I_{g}=341719 \mathrm{~cm}^{4}
\end{array}\right.
$$

Cálculo de $\delta_{S}$ conforme item 5.2.5.

$$
\delta_{s}=\frac{1}{1-\frac{\sum P_{u}}{\phi \sum P_{c}}} \Rightarrow \delta_{s}=\frac{1}{1-\frac{70308}{0,7 \times 235094}}=1,75
$$

- $M_{c}$ para o pilar de extremidade

$$
\delta_{b}=\frac{C_{m}}{1-\frac{P_{u}}{\phi \cdot P_{c}}} \quad 1,0 \quad \rightarrow \quad C_{m}=0,6+0,4 \cdot\left(\frac{M_{1 b}}{M_{2 b}}\right) \geq 0,4
$$

Como os dois momentos $\left(M_{1 b}\right.$ e $\left.M_{2 b}\right)$ são no sentido horário, o pilar será fletido com dupla curvatura, sendo portanto, $M_{l b}$ negativo.

$$
\frac{M_{1 b}}{M_{2 b}} \rightarrow \text { é negativo (dupla curvatura) }
$$




$$
\begin{aligned}
& C_{m}=0,6+0,4 \cdot\left(-\frac{16948}{19931}\right)=0,260 \quad 0,4 \quad \rightarrow \quad C_{m}=0,4 \\
& P_{c}=\frac{\pi^{2} E I}{\left(k \ell_{u}\right)^{2}} \Rightarrow \ell_{\mathrm{u}}=470 \mathrm{~cm} / E I=273217450 \mathrm{kN} \cdot \mathrm{cm}^{2} \\
& P_{c}=\frac{\pi^{2} \times 273217450}{(0,75 \times 470)^{2}}=21702 \mathrm{kN} \\
& \delta_{b}=\frac{0,4}{1-\frac{2082}{0,7 \times 21702}}=0,464 \quad 1 \Rightarrow \delta_{b}=1
\end{aligned}
$$

Para o pilar de extremidade o momento fatorado $\left(M_{c}\right)$ é igual a:

$$
M_{c}=1 \times 19931+1,75 \times 5975=30387 \mathrm{kN} . \mathrm{cm}
$$

\section{Resumindo tem-se:}

Pilar extremidade: $P_{u}=2082 \mathrm{kN}$ e $M_{c}=30387 \mathrm{kN} . \mathrm{cm}$

\subsubsection{Determinação da armadura}

$$
\begin{aligned}
& e=\frac{M_{c}}{P_{u}}=\frac{30387}{2082}=14,6 \mathrm{~cm} \\
& \frac{e}{h}=\frac{14,6}{45}=0,324 \geq 0,2 \mathrm{~cm} \Rightarrow \text { armadura apenas em } 2 \text { faces }
\end{aligned}
$$

Adotando-se o recobrimento indicado na figura 5.4 e supondo um determinado diâmetro da armadura, calcula-se $(\delta)$.

$$
\delta=\frac{\text { dist. entre niveis de armadura }}{\text { altura do pilar }} \rightarrow \delta=\frac{45-2 \cdot(2,5+0,63+0,625)}{45}=0,833
$$

Para que se possa utilizar o ábaco da figura $5.14\left(n^{\circ} 7.14 .3\right)$ e o ábaco da figura $5.15\left(n^{\circ} 7.14 .4\right)$, devem-se calcular os seguintes valores:

- $\frac{P_{u}(\text { Kip })}{A_{g}\left(i n^{2}\right)}=\frac{2082 \mathrm{kN}}{45 \times 45 \mathrm{~cm}^{2}}=1,49 \mathrm{Kip} / \mathrm{in}^{2}=1,49 \mathrm{Ksi}$

- $\frac{M_{u}(\text { Kip.in })}{A_{g} \cdot h\left(\text { in }^{3}\right)}=\frac{30387 \mathrm{kN}}{45 \times 45 \times 45 \mathrm{~cm}^{2}}=0,484 \mathrm{Kip} / \mathrm{in}^{2}=0,484 \mathrm{Ksi}$ 


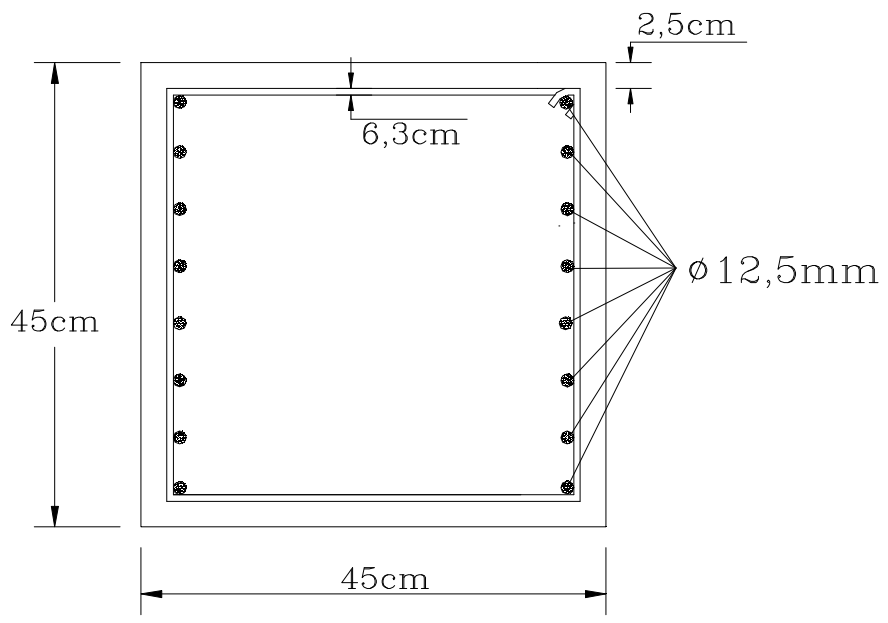

FIGURA - 5.4 - Recobrimento e dimensões do pilar - (cálculo de $\delta$ )

Para $\delta=0,75 \rightarrow \rho_{t}=0,01$ e para $\delta=0,90 \rightarrow \rho_{\ell}=0,01$

Interpolando para $\delta=0,833 \rightarrow \rho_{\ell}=0,01$

$A_{s t}=\rho_{\ell} A_{g} \rightarrow A_{s t}=0,01 \times 45 \times 45=20,25 \mathrm{~cm}^{2}$

Adotando-se $\phi 12,5 \mathrm{~mm} \rightarrow$ tem-se 16 barras, conforme figura 5.5.

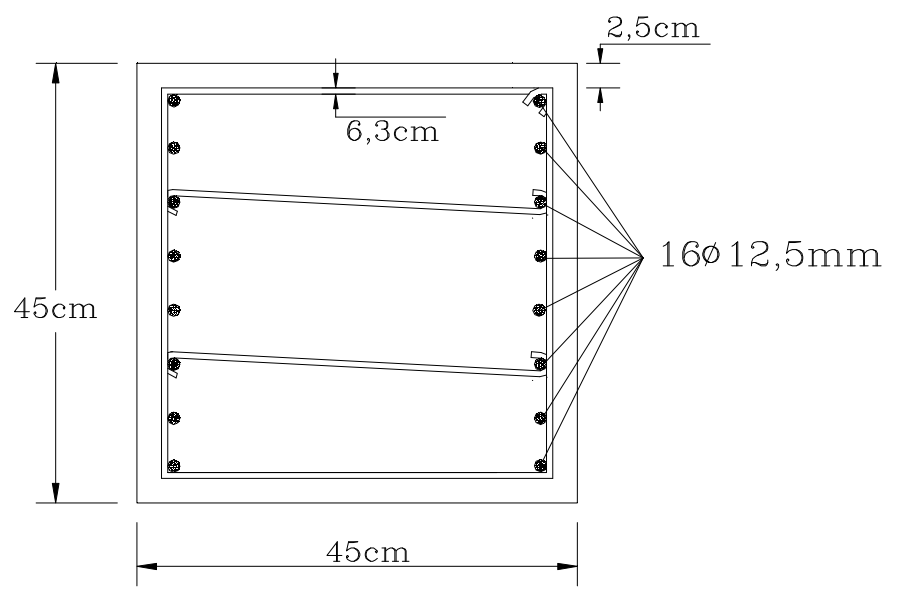

FIGURA - 5.5 - Seção transversal e armadura adotadas (pilar de extremidade).

\subsection{DIMENSIONAMENTO DE PILAR DE CANTO}

Considerou-se para este exemplo um pilar submetido a uma carga axial $P_{u}=1600 \mathrm{kN}$, a momentos $M_{u x}=9500 \mathrm{kN} . \mathrm{cm}$ e $M_{u y}=10845 \mathrm{kN} . \mathrm{cm}, f_{y}=414 \mathrm{MPa}$ e $f^{\prime}{ }_{c}=55 \mathrm{MPa}$. 
5.4.1 Pré dimensionamento da seção do pilar $\left(\rho_{\ell}=\mathbf{0 , 0 1 5}\right)$

$$
A_{g} \geq \frac{P_{u}}{0,45 \cdot\left(f_{c}^{\prime}+f_{y} \cdot \rho_{\ell}\right)} \geq \frac{1600}{0,45 \cdot(5,5+41,4 \times 0,015)}=580,88 \mathrm{~cm}^{2}
$$

Adota-se $35 \mathrm{~cm}$ x $35 \mathrm{~cm}$ para seção transversal, conforme figura 5.6.

\subsubsection{Cálculo de $\delta$}

$$
\delta=\frac{\text { dist. centro das arm. }}{\mathrm{h} \text { (pilar) }}=\frac{35-2 \times(2,5+0,63+0,5)}{35}=0,79
$$

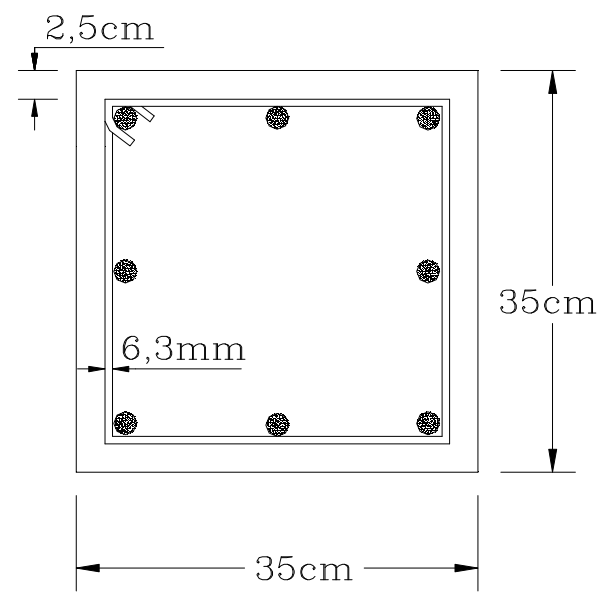

FIGURA - 5.6 - Recobrimento e dimensões do pilar - (cálculo de $\delta$ )

\subsubsection{Cálculo de $e_{x}, e_{y}$ e $e_{o x}$ ou $e_{o y}$}

$e_{x}=\frac{M_{u y}}{P_{u}}=\frac{10845}{1600}=6,778 \mathrm{~cm} \quad, \quad e_{y}=\frac{M_{u x}}{P_{u}}=\frac{9500}{1600}=5,938 \mathrm{~cm}$

$\frac{e_{x}}{x}=\frac{6,778}{35}=0,194 \quad, \quad \frac{e_{y}}{y}=\frac{5,938}{35}=0,170$

$\operatorname{Logo} \frac{e_{x}}{x}=0,194>\frac{e_{y}}{y}=0,170$

Para $\frac{P_{u}}{f_{c}^{\prime} \cdot A_{g}}=\frac{1600}{5,5 \times 35 \times 35}=0,237<0,4$ tem-se que $\alpha$ é dado por:

$$
\begin{aligned}
& \alpha=\left(0,5+\frac{P_{u}}{f_{c}^{\prime} \cdot A_{g}}\right) \cdot \frac{f_{y}+40000}{100000} \geq 0,6 \text { (psi) } \\
& \alpha=\left(0,5+\frac{1600}{5,5 \times 35 \times 35}\right) \cdot \frac{60000+40000}{100000} \geq 0,6 \text { (psi) } \Rightarrow 0,737 \geq 0,6 \text { Ok! }
\end{aligned}
$$




$$
e_{o x}=e_{x}+\frac{\alpha \cdot e_{y}}{y} \cdot x=6,778+\frac{0,737 \times 5,938}{35} \cdot 35=11,154 \mathrm{~cm}
$$

\subsubsection{Cálculo do momento equivalente}

Assim, o momento equivalente em uma única direção é:

$$
M_{o y}=P_{u} \cdot e_{o x}=1600 \times 11,154=17847 \mathrm{kN} . \mathrm{cm}
$$

\subsubsection{Cálculo de $\left(\rho_{\ell}\right)$ através de diagramas de interação}

Uma vez que o pilar tem momento atuando em duas direções, deve-se utilizar armadura nas 4 faces.

Para que se possa utilizar os ábacos das figuras $5.10\left(n^{\circ} 7.7 .3\right)$ e 5.11 $\left(n^{\circ}\right.$ 7.7.4) devem-se calcular os seguintes valores:

$$
\begin{aligned}
& \text { - } \frac{P_{u}(\text { Kip })}{A_{g}\left(\text { in }^{2}\right)}=\frac{1600 \mathrm{kN}}{35 \times 35 \mathrm{~cm}^{2}}=1,89 \mathrm{Kip} / \mathrm{in}^{2}=1,89 \mathrm{Ksi} \\
& \text { - } \frac{M_{u}(\text { Kip.in })}{A_{g} \cdot h\left(\text { in }^{3}\right)}=\frac{17847 \mathrm{kN}}{35 \times 35 \times 35 \mathrm{~cm}^{2}}=0,60 \mathrm{Kip} / \mathrm{in}^{2}=0,60 \mathrm{Ksi}
\end{aligned}
$$

Para $\delta=0,75 \rightarrow \rho_{\ell}=0,01$ e para $\delta=0,90 \Rightarrow \rho_{\ell}=0,01$

Interpolando para $\delta=0,79 \Rightarrow \rho_{\ell}=0,01$

$A_{s t}=\rho_{\ell} A_{g} \Rightarrow A_{s t}=0,01 \times 35 \times 35=12,25 \mathrm{~cm}^{2}$

Adotando-se $\phi 10 \mathrm{~mm} \Rightarrow$ tem-se 16 barras, conforme figura 5.7.

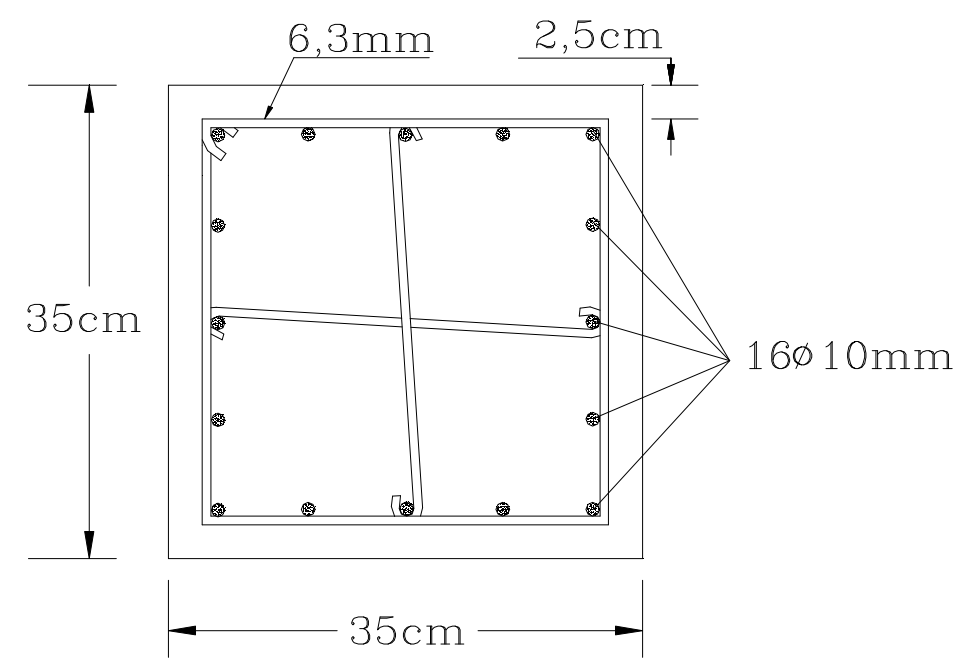

FIGURA - 5.7 - Seção transversal e armaduras adotadas (pilar de canto). 


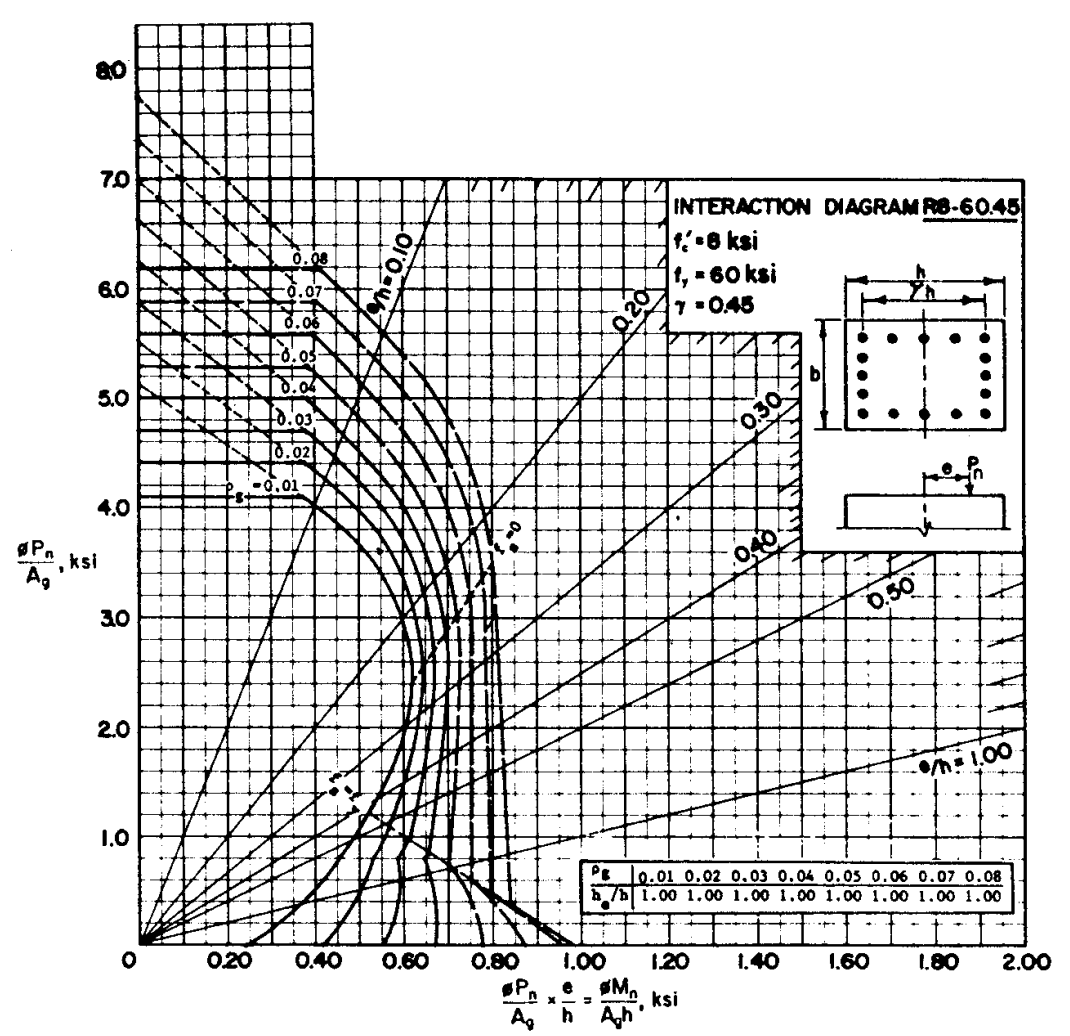

FIGURA - 5.8 - Diagrama de interação carga-momento para pilares. FONTE: ACI 318-83, sec.9.32.2 e 10.3 ( $\left.n^{\circ} 7.7 .1\right)$.

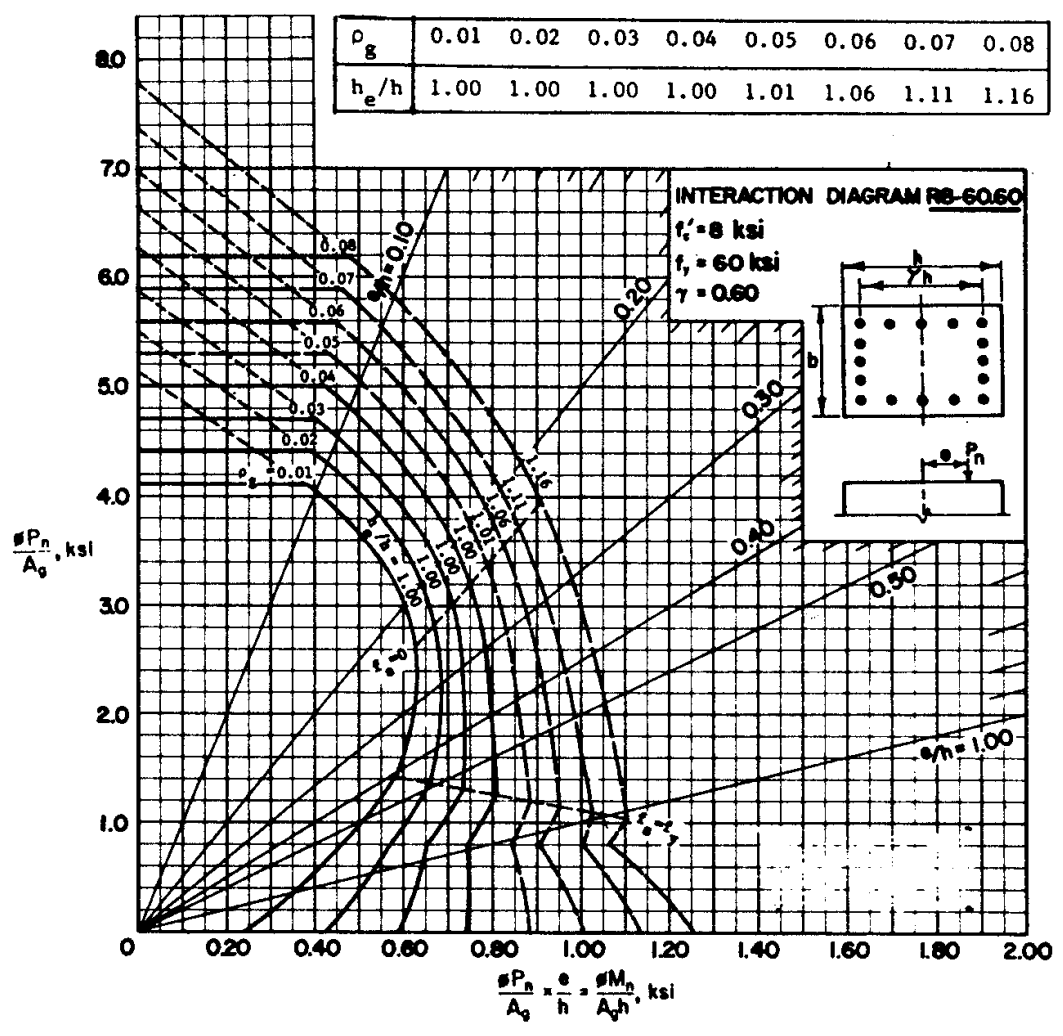

FIGURA - 5.9 - Diagrama de interação carga-momento para pilares. FONTE: ACI 318-83, sec.9.32.2 e 10.3 ( $n^{\circ}$ 7.7.2). 


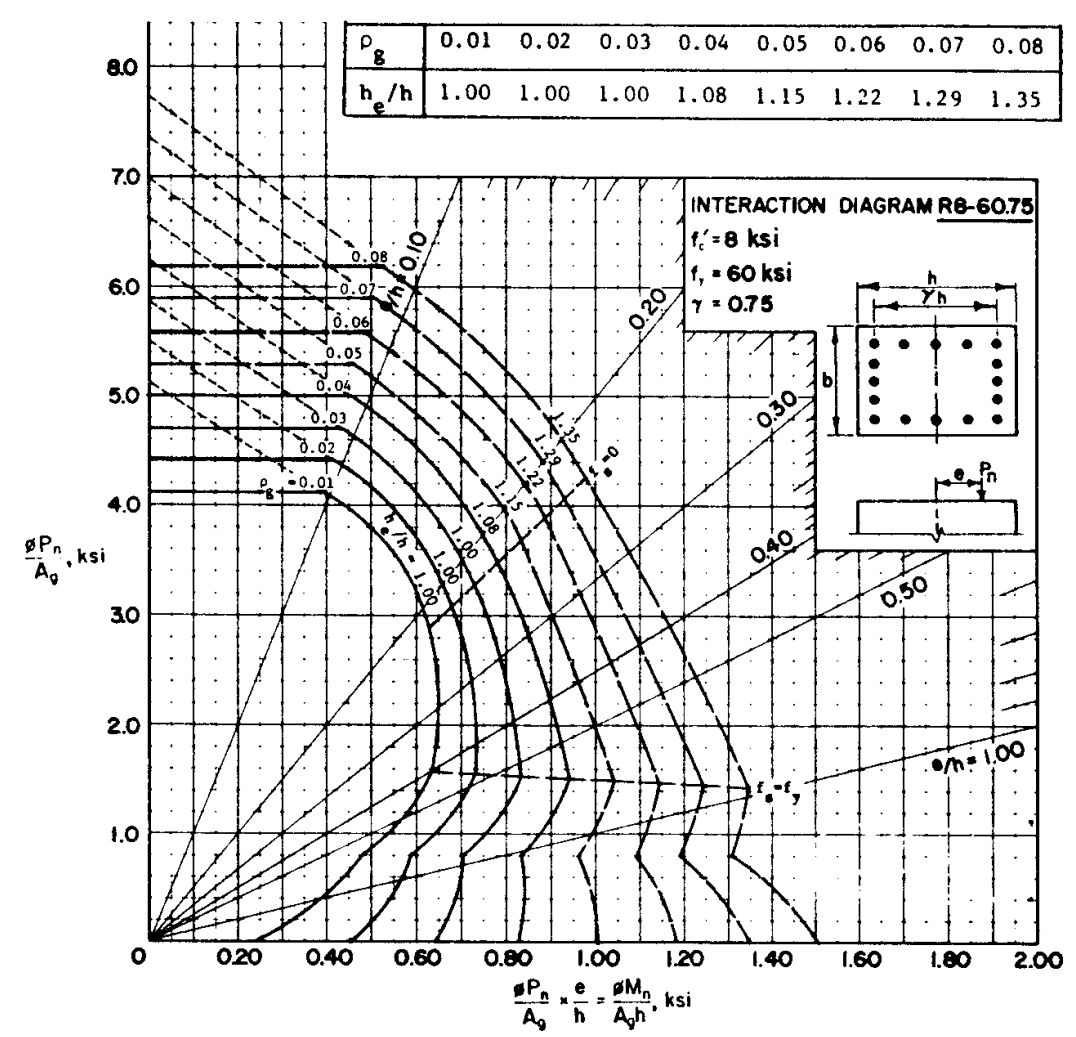

FIGURA - 5.10 - Diagrama de interação carga-momento para pilares. FONTE: ACI 318-83, sec.9.32.2 e 10.3 ( $n^{\circ}$ 7.7.3).

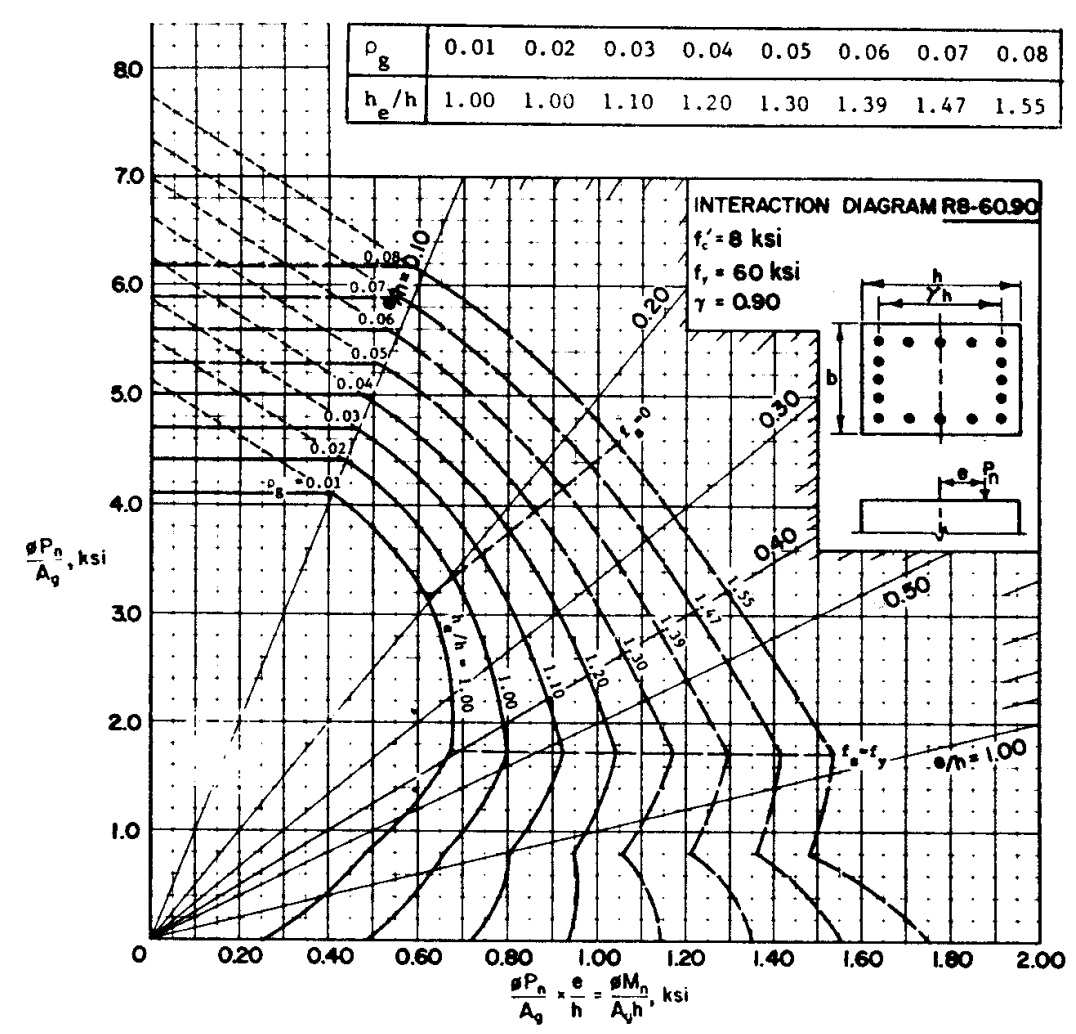

FIGURA - 5.11 - Diagrama de interação carga-momento para pilares. FONTE: ACI 318-83, sec.9.32.2 e 10.3 (n 7.7.4). 


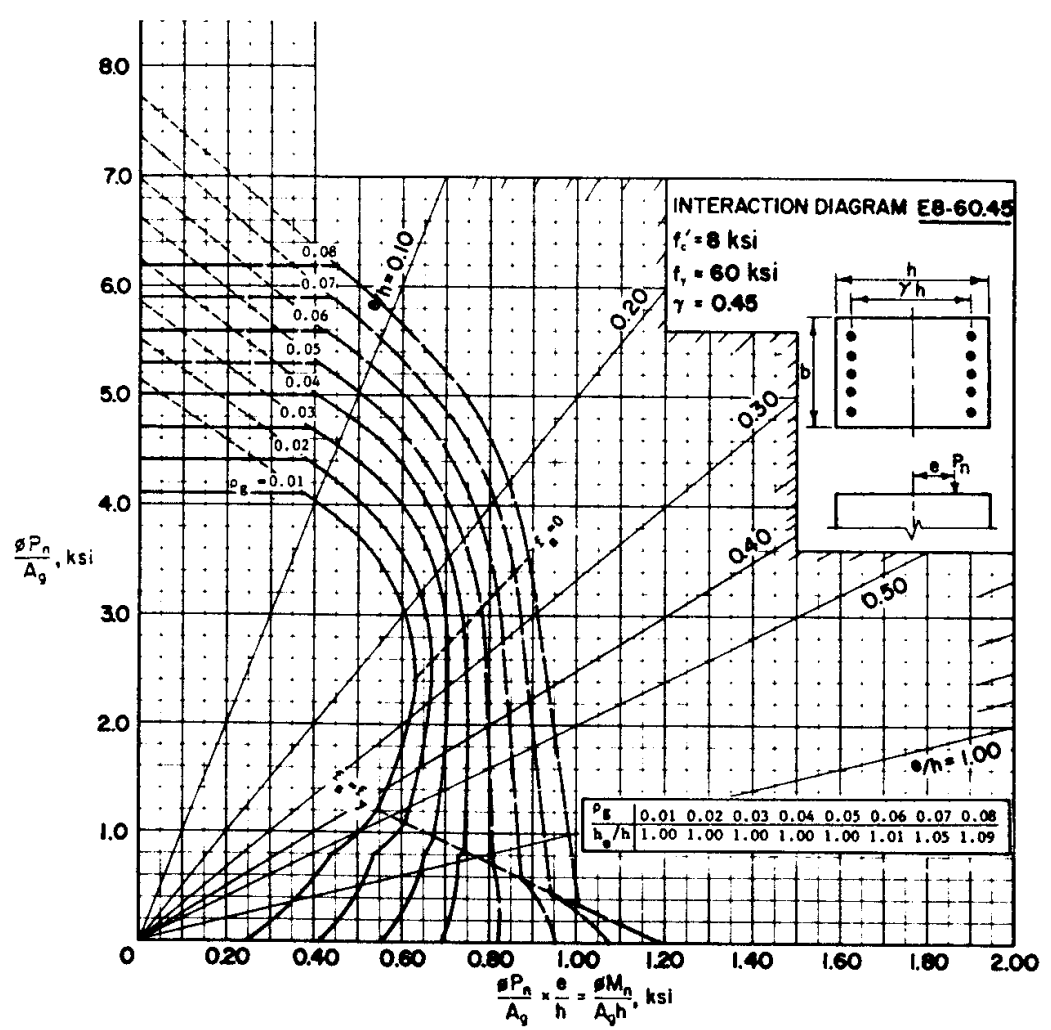

FIGURA - 5.12 - Diagrama de interação carga-momento para pilares. FONTE: ACI 318-83, sec.9.32.2 e 10.3 ( $\left.n^{\circ} 7.14 .1\right)$.

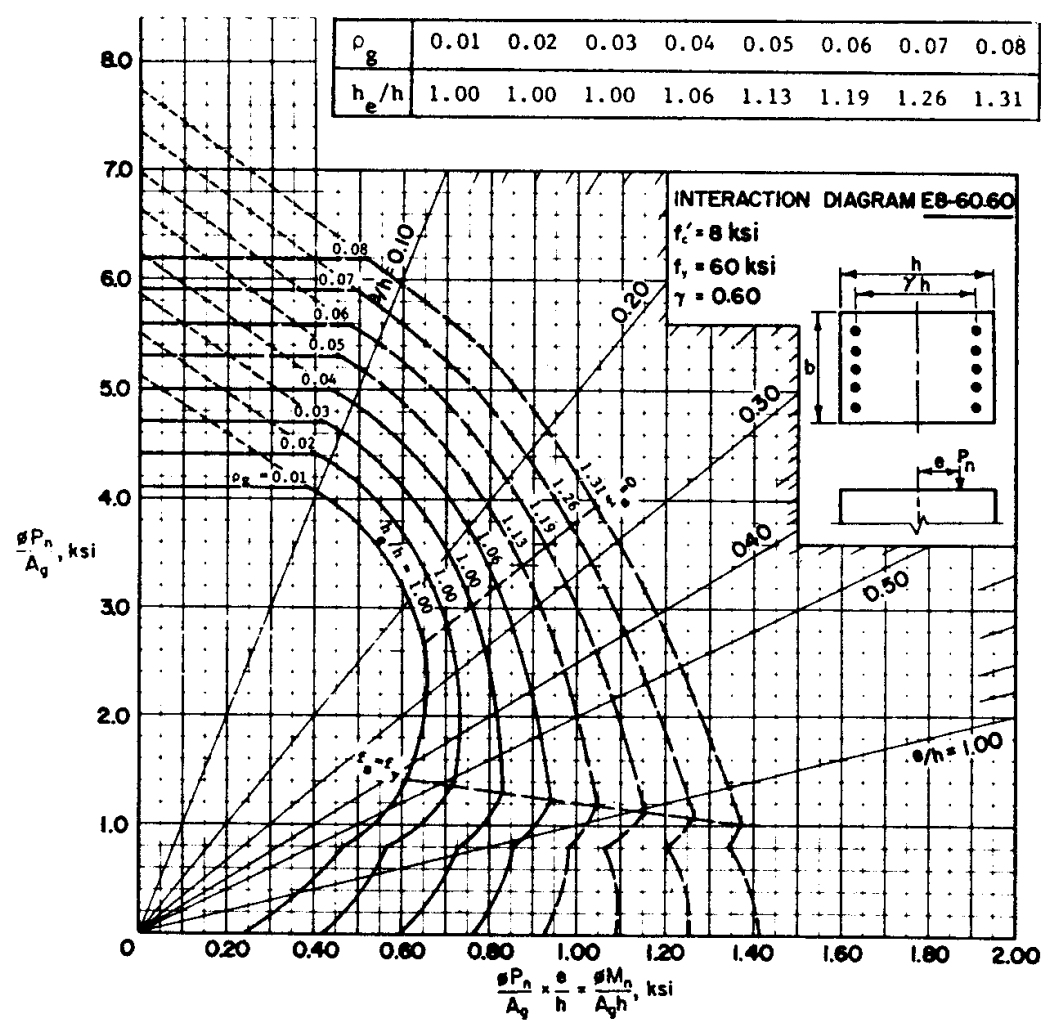

FIGURA - 5.13 - Diagrama de interação carga-momento para pilares. FONTE: ACI 318-83, sec.9.32.2 e 10.3 ( $\left.n^{\circ} 7.14 .2\right)$. 


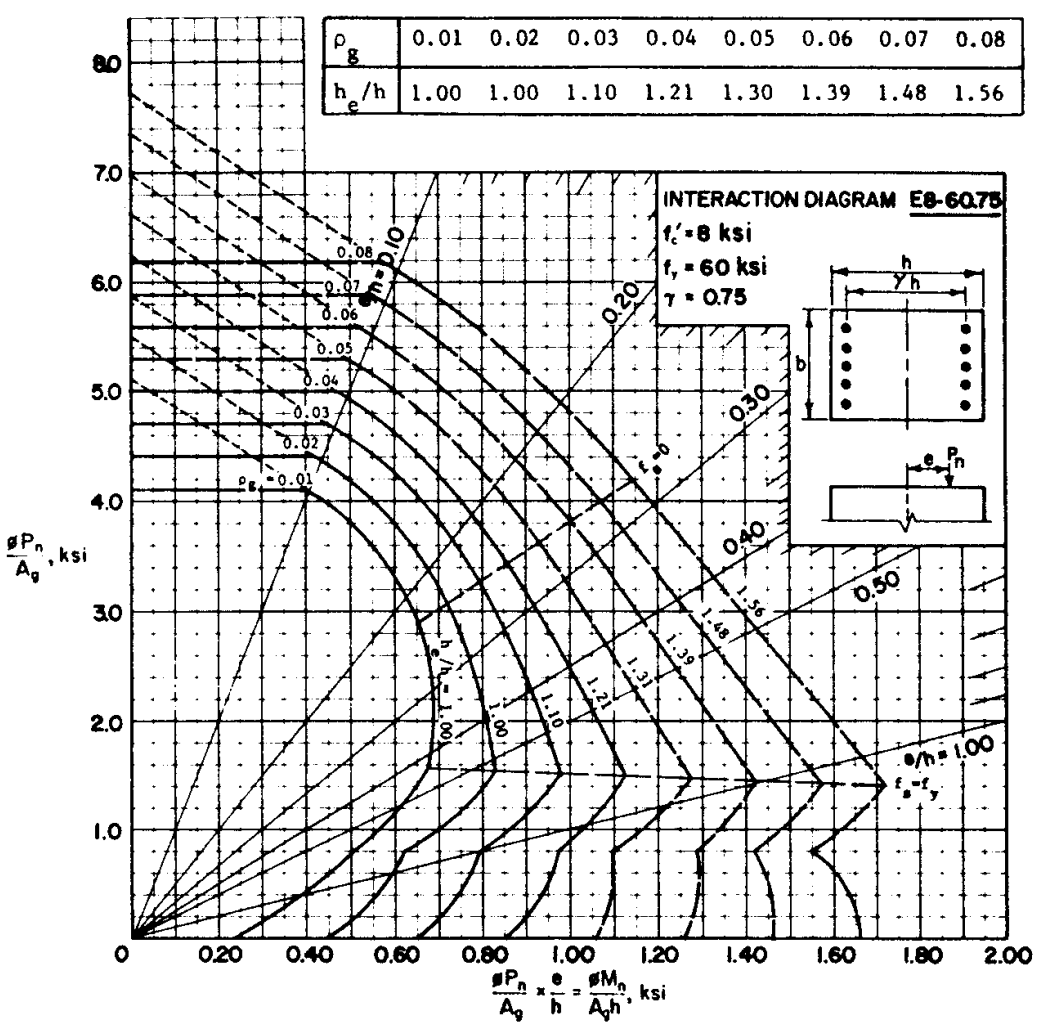

FIGURA - 5.14 - Diagrama de interação carga-momento para pilares. FONTE: ACI 318-83, sec.9.32.2 e 10.3 ( $n^{\circ}$ 7.14.3).

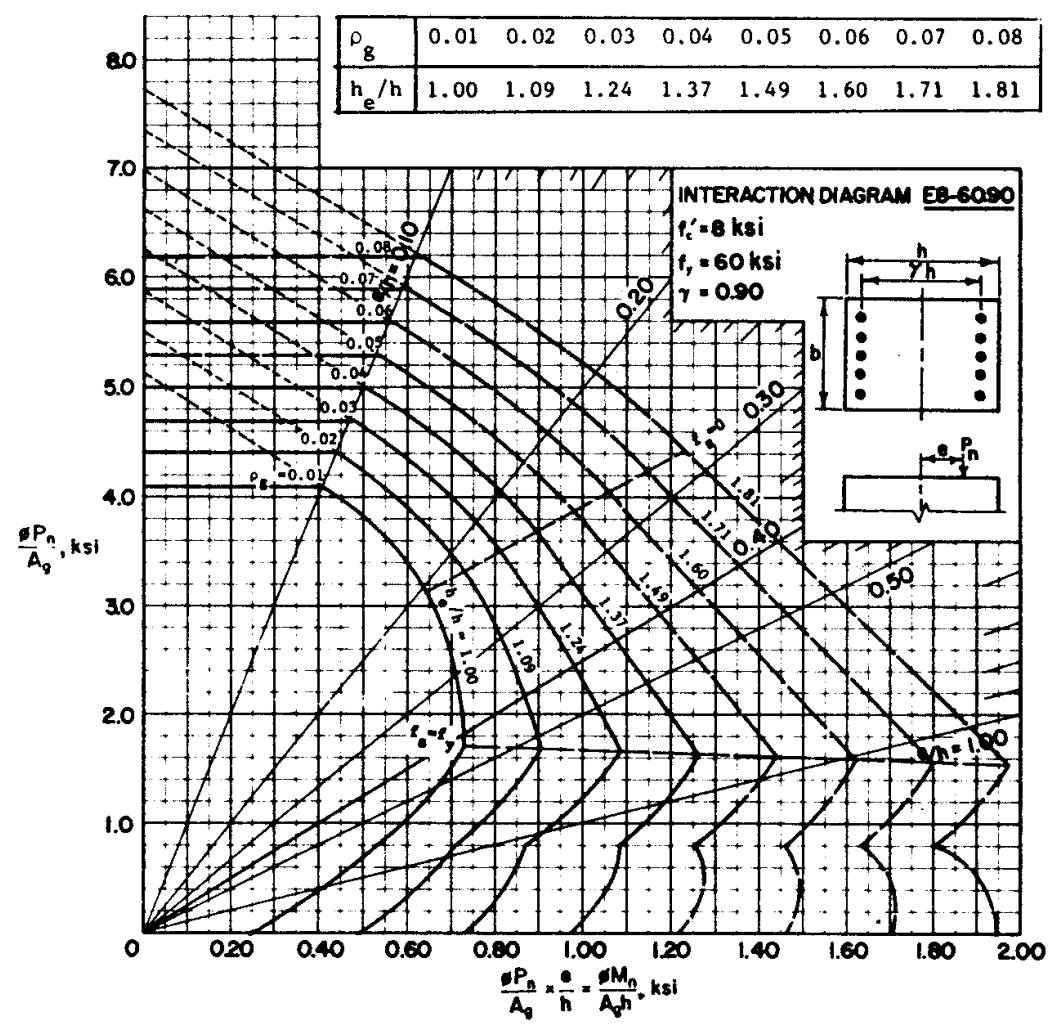

FIGURA - 5.15 - Diagrama de interação carga-momento para pilares. FONTE: ACI 318-83, sec.9.32.2 e 10.3 ( $\left.n^{\circ} 7.14 .4\right)$. 


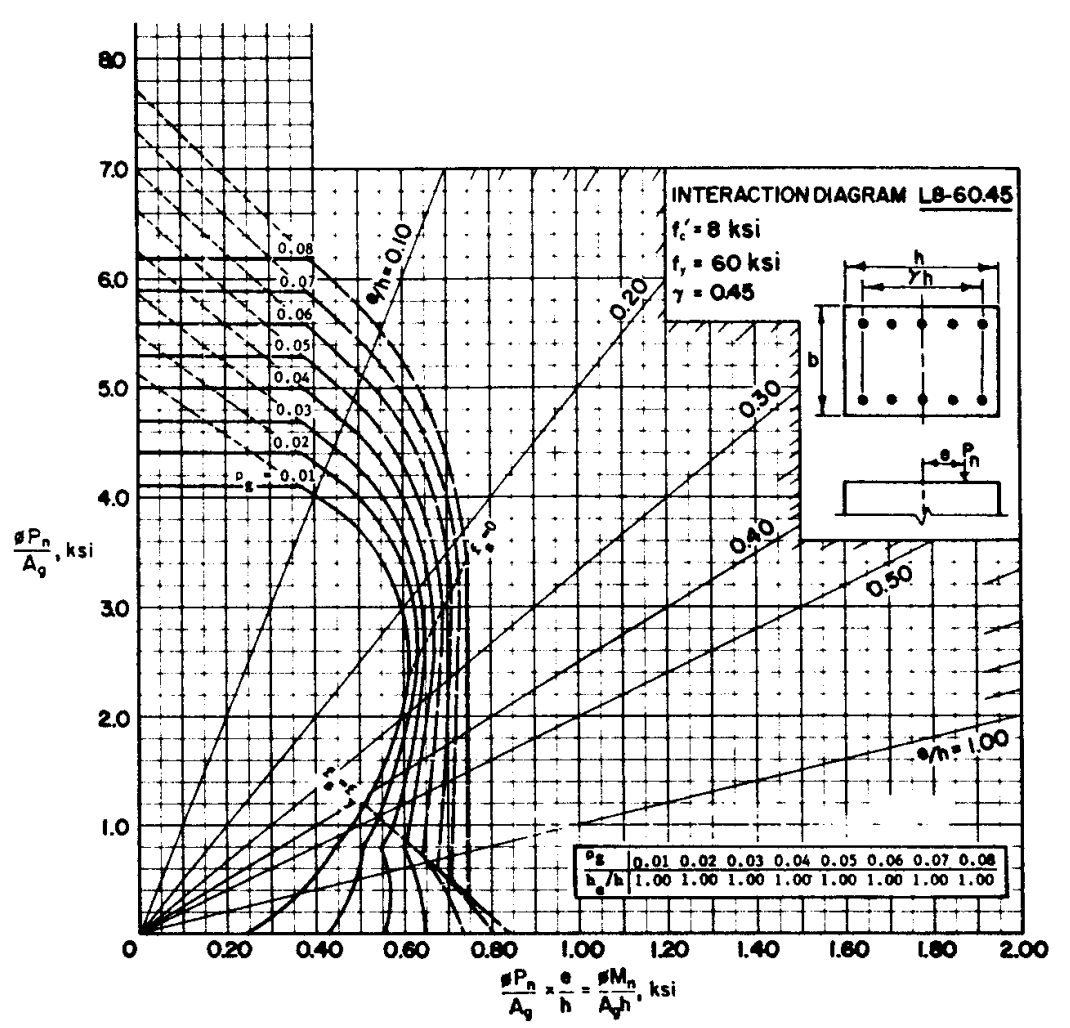

FIGURA - 5.16 - Diagrama de interação carga-momento para pilares. FONTE: ACI 318-83, sec.9.32.2 e 10.3 ( $\left.n^{\circ} 7.21 .1\right)$.

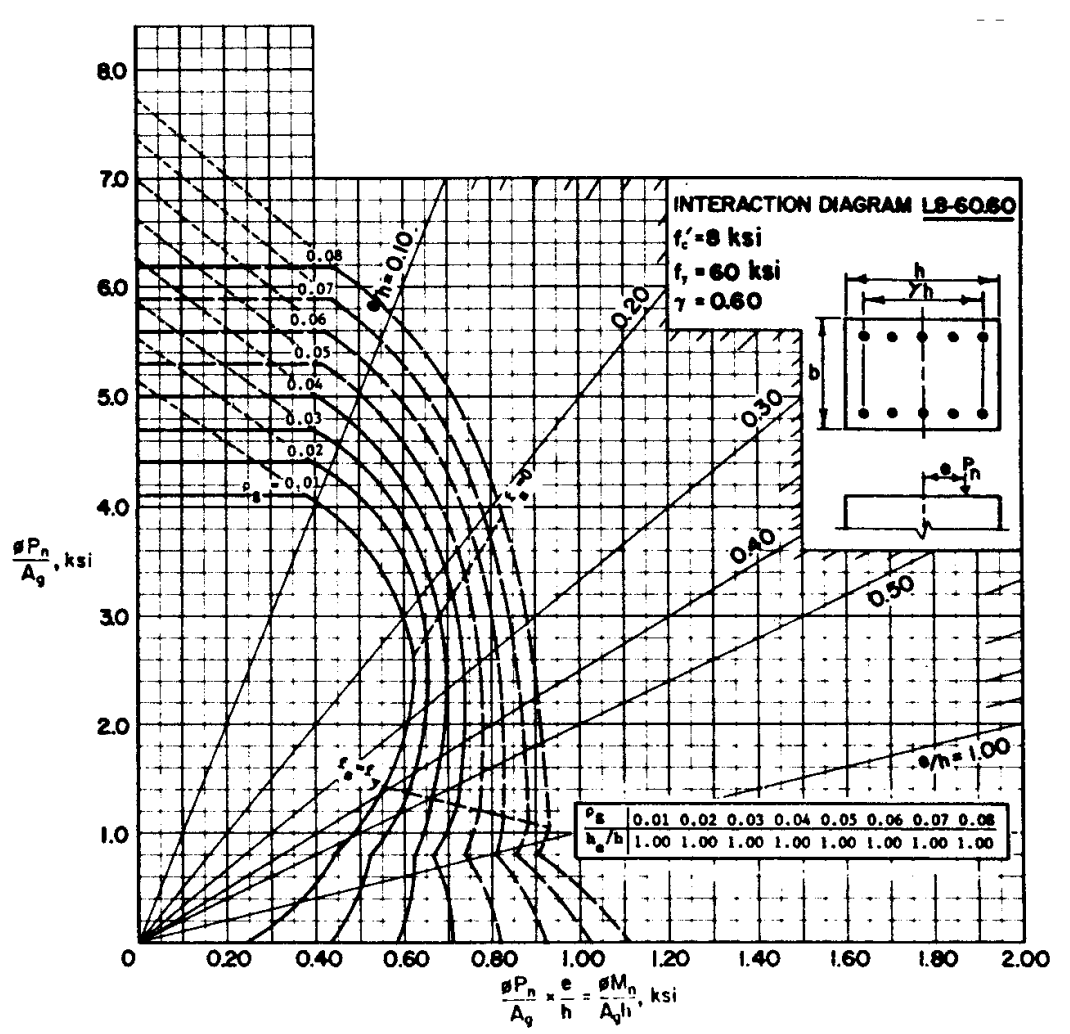

FIGURA - 5.17 - Diagrama de interação carga-momento para pilares. FONTE: ACI 318-83, sec.9.32.2 e 10.3 ( $\left.n^{\circ} 7.21 .2\right)$. 


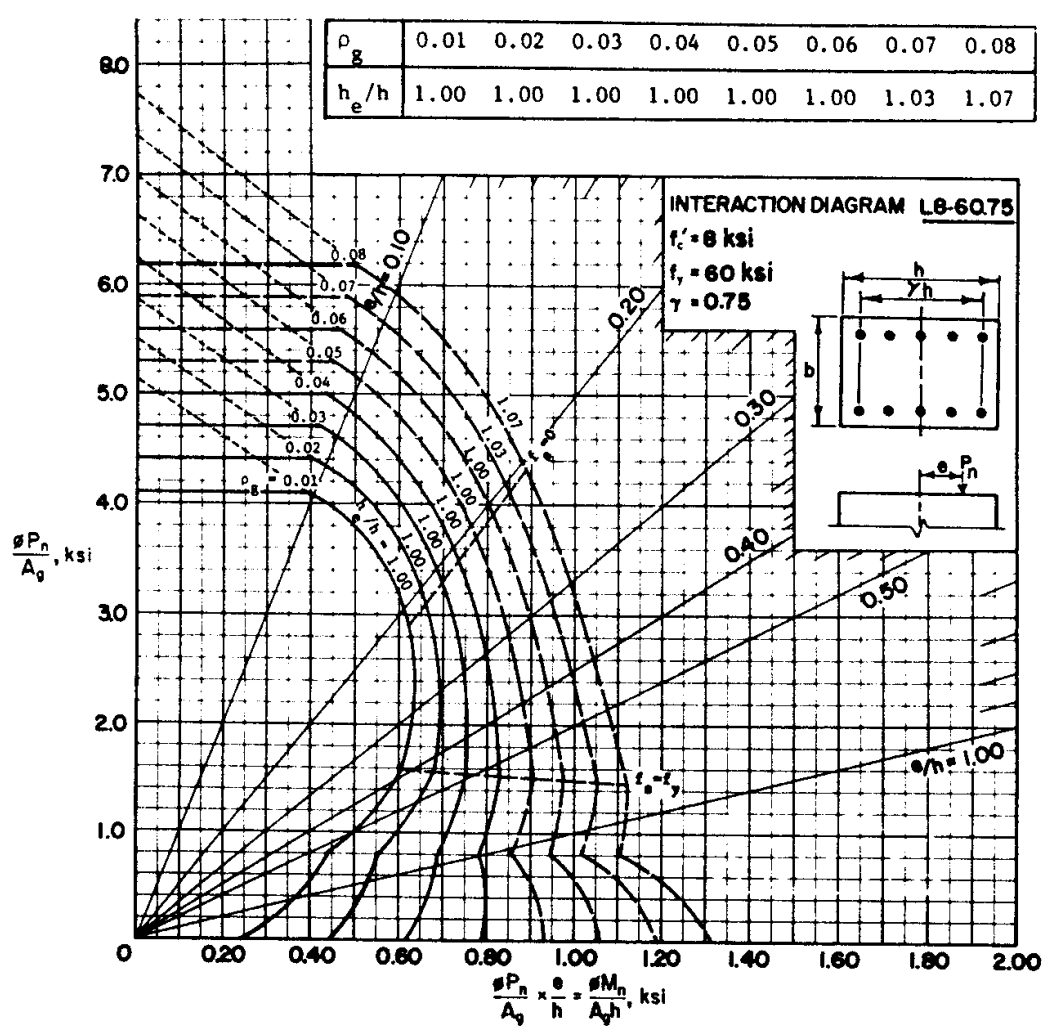

FIGURA - 5.18 - Diagrama de interação carga-momento para pilares. FONTE: ACI 318-83, sec.9.32.2 e 10.3 ( $\left.n^{\circ} 7.21 .3\right)$.

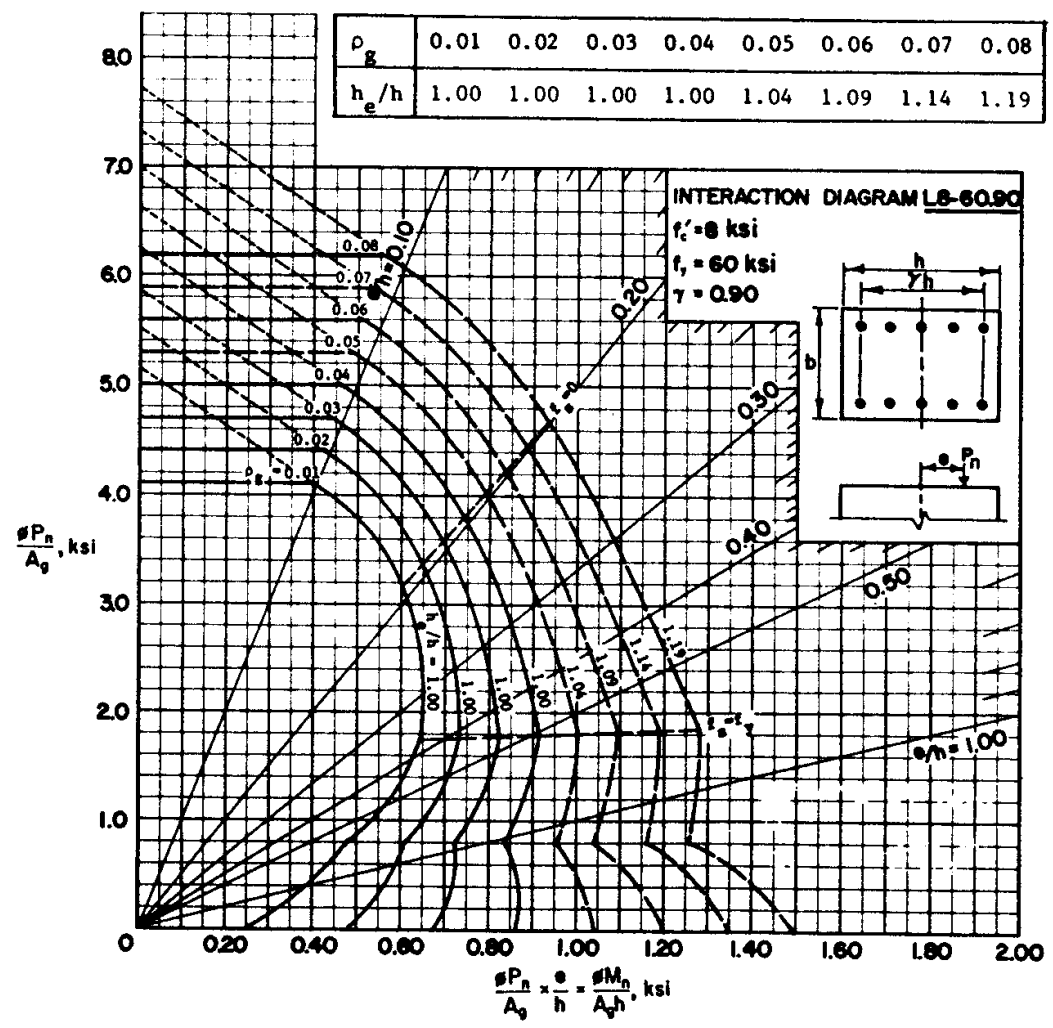

FIGURA - 5.19 - Diagrama de interação carga-momento para pilares. FONTE: ACI 318-83, sec.9.32.2 e 10.3 ( $\left.n^{\circ} 7.21 .4\right)$. 


\subsection{DIMENSIONAMENTO DE PILAR CONTRAVENTADO SEGUNDO A NORMA INGLESA - BS 8110}

A seguir tem-se o cálculo de um pilar contraventado conforme as indicações da BS 8110. O cálculo será feito para o tramo de pilar entre o pavimento térreo e o $1^{\circ}$ andar. O pilar apresenta seção transversal de $30 \mathrm{~cm}$ x $30 \mathrm{~cm}$, conforme indicado na figura 5.20.

\subsubsection{Dados do edifício}

Neste exemplo considerou-se resistência do concreto à compressão $\left(f_{c u}=40 \mathrm{MPa}\right.$ referida ao corpo-de-prova cúbico), resistência característica a plastificação da armadura $\left(f_{y}=460 \mathrm{MPa}\right)$ e revestimento do concreto igual a $30 \mathrm{~mm}$. A seguir tem-se os esforços atuantes no pilar.

TABELA 5.2 - Esforços nos pilares devidos ao peso próprio.

\begin{tabular}{||c|c||}
\hline Carga axial $(N)$ & $2146 \mathrm{kN}$ \\
\hline Momento $1^{\circ}$ andar $($ eixo $x-x)$ & 2100 kN.cm \\
\hline Momento térreo (eixo $x-x)$ & 0 \\
\hline
\end{tabular}

Condições de vinculação:

- $\operatorname{Eixo}(\boldsymbol{x})$ - Topo $\rightarrow$ engastado, Base $\rightarrow$ articulada.

- Eixo $(y)$ - Topo $\rightarrow$ parcialmente engastado, Base $\rightarrow$ articulada.

\subsubsection{Cálculo do comprimento efetivo}

a) Para flexão em relação ao eixo (x)

$\ell_{e}=\beta \times \ell_{0} \rightarrow$ a partir da tabela (4.6), tem-se $\beta=0,9$

$\ell_{0}=5,5-0,50=5,0 \mathrm{~m}$

$\ell_{e x}=0,90 \times 5,0=4,5 \Rightarrow \frac{\ell_{e x}}{h}=\frac{4,5}{0,30}=15$ OK! 


\section{b) Para flexão em relação ao eixo (y)}

$$
\begin{aligned}
& \ell_{e}=\beta \times \ell_{0} \rightarrow \text { a partir da tabela (4.6), tem-se } \beta=0,95 \\
& \ell_{0}=5,5-0,175=5,325 \mathrm{~m} \\
& \ell_{e y}=0,95 \times 5,325=5,059 \mathrm{~m} \rightarrow \frac{\ell_{e y}}{h}=\frac{5,059}{0,30}=16,86>15 \quad \text { (pilar esbelto de }
\end{aligned}
$$

acordo com item 4.6.2).

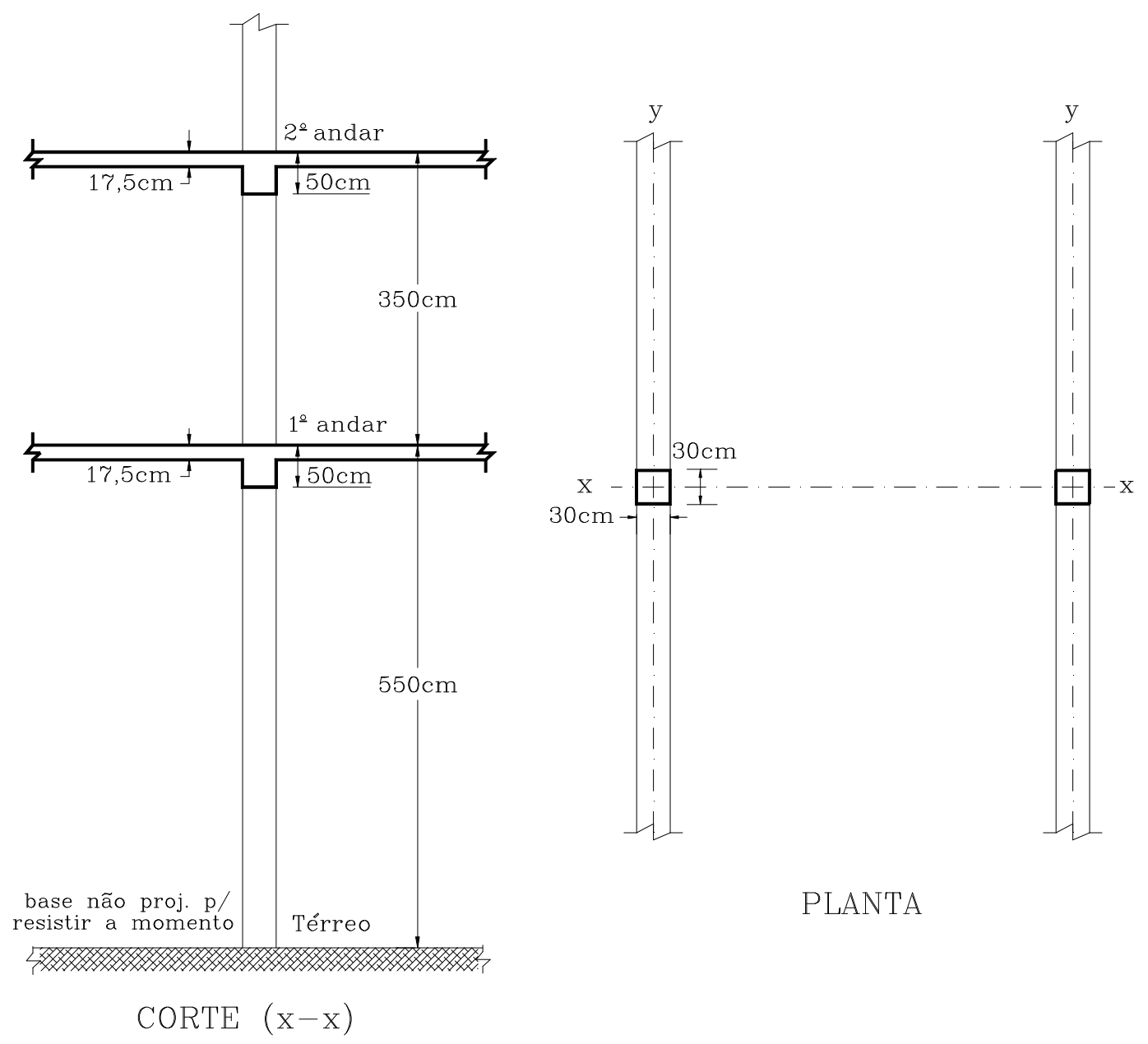

FIGURA - 5.20 - Esquema da estrutura dos pavimentos

\subsubsection{Determinação do momento de cálculo $\left(M_{x}\right)$}

$$
M_{a d d}=N \cdot \beta_{a} \cdot K \cdot h \rightarrow\left\{\begin{array}{l}
N=2146 \mathrm{kN} \\
K=1 \text { (adotado) } \\
\mathrm{h}=30 \mathrm{~cm} \\
\text { sup. } \phi 16 \mathrm{~mm} \Rightarrow \mathrm{b}^{\prime}=26,20 \mathrm{~cm}
\end{array}\right.
$$




$$
\begin{aligned}
& \beta_{a}=\frac{1}{2000} \cdot\left(\frac{\ell_{e}}{b^{\prime}}\right)^{2}=\frac{1}{2000} \cdot\left(\frac{4,50}{0,262}\right)^{2}=0,1475 \\
& M_{a d d}=2146 \times 0,1475 \times 1 \times 0,30=94,96 \mathrm{kN} \cdot \mathrm{m} \\
& M_{\text {min }}=N \cdot e_{\text {min }} \rightarrow e_{\text {min }}=0,05 \times 300=15 \mathrm{~mm}(\text { conf. item } 4.6 .3) \\
& M_{\text {min }}=2146 \times 0,015=32,19 \mathrm{kN} \cdot \mathrm{m} \\
& M_{i}=0,4 M_{1}+0,6 M_{2} \rightarrow\left\{\begin{array}{l}
M_{2}=21 \mathrm{kN} \cdot \mathrm{m} \\
M_{1}=0
\end{array}\right. \\
& M_{i}=0,4 \cdot(0)+0,6 \cdot(21)=12,60 \mathrm{kN} \cdot \mathrm{m}
\end{aligned}
$$

O momento de cálculo é igual ao maior valor obtido a partir dos seguintes itens:

- $M_{2}=21 \mathrm{kN} \cdot \mathrm{m}$

- $M_{i}+M_{a d d}=12,60+94,96=107,56 \mathrm{kN} . \mathrm{m}$

- $M_{1}+\frac{M_{a d d}}{2}=0+\frac{94,96}{2}=47,48 \mathrm{kN} \cdot \mathrm{m}$

- $M_{\min }=32,19 \mathrm{kN} \cdot \mathrm{m}$

Logo o momento de cálculo $M_{x}$ é igual a 107,56 kN.m

\subsubsection{Utilização do ábaco}

- $\frac{N}{b \cdot h}\left(N / \mathrm{mm}^{2}\right)=\frac{2146 \mathrm{kN}}{30 \times 30 \mathrm{~cm}^{2}}=2,38 \mathrm{kN} / \mathrm{cm}^{2}=23,84 \mathrm{~N} / \mathrm{mm}^{2}$

- $\frac{M}{b \cdot h^{2}}\left(\mathrm{~N} / \mathrm{mm}^{2}\right)=\frac{10756 \mathrm{kN} \cdot \mathrm{cm}}{30 \times 30^{2} \mathrm{~cm}^{3}}=0,398 \mathrm{kN} / \mathrm{cm}^{2}=3,98 \mathrm{~N} / \mathrm{mm}^{2}$

- $\frac{d}{h} \rightarrow$ assumindo utilização de $\phi 16 \mathrm{~mm}$

$\frac{d}{h}=\frac{30-3-0,8}{30}=0,873$

A partir do ábaco da figura 5.24 tem-se:

$$
100 \cdot \frac{A_{s c}}{b \cdot h}=4,2 \rightarrow \text { fator } k=0,42
$$

Com o valor de $k=0,42$ encontrado, deve-se multiplicar pelo valor do momento até que o novo valor de $k$ se aproxime de um valor constante. Momento calculado modificado $=12,60+0,42(94,96)=52,48 \mathrm{kN} . \mathrm{m}$

$$
M_{x}=52,48 \mathrm{kN} \cdot \mathrm{m}>M_{\text {mím }}=32,19 \mathrm{kN} \cdot \mathrm{m}
$$


- $\frac{N}{b \cdot h}\left(\mathrm{~N} / \mathrm{mm}^{2}\right)=23,84 \mathrm{~N} / \mathrm{mm}^{2}$

- $\frac{M}{b \cdot h^{2}}\left(\mathrm{~N} / \mathrm{mm}^{2}\right)=\frac{5248 \mathrm{kN} \cdot \mathrm{cm}}{30 \times 30^{2} \mathrm{~cm}^{3}}=0,194 \mathrm{kN} / \mathrm{cm}^{2}=1,94 \mathrm{~N} / \mathrm{mm}^{2}$ $100 \cdot \frac{A_{s c}}{b \cdot h}=2,80 \rightarrow$ fator $k=0,26$

Momento calculado modificado $=12,60+0,26(94,96)=37,29 \mathrm{kN} \cdot \mathrm{m}$ $M_{x}=37,29 \mathrm{kN} . \mathrm{m}>M_{\text {mim }}=32,19 \mathrm{kN} . \mathrm{m}$

- $\frac{N}{b \cdot h}\left(\mathrm{~N} / \mathrm{mm}^{2}\right)=21,46 \mathrm{~N} / \mathrm{mm}^{2}$

- $\frac{M}{b \cdot h^{2}}\left(\mathrm{~N} / \mathrm{mm}^{2}\right)=\frac{3729 \mathrm{kN} \cdot \mathrm{cm}}{30 \times 30^{2} \mathrm{~cm}^{3}}=0,138 \mathrm{kN} / \mathrm{cm}^{2}=1,38 \mathrm{~N} / \mathrm{mm}^{2}$ $100 \cdot \frac{A_{s c}}{b \cdot h}=2,5 \rightarrow$ fator $k=0,20$

Momento calculado modificado $=12,60+0,20(94,96)=31,59 \mathrm{kN} \cdot \mathrm{m}$ $M_{x}=31,59 \mathrm{kN} . \mathrm{m}<M_{\text {mim }}=32,19 \mathrm{kN} . \mathrm{m}$

- $\frac{N}{b \cdot h}\left(\mathrm{~N} / \mathrm{mm}^{2}\right)=21,46 \mathrm{~N} / \mathrm{mm}^{2}$

- $\frac{M}{b \cdot h^{2}}\left(\mathrm{~N} / \mathrm{mm}^{2}\right)=\frac{3219 \mathrm{kN} \cdot \mathrm{cm}}{30 \times 30^{2} \mathrm{~cm}^{3}}=0,119 \mathrm{kN} / \mathrm{cm}^{2}=1,19 \mathrm{~N} / \mathrm{mm}^{2}$ $100 \cdot \frac{A_{s c}}{b \cdot h}=2,4 \rightarrow$ fator $k=0,17 \Rightarrow 100 \cdot \frac{A_{s c}}{300 \times 300}=2,4$

$A_{s c}=2160 \mathrm{~mm}^{2} \Rightarrow A_{s c}=21,60 \mathrm{~cm}^{2}$

Adotando-se $\phi 16 \mathrm{~mm} \quad \rightarrow$ tem-se 12 barras, conforme figura 5.21.

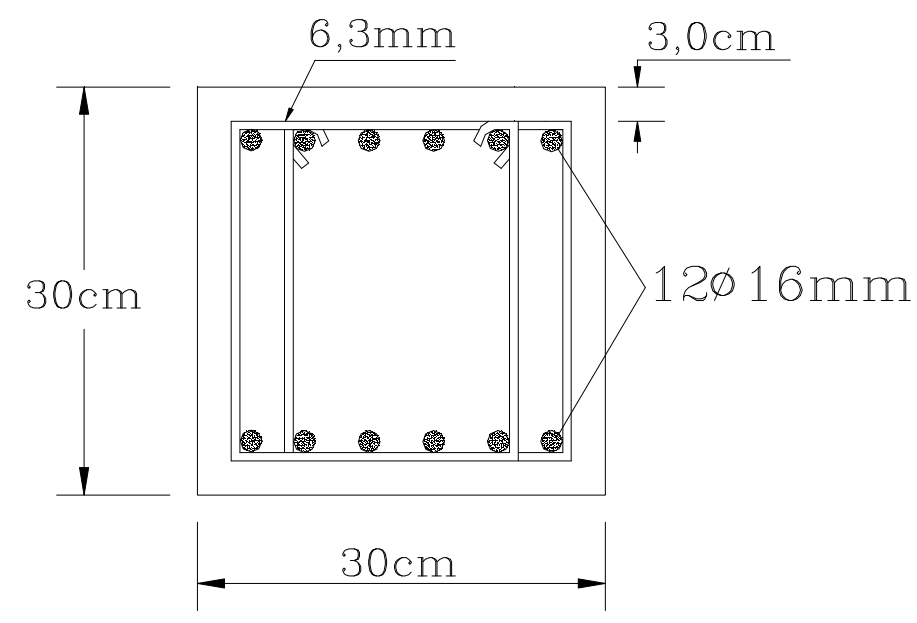

FIGURA - 5.21 - Seção transversal e armaduras adotadas 


\subsection{DIMENSIONAMENTO DE PILAR NÃO CONTRAVENTADO SEGUNDO A NORMA INGLESA - BS 8110}

Tem-se no exemplo seguinte um edifício de 4 pavimentos, com pilares não contraventados suportando vigas nas duas direções. Os pilares apresentam as dimensões de $40 \mathrm{~cm} \times 40 \mathrm{~cm}$ para seção transversal, enquanto que as vigas apresentam $30 \mathrm{~cm}$ de largura e $50 \mathrm{~cm}$ de altura. As vigas vencem um vão de $6 \mathrm{~m}$.

\subsubsection{Dados do problema}

A altura entre o topo da fundação e a base do $1^{\circ}$ andar é de $5,50 \mathrm{~m}$ e acima desse nível é de 3,50 m, conforme figura 5.22. Adotou-se como resistência do concreto à compressão $\left(f_{c u}=40 \mathrm{MPa}\right.$ referida ao corpo de prova cúbico), resistência de plastificação da armadura $\left(f_{y}=460 \mathrm{MPa}\right)$ e revestimento do concreto igual a $30 \mathrm{~mm}$. A seguir, tem-se o procedimento de cálculo indicado pela BS 8110, para um pilar interior do nível fundação até o $1^{\circ}$ andar. O carregamento considerado é o indicado na tabela 5.3.

A fundação foi projetada para resistir aos momentos atuantes.

TABELA 5.3 - Esforços nos pilares devido ao peso próprio.

\begin{tabular}{||c|c|c|c|c||}
\hline \hline \multirow{2}{*}{ Carga axial } & \multicolumn{2}{|c|}{ Momento (eixo x-x) } & \multicolumn{2}{c||}{ Momento (eixo y-y) } \\
\hline \multirow{2}{*}{$3200 \mathrm{kN}$} & Topo & Base & Topo & Base \\
\cline { 2 - 5 } & $7600 \mathrm{kN} . \mathrm{cm}$ & $3800 \mathrm{kN} . \mathrm{cm}$ & $6800 \mathrm{kN} . \mathrm{cm}$ & $3400 \mathrm{kN} . \mathrm{cm}$ \\
\hline
\end{tabular}

Condições de vinculação:

- $\operatorname{Eixo}(\boldsymbol{x})$ - Topo $\rightarrow$ engastado, Base $\rightarrow$ engastado.

- $\boldsymbol{E}$ ixo $(\boldsymbol{y})$ - Topo $\rightarrow$ engastado, Base $\rightarrow$ engastado.

\subsubsection{Cálculo do comprimento efetivo}

a) Para flexão em relação ao eixo $(x)$

$\ell_{e}=\beta \times \ell_{0} \rightarrow$ a partir da tabela (4.7), tem-se $\beta=1,2$

$\ell_{0}=5,50-0,5=5,0 \mathrm{~m}$

$\ell_{e x}=1,2 \times 5,0=6,0 \Rightarrow \frac{\ell_{e x}}{h}=\frac{6,0}{0,40}=15>10 \quad$ (pilar esbelto, item 4.6.2).

b) Para flexão em relação ao eixo (y) 
$\ell_{e}=\beta \times \ell_{0} \rightarrow$ a partir da tabela (4.7), tem-se $\beta=1,2$

$$
\begin{aligned}
& \ell_{0}=5,50-0,5=5,0 \mathrm{~m} \\
& \ell_{e y}=1,2 \times 5,0=6,0 \mathrm{~m} \rightarrow \frac{\ell_{e y}}{b}=\frac{6,0}{0,40}=15>10 \text { (pilar esbelto, item 4.6.2). }
\end{aligned}
$$

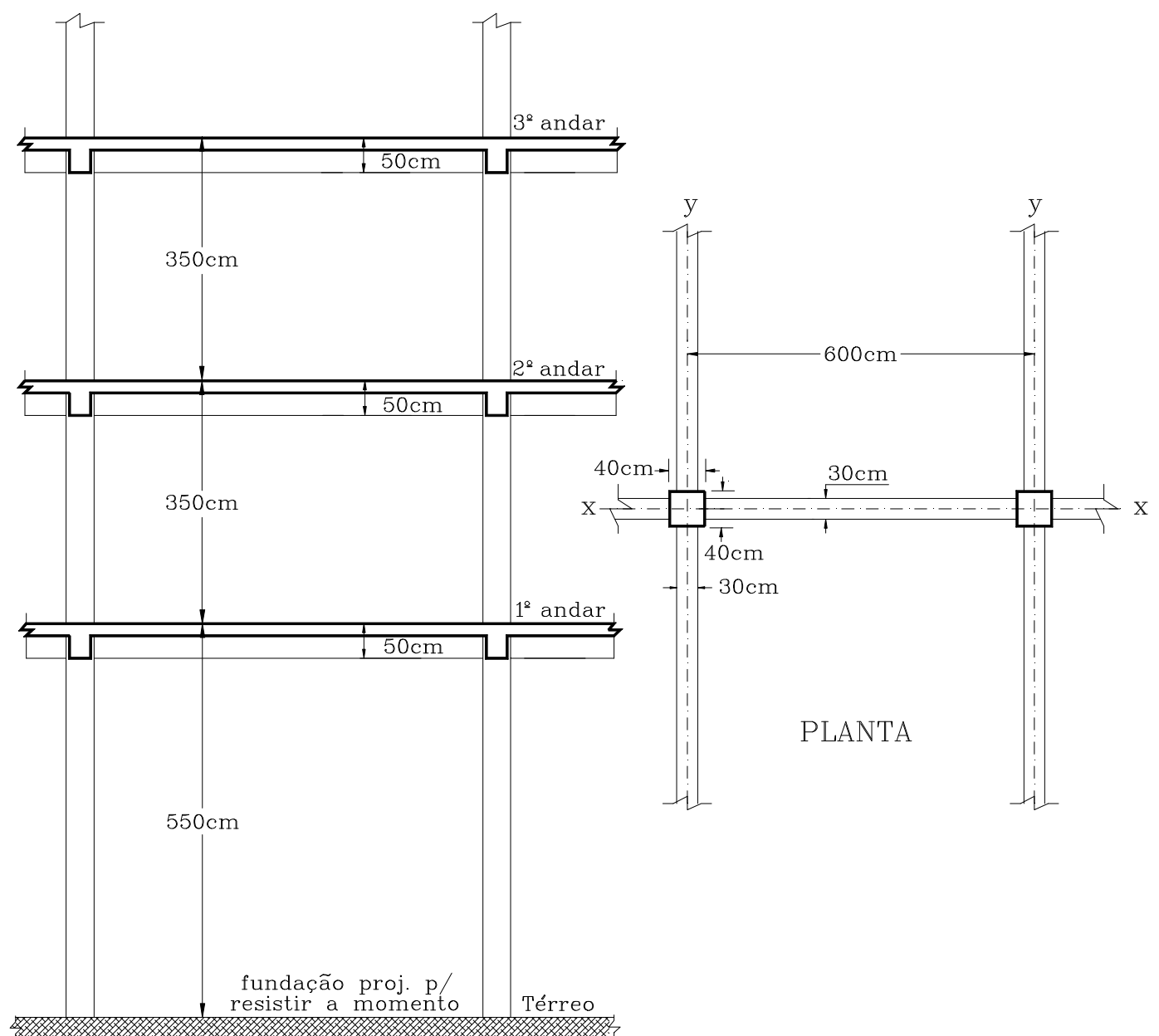

CORTE $(x-x)$

FIGURA - 5.22 - Esquema da estrutura dos pavimentos

\subsubsection{Cálculo do momento mínimo}

$$
\begin{aligned}
& M_{\text {min }}=N \times e_{\text {min }} \Rightarrow e_{\text {mim }}=20 \mathrm{~mm}(\text { conforme item 4.6.3). } \\
& M_{\text {min }}=3200 \times 0,020=64 \mathrm{kN} \cdot \mathrm{m}=6400 \mathrm{kN} \cdot \mathrm{cm}
\end{aligned}
$$

Os momentos iniciais são maiores que o momento mínimo, sendo, portanto, necessário levar em conta a atuação dos momentos nas duas direções, para o cálculo 
do pilar.

\subsubsection{Cálculo dos momento $M_{x}$ e $M_{y}$}

$M_{x}=$ maior momento com relação ao eixo de maior inércia.

$M_{y}=$ maior momento com relação ao eixo de menor inércia.

\section{a) Cálculo de $M_{y}$}

$$
M_{a d d}=N \cdot \beta_{a} \cdot K \cdot h \Rightarrow K=1, \quad h=0,40, \quad \beta_{a}=\frac{1}{2000} \cdot\left(\frac{\ell_{e}}{b^{\prime}}\right)^{2}
$$

Supondo a utilização de $\phi 16 \mathrm{~mm}, b^{\prime}=40-3-0,8=36,20 \mathrm{~mm}$

$$
\begin{aligned}
& \beta_{a}=\frac{1}{2000} \cdot\left(\frac{\ell_{e}}{b^{\prime}}\right)^{2}=\frac{1}{2000} \cdot\left(\frac{6,0}{0,362}\right)^{2}=0,137 \\
& M_{a d d}=3200 \times 0,137 \times 1 \times 0,40=175,36 \mathrm{kN} \cdot \mathrm{m}
\end{aligned}
$$

ou

$$
M_{y}=M_{\min }=64 \mathrm{kN} . \mathrm{m}
$$

ou

$$
M_{y}=M_{2}+M_{a d d}=68+175,36=243,36 \mathrm{kN} \cdot \mathrm{m}
$$

Logo o valor do momento é $M_{y}=243,36 \mathrm{kN} . \mathrm{m}$

\section{b) Cálculo de $M_{x}$}

$$
\begin{aligned}
& M_{a d d}=N \cdot \beta_{a} \cdot K \cdot h \Rightarrow K=1, h=0,40, \beta_{a}=\frac{1}{2000} \cdot\left(\frac{\ell_{e}}{b^{\prime}}\right)^{2}, \quad b^{\prime}=36,20 \\
& \beta_{a}=\frac{1}{2000} \cdot\left(\frac{\ell_{e}}{b^{\prime}}\right)^{2}=\frac{1}{2000} \cdot\left(\frac{6,0}{0,362}\right)^{2}=0,137 \\
& M_{a d d}=3200 \times 0,137 \times 1 \times 0,40=175,36 \mathrm{kN} \cdot \mathrm{m} \\
& \quad \text { ou } \\
& M_{x}=M_{\text {min }}=64 \mathrm{kN} \cdot \mathrm{m} \\
& M_{x}=M_{2}+M_{a d d}=76+175,36=251,36 \mathrm{kN} \cdot \mathrm{m}
\end{aligned}
$$


Logo o valor do momento é $M_{x}=251,36 \mathrm{kN}$.m

c) Cálculo de $\frac{M_{x}}{h^{\prime}}$ e $\frac{M_{y}}{b^{\prime}}$

$$
\begin{aligned}
& \frac{M_{x}}{h^{\prime}}=\frac{25136}{(40-3-0,8)}=694,37 \mathrm{kN} \text { e } \frac{M_{y}}{b^{\prime}}=\frac{24336}{(40-3-0,8)}=672,27 \mathrm{kN} \\
& \frac{M_{y}}{b^{\prime}}<\frac{M_{x}}{h^{\prime}} \Rightarrow M_{x}^{\prime}=M_{x}+\beta \cdot\left(\frac{h^{\prime}}{b^{\prime}}\right) \cdot M_{y} \\
& \frac{N}{f_{c u} \cdot b \cdot h}=\frac{3200}{4 \times 40 \times 40}=0,500
\end{aligned}
$$

A partir da tabela 4.9 tem-se $\beta=0,42$.

$$
M_{x}^{\prime}=251,36+0,42 \cdot\left(\frac{36,20}{36,20}\right) \cdot 243,36=353,57 \mathrm{kN} . \mathrm{m}
$$

\subsubsection{Utilização do ábaco}

- $\frac{N}{b \cdot h}\left(\mathrm{~N} / \mathrm{mm}^{2}\right)=\frac{3200 \mathrm{kN}}{40 \times 40 \mathrm{~cm}^{2}}=2,0 \mathrm{kN} / \mathrm{cm}^{2}=20 \mathrm{~N} / \mathrm{mm}^{2}$

- $\frac{M}{b \cdot h^{2}}\left(\mathrm{~N} / \mathrm{mm}^{2}\right)=\frac{35357 \mathrm{kN} \cdot \mathrm{cm}}{40 \times 40^{2} \mathrm{~cm}^{3}}=0,552 \mathrm{kN} / \mathrm{cm}^{2}=5,53 \mathrm{~N} / \mathrm{mm}^{2}$

- $\frac{d}{h} \rightarrow$ assumindo utilização de $\phi 16 \mathrm{~mm}$

$$
\frac{d}{h}=\frac{40-3-0,8}{40}=0,905
$$

A partir do ábaco da figura 5.24 tem-se:

$$
100 \cdot \frac{A_{s c}}{b \cdot h}=4,5 \rightarrow \text { fator } k=0,58
$$

Logo deve-se calcular novo valor de $M_{y}$ e $M_{x}$ para $k=0,58$

$$
\begin{aligned}
& M_{x}=76+0,58(175,36)=177,71 \mathrm{kN} . \mathrm{m} \\
& M_{y}=68+0,58(175,36)=169,71 \mathrm{kN} . \mathrm{m}
\end{aligned}
$$




$$
\begin{aligned}
& M_{x}^{\prime}=M x+\beta \cdot\left(\frac{h^{\prime}}{b^{\prime}}\right) \cdot M_{y} \\
& M_{x}^{\prime}=177,71+0,42 \cdot\left(\frac{36,20}{36,20}\right) \cdot 169,71=248,99 \mathrm{kN} \cdot \mathrm{m}
\end{aligned}
$$

- $\frac{N}{b \cdot h}\left(N / \mathrm{mm}^{2}\right)=20 \mathrm{~N} / \mathrm{mm}^{2}$

- $\frac{M}{b \cdot h^{2}}\left(\mathrm{~N} / \mathrm{mm}^{2}\right)=\frac{24899 \mathrm{kN} \cdot \mathrm{cm}}{40 \times 40^{2} \mathrm{~cm}^{3}}=0,389 \mathrm{kN} / \mathrm{cm}^{2}=3,89 \mathrm{~N} / \mathrm{mm}^{2}$

$$
100 \cdot \frac{A_{s c}}{b \cdot h}=3,3 \rightarrow \text { fator } \mathrm{k}=0,49
$$

Logo deve-se calcular novo valor de $M_{y}$ e $M_{x}$ para $k=0,49$

$$
\begin{aligned}
& M_{x}=76+0,49(175,36)=161,93 \mathrm{kN} \cdot \mathrm{m} \\
& M_{y}=68+0,49(175,36)=153,93 \mathrm{kN} . \mathrm{m}
\end{aligned}
$$$$
M_{x}^{\prime}=M_{x}+\beta \cdot \frac{h^{\prime}}{b^{\prime}} \cdot M_{y}
$$$$
M_{x}^{\prime}=161,93+0,42 \cdot\left(\frac{36,20}{36,20}\right) \cdot 153,93=226,58 \mathrm{kN} . \mathrm{m}
$$

- $\frac{N}{b \cdot h}\left(\mathrm{~N} / \mathrm{mm}^{2}\right)=20 \mathrm{~N} / \mathrm{mm}^{2}$

- $\frac{M}{b \cdot h^{2}}\left(\mathrm{~N} / \mathrm{mm}^{2}\right)=\frac{22658 \mathrm{kN} \cdot \mathrm{cm}}{40 \times 40^{2} \mathrm{~cm}^{3}}=0,354 \mathrm{kN} / \mathrm{cm}^{2}=3,54 \mathrm{~N} / \mathrm{mm}^{2}$

$$
100 \cdot \frac{A_{s c}}{b \cdot h}=3,0 \rightarrow \text { fator } k=0,47
$$

$$
A_{s c}=\frac{400 \times 400 \times 3,0}{100}=4800 \mathrm{~mm}^{2} \Rightarrow A_{s c}=48,00 \mathrm{~cm}^{2}
$$

Adotando-se $\phi 25 \mathrm{~mm} \rightarrow$ tem-se 10 barras conforme figura 5.23. 


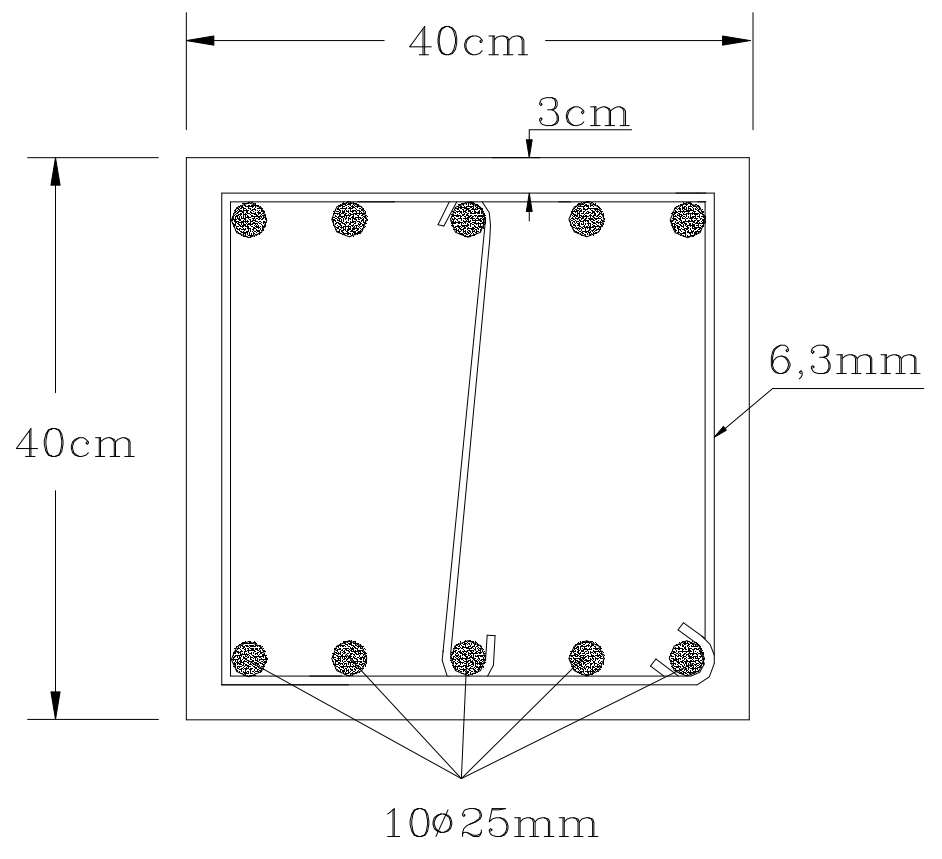

FIGURA - 5.23 - Seção transversal e armaduras adotadas

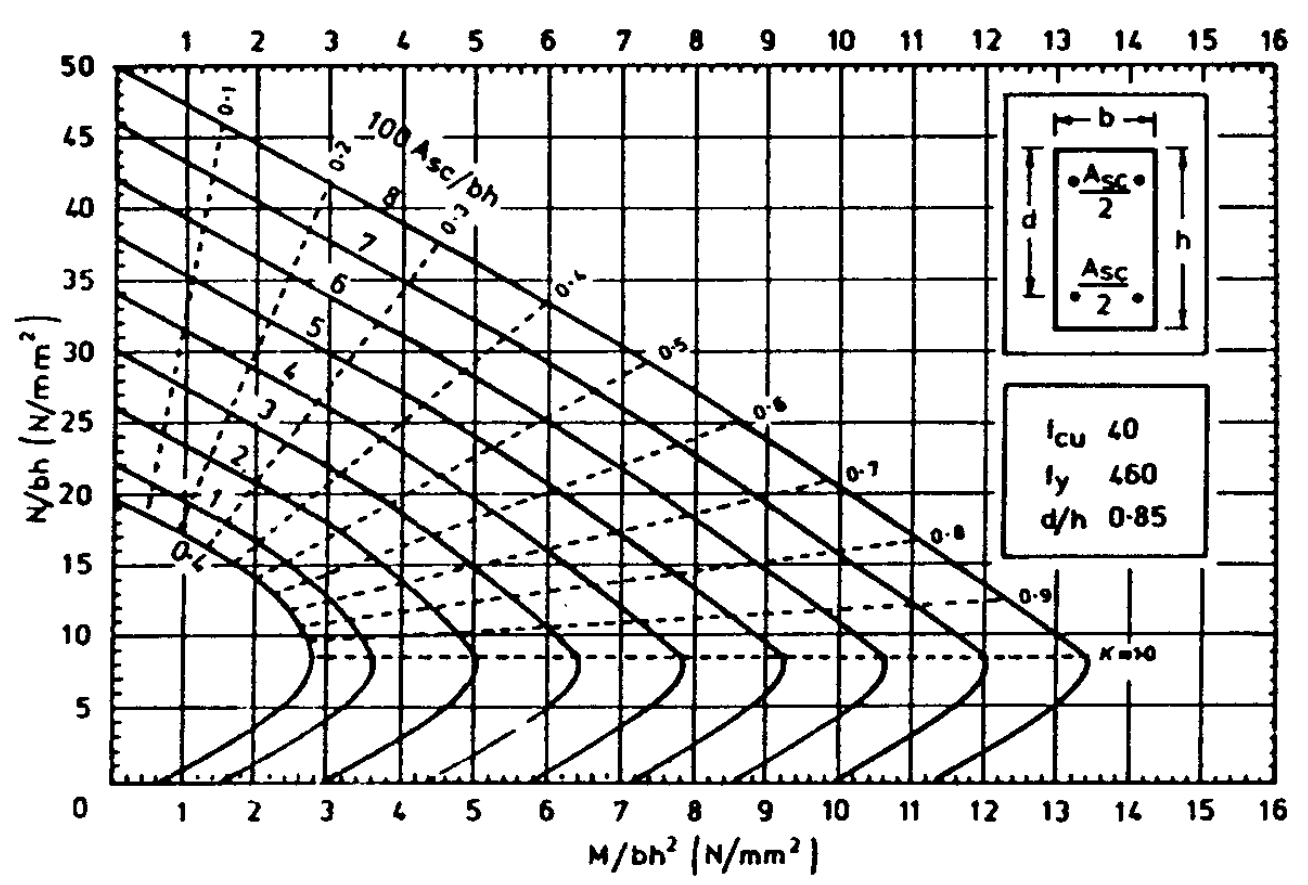

FIGURA - 5.24 - Ábaco para dimensionamento de pilar FONTE: KONG \& EVANS (1987). 


\section{CONCLUSÕES}

Neste capítulo têm-se alguns aspectos conclusivos a respeito dos materiais constituintes do concreto de alto desempenho e suas propriedades mecânicas. Têmse também algumas conclusões a respeito do comportamento e critérios de projeto de pilares de concreto de alto desempenho.

\subsection{MATERIAIS CONSTITUINTES DO CAD}

Os materiais constituintes são em princípio os mesmos empregados para o concreto tradicional. Entretanto, em função da necessidade de elevadas resistências à compressão, devem-se utilizar materiais selecionados, baixas relações água/cimento, aditivos superplastificantes e, em certos casos, adições minerais.

- Cimento - não existem critérios científicos que especifiquem o cimento mais apropriado, podendo-se utilizar o cimento Portland comum ou o cimento ARI.

- Agregado graúdo - devem-se evitar partículas planas, alongadas e polidas, pois estes tipos de partículas reduzem a ligação pasta-agregado. Segundo MEHTA \& AITCIN (1990), maiores resistências são obtidas quando a dimensão máxima do agregado varia no intervalo de $10 \mathrm{~mm}$ a $12 \mathrm{~mm}$.

- Agregado miúdo - devem apresentar partículas planas e polidas, de maneira a reduzir a demanda de água. GONZALEZ (1993) recomenda a utilização de um módulo de finura variando no intervalo de 3,0 a 3,2, para se evitar a formação de um concreto com consistência pegajosa. 
- Ślica ativa - a utilização da sílica ativa no concreto modifica suas propriedades tanto no estado fresco (trabalhabilidade, coesão, estabilidade, segregação, exsudação, etc.), como no estado endurecido (resistência à compressão, resistência à tração, fluência, permeabilidade e durabilidade). Segundo AITCIN (1997), concretos produzidos sem sílica ativa podem alcançar resistências de até $90 \mathrm{MPa}$ aos 28 dias, embora com certa dificuldade. Acima dessa resistência faz-se necessária a utilização da sílica ativa.

- Aditivo superplastificante - No concreto de alto desempenho, em função da baixa relação água/(material cimentício), é indispensável a utilização do aditivo superplastificante. Este deve ser empregado em duas fases: a primeira durante o amassamento e a segunda durante a concretagem.

\subsection{PROPRIEDADES MECÂNICAS}

A qualidade do concreto é caracterizada pelas suas propriedades mecânicas. A seguir têm-se algumas diferenças existentes em algumas propriedades do concreto de alto desempenho, quando comparado com o concreto de resistência usual.

\subsubsection{Resistência à compressão}

A relação entre a resistência à compressão para cargas permanentes e instantâneas é ligeiramente superior nos concretos de alto desempenho, quando comparada com os concretos de resistência usual.

Para os concretos de resistência usual esse valor varia no intervalo de 0,70 a 0,80, enquanto que para o CAD, segundo SMADI (1985), esse valor varia no intervalo de 0,80 a 0,85 .

Segundo MAAGE (1990), concretos de alto desempenho contendo sílica ativa apresentam um ganho de resistência menor depois de 28 dias, quando comparado com concretos de alto desempenho sem sílica ativa, com a mesma relação água/cimento. 


\subsubsection{Resistência à tração}

A resistência à tração aumenta com o crescimento da resistência à compressão, embora de forma não diretamente proporcional.

É freqüentemente assumido que a resistência à tração indireta seja por volta de $10 \%$ da resistência à compressão, o que não é válido para concreto de alto desempenho. Segundo um programa de ensaios realizados pela INTEMAC, em 1992, concluiu-se a partir de resultados obtidos que a resistência à tração indireta pode ser estimada como sendo $8 \%$ da resistência média à compressão. Já DEWAR apud GONZALEZ (1993) indica que, para resistências à compressão do concreto superiores a $84 \mathrm{MPa}$, a resistência à tração deve ser estimada como 5\% da resistência à compressão. Existem na literatura várias expressões para previsão da resistência à tração em função da resistência à compressão; entretanto, a partir da comparação dos resultados dos ensaios experimentais realizados por OLUOKUN et. al. (1991b), GRIEB \& WERNER (1962) e FERRARI et. al. (1995) com algumas expressões teóricas conforme item 3.6.5 (a), pode-se concluir que a expressão do ACI-363 (1994), $f_{c t}=0,53 \sqrt{f_{c k}}$, em MPa, válida para o intervalo de $21 \mathrm{MPa}<f_{c k}<83 \mathrm{MPa}$ como sendo a mais recomendada para estimativa da resistência à tração direta do concreto, com base nos resultados dos ensaios analisados.

\subsubsection{Módulo de deformação longitudinal}

O módulo de deformação longitudinal do concreto está estritamente relacionado com as propriedades da pasta de cimento, com o módulo de rigidez dos agregados e com o método de sua determinação.

Em geral, quanto maior o módulo de rigidez do agregado graúdo empregado, maior é o módulo resultante do concreto. Portanto, o módulo de deformação longitudinal tende a ser maior nos concretos de alto desempenho do que nos concretos de resistência usual, uma vez que são utilizados agregados selecionados e de melhor qualidade.

São encontradas na literatura várias expressões para previsão do módulo de 
deformação longitudinal do concreto, em função da resistência à compressão; entretanto, a partir da comparação dos dados experimentais de OLUOKUN et al. (1991a) e FERRARI et al. (1995) com algumas expressões teóricas, conforme item 3.6 .5 (b), pode-se concluir que a expressão da NS $3473(1992), E_{c}=9500 \cdot f_{c k}^{0,3}$, em MPa, válida para $f_{c k}<83 \mathrm{MPa}$, é a mais recomendada para a previsão do módulo de deformação longitudinal do concreto.

\subsubsection{Coeficiente de Poisson}

Com base em informações experimentais disponíveis, o coeficiente de Poisson para concreto de alto desempenho no limite elástico parece comparável ao limite de valores esperados para o concreto de resistência usual, variando no intervalo de 0,20 a 0,28 .

\subsubsection{Relação tensão-deformação na compressão}

Segundo FIP/CEB-197 (1990), as principais diferenças entre as curvas tensão-deformação para concreto tradicional e de alto desempenho são: maior linearidade na parte ascendente da curva tensão-deformação para uma maior porcentagem da tensão máxima nos concretos de alto desempenho; deformação ligeiramente maior para tensão máxima nos CAD; a parte descendente da curva tensão-deformação torna-se mais íngreme à medida que a resistência à compressão do concreto aumenta.

\subsection{PERDA DO RECOBRIMENTO}

A perda do recobrimento tem sido verificada em ensaios de pilares de concreto de alto desempenho. BEJERKELI et al. (1990) constataram a perda do recobrimento quando o carregamento aplicado estava em torno de $85 \%$ a $90 \%$ da capacidade do pilar. As razões para a perda do recobrimento não estão bem claras. Entretanto, parece que altas tensões presentes no concreto levam a uma instabilidade da camada externa, especialmente se existe um espaçamento muito pequeno entre a armadura transversal que delimita o núcleo e a face do pilar. 
A partir de ensaios realizados por YONG et al. (1988), RANGAN et al. (1991), AGOSTINI (1992), PAIVA (1994) e LIMA (1997), percebeu-se que um grande número de ensaios tiveram colapso abaixo do valor previsto teoricamente, considerando como seção resistente a seção total do pilar. Isso pode ser explicado pela perda prematura do recobrimento. Dessa forma, concluiu-se que, para a previsão da capacidade resistente de pilares submetidos à compressão simples, deve-se considerar apenas a área do núcleo do pilar, ou seja, a área delimitada pelas armaduras transversais, não levando em conta a capacidade resistente do recobrimento.

\subsection{CONFINAMENTO}

Os pilares de concreto de alto desempenho apresentam um comportamento mais frágil do que o apresentado pelos concretos de resistência usual. Para melhorar a capacidade de deformação axial e aumentar a resistência do núcleo, proporcionando um colapso gradual e dúctil, deve-se aumentar a pressão de confinamento. A pressão de confinamento depende da quantidade, resistência, espaçamento e detalhamento da armadura de confinamento, dimensão e geometria do elemento, quantidade e distribuição da armadura longitudinal, espessura do recobrimento e resistência do concreto.

XIE et. al. (1997), através de um estudo paramétrico baseado em análise numérica de pilares de concreto de alto desempenho (37,5 $\mathrm{MPa}$ a $75 \mathrm{MPa}$ ), armados com estribos, submetidos a um carregamento de compressão excêntrica, concluíram que a taxa mínima de armadura transversal a ser utilizada deve ser a taxa de armadura recomendada pelo ACI 318-89 (sec. 21.4.4.1) para a ação de sismo, a fim de que o pilar tenha um confinamento adequado, conforme item 4.3.5 do presente trabalho.

Com relação à taxa mínima de armadura longitudinal, a Norma Norueguesa indica o maior dos seguintes valores:

- $0,01 \cdot A_{C}$

- $0,2 \cdot \frac{A_{c} \cdot f_{c n}}{f_{s k}}$ 
Já a Norma Inglesa recomenda, como taxa mínima para armadura longitudinal, 0,4\% da área da seção transversal.

\subsection{HIPÓTESES DE CÁLCULO}

Uma modificação importante entre o concreto de alto desempenho e o concreto de resistência usual, e que deve ser levada em conta nas hipóteses de cálculo, diz respeito à forma do diagrama de tensão-deformação. A curva tensãodeformação para o CAD apresenta maior linearidade na parte ascendente da curva, deformação ligeiramente maior para a tensão máxima e a parte descendente da curva torna-se mais íngreme à medida que a resistência aumenta, conforme pode ser visto na figura 4.8. Para concretos submetidos à compressão, COLLINS et al. (1993) propuseram a relação tensão-deformação indicada no item 4.4, que se aplica a todas as classes de concreto. Essa variação na forma do diagrama tensãodeformação com a resistência do concreto representa uma dificuldade na elaboração de ábacos para dimensionamento, uma vez que é necessário fixar a resistência do concreto para um determinado ábaco. Fixando a resistência do concreto, torna-se necessária a confecção de inúmeros ábacos, sendo neste caso mais aconselhável o desenvolvimento de programas para dimensionamento.

\subsection{PROJETO DE PILARES}

Para proporcionar um colapso gradual e dúctil para os pilares de concreto de alto desempenho, é fundamental um detalhamento adequado. Devem-se levar em conta algumas recomendações, tais como: dimensões mínimas para seção transversal (item 4.3.1), escolha do tipo de armadura transversal na forma de estribo ou espiral (item 4.3.2), diâmetros mínimos para estribos (item 4.3.3), espaçamento máximo para estribos (item 4.3.4), taxa mínima para armadura transversal (item 4.3.5), escolha da configuração dos estribos (item 4.3.6), resistência à plastificação da armadura transversal (item 4.3.7) e taxa mínima para armadura longitudinal (item 4.3.8). 


\subsection{SUGESTÕES PARA CONTINUAÇÃO DO TRABALHO}

No capítulo 3, foram estudadas algumas propriedades mecânicas, como resistência à compressão, resistência à tração, relação tensão-deformação na compressão, módulo de elasticidade estático e coeficiente de Poisson. Recomendase o estudo de outras propriedades, como retração, fluência, aderência, comportamento sob fadiga, e características de durabilidade, tais como: porosidade, permeabilidade e resistência à abrasão.

Ainda no capítulo 3, foram feitas comparações entre algumas expressões para previsão da resistência à tração do concreto e do módulo de elasticidade, com resultados de ensaios experimentais cujas resistências à compressão variaram no intervalo entre $35 \mathrm{MPa}$ e $68 \mathrm{MPa}$. Entretanto, recomenda-se a comparação dessas expressões com mais dados experimentais, com resistência à compressão variando principalmente no intervalo de $60 \mathrm{MPa}$ a $90 \mathrm{MPa}$, valores que praticamente não estavam disponíveis nos ensaios considerados.

Propõe-se também o desenvolvimento de rotinas para verificação da estabilidade de edifícios, com exemplos de aplicação.

No capítulo 5 foram feitos exemplos de dimensionamento de pilar central, de extremidade e de canto, com seção quadrada, de acordo com os procedimentos recomendados pelo ACI 318-89, e exemplos de dimensionamento de pilar contraventado e não contraventado, de acordo com a Norma Inglesa BS 8110. Recomenda-se, para continuação do trabalho, o dimensionamento de pilares empregando-se seção transversal retangular e uso de procedimentos indicados em outras normas, como a Francesa, a Norueguesa e a Canadense, por exemplo. 


\section{REFERÊNCIAS BIBLIOGRÁFICAS}

AGOSTINI, L.R.S. (1992). Pilares de concreto de alta resistência. São Paulo. Tese (Doutorado) - Escola Politécnica, Universidade de São Paulo.

ALLEN, A.H., ed. (1995). Reinforced concrete design to BS 8110. Great Britain, J.W. Arrowsmith Ltd. 239 p.

AMERICAN CONCRETE INSTITUTE (1983). - Design handbook: in accordance with the strength design method of ACI 318-83. v.2.

AMERICAN CONCRETE INSTITUTE (1989). ACI 318-89 - Building code requirementes for reinforced concrete. Detroit, ACI.

AMERICAN CONCRETE INSTITUTE (1992). ACI 363R-92 - State-of-art report on high strength concrete. Detroit, ACI.

ASSOCIAÇÃO BRASILEIRA DE NORMAS TÉCNICAS (1978). NBR 6118 - Projeto e execução de obras de concreto armado. Rio de Janeiro, ABNT.

BACCIN, A.G.C.; PINHEIRO, L.M. (1997). Propriedades mecânicas do concreto de alto desempenho para aplicação em edifícios. In: REUNIÃO DO IBRACON, 39., São Paulo, 1997. v.2, p.687-700.

BS 8110 (1985). Structural use of concrete - Part 1: Code of practice for design and construction. London, British Standards Institution.

COOK, J.E. (1989). Research and application of high-strength concrete: 10000 psi concrete. Concrete International, p.67-75. Oct.

COLLINS, M.P.; MITCHELL D.; MACGREGOR, J.G. (1993). Structural design considerations for high-strength concrete. Concrete International: Design and Construction, v.15, n.5, p.27-34. May. 
DAL MOLIN, D.C.C. (1995). Contribuição ao estudo das propriedades mecânicas dos concretos de alta resistência com e sem adições de microssílica. São Paulo. 224p. Tese (Doutorado) - Escola Politécnica, Universidade de São Paulo.

EUROCODE 2 (1992). Design of concrete structures - Part 1: general rules and rules for buildings. Brussels, CEN.

FERRARI A.A.; FLOR J.M.; CALIXTO, J.M.F. (1995). Propriedades mecânicas do concreto de alto desempenho. In: JORNADAS SUDAMERICANAS DE INGENIERIA ESTRUCTURAL, 27., Tucuman, Argentina, sept. Memorias. v.5, p.93-102.

FIP-CEB Working Group on High-Strength Concrete (1990). High strength concrete: state of the art report. CEB Bulletin d'Information, n. 197, August.

GONZALEZ-IZABEL, G. (1993). Hormigon de alta resistencia. Madrid, Intemac. $297 p$.

GRIEB, W.E.; WERNER, G. (1962). Comparison of splitting tensile strength of concrete with flexural and compressive strengths. Public Roads, v.32, n.5.

HAN, N.; WALRAVEN, J.C. (1994). Properties of high-strength concrete subjected to uniaxial loading. In: MALHOTRA, V.M. High performance concrete. (Proceedings ACI International Conference Singapore, 1994). Detroit, ACI. p.269-280.

KHAN, A.A.; COOK, W.D.; MITCHELL, D. (1995). Early age compressive stressstrain properties of low-medium, and high-strength concretes. ACI Materials Journal, v.92, n.1, p.617-624. November - December.

KONG, F.K.; EVANS, R.H. (1987). Reinforced and prestressed concrete. 3.ed. Wokingham, UK, Van Nostrand Reinhold. 509p.

LIMA, F.B. (1997). Pilares de concreto de alto desempenho: fundamentos $e$ experimentação. São Carlos. Tese (Doutorado) - Escola de Engenharia de São Carlos, Universidade de São Paulo. 
LIMA, F.B.; GIONGO, J.S.; PINHEIRO, L.M. (1997). Capacidade última de pilares de concreto de alto desempenho. In: JORNADAS SULAMERICANAS DE ENGENHARIA ESTRUTURAL, 28., São Carlos, set. 1997. Estruturas e fundações. São Carlos, EESC-USP/ASAEE. v.2, p.467-476.

MACGREGOR, J. G. (1992). Reinforced concrete mechanics and design. 2.ed., Englewood Cliffs, Prentice Hall. 848p.

MEHTA, P. K. (1990). Microstructural basis of selection of materials and mix proportions for high-strength concrete. In: INTERNATIONAL SYMPOSIUM ON UTILIZATION OF HIGH STRENGTH CONCRETE, 2., Detroit, American Concrete Institute, p.265-286. (SP-121).

MUGURUMA, H.; WATANABE, F. (1990). Ductility improvement of high strength concrete columns with lateral confinement. In: INTERNATIONAL SYMPOSIUM ON UTILIZATION OF HIGH STRENGTH CONCRETE, 2., Detroit, American Concrete Institute, p.47-60. (SP-121).

NEVILLE, A.M. Concreto de alto desempenho: visão atual. / Palestra proferida na Reunião do IBRACON, 39., São Paulo, 1997.

NS 3473 E (1992). Concrete structures: design rules. 4.ed. Oslo, Norway, NSF. (English version).

OLUOKUN, F.A.; BURDETTE, E.G.; DEATHERAGE, J.H. (1991a). Elastic modulus, Poisson's ratio, and compressive strength relationships at early ages. ACI Materials Journal, v.88, n.1, p.3-10. January-February.

OLUOKUN, F.A.; BURDETTE, E.G.; DEATHERAGE, J.H. (1991b). Splitting tensile strength and compressive strength relationship at early ages. ACI Materials Journal, v.88, n.2, p.115-121. March-April.

PAIVA, N.M.B. (1994). Pilares de concreto de alta resistência com seção transversal retangular solicitados à compressão simples. Campinas. Dissertação (Mestrado) Faculdade de Engenharia Civil, Universidade de Campinas. 
RANGAN, B.V. (1990). Strength of reinforced concrete slender columns. ACI Structural Journal, v.87, n.1, p. 32-38. January-February.

RANGAN, B.V. (1996). Studies on high-strength concrete columns under eccentric compression. ACI Structural Journal, v.93, n.6, p.631-638. November-December.

RANGAN, B.V. (1995). Design of slender reinforced concrete compression members. In: INTERNATIONAL CONFERENCE ON STRUCTURAL STABILITY AND DESIGN, Sydney. Proceedings. Rotterdam, A.A. Balkema.

RAZVI, S.R.; SAATCIOGLU, M. (1994). Strength and deformability of confined highstrength concrete columns. ACI Structural Journal, v.91, n.6, p.678-687. NovemberDecember.

SHAH, S.P.; AHMAD, S.H., (1985). Structural properties of high strength concrete and its implications for precast prestressed concrete. PCI Journal, p. 93-119. NovemberDecember.

SHAH, S.P.; AHMAD, S.H., eds.(1994). High performance concretes and applications. London, Edward Arnold. 403p.

SHEIKH, S. A.; SHAH, D. V.; KHOURY, S.S. (1994). Confinement of high-strength concrete columns. ACI Structural Journal, v.91, n.1, p.100-111. January-February.

SILVA, I.S. (1995). Concreto de alta resistência: composição, propriedades e dimensionamento. São Carlos. 129 p. Dissertação (Mestrado) - Escola de Engenharia de São Carlos, Universidade de São Paulo.

XIE, J.; ELWI, A.E.; MACGREGOR, J.G. (1995). Mechanical properties of three highstrength concretes containing silica fume. ACI Materials Journal, n.92, March-April, p.135-145.

XIE, J.; ELWI, A.E.; MACGREGOR, J.G. (1997). Performance of high-strength concrete tied columns: a parametric study. ACI Structural Journal,v.94,n.2, p.91-102. March-April. 